Title The Quarternary Glacial History of the Zanskar Range, North-West Indian Himalya

Name Peter James Taylor

This is a digitised version of a dissertation submitted to the University of Bedfordshire.

It is available to view only.

This item is subject to copyright. 


\section{The Quaternary Glacial History of the Zanskar}

\section{Range, North-west Indian Himalaya}

Peter James Taylor

A thesis submitted to the Faculty of Science, Technology and Design, University of Luton, in partial fulfilment for the degree of Doctor of Philosophy.

Submitted June 1999

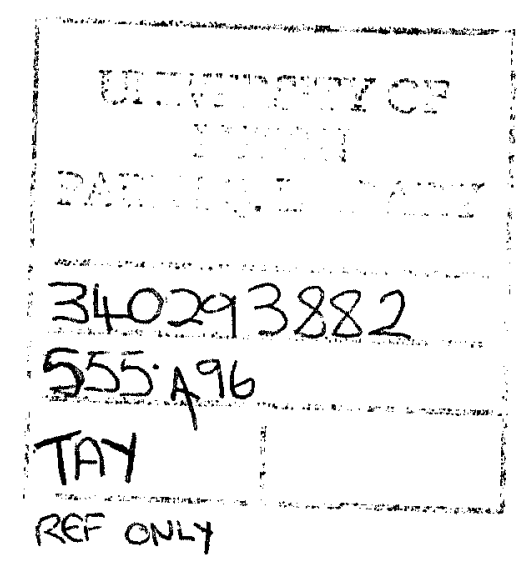




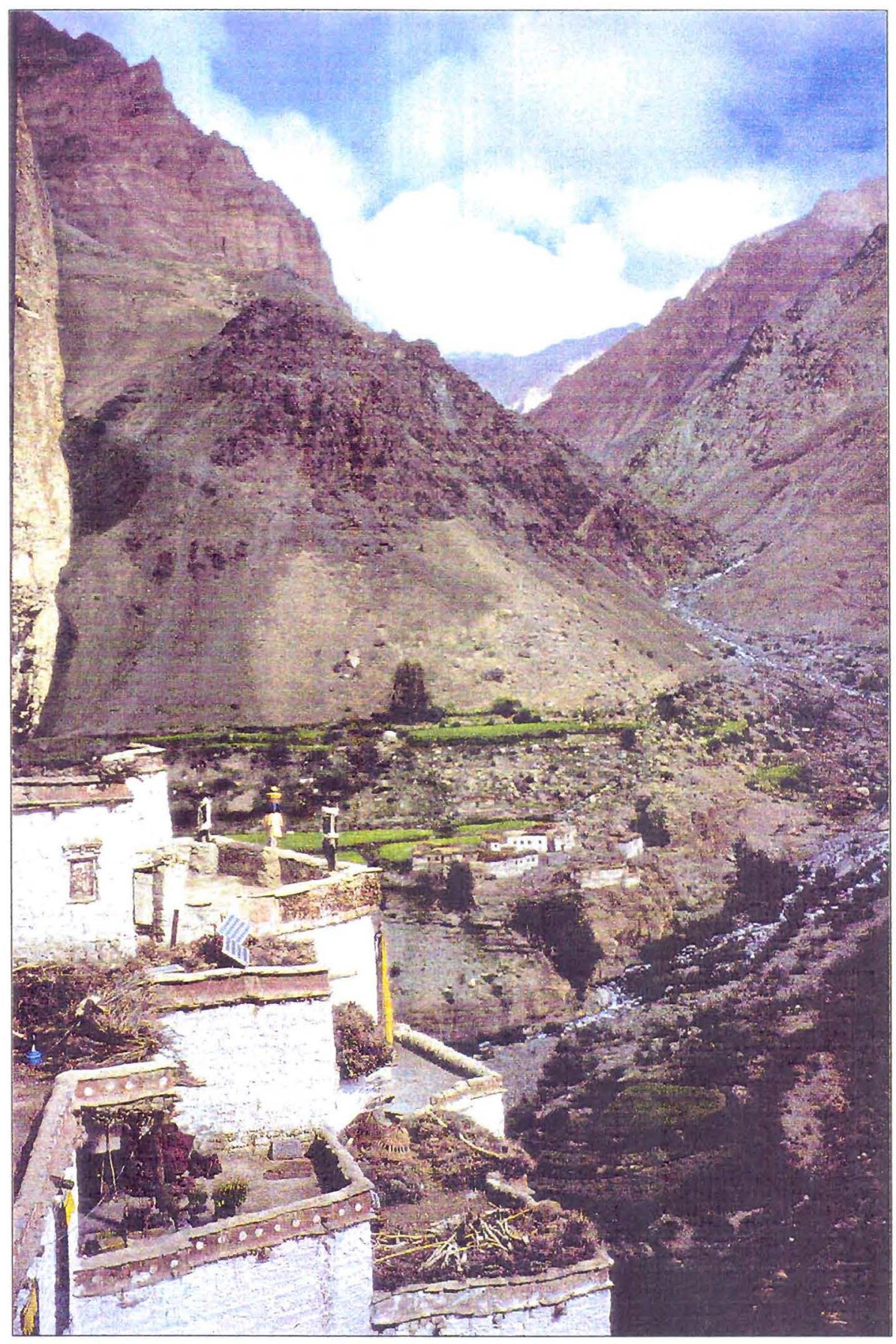

Frontispiece View from the precariously perched Phuktal Gompa (monastery) in the Tsarap valley, five days walk from the Manali-Leh road. The buildings are adhered onto a conglomerate cliff face around a cave with a sacred spring, which issues continuously even in the grips of winter. 


\section{Abstract}

Palaeoglacier margins from the Zanskar Range of the north-western Indian Himalaya are reconstructed through geomorphological mapping and sedimentology. These are dated using Optically Stimulated Luminescence (OSL) techniques on quartz extracted from related fluvioglacial and lacustrine deposits. A glaciated palaeosurface with broad, gentle slopes $>280 \mathrm{~m}$ above river level and high grade metamorphic erratics represents the oldest and most extensive glaciation, the Chandra Stage. This formed an ice-cap with its ice-shed to the south over the High Himalaya. A change from broad glacial troughs to narrow $\mathrm{V}$-shaped gorges along with large subdued moraine ridges and drift/erratic limits defines an extensive valley glaciation, the Batal Stage, with its maximum close to $78.0 \pm 12.3 \mathrm{ka}$ BP (Oxygen Isotope Stage (OIS) 4). Distinct sets of moraine ridges represent a less extensive glaciation, the Kulti Stage, which is dated to shortly after the global Last Glacial Maximum (OIS 2) and a minor advance, the Sonapani, is represented by sharp crested moraine ridges $<2 \mathrm{~km}$ from current ice bodies. The change in glacier extent and style from the Chandra Stage to the later glaciations may be related to uplift of more southerly ranges blocking monsoon precipitation and incision of the landscape such that ice reached lower altitudes over shorter horizontal distances. Batal and Kulti Stage Glacier Elevation Indexes (GEls) calculated for this and adjacent areas increase from south-west to the north-east, but decrease again towards the Indus valley, reflecting attenuation of the south-westerly monsoon and possible channelling of westerly depressions along the broad upper Indus valley. GEI values were depressed by $\sim 500 \mathrm{~m}$ during the Batal Stage and $\sim 300 \mathrm{~m}$ during the Kulti Stage. Six new OSL age estimates from the Zanskar Range greatly improve the glacial chronology of the north-west Himalaya and reinforce the emerging asynchrony between this region and the Central and Eastern Himalaya, which experienced its maximum glaciation during OIS 2 rather than OIS 4. Improved glacier mass balance data, palaeoclimatic proxy data for the summer monsoon and particularly the winter westerlies, and numerical age estimates from Himalayan glaciers are required to explain this asynchronous maximum. 
To the people of Zanskar and Ladakh. 


\section{List of Contents}

Frontispiece II

Abstract III

Dedication IV

List of contents $\quad \mathrm{V}$

List of Tables IX IX

List of Figures

Acknowledgements XIII

Declaration XIV

List of Abbreviations $\quad$ XV

1 Introduction 1

1.1 The Nature of the Problem 1

1.2 Aims of the Thesis 3

1.3 The Study Area 3

1.4 Climate 4

1.5 Geological Evolution of the Himalaya and Tibetan Plateau 10

Geological Evolution of the North-western Himalaya 12

The Timing of the Elevation of the Himalaya and Tibetan Plateau 13

$\begin{array}{ll}\text { Geology of the Zanskar Range } & 15\end{array}$

$\begin{array}{ll}\text { Late Pleistocene Rates of Uplift and Erosion } & 17\end{array}$

1.6 Quaternary Proxy Evidence for Climate Fluctuations 21

1.6.1 Fluctuations of the Indian Monsoon System 26

1.6.2 Fluctuation of the Mid-latitude Westerly System 34

$\begin{array}{ll}\text { 1.6.3 Glacial Records } & 40\end{array}$

The Zanskar Range 45

Equilibrium Line Altitude (ELA) Values for Himalayan Glaciations 49

1.7 An Ice-sheet on the Tibetan Plateau? 53

1.8 Conclusions 56

$2 \quad$ Methodology $\quad 59$

$2.1 \quad$ Geomorphological Mapping 59

2.2 Dating 62

2.2.1 Justification for Choosing the OSL Dating Method 62 
$\begin{array}{lll}\text { 2.2.2 Principles of Luminescence Dating } & 63\end{array}$

Thermoluminescence Dating $\quad 65$

Optically Stimulated Luminescence (OSL) Dating 65

2.2.3 Site Selection and Sample Collection 66

$\begin{array}{lll}2.2 .4 & \text { Preparation of Aliquots } & 69\end{array}$

Choice of Mineral and Grain Size $\quad 69$

FGQ Preparation $\quad 71$

CGQ Preparation $\quad 72$

$\begin{array}{lll}2.2 .5 & \text { Measurement } & 72\end{array}$

2.2.5.1 Initial Measurements : LISA Tests

$\begin{array}{lll}\text { 2.2.5.2 Main Measurements } & 78\end{array}$

$\begin{array}{ll}\text { Natural Normalisation } & 78\end{array}$

Dosing $\quad 78$

$\begin{array}{ll}\text { Preheating } & 79\end{array}$

$\begin{array}{ll}\text { Main Measurement } & 79\end{array}$

$\begin{array}{ll}\text { Curve Fitting } & 79\end{array}$

$\begin{array}{ll}\text { Environmental Dose Rate Calculation } & 79\end{array}$

2.2.6 Age Determination 81

$2.3 \quad$ Palaeoclimatic Reconstruction 81

Methods of ELA Calculation $\quad 83$

$\begin{array}{lll}2.4 & \text { Conclusions } & 87\end{array}$

$3 \quad$ Field Evidence for Glaciation $\quad \mathbf{8 8}$

3.1 Introduction 88

3.2 Baralacha La to the Phirtse Chu (Fig. 3.2) 88

3.3 Shingu La to the Village of Padam (Fig. 3.16) 109

$\begin{array}{lll}3.4 & \text { Sarchu Seri to Purne (Fig. 3.24) } 120\end{array}$

3.5 Whisky Nala to Mare Plains (Fig. 3.35) 134

3.6 Lun (Zara Chu) to Rong (Gya Valley) (Fig. 3.38) 140

3.7 Yar La (Khuma) to Kurma to Lungtung (Fig. 3.48) 152

$\begin{array}{lll}3.8 & \text { Markha (Fig. 3.55) } & 159\end{array}$

3.9 Skio to Rumbak to Stok to Martselang (Fig. 3.59) 166 
$\begin{array}{lll}4.1 & \text { Introduction } & 170\end{array}$

$\begin{array}{lll}4.2 & \text { Samples } & 173\end{array}$

V053, Zanskar Valley Between Pishu and Hanumil Villages 173

$\begin{array}{ll}\text { V055, Tsarap-Lingti Chu Up-valley from Reru Village } & 175\end{array}$

V056, sTondge Terminal Moraine 176

V058, Padam Sandur 176

$\begin{array}{ll}\text { V059, Kelang Seri } & 177\end{array}$

$\begin{array}{ll}\text { V060, Sarchu Seri } & 177\end{array}$

V062, Yunan Valley 179

$\begin{array}{ll}\text { V064, Pang } & 179\end{array}$

$\begin{array}{ll}\text { V065, Mouth of the Nimaling Chu } & 181\end{array}$

$\begin{array}{lr}\text { V067, Kelang Seri } & 182\end{array}$

$\begin{array}{lll}4.3 & \text { Discussion and Conclusion } & 182\end{array}$

$5 \quad$ Style and Timing of Glaciation in the Zanskar Range 185

$\begin{array}{lll}5.1 \text { A Proposed Glacial Chronology for the Zanskar Range } & 185\end{array}$

$\begin{array}{ll}\text { 5.1.1 Glacial Chronological Framework and Nomenclature } & 185\end{array}$

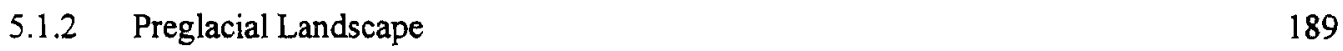

$\begin{array}{lll}\text { 5.1.3 Chandra Stage } & 189\end{array}$

$\begin{array}{lll}\text { 5.1.4 Batal Stage } & 195\end{array}$

$\begin{array}{lll}5.1 .5 & \text { Kulti Stage } & 199\end{array}$

$\begin{array}{lll}\text { 5.1.6 Sonapani Advance } & 202\end{array}$

5.1.7 Landscape Evolution and Change in Style of Glaciation in the Zanskar Range 203

5.2 Comparison with Existing Glacial Studies from the Zanskar Range and Adjacent Areas207

5.3 GEI Values from the Zanskar Range 213

$\begin{array}{lll}5.4 & \text { Conclusions } & 218\end{array}$

6 Regional Comparison and Climatic Inferences $\quad 220$

$\begin{array}{lll}6.1 & \text { Introduction } & 220\end{array}$

$\begin{array}{lll}6.2 & \text { Style of Glaciation } & 220\end{array}$

6.3 Timing of Glaciation in the North-west Himalaya 224

6.4 Asynchronous Glacial Maxima Between the North-west Himalaya, the Kunlun and Northern Karakoram Mountains, and the Central and Eastern Himalaya. 
$\begin{array}{lll}6.5 & \text { GEI Values } & 234\end{array}$

$\begin{array}{lll}6.6 & \text { Conclusions } & 236\end{array}$

7 Conclusions 238

7.1 The Number and Style of Glacial Events in the Zanskar Range 238

$\begin{array}{ll}\text { Chandra Stage } & 238\end{array}$

$\begin{array}{ll}\text { Batal Stage } & 239\end{array}$

$\begin{array}{ll}\text { Kulti Stage } & 239\end{array}$

$\begin{array}{ll}\text { Sonapani Advance } & 240\end{array}$

Style of Glaciation $\quad 240$

7.2 Timing of Glacial Events in the Zanskar Range 240

7.3 GEI Values from Lahul and the Zanskar Range 241

$\begin{array}{lll}7.4 & \text { Regional Comparisons and Implications } & 241\end{array}$

7.5 Evaluation of OSL Dating of Palaeoglacier Margins in the Zanskar Range 242

$\begin{array}{lll}7.6 & \text { Future Work } & 244\end{array}$

$\begin{array}{ll}\text { References } & 247\end{array}$

Appendix A Dose response Curves 273

Appendix B Published Paper $\quad 282$

Appendix C A Worked Example of an OSL Age Estimate 294 


\section{List of Tables}

Table 1.1 Glacial Chronologies for the Zanskar Range. 46

Table $1.2 \quad$ Present and LGM ELAs from the Himalayan region. 52

$\begin{array}{lll}\text { Table 4.1 Measurements relating to age determination. } & 174\end{array}$

Table 4.2 Summary details of samples dated. 183

Table 5.1 Chronostratigraphy and main evidence for the glaciation of the

Zanskar Range. $\quad 188$

Table 5.2 Summary of the evidence for stratigraphic separation of each glacial event. 191

$\begin{array}{lll}\text { Table 5.3 Quaternary sequences from the Zanskar Range. } & 208\end{array}$

$\begin{array}{lll}\text { Table 5.4 GEI values for the Batal and Kulti Stages from the Zanskar Range. } & 214\end{array}$

Table 5.5 GEI values for the Batal and Kulti Stages in Lahul and the Indus

valley near Leh. $\quad 216$

\section{List of Figures}

Figure 1. 1 Location of the study area showing the major rivers and mountain ranges. 2

$\begin{array}{lll}\text { Figure 1.2 Circulation over southern and eastern Asia. } & 6\end{array}$

Figure 1.3 Hadley Circulation and Reversal of the Hadley cell. 7

Figure 1.4 Climate data from Leh, recorded over 30 years. 9

Figure 1.5 Geological cross section of the Kulu-Lahul-Ladakh Himalaya. 11

Figure 1.6 Solid geology of the Zanskar Range. 16

$\begin{array}{lll}\text { Figure } 1.7 & \text { Location of north-west Himalayan uplift data. } & 18\end{array}$

Figure 1.8 Palaeoenvironmental records from the Tibetan Plateau and bordering mountains. 22

Figure 1.9 Selected proxy climatic records for the north-west Himalaya. 23

Figure 1.10 Records of monsoon strength from the Arabian Sea. 28

Figure 1.11 Comparison of high latitude (North Atlantic) and low latitude (monsoonal) palaeoclimate records. 32

Figure 1.12 A pollen record from Tso Kar, Ladakh. 35

Figure 1.13 Selected tree, shrub and vine pollen diagram from southern Italy. 37

Figure 1.14 Glacial chronologies from the north-west Himalaya. 42

Figure 1.15 Limits of glaciation in the southem Zanskar Range. 47

Figure 1.16 Modern climatic snowlines from the north-west Himalaya. 51

$\begin{array}{lll}\text { Figure 2.1 Geomorphological mapping symbols. } & 61\end{array}$ 
$\begin{array}{lll}\text { Figure 2.2 Energy band model. } & 64\end{array}$

Figure 2.3 Methods for the calculation of the Equivalent Dose. 67

Figure 2.4 FGQ methodology.

Figure 2.5 An example of $D_{E}$ values from the LISA test from sample V053.

$\begin{array}{lll}\text { Figure 2.6 Shine down curves from sample V053. } & 76\end{array}$

$\begin{array}{lll}\text { Figure 2.7 TL glow curves from sample V053. } & 77\end{array}$

$\begin{array}{lll}\text { Figure } 2.8 & \text { Additive Dose response curve from V053. } & 80\end{array}$

Figure 3.1 Location map for sections 3.2,3.3 and 3.4 showing the Tsarap-Lingti, $\begin{array}{lr}\text { Kurgiakh and Tsarap river systems. } & 89\end{array}$

$\begin{array}{lll}\text { Figure } 3.2 & \text { Location map for section 3.2. } & 90\end{array}$

Figure 3.3 Geomorphological map of the Baralacha La. 91

Figure 3.4 Sorted stripes at the Baralacha La. 93

Figure 3.5 Geomorphological map of a rock glacier, which dams the Suraj Tal. 93

Figure 3.6 The upper Bhaga valley looking north-west from the Baralacha La. 94

Figure 3.7 Geomorphological map of the western tributary of the Yunan valley. 95

Figure 3.8 Geomorphological map of the Yunan valley around Kelang Seri camping $\begin{array}{ll}\text { ground. } & 98\end{array}$

Figure 3.9 Lateral moraine ridge in the Yunan valley. 99

Figure 3.10 Moraine mound buried under sandur deposits. 99

Figure 3.11 An exposed section in the protruding part of a moraine hummock buried in outwash. 101

Figure 3.12 Ice contact sedimentation from the Sarchu Plain sandur, exposed as a series of earth pillars. 102

Figure 3.13 Gneiss erratics from the Yunan valley. 105

Figure 3.14 Geomorphological sketch map of moraine ridges in the Sarchu Nala. $\quad 106$

$\begin{array}{ll}\text { Figure 3.15 Geomorphological map of moraines in the Lingti valley. } & 107\end{array}$

Figure 3.16 Location map for section 3.3, showing the Kurgiakh and Tsarap-Lingti valleys. 111

Figure 3.17 Geomorphological map of the area around the village of Kurgiakh in the Kurgiakh valley. $\quad 112$

Figure 3.18 Geomorphological map of the area around the village of Muling in the Kurgiakh valley.

Figure 3.19 Valley fill in an abandoned section of gorge near the village of Char at the head of the Tsarap-Lingti gorge. 116

$\begin{array}{lll}\text { Figure } 3.20 \quad \text { Lake sediments from the Tsarap-Lingti valley. } & 117\end{array}$

Figure 3.21 Geomorphological map of the moraine ridges around the village of 
Reru in the Reru valley.

Figure 3.22 Tafoni boulder from a moraine ridge near Reru village.

Road cut sections in fluvioglacial deposits near Sarch Seri police check-post.

Figure 3.43

Sections from alluvial fans in the Gya valley. An ice apron and corrie glacier (with associated moraine) from the upper Kyam Lungpa valley.

Figure 3.47 Alluvial fan sediments overlying lake sediments with abundant dropstones (rainout diamict).

Figure 3.49 Geomorphological map of the upper Khurna valley.

Figure 3.50 Truncated spurs and alluvial fans from the broad, dry upper Khurna valley. 
Figure 3.51 An exhumed moraine mound in the Khurna valley.

Figure 3.52 Geomorphological map of the lower Kurma valley. 157

$\begin{array}{lll}\text { Figure } 3.53 & \text { The Kurma valley looking down-river from its headwaters. } & 158\end{array}$

$\begin{array}{lll}\text { Figure } 3.54 \quad \text { Geomorphological map of the Lungtung valley. } & 160\end{array}$

Figure $3.55 \quad$ Location map for section 3.8. 161

$\begin{array}{lll}\text { Figure } 3.56 \quad \text { Glaciers of the Nimaling Plain. } & 162\end{array}$

Figure 3.57 Geomorphological map of the upper Nimaling Plain. 163

Figure 3.58 Sediments from the mouth of the Nimaling Plain. 165

$\begin{array}{lll}\text { Figure } 3.59 & \text { Location map for section 3.9. } & 167\end{array}$

$\begin{array}{lll}\text { Figure 4.1 Location of OSL dating sample sites. } & 171\end{array}$

$\begin{array}{lll}\text { Figure 4.2 OSL dating sample sites shown on a schematic 'composite' valley. } & 172\end{array}$

$\begin{array}{lll}\text { Figure } 4.3 \quad \text { Sample site for V059. } & 178\end{array}$

$\begin{array}{lll}\text { Figure } 4.4 & \text { Sample site for V060. } & 178\end{array}$

$\begin{array}{lll}\text { Figure 4.5 Sample site for V064. } & 180\end{array}$

Figure 5.1 The Tsarap and Tsarap-Lingti rivers, showing the location of high level gneiss erratics. 193

Figure 5.2 Schematic section illustrating the northernmost possible position of the Chandra Stage ice-shed. 194

Figure 5.3 Palaeoglacier limits for the Batal, Kulti and Sonapani Stages. 198

Figure 5.4 Age estimates from the Zanskar Range. 200

Figure 5.5 Landscape evolution of the Zanskar Range. 205

Figure 5.6 Schematic of the deepening of the Kurgiakh valley. 206

Figure 5.7 GEI values along a south-east to noeth-west section through Lahul and the $\begin{array}{ll}\text { Zanskar Range. } & 217\end{array}$

Figure 6.1 Selected chronologies from the north-west Himalaya. 221

Figure 6.2 Age estimates from the north-west Himalaya. 225

Figure 6.3 Palaeomonsoon proxy indicators, Oxygen Isotope Stages and glaciation of the north-west Himalaya. 230

$\begin{array}{lll}\text { Figure 6.3 GEI depressions from the Himalaya. } & 235\end{array}$ 


\section{Acknowledgements}

In Dr. Wishart Mitchell I have first and foremost a friend and his guidance as principal supervisor has been invaluable. There are several other people I wish to thank for their supervisory input into this project. Prof. Angus Duncan is chiefly responsible for keeping me one step in front of the "marshmallow wall of administration", for which I am extremely grateful. Prior to his emigration, Dr. Lewis Owen was my external supervisor, a job that was kindly taken on by Dr. Ed Rhodes. Prof. Paul Shaw has acted as a second internal supervisor. Dr. Ben Richards is thanked for his guidance through the murky world of luminescence and for his helpful discussion. Dr. Henry Osmaston kindly allowed me to use samples he had collected from Zanskar and shared his expert knowledge of the region. Andrew Millar suffered Acute Mountain Sickness and Ed Magan prolonged illness to keep my sanity on the long isolated treks. I sincerely hope they have no lasting effects and enjoyed the wonderful experience of travelling through India. Pema Lama and her family are thanked for their hospitality, particularly for helping Andy when he was unwell and for adopting me as a family member for the festival of Raksha Bandhan. Over the three field seasons I have been assisted by Het Ram, Tashi Sr., Tashi Jr., Ram Lal, Sonam, Roshan Tshering and Kunga who carried out their tasks as cooks, horsemen and porters with friendly smiles. Het Ram and colleagues are particularly thanked for overcoming cultural traditions to treat us as equals and for entertaining me in their homes, revealing true northern Indian life. The friendliness of the Zanskari and Ladakhi people is exemplified by the actions of the Yak herders who, in spite of communication barriers, fed $\mathrm{Ed}$ and me in their skin tents when our horses deserted. I am grateful to my Mother and Father for their support, and yes Dad I'll get a proper job now! Friends and colleagues in the Graduate School have made my time at Luton a congenial one, especially the heated philosophical discussions in the alehouse. I would also like to thank the University of Luton for giving me the opportunity to undertake such an interesting and fulfilling project. The QRA and BGRG both awarded grants of $£ 200$ for which I am extremely grateful. Last but by no means least, I would like to thank Miss Bell (formerly of Shawlands Academy, Glasgow) whose enthusiasm and guidance led me into the field of physical geography and geology. It's true - 'nobody forgets a good teacher'. 


\section{Declaration}

I declare that this thesis is my own work. It is being submitted for the degree of Doctor of Philosophy at the University of Luton. It has not been submitted before for any degree or examination in any other University.

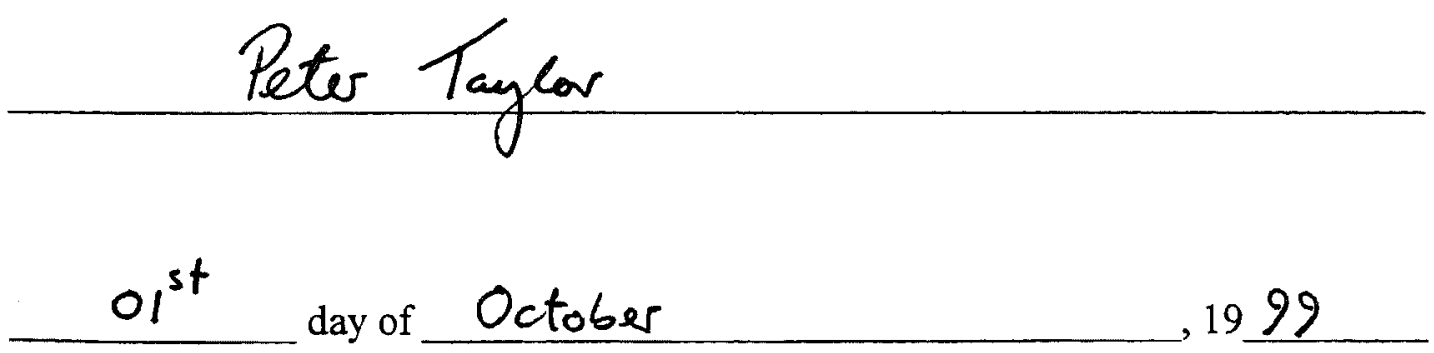




\section{List of Abbreviations}

AAR Accumulation Area Ratio

a.r.l. Above river level

a.s.1. Above sea level

B.P. Before Present

BR Balance Ratio

CGQ Coarse Grained Quartz

$\mathrm{D}_{\mathrm{E}} \quad$ Equivalent Dose

ELA Equilibrium Line Altitude

FGQ Fine Grained Quartz

FGPM Fine Grained Poly Mineral

Fig. $\quad$ Figure

GCM General Circulation Model

GEI Glacier Elevation Index

GLSL Green Light Stimulated Luminescence

GPS Global Positioning System

GT Glaciation Threshold

IRSL Infra-red Stimulated Luminescence

ISZ Indus Suture Zone

ka Thousand years

LGM Last Glacial Maximum

LISA Luminescence Initial Sample Assessment

$\mathrm{Ma} \quad$ Million years

MELM Maximum Elevation of Lateral Moraines

NAA Neutron Activation Analysis

OIS Oxygen Isotope Stage

OSL Optically Stimulated Luminescence

PMT Photo Multiplier Tube

SAH South Asian High 
SST Sea Surface Temperature

TEJ Tropical Easterly Jet

THAR Toe-Headwall Altitude Ratio

TL Thermoluminescence

TOC Total Organic Carbon

yr Year

ZNF Zanskar Normal Fault 


\section{Introduction}

\subsection{The Nature of the Problem}

The Himalaya are the highest, most tectonically active belt of mountains in the world. The presence of this elevated area, along with the Tibetan Plateau, affects Northern Hemisphere climate through driving monsoon circulation and diverting westerly circulation (Ruddiman et al. 1997). It has long been recognised that the Himalaya have experienced periods of glaciation during the Quaternary (Hendin, 1899-1909, 1922; Huntington, 1906; Trinkler, 1930). Nevertheless, many basic questions regarding the extent, style and timing of glacial advances remain unanswered and "...there is an urgent need for... systematic and comprehensive studies [from the Himalaya] in order to construct accurate palaeoenvironmental conditions at various stages and to provide appropriate models" (Owen et al., 1998, p113). The Zanskar Range of the north-western Indian Himalaya is an area where these questions might be addressed (Fig. 1.1).

There is a strong climatic gradient across the five main ranges of the Himalaya from the monsoon dominated Pir Panjal to the high desert of the Ladakh Range, which will be reflected in the glaciation of each range. The glacial history of the Zanskar Range is investigated to further a transect along this gradient. Palaeoclimatic records from the north-west Himalaya (Krishnamurthy et al., 1982; Bhattacharyya, 1989) have been coupled to fluctuations of mid-latitude westerlies (Bhattacharyya, 1989; Benn and Owen, 1998) in addition to the south-west (summer) Indian Monsoon. The glacial history of the Zanskar Range, therefore, has the potential to reveal the relative roles of these climatic systems. A framework chronology for the glacial record of the Zanskar Range has been proposed by Osmaston (1994), building on the early work of 
Chapter 1. Introduction

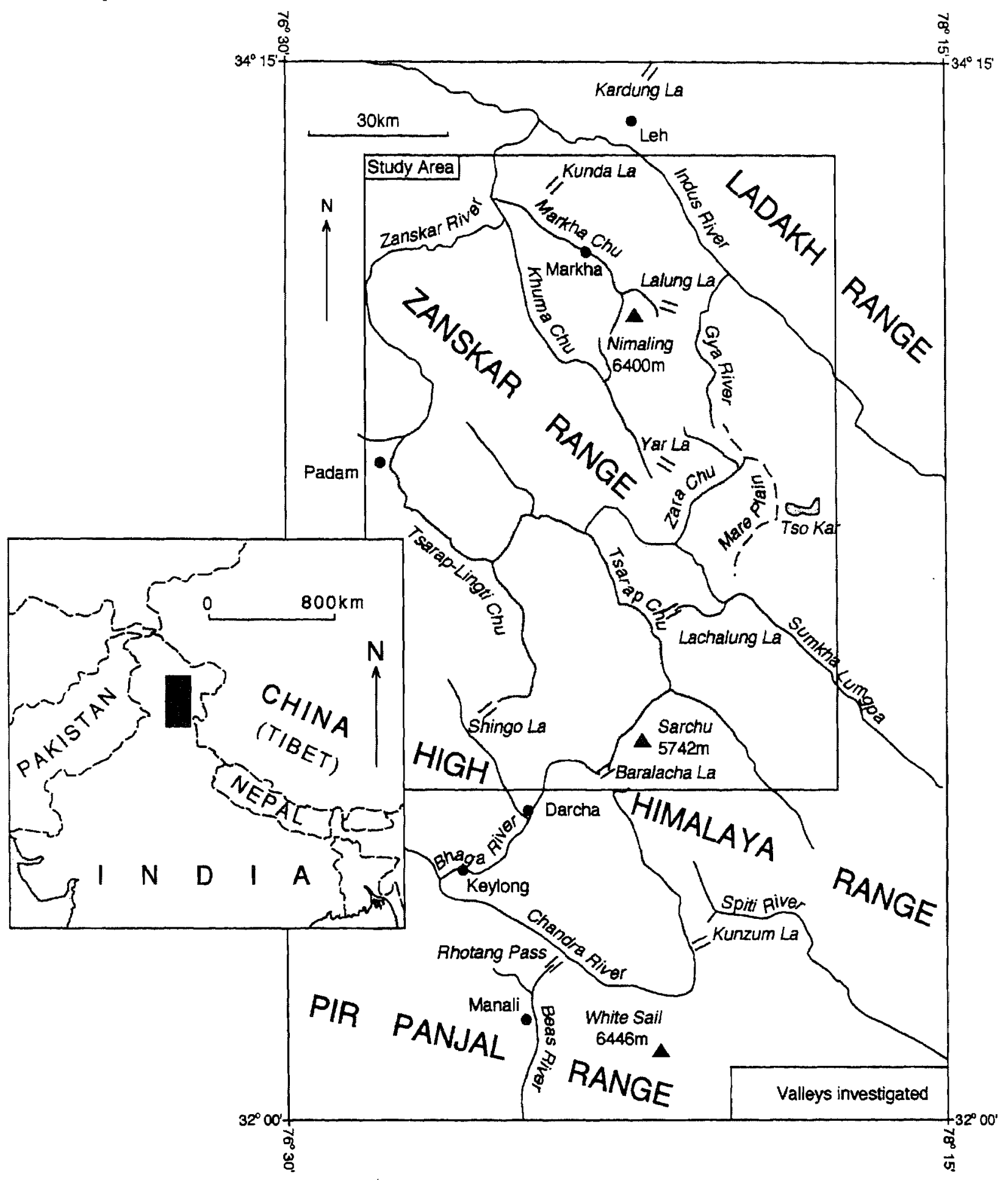

Figure 1.1 Location of the study area showing the major rivers and mountain ranges. 
Dainelli (1923), de Terra and Paterson (1939) and Fort (1983), yet glacial limits remain undated and much of the area has not been investigated.

\subsection{Aims of the Thesis}

Specific aims of the thesis are:

(1) To reconstruct former glacial limits in the Zanskar Range through detailed geomorphological mapping and sedimentology in order to determine the number of distinct glacial advances, and the style and spatial distribution of these former glacial events.

(2) To produce, through the application of Optically Stimulated Luminescence (OSL) dating techniques, a chronology for the glacial sequence.

(3) To attempt, from the above, to establish the palaeoclimatic evolution of the Zanskar Range.

(4) To interpret the results within a regional context, through comparison with existing Himalayan glacial chronologies and with proxy palaeoclimatic data from a variety of independent sources.

\subsection{The Study Area}

The Himalaya and Tibetan Plateau form the most extensive and highest area of elevated land on Earth extending for over $2000 \mathrm{~km}$ from the mountains of the Hindu Kush in the west to those of Sikkim and Bhutan in the east with numerous peaks rising to $7000 \mathrm{~m}$ above sea level (a.s.l.) including peaks of over $8000 \mathrm{~m}$. Within northwest India, the ranges that comprise the Himalaya chain are, from south-west to north-east, the Pir Panjal (or Lesser Himalaya), the High Himalaya (or Great Himalaya), the Zanskar and Ladakh Ranges, and the Karakoram Range (Fig. 1.1). 
The Zanskar (Zansgkar) Range is a broad belt of arid mountains, which lie to the north-east of the monsoon dominated ranges of the Pir Panjal and High Himalaya and to the south of the River Indus, in the Indian state of Jammu and Kashmir (Fig. 1.1). The Zanskar Range lies within the Ladakh and Zanskar regions, however when reference is made to 'Zanskar', this will relate to the mountain range rather than the cultural/political region.

Several tributaries of the Zanskar River, itself a major tributary of the upper Indus River, drain the area including the Tsarap-Lingti, Khurna and Markha systems (Fig. 1.1). Nowhere are valley floors below $3500 \mathrm{~m}$ a.s.l. and slopes are steep, arid and rock strewn with little vegetation, leading to summits between $5500 \mathrm{~m}$ and $6000 \mathrm{~m}$ a.s.l., with the highest being Nimaling at $\sim 6400 \mathrm{~m}$ a.s.l. High passes such as the Tanglang $\mathrm{La}(5200 \mathrm{~m}$ a.s.l.) are blocked by snow for much of the year and the weather can be harsh with hot dry summers and extremely cold dry winters. This creates a naturally inaccessible area, a problem which is further compounded by its political sensitivity. The region is close to two cease-fire lines and has several areas campaigning for independence, notably Kashmir. Consequently the climate and geology of the region are poorly understood.

\subsection{Climate}

This study employs palaeoglacier fluctuations as a potential tool to examine former climate. It is therefore important that the current climate of the study area and, to allow regional discussion, the climate of the wider Himalayan/Tibetan area are understood. The Himalaya and Tibetan Plateau form one of the least known parts of the Earth in terms of climate, with a broad climatic picture only now emerging with aerial surveys and meteorological satellites providing such data as area of snow and cloud cover (e.g. Singh and Mishra, 1998). 
The Tibetan Plateau affects the large scale circulation of the Earth's atmosphere in two ways (Ye and Gao, 1981; Flohn, 1981, 1987; Murakami, 1987) :

(1) Physically, by creating an obstacle to global circulation, which divides westerly winds into northern and southern branches and blocks cold northerly continental air from flowing towards India.

(2) Thermally, by acting as a heat source during the summer and, if snow covered, as a cold sink in winter, creating the Indian Monsoon.

Summer warming, which results from turbulent flux of sensible heat in arid western and northern parts of the plateau and latent heat released from precipitation in the relatively humid south-eastern part, causes air temperatures to become elevated above the zonal mean for the latitude. This is expressed as a permanent upper anticyclone at about 9-17km height - the South Asian High (SAH) - which is responsible for reorganising the quasistationary troughs and ridges of the westerlies over the whole of the Asian region (Zhu et al., 1981; Flohn, 1987; O'Hare, 1997).

The diverging advected air from the summer SAH is carried off towards Japan by westerlies and flows in an anticyclonic direction round the eastern flank of the plateau to become the Tropical Easterly Jet (TEJ) (Fig. 1.2). The persistent and strong TEJ lies above low level south-westerly winds, in the upper troposphere, in contrast to the global atmospheric circulation of Hadley cells (Figs. 1.2 and 1.3).

At a lower level, the two main weather patterns which affect the north-western Himalaya are extratropical weather systems, which move across the north of the subcontinent providing precipitation from the west to east in the winter months, and summer monsoon winds from the south-west, which supply orographically induced precipitation predominantly to the southern ranges. The Himalaya block cold central Asian air from moving south across India, exceptions being westerly disturbances, of which there can be six or seven per month in the winter. As the low pressure systems proceed they bring thunder clouds, heavy precipitation and cold winds to the southern 

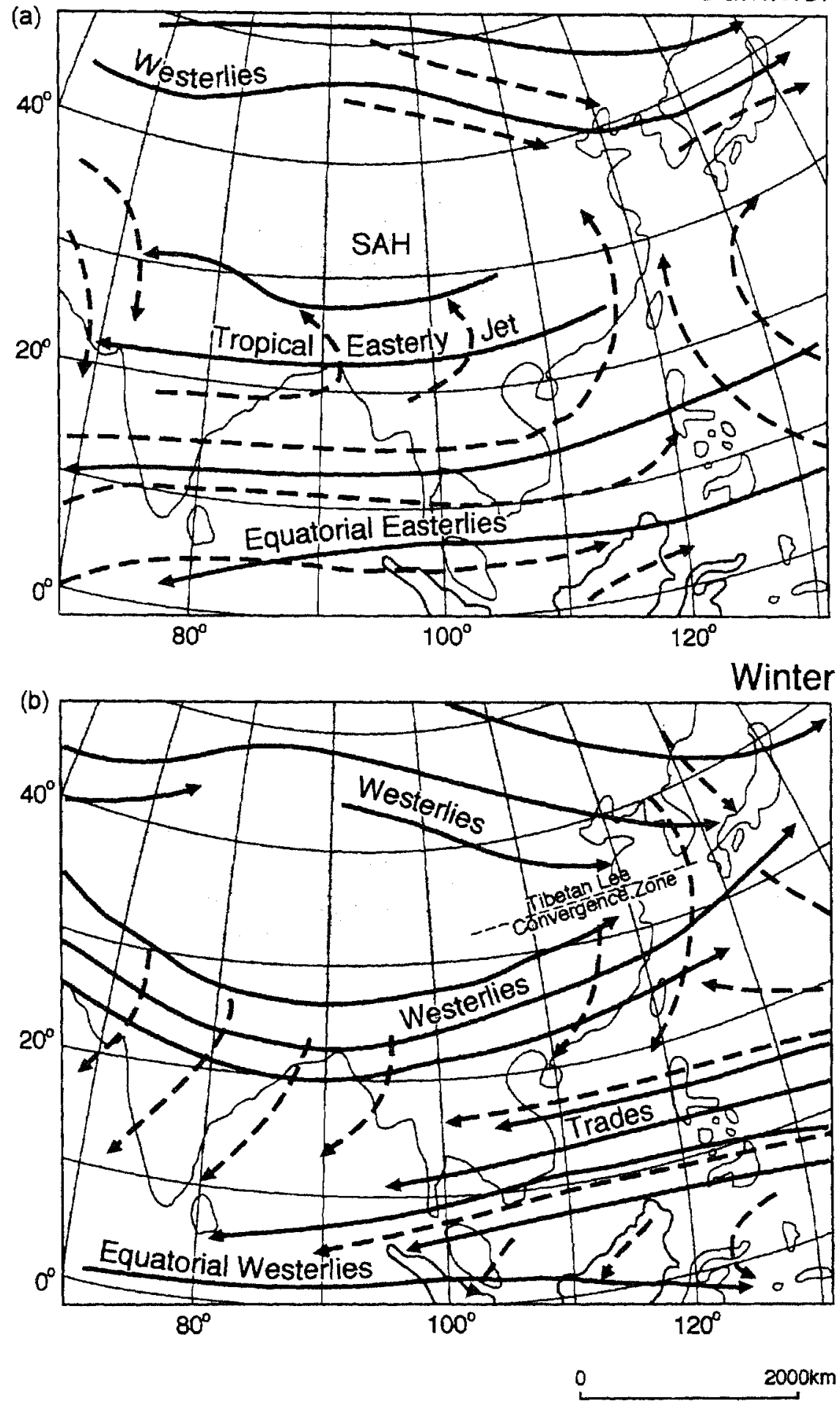

Figure 1.2 Circulation over southern and eastern Asia in summer (a) and winter (b), adapted from Barry and Chorley (1992) and O'Hare (1997). Winds at $3000 \mathrm{~m}$ are shown by solid lines and winds at $600 \mathrm{~m}$ are shown by dashed lines. 


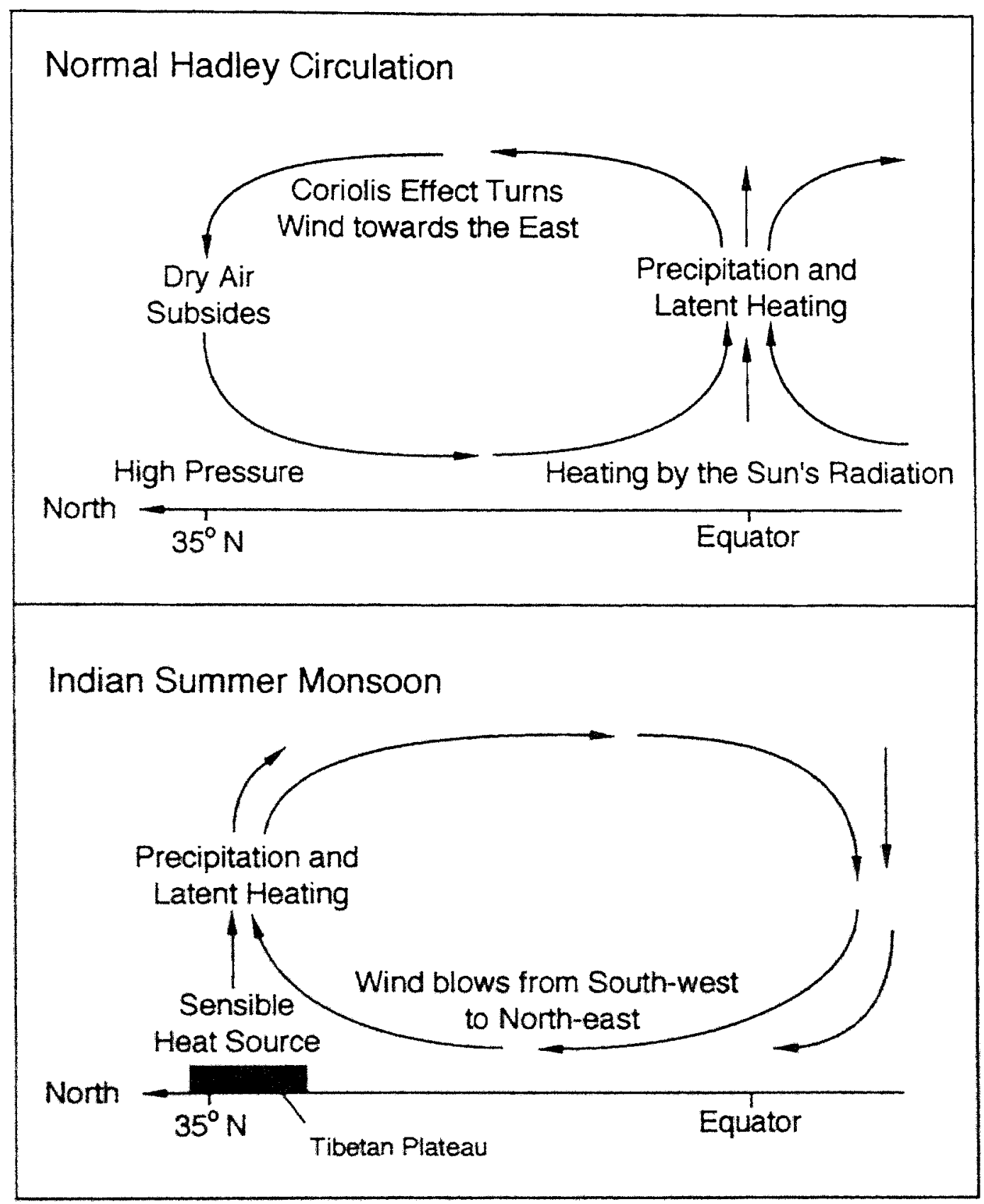

Figure 1.3 (a) Hadley Circulation (b) Reversal of the Hadley cell, after Molnar et al. (1993) 
periphery of the Himalaya (Barry, 1981; Mani, 1981). During the summer southwesterly winds block these westerly depressions. Only general reference to midlatitude westerlies is made in the literature (e.g. Barry and Chorley, 1992) with no specific comment regarding westerlies of the north-west Himalaya.

In the summer, advected air over the Tibetan Plateau descends over the equator, with the resultant winds blowing from the south-west to the north-east due to the Coriolis effect. These oceanic winds bringing precipitation to the Indian subcontinent as they are drawn into the rising air over the Tibetan Plateau (Fig. 1.3b). Monsoonal circulation has the opposite sense in the winter, with radiative cooling of the Tibetan Plateau and the sinking of cold dry air. The resultant wind blows out across the ocean. with the Coriolis effect causing it to flow from north-east to south-west (Flohn, 1981, 1987; Mani, 1981; O'Hare, 1997).

Ladakh and Zanskar receive their limited precipitation from an attenuated summer monsoon. which irregularly breaches the mountain barriers to the south-west, and from winter westerly depressions. Osmaston et al. (1994) compare meteorological data collected over one year from the central Zanskar valley with records from Leh (Fig. 1.1) and Dras and Kargil $>100 \mathrm{~km}$ to the west-north-west. The 30 year record for the Leh station $\left(34^{\circ} 09^{\prime} \mathrm{N}, 77^{\circ} 34^{\prime} \mathrm{E}, 3514 \mathrm{~m}\right.$ a.s.l.) was found to be most representative. This shows an annual precipitation of $-115.0 \mathrm{~mm},-41 \%$ of which falls in July. August and September and $-35 \%$ arriving in December, January, February and March, with the spring and autumn being very arid (Fig. 1.4b). No individual month receives an average of more than $20 \mathrm{~mm}$, with monthly precipitation varying from $111.5 \mathrm{~mm}$ to $0 \mathrm{~mm}$. Summer-time field measurements and information from local people from the central Zanskar valley (Osmaston, et al., 1994) show: precipitation to be higher than for l,eh, suggested as $200-250 \mathrm{mma}^{-1}$.

Air temperature at Leh also varies greatly throughout the year with a mean maximum and minimum of $-2.8^{\circ} \mathrm{C}$ and $-14.0^{\circ} \mathrm{C}$ for January and $24.7^{\circ} \mathrm{C}$ and $10.2^{\circ} \mathrm{C}$ for July respectively. Limited temperature measurements from sTongde and Padam in the 


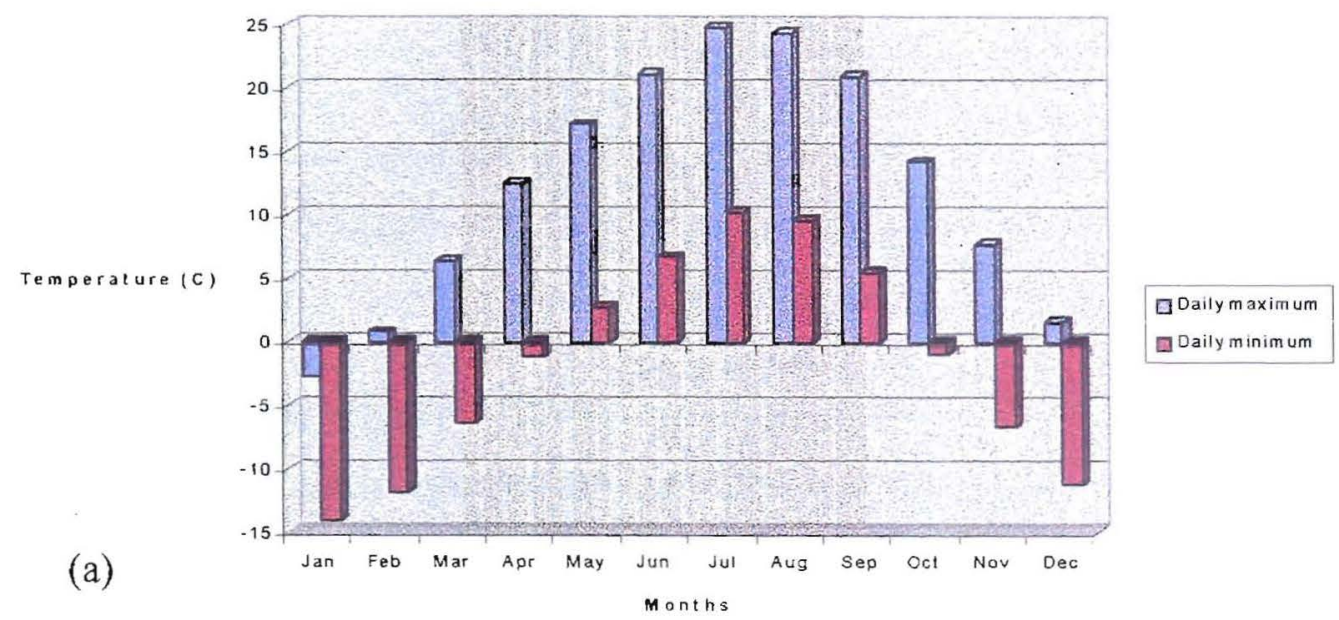

Precipitation

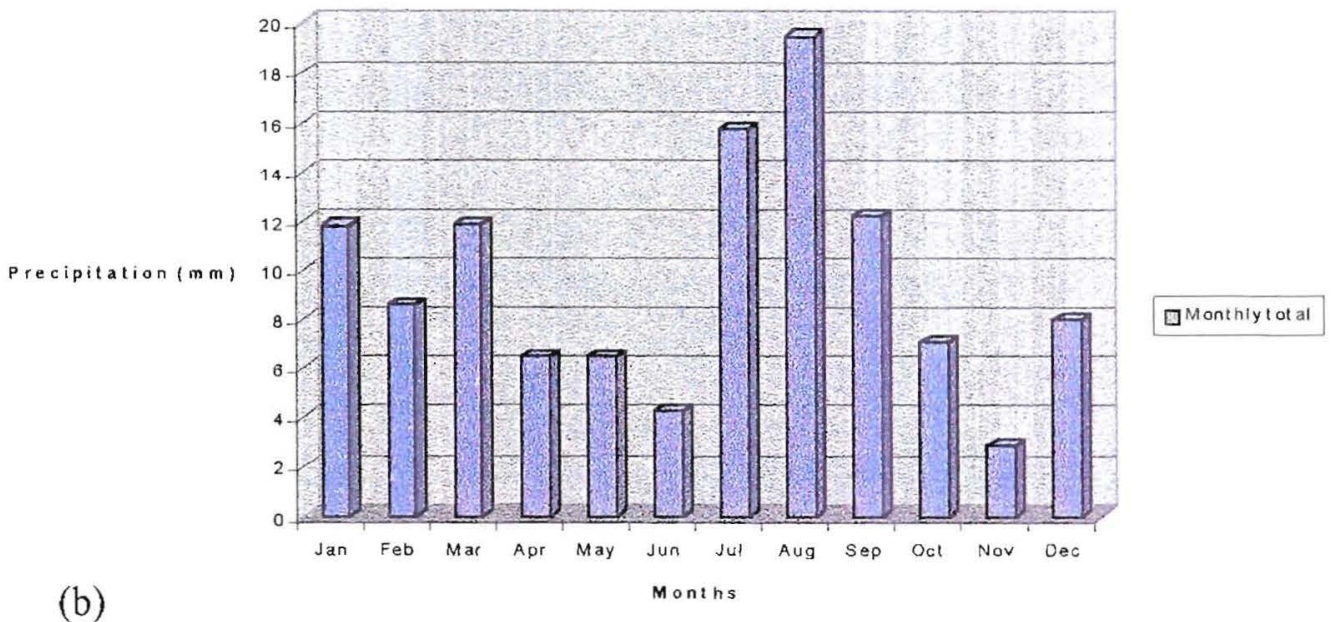

Figure 1.4 Climate data from Leh, recorded over 30 years. (a) Average daily maximum and minimum temperatures for each month. (b) Average monthly precipitation (Government of India, Indian Meteorological department climatological tables of observations in India, pages 129-130). 
Zanskar valley made by Osmaston et al. and later by Punchok Dawa (Osmaston, et al., 1994) show little difference to those from Leh which is at a similar altitude, although it is suggested that winter extremes of cold can be greater. Winds are predominately from the south or south-west in summer and from the north-east in the winter, reflecting the monsoon reversal, and are low with no monthly average exceeding $7 \mathrm{kmh}^{-1}$. No mention is made of winter westerlies depressions.

There are, however, problems with extrapolation from the Leh record, including the measurement station being moved and faulty instrumentation (Osmaston et al., 1994). Moreover, present glaciers are generally above $5000 \mathrm{~m}$ a.s.l., $1500 \mathrm{~m}$ higher than the Leh weather station and situated in a mountainous landscape quite distinct from, and often at a considerable distance from, the broad upper Indus River, and as such this climate record must be treated as a rough guide when inferences are drawn.

\subsection{Geological Evolution of the Himalaya and Tibetan Plateau}

This section places the study area in its geological context and provides a background to subjects such as tectonic uplift, which will become pertinent to later discussion of glaciation.

The north-west Himalaya consists of six major lithotectonic units (Fig. 1.5; Gansser, 1964), which are from north to south:

(1) The Lower Tertiary Trans-Himalayan granite batholith, which forms the Ladakh Range.

(2) The Permian to Upper Cretaceous Indus suture zone (ISZ) and Tertiary molasse sediments, which lie along the Indus valley.

(3) The Cambrian to Eocene Tethys (or Tibetan) zone and remnant ophiolite klippen, which form the Zanskar Range. 


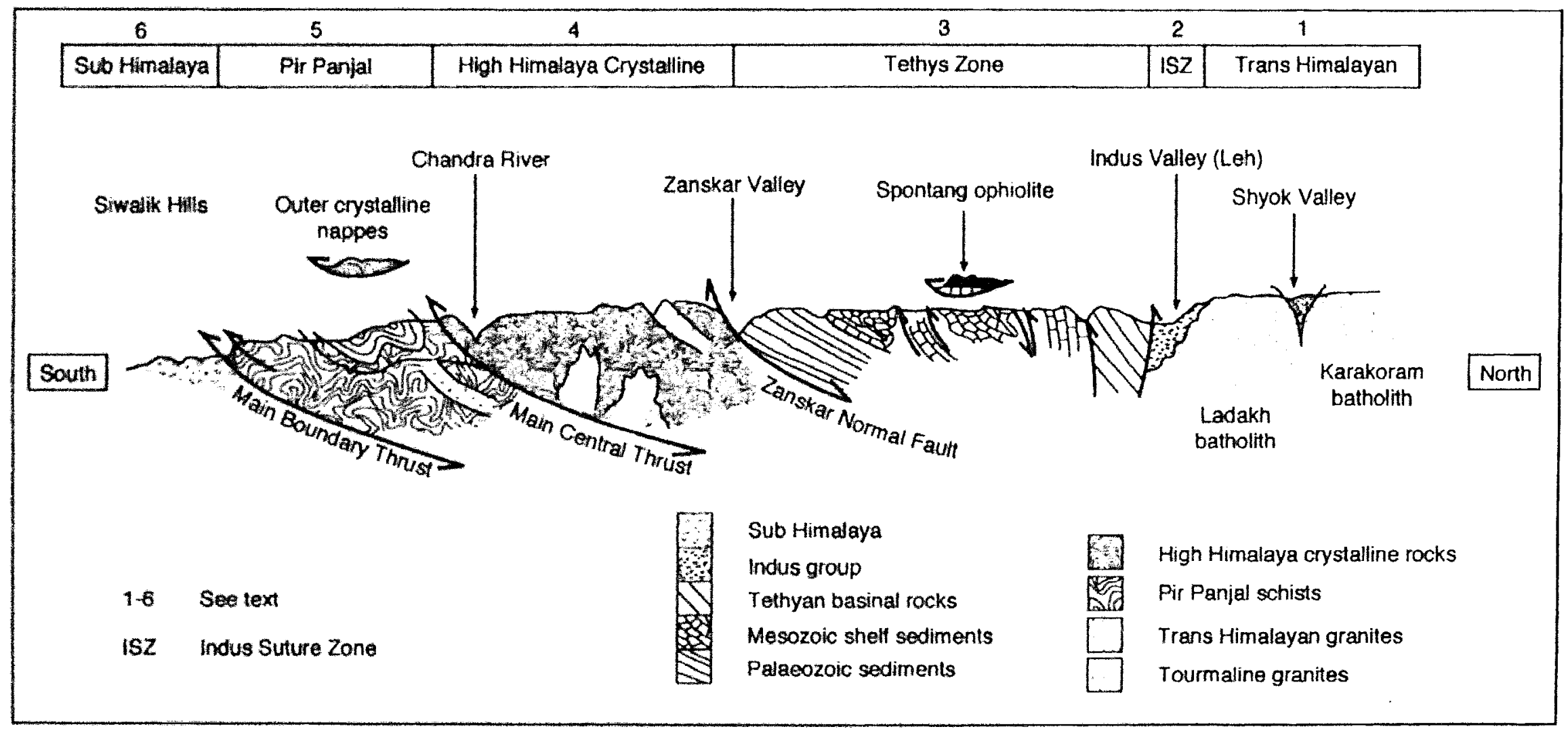

Figure 1.5 Geological cross section of the Kulu-Lahul-Ladakh Himalaya (modified from Gansser, 1964, 1979). 
(4) The Precambrian, Palaeozoic and Mesozoic crystalline rocks, of the High Himalaya Range.

(5) The sedimentary and volcanic rock overlain by crystalline thrust sheets of the Pir Panjal.

(6) Tertiary Siwalik sediments of the sub-Himalaya zone.

\section{Geological Evolution of the North-western Himalaya}

The Himalaya mountain belt is the product of a major plate reorganisation around the Cretaceous-Tertiary boundary ( $65 \mathrm{Ma})$, when the Indian plate moved north towards the Asian plate following the break up of Gondwana. Prior to the India-Asia collision, India's northern continental periphery was a passive margin of the Tethys Ocean, with late Permian and Mesozoic shelf carbonates deposited over Permian volcanics and Palaeozoic sediments (Searle et al., 1997). During the Cretaceous, ophiolite slabs were obducted from the margins of the Tethys basin (Searle, 1983; Sinha, 1992; Osmaston, 1994; Searle et al., 1997) and the fore-arc basin of the Dras island arc was closed. Northward subduction of Mesozoic oceanic crust created an Andean style destructive plate margin and the emplacement of the Trans-Himalayan granite batholith ( 1 in Fig. 1.5) along the southern boundary of the Asian plate. Continued northward subduction in the Eocene resulted in southward thrusting in the Tethys zone ( 3 in Fig. 1.5) and the deposition of molasse as the remaining narrow basin closed. Suturing of the continents occurred at $\sim 55 \mathrm{Ma}$, which coincides with a slowing of India's northward progress from $180-195 \mathrm{mma}^{-1}$ to $45 \mathrm{mma}^{-1}$ (Klootwijk et al., 1992).

The Himalaya have been under persistent north-south compression since the time of the India-Asia collision (Searle et al., 1987; Molnar, 1988). This sustained compression has caused post-Eocene steepening of southward thrusting, isoclinal folds and northward thrusting of the northern margin of the Tethys zone over the ISZ 
(Fig. 1.5). Following closure of the Tethys basin, a new zone of underthrusting formed, the Main Central Thrust. The lower crust has deformed by plastic, ductile flow and is detached from the upper crust along large scale normal faults, the South Tibetan Detachment System (e.g. the Zanskar Normal Fault). High grade metamorphic rocks and leucogranites formed under Tibet have moved south eventually being uplifted, exhumed and eroded along a migrating Himalayan axis (Searle, 1999). Thus the leucogranites young to the north from $\sim 23 \mathrm{Ma}$ to $12 \mathrm{Ma}$ BP as they are extruded southwards (Searle, 1999). The climax of the orogenic deformation and metamorphism of the High Himalaya occurred in the Oligocene to Miocene. Tectonic activity in High Himalaya ceased by the Pliocene to Pleistocene, with activity moving southwards to Main Boundary Thrust and the formation of the Pir Panjal Range (Searle, 1983, 1999).

\section{The Timing of the Elevation of the Himalaya and Tibetan Plateau}

The Himalaya and Tibetan Plateau has an immense effect on the climate of Asia, as well as on patterns of global circulation, as demonstrated by modelling experiments (Ruddiman and Kutzbach, 1989; Manabe and Broccoli, 1990; Kutzbach et al., 1993). Indeed, the surface uplift of the Himalaya and Tibetan Plateau has been proposed as a cause of global Cenozoic cooling, through physical perturbation of the atmosphere (Ruddiman and Kutzbach, 1989; Kutzbach et al., 1989, 1997) and various feedback mechanisms, particularly a tectonically driven increase in chemical weathering, which is proposed as causing a decrease in atmospheric $\mathrm{CO}_{2}$ (Raymo et al., 1988; Raymo and Ruddiman, 1992; Kutzbach et al., 1997). This elevation of the plateau surface becomes particularly relevant to Late Pleistocene glacial studies if the more extreme views are adopted (Zheng, 1989c).

Surface uplift of the Tibetan Plateau has been suggested as having been extremely recent (Li et al., 1979; Huang, 1980; Zheng, 1989c) with the altitude of the plateau being $\sim 1000 \mathrm{~m}$ at the beginning of the Pleistocene. This proposal is based on fossil 
evidence showing free faunal migration between India and China, with the present altitude of $>4500 \mathrm{~m}$ only achieved by the Late Pleistocene. The arguments for a postMiocene uplift based on paleaoecological evidence has a number of flaws, not least the difficulties in separating the effects of altitude change and climate change, the problems of dating fossils and the lack of modern species for comparison of ecological range (Fort, 1996; Copeland, 1997).

There are strong arguments for the Himalaya and Tibetan Plateau having been close to their present elevation for a longer period. For example:

(1) Murphy et al. (1997) show, through mapping of the Lhasa Block of southern Tibet, that parts of the plateau were already thickened through continental accretion and were at perhaps of $3-4 \mathrm{~km}$ elevation before Indo-Asian collision ( $55 \mathrm{Ma} \mathrm{BP})$, with little additional shortening/uplift during the Cenozoic.

(2) The onset of basic volcanism on the Tibetan Plateau is linked to loss or thinning of the lithospheric mantle, which was replaced by hotter asthenosphere, causing rapid uplift. This has been dated to $20 \mathrm{Ma} B P$ in the west of the plateau (Tumer, et al., 1993) and since $40 \mathrm{Ma}$ BP in the east (Chung, et al., 1998). Similarly, normal faulting, also associated with an early rapid phase of uplift dates to $\sim 8 \mathrm{Ma} \mathrm{BP}$ (Molnar et al., 1993).

(3) The commencement of east-west extension, dated using hydrothermal fault minerals to $\sim 14 \mathrm{Ma} \mathrm{BP}$, has been associated with gravitational collapse of an already uplifted plateau (Coleman and Hodges, 1995).

(4) The loess record of Central China has been shown to record fluctuations in the East Asian Monsoon throughout the Quaternary (e.g. Ding et al., 1992). Modelling experiments (Prell and Kutzbach, 1992) show that, in order to achieve penetration of monsoon winds to the loess plateau, the surface of the Tibetan Plateau must have been at over half of its present altitude at the beginning of the Quaternary (Fort, 1996). Gravel deposits on the northern 
margin of the Tibetan Plateau show a change from tectonic accumulations of molasse, with lacustrine deposits, to climatic induced arid environment sedimentation (Lui et al., 1996). It is argued that, to provide the necessary barrier to moist/warm air from the south and south-east, the Tibetan Plateau must have been close to its present altitude by $\sim 1$ Ma BP (Lui et al., 1996).

The age of initiation and cessation of many important tectonic structures in the uplift of the Himalaya is known. For example, leucogranites formed from crustal melts have been dated and their association with both normal and thrust faults recorded in Nepal (Searle, 1999). However, evaluation of the relationships between tectonic structures and the former elevation of the surface is not straightforward (Copeland, 1997). Consequently, only general statements about the surface evolution of the Himalaya and Tibetan Plateau can be made, such as "about $25-27 \mathrm{~km}$ of overburden has been removed [from the High Himalaya in northwest India] since 25Ma" (Searle 1992, p772).

\section{Geology of the Zanskar Range}

The Zanskar Range is composed predominantly of intensely folded and thrusted rocks of the Indian continental margin. bounded to the north by the Indus Suture Zone (ISZ) (Figs. 1.5 and 1.6). The ISZ marks the area where the continents joined and contains remnants of ophiolitic melange zones, pre-collision Tethys Mesozoic sediments, Jurassic to Cretaceous island arc volcanics with fore-arc basin sediments and post-collision molasse (Searle et al., 1997). The shelf sediments exposed in the field area form three distinct structural zones (1-3 in Fig. 1.6). Palaeozoic sedimentary basement to Mesozoic shelf sequences form zone 1, with zones 2 and 3 composed of upper Permian and Mesozoic passive margin shelf sediments. To the south. the north-east dipping Zanskar Normal Fault (part of the South Tibetan Detachment System) places the shelf sediments against Precambrian, Palaeozoic and 


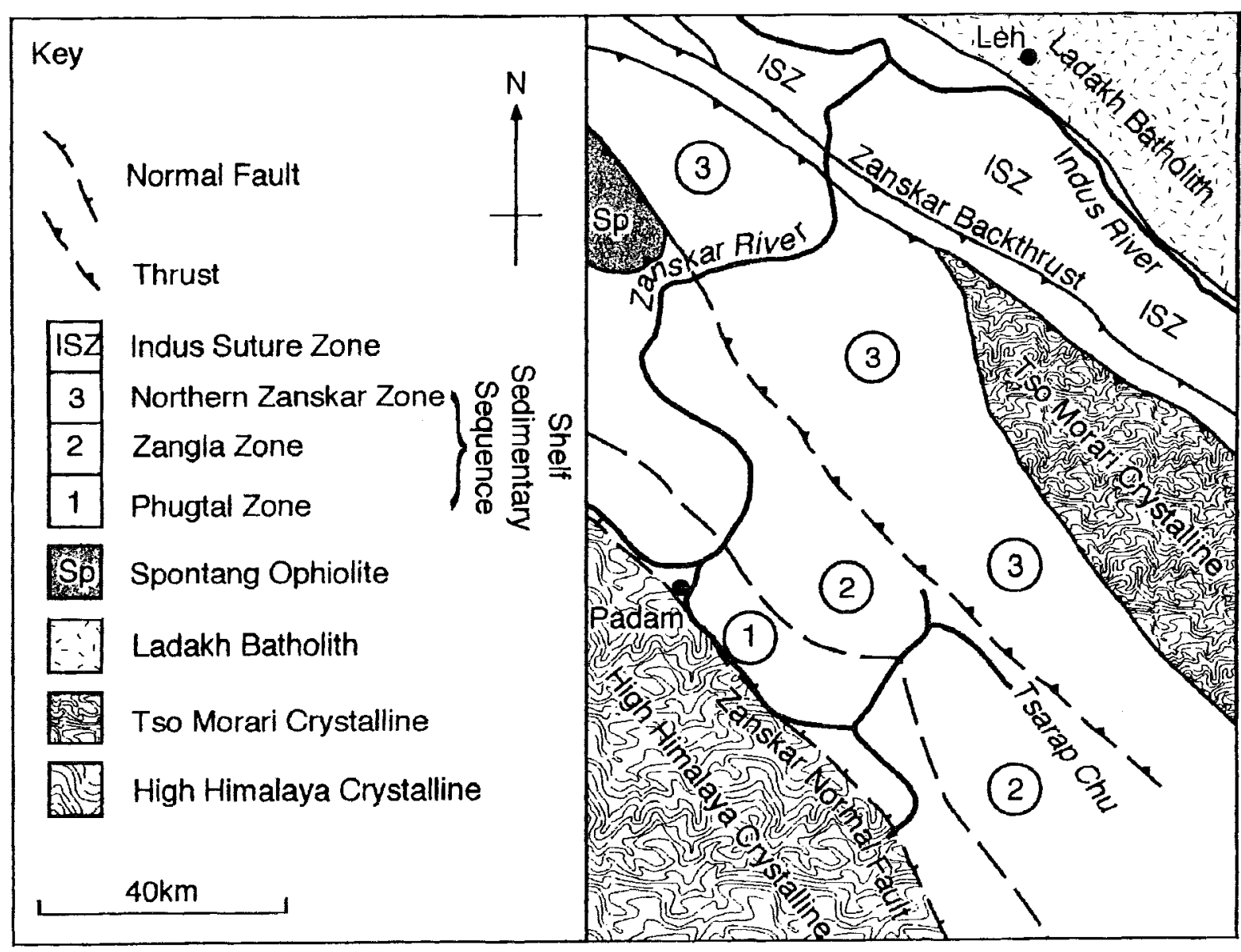

Figure 1.6 Solid geology of the Zanskar Range, modified from Searle (1997). 
Mesozoic metapelites, amphibolites, marbles, quartzites and orthogneisses (Figs. 1.5 and 1.6).

The stratigraphy of the Mesosoic and early. Tertiary sediments is described in detail by Fuches (1979, 1982, 1986), Andrews-Speed and Brookfield (1982), Baud et al. (1983, 1984), Brookfield and Andrews-Speed (1984), Garzanti et al. (1987) and Gaetani and Garzanti (1991), and the structure has been investigated in detail by Searle $(1983,1986)$ and Searle et al. $(1987,1988,1997)$.

Several rock types have the potential to be used as indicator erratics for the study of former glaciation. High-grade gneisses, migmatites and leucogranites from the High Himalaya Crystalline and granites from the Tso Morari Crystalline are particularly favourable, as they have known boundaries, are easily identifiable in the field and contrast with the fine grained sedimentary rocks which make up much of the field area. These characteristics are especially true of the Rupshu Granite (Berthelsen, 1953) of the Nimaling Massif (Fig. 1.6), which are coarse grained porphyric two mica granites, with distinctive microcline phenocrysts of $150 \mathrm{~mm}$ length.

\section{Late Pleistocene Rates of Uplift and Erosion}

Glaciations are likely to have been influenced by tectonically induced climatic changes, particularly with regards to the blocking of the monsoon through the Pliocene-Pleistocene growth of the Pir Panjal. Moreover, in active tectonic regions Equilibrium Line Altitude (ELA) values calculated from reconstructed palaeoglacier margins may be erroneous due to uplift of glacial evidence. For these reasons, the pattern and rate of uplift in the area of study must be considered.

Surface uplift is the upward movement of the landsurface with respect to a specific datum, whereas crustal uplift is the upward movement of the rock column with respect to a datum (Summerfield, 1991, p371). Most uplift measurements refer to the uplift of the rock column rather than to surface uplift, which refers to the absolute 


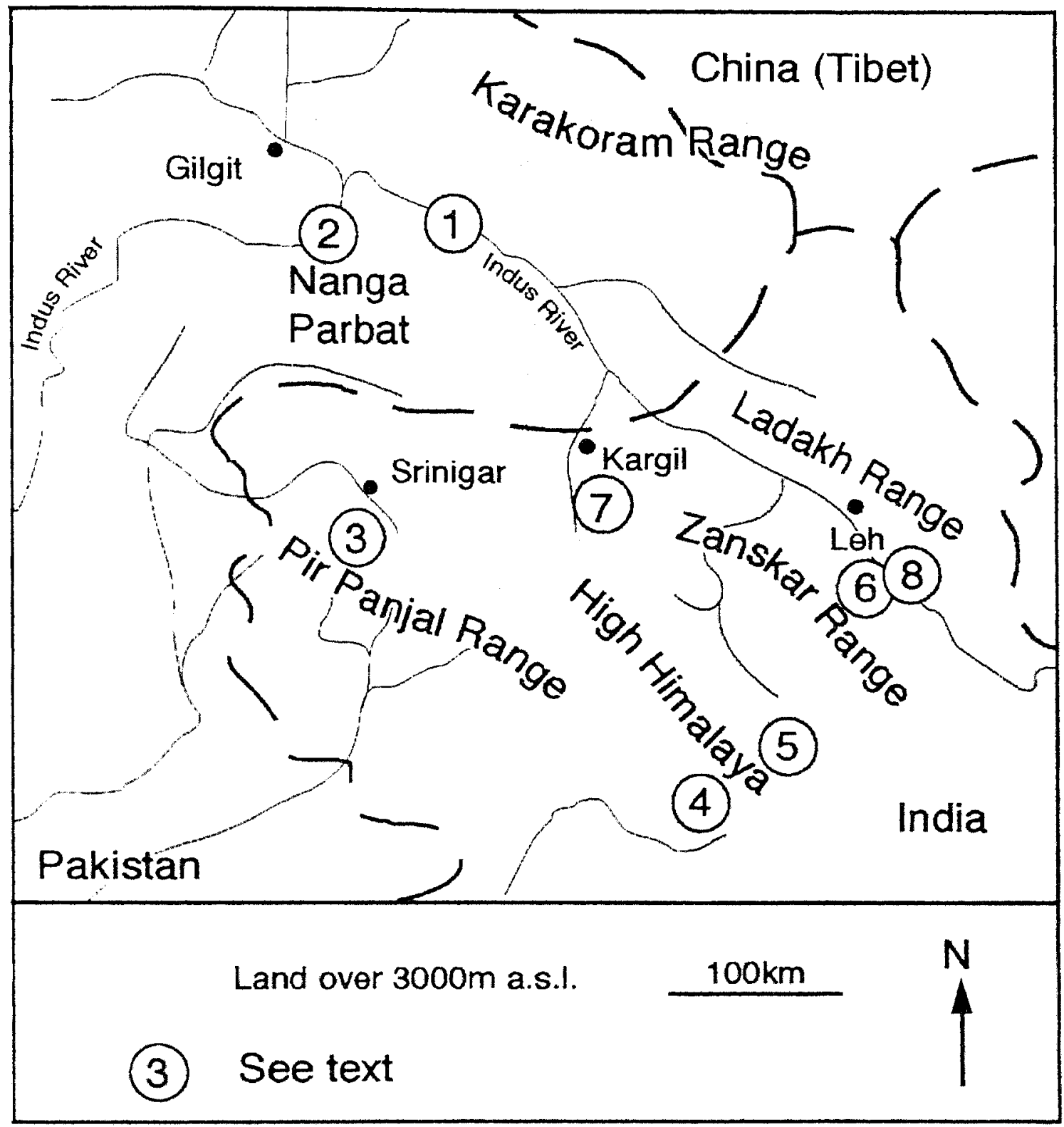

Figure 1.7 Location of north-west Himalayan uplift data. 
altitude gain (crustal uplift minus erosion). Although net uplift can be measured, near unique geological circumstances are required. For example, Abbot et al. (1997) were able to calculate surface uplift for the Finisterre Range of Papua New Guinea because they were able to demonstrate that erosion had been minimal. The uppermost formation has a porosity which indicates that it had never been weighed down by more than a few tens of metres of overburden and that the soft rock is currently eroding through the formation of karst dolines leaving the depositional surface intact. Beyond coastal areas, where sea-level provides a reference, it is notoriously difficult to quantify bedrock uplift rates (England and Molnar, 1990; Molnar and England. 1990). Nevertheless, Burbank et al. (1996) have attempted this in the Middle Indus valley, where cosmogenic dating of abandoned river straths have shown incision to have kept pace with tectonic uplift, with valley slopes adjusting through landsliding, (1 in Fig. 1.7). Errors are high with the calculated rate ranging from $2-12 \mathrm{mma}^{-1}$ measured over the last $0.65 \mathrm{Ma}$ (Burbank et al., 1996; Leland et al., 1998). In the same area, close to the Nanga Parbat massif, rates of $4.5 \mathrm{mma}^{-1}$ over $0.7 \mathrm{Ma}$ based on fission track methods (Zeitler, 1985) are also especially high (2 in Fig. 1.7). These data, however, are thought to be a regional anomaly due to "locally vigorous collision of India with Eurasia near a promontory of Indian crust..." (Zeitler, 1985, p127) and as such has little consequence for the Zanskar Range of India.

A conglomerate deposited onto what has become the flank of the Pir Panjal Range is dated using palaeomagnetism to $-0.4 \mathrm{Ma} \mathrm{BP}$ and can be demonstrated to have undergone a post-depositional elevation of at least $1400 \mathrm{~m}-1700 \mathrm{~m}$, giving a surface uplift rate of 3.4-10.0 $\mathrm{mma}^{-1}$ (Burbank, 1982; Burbank and Johnson, 1982, 1983) (3 in Fig. 1.7). Sharma et al. (1978) and Mehta (1980), employing mineral cooling temperatures, calculate crustal uplift rates of $0.7-0.8 \mathrm{mma}^{-1}$ over the past $25 \mathrm{Ma}$ and $0.55 \mathrm{mma}^{-1}$ over the past $8 \mathrm{Ma}$ respectively for the Kulu-Mandi Belt of Pir Panjal Range to the south of the study area (4 in Fig. 3.7). Geodetic data from the same area gives similar results Narain, 1975). Pressure, temperature and time constraints on metamorphism, based on rocks from the High Himalaya in eastern Zanskar and 
Kashmir (5 in Fig. 1.7), give an exhumation rate of $1.0-1.1 \mathrm{mma}^{-1}$ for the last $\sim 25 \mathrm{Ma}$ (Searle and Fryer, 1986; Searle et al., 1992).

A rate of $\sim 1.0 \mathrm{mma}^{-1}$ over $30 \mathrm{Ma}$ for the Zanskar Range ( 6 in Fig. 1.7) is interpreted by Holmes (1993) from the palaeontological evidence of Lakhanpal et al. (1983). Lakhanpal et al. (1983) present fossil evidence from near Hemis Gompa at $\sim 4000 \mathrm{~m}$ a.s.l. that suggests "moist tropical" conditions during the Eocene - Oligocene. This gives an uplift rate of $<0.1 \mathrm{mma}^{-1}$, assuming an elevation from close to sea-level, not $1.0 \mathrm{mma}^{-1}$ as incorrectly cited in Holmes (1993). Similar evidence for the Zanskar Range ( 7 in Fig. 3.7) (Guleria et al., 1983) when interpreted gives a rate of $0.15 \mathrm{mma}^{-1}$ over the last $\sim 20 \mathrm{Ma}$. Burbank and Fort $(1985, \mathrm{p} 147)$ suggest that Pleistocene uplift in the Ladakh Range ( 8 in Fig. 1.7) has been "limited" based on the geomorphological observation that "extensive fan-head deposits, linear mountain fronts and undissected fans (Bull and $M^{c}$ Fadden, 1977) are generally absent". It is noted, however, that this is negative evidence, which suggests, but does not prove minimal uplift.

The surface uplift rate calculated by Burbank (1982) is of great potential significance to this study for two reasons:

(1) Although not considering erosion of the crests, it suggests that surface uplift of the Pir Panjal may have been several hundreds of metres over the last few glacial/interglacial cycles, which may have significantly attenuated monsoon precipitation to the High Himalaya and Zanskar Ranges.

(2) It implies that glacial evidence might have been elevated by as much as $1000 \mathrm{~m}$, assuming, for the sake of example, a glacial event of $140 \mathrm{ka} \mathrm{BP}$ and an average surface uplift rate of $7 \mathrm{mma}^{-1}$.

This data, however, is $-350 \mathrm{~km}$ from the area of study and is consequently, like most of the examples, too distant for a confident correlation to be made, given that uplift is unlikely to have been uniform - even within the major lithotectonic zones. The few 
published rates are also for inappropriate time periods, with the majority relating to a period of $>20 \mathrm{Ma}$, which says little about uplift during the last two to three glacial/interglacial cycles. Within this interval uplift could have accelerated, decelerated or proceeded episodically. Nevertheless, tentative uplift rates for the Pleistocene appear to have been $\sim 0.1 \mathrm{mma}^{-1}$ for the Ladakh and Zanskar ranges, $\sim 1.0 \mathrm{mma}^{-1}$ for the High Himalaya and may have been several times higher for the Pir Panjal Range. In the absence of reliable uplift rates, which are relative to the Zanskar Range during the Late Pleistocene, use of uplift data to correct ELA values must be viewed as being a rough guide at best.

\subsection{Quaternary Proxy Evidence for Climate Fluctuations}

Most mountain glaciers are relatively simple mass transfer systems controlled essentially by precipitation and temperature, recording changes in those parameters by advancing and retreating (Clapperton, 1995). It is useful to view records of glacier fluctuations in conjunction with data for climate change from independent sources, particularly given the difficulty in separating the effects of changes in temperature and precipitation. As past climate cannot be observed directly, proxy measures have to be employed to gauge climatic fluctuations, particularly with respect to temperature and precipitation variation. The following section introduces the climatic proxy measures employed in connection with the Himalaya and highlights some of the problems of interpretation and correlation before examining the two main climatic systems to effect the region, the summer Indian Monsoon (Section 1.6.1) and the winter Westerlies (Section 1.6.2). The final part of this section examines previous work on glacial record of the Himalaya (Section 1.6.3).

Many varied proxy records have been used to investigate former climate of the Himalaya and environs (Figs. 1.8 and 1.9), some examples of which are described below. Palaeoshorelines in Rajasthan (e.g. Swain et al., 1983) and the Tibetan 


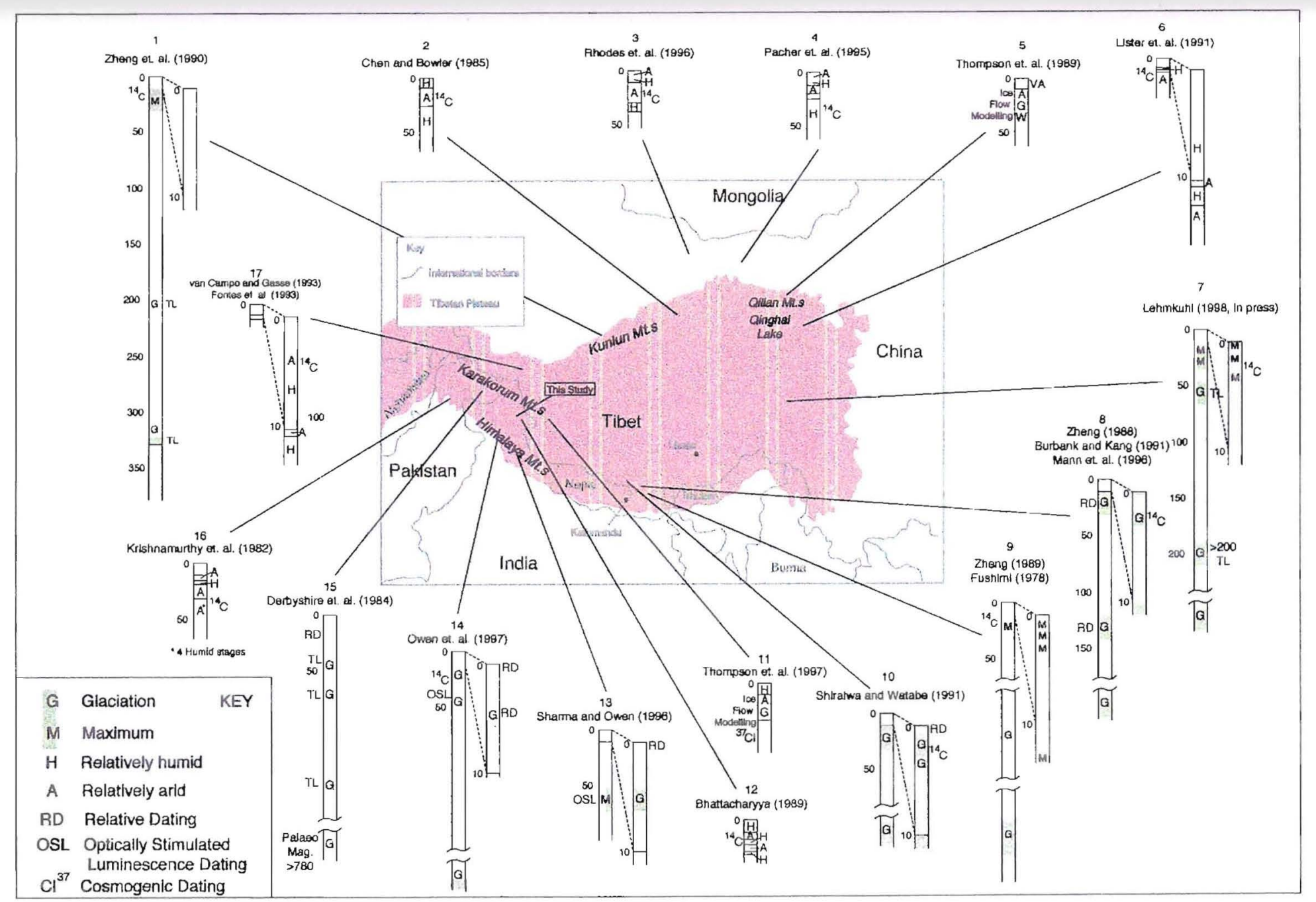

Figure 1.8 Palaeoenvironmental records from the Tibetan Plateau and bordering mountains. 


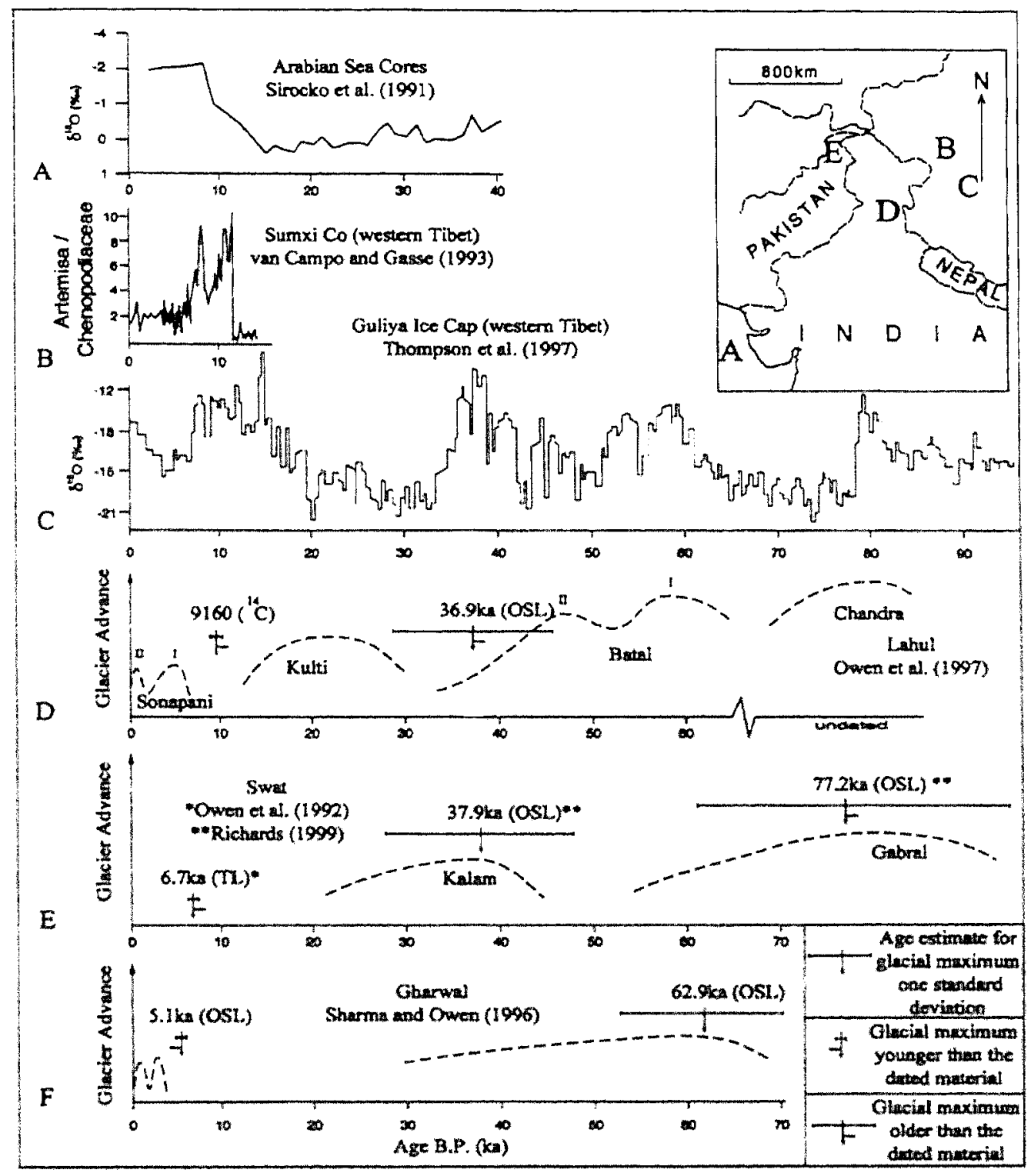

Figure 1.9 Selected proxy climatic records for the north-west Himalaya. (A) $\delta^{18} \mathrm{O}$ record from the northern Arabian sea (Sirocko et al., 1991). (B) Pollen record from Sumxi Co, western Tibet (van Campo and Gasse, 1993). (C) $\delta^{18} \mathrm{O}$ record from the Guliya Ice-cap, western Tibet (Thompson et al, 1997). (D) Glacial record from Lahul (Owen et al., 1997). (E) Glacial record from Swat, Pakistan (Owen et al., 1992; Richards, 1999). (F) Glacial record from Garhwal (Sharma and Owen, 1996). 
Plateau (e.g. de Terra and Huntington, 1934), which indicate raised former lake levels, have long been interpreted as representing relatively humid periods and/or relatively warm phases where supplied by glacial melt water. Lake sediments from these regions have been cored and the clastic, chemical and biological components of the sediment, which reflect environmental conditions of the water and surrounding land, have been studied. Of the many components investigated two of the most widely used are diatoms and pollen. The former, through the relative distribution of species and water chemistry of their tests (particularly stable isotope concentrations), have been used to infer conditions such as water temperature and salinity (Fontes $e t$ al., 1993). The latter reflects local vegetation and the associated climatic conditions required for its survival (e.g. van Campo and Gasse, 1993).

Pollen analysis of sediment from Indian Ocean cores has also been used to show changes in vegetation on nearby land (van Campo et al., 1982; van Campo, 1986; Prell and van Campo, 1986). Foraminifera tests from these cores have been studied in a number of ways. In particular, the biogeography (Prell et al., 1980) and relative abundance (e.g. Clemens et al., 1991; Reichart et al., 1997) of species known to favour specific environmental conditions have been investigated. In addition, $\delta^{18} \mathrm{O}$ concentration is often measured, which relates to fresh water input, evaporation rate and global ice volume (Duplessy, 1982; Prell and van Campo, 1986; Sarkar et al., 1990). Other biological indicators of climate that have been used include, Total Organic Carbon (TOC) (Schulz et al., 1998), alkenone records from phytoplanktonic algae (Rostek et al., 1993), coccoliths (Beaufort, 1996), biogenic opal from radiolaria and diatoms (Sirocko et al., 1993), and ${ }^{13} \mathrm{C} /{ }^{14} \mathrm{C}$ ratios of organic carbon (Fontugne and Duplessy, 1986). $\delta^{18} \mathrm{O}$ fluctuations are also recorded, along with dust and anion records, from a core in the Guliya ice-cap on the western Tibetan Plateau and have been used to infer climate change (Thompson et al., 1997).

These records are linked to climate through a number pathways, responding differently to climatic fluctuations. As such, the mechanisms of each palaeoclimatic 
proxy indicator must be carefully considered before interpretation and if possible several independent indices should be examined.

Interpretation and comparison of palaeoclimatic records can be difficult for the following reasons:

(1) Often different temporal periods are covered. Potentially long continuous records from ocean cores, which can cover hundreds of thousands of years (e.g. Clemens et al., 1991; Emeis et al., 1995), and ice cores of over 100ka (A and $C$ in Fig. 1.9), are difficult to compare to shorter lacustrine records of $13 \mathrm{ka}$ ( $\mathrm{B}$ in Fig. 1.9) or discontinuous terrestrial records (D, E and $\mathrm{F}$ in Fig. $1.9)$.

(2) Relatively low sampling resolutions from cores can miss short-lived climatic fluctuations, which may be manifest in higher resolution studies.

(3) Correlation between widely spaced sites is often made. For example, it is tempting to compare glacial records from the north-west Himalaya with the long lacustrine records from the far north of the Tibetan Plateau (sites 2, 3 and 4 in Fig 1.8), particularly given that there are no local records covering a similar time span.

(4) The relationship between the proxy climatic indicator and the climate may not be well understood, or be dependent on several factors.

(5) The same climatic proxy data can be given conflicting interpretations, particularly $\delta^{18} \mathrm{O}$ (cf. Gupta et al., 1992b), and can be expressed differently (e.g. as humid/arid or warm/cold, terms which are not necessarily interchangeable).

(6) Dating is often poorly constrained, leading to uncertainties in correlation (e.g. E in Fig. 1.9). 


\subsubsection{Fluctuations of the Indian Monsoon System}

The south-west Indian Monsoon causes a summer precipitation maximum in all but the extreme western parts of the Himalaya, with the consequence that many glaciers, particularly those in the central and eastern Himalaya, are summer accumulation types ( $c f$. Ageta and Kadota. 1992; Kulkarni, 1992). It is important, therefore, to examine fluctuations of this climatic system if the glaciation of the Himalaya is to be considered.

Palaeoclimatic records from both terrestrial sediments from northern India, the Himalaya and the Tibetan Plateau, and from Indian Ocean sediments have been interpreted as showing variations in the Indian Monsoon. Evolution of monsoon circulation over time scales of tens to hundreds of thousands of years has been studied using biological, biogeochemical and lithological evidence from ocean cores (Clemens et al., 1991; Emeis et al., 1995) and General Climate Models (GCMs) (Prell and Kutzbach, 1992, 1997; Anderson and Prell, 1993). The sedimentary record from the Arabian Sea exhibits major compositional oscillations that are synchronous with the 100ka periodicity of global ice volume changes (Shimmield, 1992). These cycles result from the dilution of carbonate sedimentation by lithogenic terrigenous aeolian sediment. The latter is an indicator of continental aridity, with high fluxes during glacial periods when the source areas of the Somalian and Arabian peninsulas had decreased vegetation covers and, therefore, increased deflation (van Campo et al., 1982; Clemens and Prell, 1990; Weedon and Shimmield, 1991). The biogeochemical sedimentary record in the Arabian Sea, however, is largely the history of monsoon induced upwelling (Shimmield, 1992). Strong winds associated with the Summer Monsoon cause upwelling along the Arabian coast. A number of indices have been related through various pathways to this upwelling and hence to monsoon strength:

Globigerinoides bulliodes (Fig. 1.10 A). This planktonic foraminifera is typically found in sub-polar water, but is also in high abundance in the cool nutrient-rich water associated with tropical upwelling. As such, the percentage abundance 
relative to other species is inversely correlated with Sea Surface Temperatures (SST) (Prell and Curry, 1981). With a relationship between SSTs and windinduced upwelling (Prell and Streeter, 1982), G. bulliodes has been used as palaeomonsoon upwelling index (e.g. Clemens et al., 1991; Emeis et al., 1995).

Opal flux (Fig. 1.10 B). A high opal flux, from radiolaria and diatoms, indicates high productivity and is therefore used as an index of silica productivity associated with monsoon-induced upwelling (e.g. Clemens et al., 1991).

Lithogenic grain size (Fig. $1.10 \mathrm{C}$ ). This reflects the competence of the monsoon winds, with stronger winds able to transport larger dust particles from desert source areas (Clemens and Prell, 1990). As titanium is concentrated in the coarser sediment fraction, the ratio of $\mathrm{Ti}$ to $\mathrm{Al}$ has also been employed as a palaeo-wind strength proxy indicator (Weedon and Shimmield, 1991).

Barium (Fig. 1.10 D). This element concentrates on the tests of marine plankton (principally diatoms) and is a potentially useful palaeoproductivity indicator for areas where organic carbon, opal and calcium carbonate records have been modified, as it is resistant to dissolution (Schmitz, 1987). However, Ba/Al, P/Al and $\mathrm{Ni} / \mathrm{Al}$ records are more strongly linked to the 100ka record of global ice volume than the other monsoon indicator records. This may be due to nutrient provision from continental runoff, and hence aridity, supplied by intermediate water (Weedon and Shimmield, 1991).

Organic Carbon (Fig. 1.10 E). Stable isotope studies can distinguish marine from terrigenous organic carbon (Reichard et al, 1997). Fluctuations in marine organic carbon are, therefore, controlled by variations in marine-produced organic matter either due to greater surface water productivity, or enhanced preservation (Reichard et al., 1997).

In spite of the difference in character of the records (Fig 1.10), the palaeomonsoon proxy indicators show similar large scale patterns. Differences between the records 


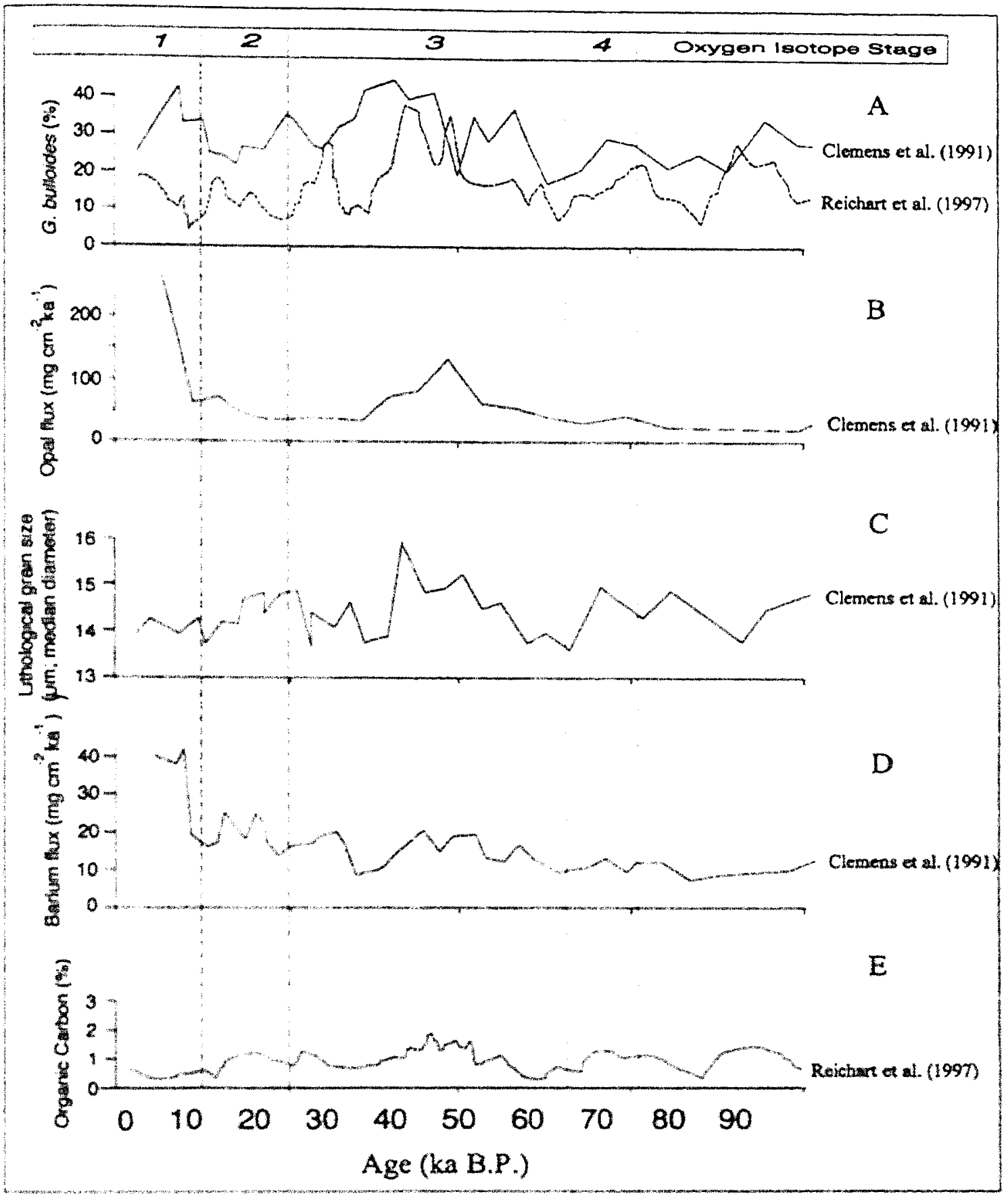

Figure 1.10 Records of monsoon strength from the Arabian Sea (A) G. bulloides, (B) Opal Flux, (C) Lithogenic Grain Size, (D) Ba/Al ratio and (E) Organic Carbon. The shaded area represents periods of strong monsoon See text for further explanation After. (lemens et al. (1991), Murry and Prell (1992) and Reichart et al. (1997) 
are attributed to differential opal and carbonate dissolution, dust-source area changes, sediment winnowing and ecosystem dynamics (Clemens et al., 1991).

Summer monsoon winds respond directly to changes in the distribution of solar radiation as determined by cyclical variation in the orbit of the Earth and indirectly through response to glacial boundary conditions. Cross spectral analysis of potential orbital forcing mechanisms and monsoon tracers shows that strengthened summer monsoon circulation occurs lagging Northern Hemisphere radiation maxima by $\sim 8 \mathrm{ka}$, with a strong coherence to the $23 \mathrm{ka}$ precession cycle and a moderate coherence to the $41 \mathrm{ka}$ obliquity cycle (Clemens et al., 1991). A $\delta^{18} \mathrm{O}$ record from the Guliya ice-cap of western Tibet also shows sub-tropical climate to be forced more strongly by precession than obliquity (Thompson et al., 1997). Only a weak coherence between records of monsoon strength and the $\delta^{18} \mathrm{O}$ record of global ice volume was indicated by phase relations (Clemens et al., 1991), in contrast to GCM simulations (Anderson and Prell, 1993). A near-shore 500ka long monsoon record shows a strong relationship between upwelling induced productivity and glacial boundary conditions, which relate to the 100ka eccentricity cycle (Emeis et al., 1995), although they have no spectral analysis to back this up.

Notwithstanding differences in the amplitude of response from the different palaeomonsoon proxy records, strong events appear to have peaked at 9, 50, 125, 215 and $261 \mathrm{ka} \mathrm{BP}$ and the monsoon seems to have been weak during Oxygen Isotope Stage (OIS) 2 and 4 (Clemens et al., 1991). Oxygen and carbon stable isotopes in pedogenic calcrete from the Indian Thar desert have also been interpreted as showing relatively weak summer monsoons during glacials for the last two cycles (Andrews $e t$ al., 1998).

Many studies of climatic proxy records, however, focus on the last glacial-interglacial transition. Vegetation changes on the Indian subcontinent, recorded by pollen in Arabian Sea cores, where $\delta^{18} \mathrm{O}$ records provide a time-scale, show aridity during the Last Glacial Maximum (LGM) of $\sim 18 \mathrm{ka} \mathrm{BP}$ (van Campo, 1986). This aridity reflects 
the weakened summer monsoon as recorded by records of wind induced upwelling intensity (Duplessy, 1982; Clemens and Prell, 1990; Sirocko et al., 1991; Weedon and Shimmield, 1991; Emeis et al., 1995). Terrigenous and biogenic sediments from Arabian Sea cores show that upwelling did not cease entirely during periods of weak south-west monsoon, but rather persisted for a shorter duration (Sirocko et al., 1991). Conversely, productivity in areas of the Arabian Sea, where it is dependent on terrestrial organic matter, increased during the global LGM indicating a strengthened north-east monsoon (Fontugne and Duplessy, 1986).

Terrestrial records of monsoon fluctuation, which are close to the study area and extend to the last glaciation, are scarce. Two lacustrine/terrestrial sedimentary climate records from north-west Indian Himalaya and western Tibet are available, although both are of a low resolution. Pollen from close to the field area of this study in the Zanskar Range (Bhattacharyya, 1989) and stable isotope studies of organic carbon from the Kashmir Basin (Krishnamurthy et al., 1982) indicates that there was widespread aridity during the last glaciation. These records have also been linked to westerly circulation and as such are discussed in greater detail in Section 1.6.2.

Long non-glacial terrestrial records exist from the far north-east of the Tibetan Plateau (Pachur et al., 1995), which combined with records from the Dunde ice core (Thompson et al., 1989, 1990) and loess from central China (Kukla and An, 1989), also show LGM aridity in Central Asia. These records are, however, associated with the East Asian Monsoon and are far from the Himalaya (sites 4, 5 and 6 in Fig 1.8).

Following the LGM, from $\sim 12.5 \mathrm{ka}$ BP and $11.5-11 \mathrm{ka}$ BP, the Indian Monsoon strengthened, as recorded by authigenic calcite from the Sumxi Co basin in western Tibet, which reflects relatively humid soil forming conditions with greater pedogenic $\mathrm{CO}_{2}$ inputs in the lake water (Fontes et al., 1993; van Campo and Gasse, 1993) (site 17 in Fig. 1.8). A dominance of the detrital calcite phase and rare pollen from arid plants from these records suggests a return to aridity from $11 \mathrm{ka} B P$ until $\sim 10 \mathrm{ka} B P$, possibly representing the Younger Dryas event. Relatively humid conditions 
followed this, as recorded by enhanced pedogenesis, increased vegetation in the catchment and an increase in aquatic life. A maximum in monsoon intensity was reached during the Early Holocene lagging the Northern Hemisphere summer insolation maximum, as recorded in lake core records from Rajasthan in India (Bryson and Swain, 1981: Swain et al., 1983), the Tibetan Plateau (van Campo and Gasse, 1993; Fontes er al. 1993), and from Arabian Sea cores (Prell and van Campo, 1986; van (ampo, 1986; van Campo et al., 1993).

Palaeoclimate simulations of GCMs are increasingly sophisticated and show the same general fluctuations of the monsoon recorded in the above geological records (Kutzbach et al, 1998). Although the spatial resolution is low, the south-west monsoon is simulated as having been weaker at $21 \mathrm{ka} \mathrm{BP}$, with a corresponding reduction in precipitation over south-east Asia and, due to reduced cloud cover, a reduction in effective precipitation (precipitation minus evaporation), particularly over the central and eastern Himalaya. Temperatures are modelled as being relatively low, particularly in the north-west Himalaya. Summer monsoon winds, precipitation and effective precipitation increased along with both summer and winter temperatures at $16 \mathrm{ka} \mathrm{BP}$. At $11 \mathrm{ka}$ BP there was an increase in seasonality, with a greater contrast between summer and winter temperatures, due to greater summer time insolation. The summer monsoon was strong and both precipitation and effective precipitation were also inereased. At $6 \mathrm{ka}$ BP the summer monsoon was stronger still, temperatures were higher and seasonality was only slightly less pronounced than for $11 \mathrm{ka} \mathrm{BP}$.

Monsoon variation cannot be explained solely through changes in insolation. An increase in albedo during glacial periods in Central Asia, due to greater snow and ice cover at high and mid Asian latitudes, has also been proposed to explain the observed wind driven upwelling fluctuations (Duplessy, 1982; Sirocko et al., 1991; 1993). This higher albedo is thought to have delayed the warming of the continent during glacial summers, resulting in a reduced contrast in the heatpressure gradient and thus a weakening of the summer monsoon. Conversely, in glacial winters the continent 


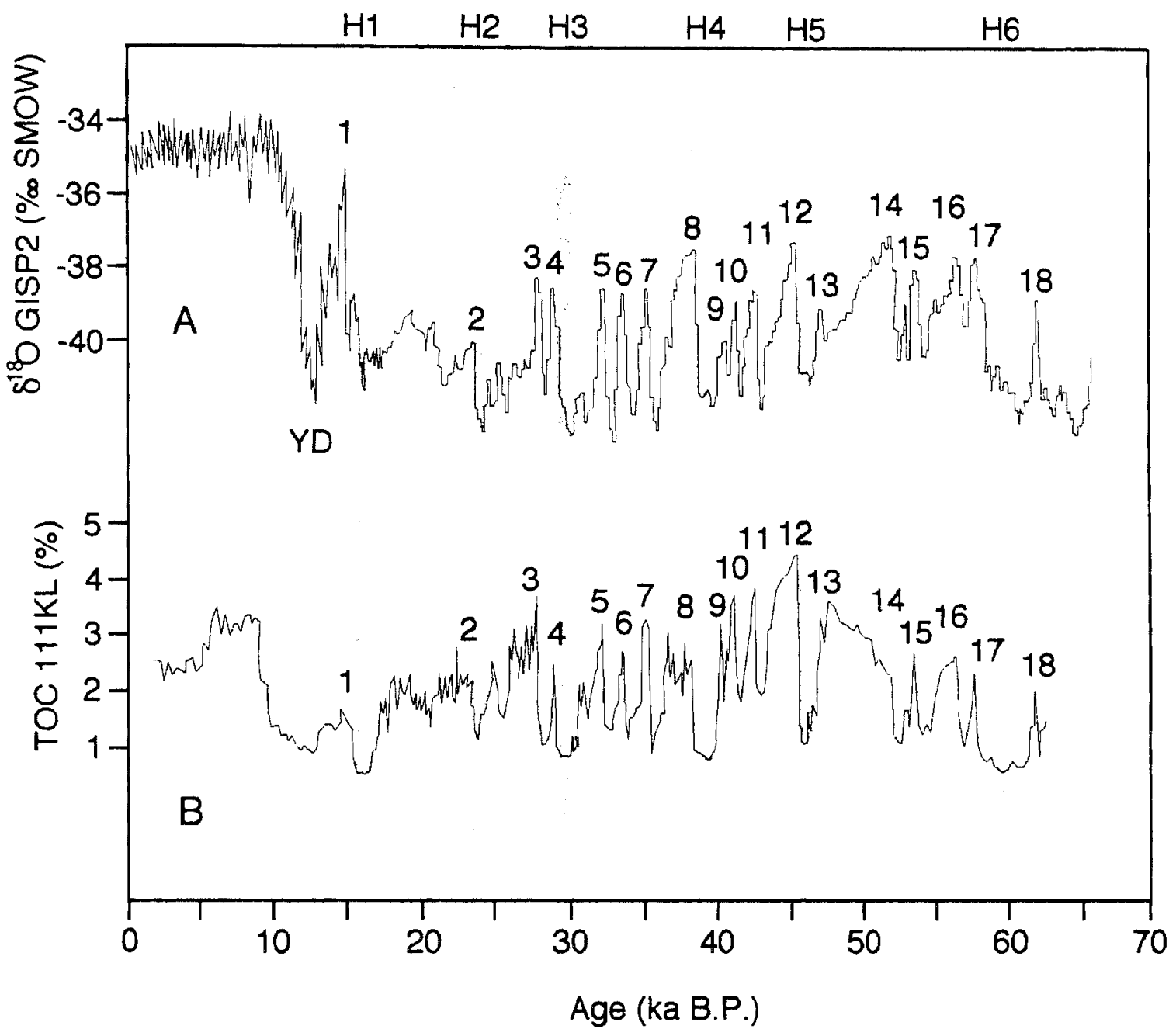

Figure 1.11 Comparison of high latitude (North Atlantic) and low latitude (monsoonal) palaeoclimate records, after Schulz et al. (1998). (A) Greenland GISP2 $\delta^{18} \mathrm{O}$ ice record. (B) High resolution marine TOC-record of core SO90-136KL off Pakistan, indicating variability of monsoonal surface water productivity and bottom water oxygenation. Numbers represent the Greenland interstadials and equivalent Arabian Sea monsoonal events. H1-H6 indicate northern Atlantic Heinrich meltwater events. 
would be cooler relative to the ocean, enhancing the heat contrast/pressure gradient and therefore strengthening the winter monsoon. Modern meteorological data shows that cold Northern Hemisphere winters precede seasons of weakened Indian summer monsoons, lending support to this reasoning.

Explanations of monsoon fluctuation that involves changes in albedo on the Tibetan Plateau have cited a Tibetan-wide ice-sheet ( $c f$. Section 1.7; Kulhe, 1986; 1998) as supporting evidence (e.g. Emeis et al., 1995). Although this ice-sheet hypothesis is firmly rejected by numerous authors (e.g. Derbyshire et al., 1991), the importance of such changes cannot be discounted. An intensification and change in position of the Siberian High caused by the growth of mid-latitude Northern Hemisphere ice-sheets may have, in combination with lower average continental temperatures, increased the albedo of the Tibetan Plateau through vegetation and snow cover changes (Ding, et al., 1995). This would have delayed the formation of the summer low pressure and possibly influenced the seasonal position of the southern branch of the westerly jet (Benn and Owen, 1998).

Recent studies (Thompson et al., 1997; Schulz et al., 1998) provide high resolution palaeoclimatic records which show low latitude monsoonal climate to be more complex than previously appreciated, exhibiting many of the high frequency fluctuations on time scales of millennia and centuries observed in high latitude records (Fig. 1.11). A comparison of South Asian Monsoon (Arabian Sea cores) and North Atlantic (Greenland ice cores) records show that Dansgaard-Oeschger and Heinrich events are strongly expressed in low latitude monsoonal climate variability, illustrating the importance of common forcing agents like, perhaps, atmospheric moisture (Schulz et al, 1998). A 125ka record extracted from an ice core from the western Tibetan Plateau also exhibits high frequency climatic fluctuations of the monsoon thought to represent a possible 200 year cycle of sun spot activity (Thompson et al., 1997). This added complexity may be significant for Himalayan glaciations, with those glaciers particularly sensitive to monsoonal precipitation advancing following precipitation peaks, whereas those more sensitive to ablation 
having maxima closer to $\sim 20 \mathrm{ka} B P$ - a period with no large peaks in monsoon activity, but of low global temperatures.

\subsubsection{Fluctuation of the Mid-latitude Westerly System}

The extreme western parts of the Himalaya and environs have a winter precipitation maximum associated with mid-latitude westerlies bringing moisture from the Mediterranean, Black and Caspian Seas (Benn and Owen, 1998). It is, therefore, important for the study of Himalayan glaciation to examine fluctuations of this climatic system.

Only two palaeoclimatic records from the Himalaya have been linked to fluctuations of the mid-latitude westerlies. A study of pollen from Tso Kar, a lake in Ladakh a few tens of kilometres from the field area for this study, shows the period from $\sim 28$ $30 \mathrm{ka} \mathrm{BP}$ to $10 \mathrm{ka} \mathrm{BP}$ as arid with a $3 \mathrm{ka}$ period of relative humidity at $\sim 20 \mathrm{ka} B P$, as indicated by an increase in Juniperus pollen ( $\mathrm{A}$ in Fig. 1.12; Bhattacharyya, 1989). This record, however, has a low resolution, with the pollen diagram showing only 12 samples covering $>20 \mathrm{ka}$, and a poor dating control, with the ${ }^{14} \mathrm{C}$ age estimate closest to the Juniperus peak displaying an error of $\pm 2 \mathrm{ka}$ (Fig. 1.12). Further to the southwest in Kashmir, Krishnamurthy et al. (1982) studied Plio-Pleistocene infillings in the intermontane Kashmir Basin, using among other proxy measures, $\delta^{13} \mathrm{C}$ values from organics in buried soils to show the relative abundance of $\mathrm{C} 4$ plants, indicative of deserts and salt marshes, to $\mathrm{C} 3$ plants, indicative of less marginal environments, which show a warm/wetter phase from $\sim 18-15 \mathrm{ka}$.

These two relatively humid periods at $\sim 20 \mathrm{ka} \mathrm{BP}$ and $18-15 \mathrm{ka}$ BP have been correlated and linked to moisture advection from westerly atmospheric circulation. This connection has been made on the basis that the records are in phase with parts of the Mediterranean which were also wetter (van Zeist and Bottema, 1982), but not with areas to the south of the north-west Himalaya (Bhattacharyya, 1989; Benn and Owen, 1998). The study carried out by van Zeist and Bottema (1982) looked at a 


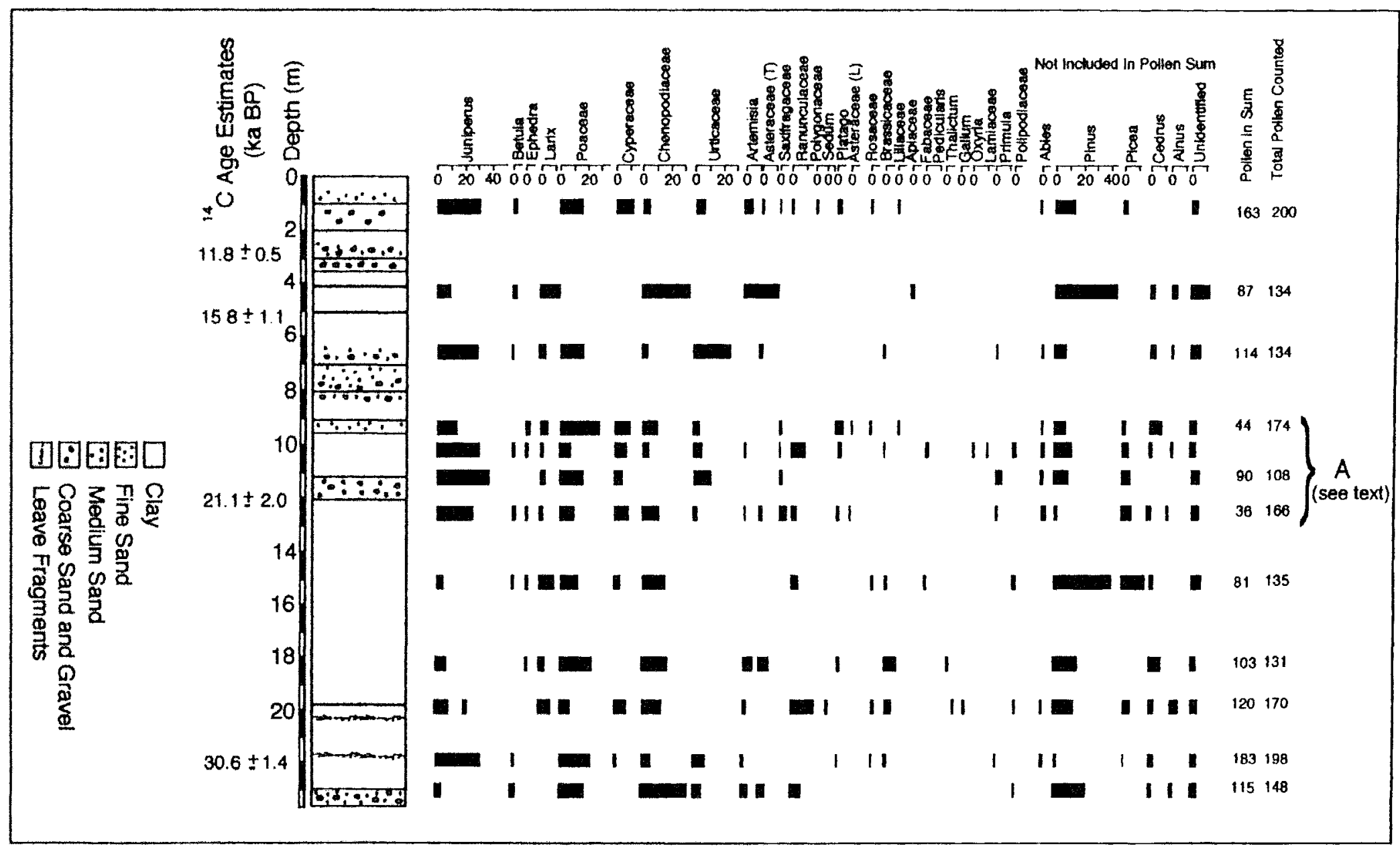

Figure 1.12 A pollen record from Tso Kar, Ladakh (after Bhattacharyya, 1989). 
number of pollen sites from the eastern Mediterranean and Near East. They produced curves of relative humidity with time based on a Aboreal/non-Aboreal pollen index. Of the seven records that extend to $20 \mathrm{ka} B P$, two show a slight increase in moisture at 20-18ka BP and one before 20ka BP. There are a few ${ }^{14} \mathrm{C}$ dates from some of the cores investigated, but no numerical age estimates directly constraining the periods of relatively increased humidity with ages inferred using sedimentation rates. The authors themselves describe their ideas as "highly speculative" due to the "many uncertainties", not least the lack of dating (van Zeist and Bottema, 1982, p317).

With the lack of data from the Himalaya region, records from the west, which also lie on the path of the Northern Hemisphere westerly circulation, must be considered. Several recently investigated palaeoclimatic records from lake (Leroy et al., 1996, Watts et al., 1996) and marine (Rossingnol-Strick, 1995; Zonneveld, 1996) cores exist for the eastern Mediterranean. Summer climate is dominated by the subsidence of subtropical dry air, whereas winter climate is dominated by cyclonic rain bearing westerlies. The general climate of the eastern Mediterranean, as deduced from a lacustrine pollen record from Italian lakes, shows Oxygen Isotope Stage (OIS) 4 and especially OIS 2 to have been cold and arid, with OIS 3 exhibiting seven warm/humid pulses (Fig. 13; Leroy et al., 1996; Watts et al., 1996). The variations in Mediterranean climate have been shown to correlate with the Dansgaard-Oeschger and Heinrich events of the north Atlantic record (Watts et al., 1996). A cold, dry last glaciation is also identified through study of pollen and Dinoflagellate cysts from an eastern Mediterranean Sea core (Zonneveld, 1996). From 13.2ka BP, temperatures increased accompanied by increased freshwater input from the River Po, caused by melting of glaciers from the Alps and Apennines. Records of glaciation and pollen suggest that two further increases in freshwater input at $12.8-12.2 \mathrm{ka} \mathrm{BP}$ and $12-$ $11.2 \mathrm{ka} \mathrm{BP}$ do not relate to melting of ice or summer precipitation, but to an increase in winter precipitation (Zonneveld, 1996). Between $11 \mathrm{ka} \mathrm{BP}$ and 10ka BP the climate was cold and arid, becoming warm and humid after 10ka BP. No mention is 


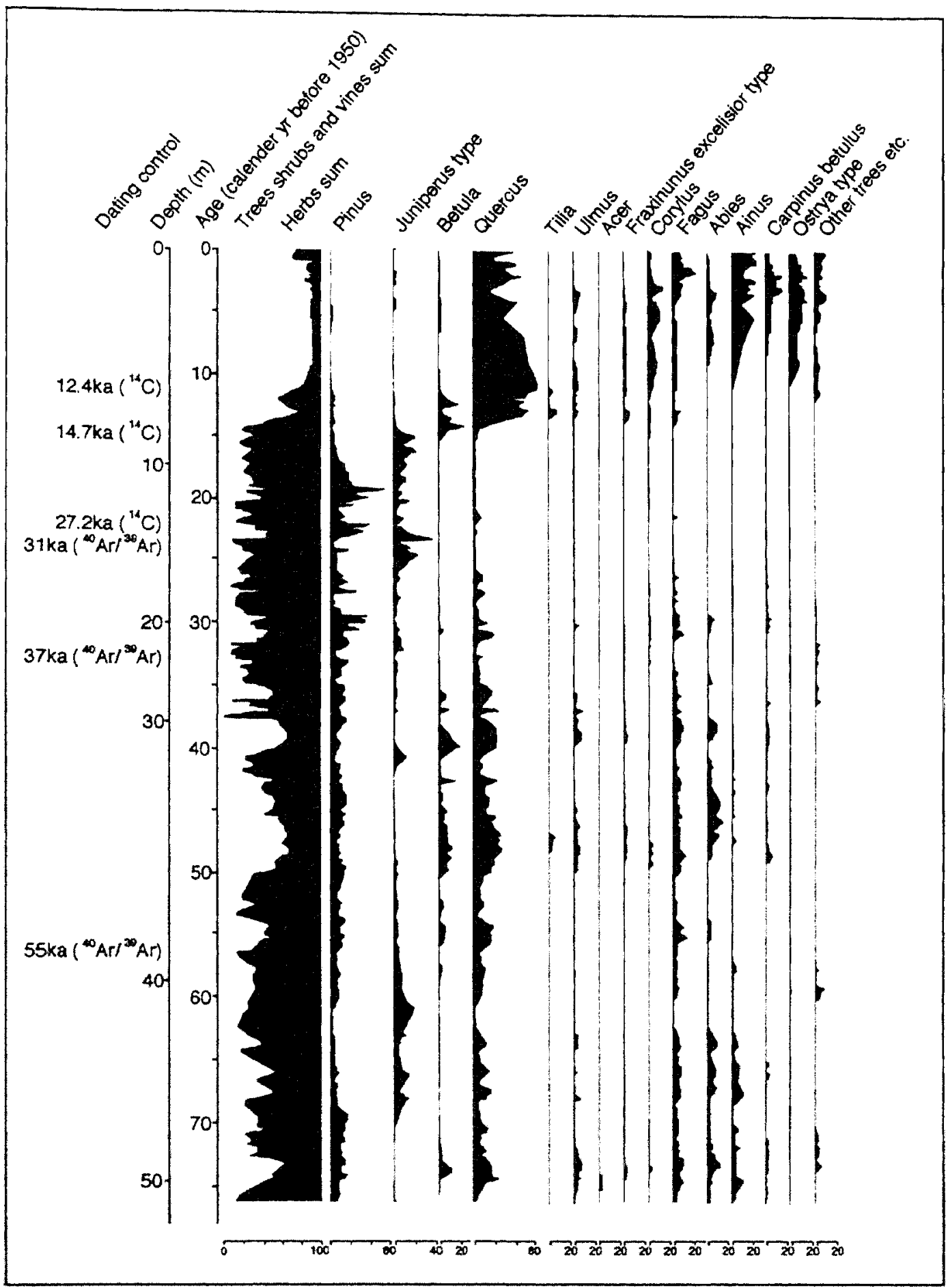

Figure 13 Selected tree, shrub and vine pollen diagram from a lake core in Lago Grande di Monticchio, southern Italy (after Watts et al., 1996). 
made of warming or increased precipitation, which could be correlated with the north-western Himalayan records.

A more recent pollen and diatom study from an Italian lake core focuses on a brief interstadial during OIS 2, from 23.7-21.2ka BP, showing that Mediterranean climate was more variable than previously supposed (Nimmergut et al., 1999). With this new work from the Mediterranean, the correlation made between this region and the northwest Himalaya has increased validity. However, the low resolution and poor dating control of the north-western Himalayan studies are still problematical. For example, if the dating is too old the warmer/wetter phase in the Himalaya could represent monsoon precipitation, which is simulated by General Circulation Modelling as having increased by 16ka BP (Kutzbach et al., 1998).

Environmental reconstruction from central Turkey shows high lake levels before $28.3 \mathrm{ka} \mathrm{BP}$, three phases from 22.1-20.6ka BP, 19.5-19.0ka BP and 18.5-17.0ka BP, and from 13.5-11.0ka BP (Fontugne et al., 1999). As palynological studies indicate that the climate was dry during the LGM (Rossingnol-Strick, 1995), the three phases of high lake levels from 22.1-17.0ka BP are attributed to reduced evaporation and increased precipitation at altitude (Fontugne et al., 1999). Reduced evaporation may have been cause by lower insolation, lower temperatures, more cloud cover and longlasting ice on the lake. Complementary to this, the westerly cyclonic circulation may have provided increased precipitation to the Tauns Mountains in winter, which may have fed the lake basin. This supposition is, however, based on the circumstantial evidence of there having been expanded glaciers in Taurus Mountains as demonstrated by moraines (Fontugne et al., 1999). These moraines are not dated and may not correspond to the high lake levels (cf. Gillespie and Molnar, 1995). Moreover, the glacier advance could have been due solely to a decrease in temperature without increased precipitation.

Mid-latitude westerlies are split into northern and southern branches by the Tibetan Plateau. Two lacustrine sediment records from the north of the Tibetan Plateau may 
reflect fluctuations in the northern branch of this system (Chen and Bowler, 1985; Rhodes et al., 1996; sites 2 and 3 in Fig. 1.8). Employing various chemical and biological climatic proxies, both records of $\sim 40 \mathrm{ka}$ show relatively humid conditions prior to $32-30 \mathrm{ka} \mathrm{BP}$, followed by aridity during the last glaciation and increased humidity during the early Holocene. Rhodes et al. (1996) also report a minor humid phase at $\sim 12 \mathrm{ka}$ BP. These records, like those recording the winter East Asia Monsoon (site 4 in Fig. 1.8), however, may relate more to fluctuations in the Mongolian High, the position and strength of which is associated with the formation of mid-latitude ice-sheets (Xiao et al., 1995).

GCM simulation shows relatively strong mid-latitude westerlies at $21 \mathrm{ka} \mathrm{BP}$ (Kutzbach et al., 1998), which may also be reflected in palaeoclimatic records from the north-west Himalaya (Krishnamurthy et al., 1982; Bhattacharyya, 1989) and from the eastem Mediterranean (van Zeist and Bottema, 1982). There is a paucity of data for mid-latitude westerlies over the north-western Himalaya, forcing the use of climatic proxy records from distant areas, the results of which are not consistent and may be of little relevance.

In addition to vigour of the westerly system, moisture availability may have been an important factor. The area of the Caspian Sea, which is a potential moisture source for westerly winds, has fluctuated over the Late Pleistocene. Relative to the present level of $-28.5 \mathrm{~m}$ a.s.l., the Caspian Sea surface was relatively high prior to $75 \pm 2.6 \mathrm{ka}$ BP (Uranium-Ionium dating), but then underwent a regression period during OIS 4, followed by a transgression (Mamedov, 1997). The latter event has been difficult to date due to contamination of radiocarbon and uranium series samples and inaccuracies in early Thermoluminescence (TL) methods. New TL age estimates bracket the event to between $32 \pm 3 \mathrm{ka} \mathrm{BP}$ and $24 \pm 2 \mathrm{ka} \mathrm{BP}$ (references in the review of Russian literature by Mamedov, 1997). After a regression to $-133 \mathrm{~m}$ a.s.l., at 24-17ka BP $\left({ }^{14} \mathrm{C}\right)$ (Mamedov, 1997) or 22-20ka BP $\left({ }^{14} \mathrm{C}\right)$ (Karpytchev, 1993), the level of the Caspian Sea increased to $-0 \mathrm{~m}$ a.s.l. until $11300 \pm 180 \mathrm{yr}$ BP $\left({ }^{14} \mathrm{C}\right)$ after which it 
underwent a regression decreasing to $-133 \mathrm{~m}$ a.s.l. or lower by $9300 \pm 180 \mathrm{yr} \mathrm{BP}\left({ }^{14} \mathrm{C}\right)$. The inland sea was again high by 7600-8300yr BP (Karpytchev, 1993). Fluctuations in melt water are proposed as the primary factor in controlling Caspian Sea level throughout the Late Quaternary, with transgression events associated with climatic warming and regression events with cold periods (Mamedov, 1997). Relative to transgressions, little is known of regression events, although Mamedov (1997) infers a decrease in Caspian Sea level for OIS 4 of equivalent magnitude to that of OIS 2. It would seem, therefore, that the surface area of the Caspian Sea available for the supply of moisture to westerly circulation through evaporation was less during OIS 4 and 2 relative to OIS 3 and 1 .

There is scant palaeoclimatic data available for fluctuations of the westerly circulation, which may have affected glaciation in the north-west Himalaya. Nevertheless, winds during OIS 2 appear to have brought relatively little moisture to the region, but may have had a humid phase at 20ka BP (cf. Nimmergut, 1999).

\subsubsection{Glacial Records}

There are many glaciers of varying dimensions in the Himalaya and Tibetan Plateau, with some areas such as the Karakoram Range and Khumbu Himal heavily glaciated with other parts, such as the Zanskar Range, with minimal glacier cover. Geological evidence for Pleistocene glaciation has long been recognised from the Himalaya and Tibetan Plateau (e.g. Hendin, 1899-1902; Dainelli, 1923), with a resurgence of interest in the problems of glaciation over the last fifteen years (e.g. Williams, 1983; Burbank and Fort, 1985; Holmes and Street-Perrott, 1989; Osmaston, 1989, 1994, in prep. a; Burbank and Kang, 1991; Shiraiwa and Watanabe, 1991; Kulkarni, 1992; Holmes, 1993; Mann et al., 1996; Mazari, 1996; Mitchell et al., 1996; Owen et al., 1996, 1997, 1998; Sharma and Owen, 1996).

The Himalaya is a tectonically active mountain belt with high relative relief that acts as a strong climatic divide between the monsoon dominated southern slopes and rain 
shadow to the north, and as such presents particular problems for the study of former glaciation. For example, on the southern monsoon dominated side, vegetation can obscure, and frequent mass-movement events can rework, glacial landforms and sediments. On the arid northern side there is a lack of organic material suitable for traditional dating methods and degradation of landforms by active periglacial processes (Fort, 1995). In spite of these difficulties and of distinguishing between glacial and non-glacial diamicts (Derbyshire and Owen, 1990; Hewitt, 1999), the sediments and landforms relating to Himalayan glaciations have been successfully employed in palaeoglacier reconstruction (e.g. Owen et al., 1996, 1997).

There is a general consensus that the north-west Himalaya and Karakoram Mountains have experienced three major glaciations and a number of minor advances. However, there are many unresolved issues regarding the number of stades each event had and the assignment of sediments to particular events (cf. Shroder et al., 1993). High level glaciated surfaces, which are deeply incised by the present valley system are recorded in most of the areas studied in the north-west Himalaya, with ice interpreted as having occupied broad valleys (Porter, 1970; Zhang and Shi, 1980; Derbyshire, et al., 1984; Owen, 1988; Shroder et al., 1989, 1993; Osmaston, 1994; Owen et al., 1996; 1997, 1998; Derbyshire and Owen, 1997; Mitchell et al., 1999). In the Hunza Valley of northem Pakistan, Derbyshire et al. (1984) distinguished two palaeosurfaces with weathered erratics, ascribing these to the Shanoz and Yunz glacial stages (Fig. 1.14). As for the other areas, there are no numerical age estimates for these early glaciations. There must have been, however, enough time to have allowed $>300 \mathrm{~m}$ erosion to form the present valley system and, they must be older than dated sediments from close to modern valley floors.

A major valley glaciation with evidence in the form of large moraines from within the current valleys is recognised by all the studies, a few of which are partly constrained by numerical age estimates. In the Hunza valley the glaciation which represents the maximum advance in the deep troughs, the Borit-Jheel, is dated as older than 139.0 $12.5 \mathrm{ka}$ BP (Derbyshire et al., 1984). The reliability of this age estimate, 

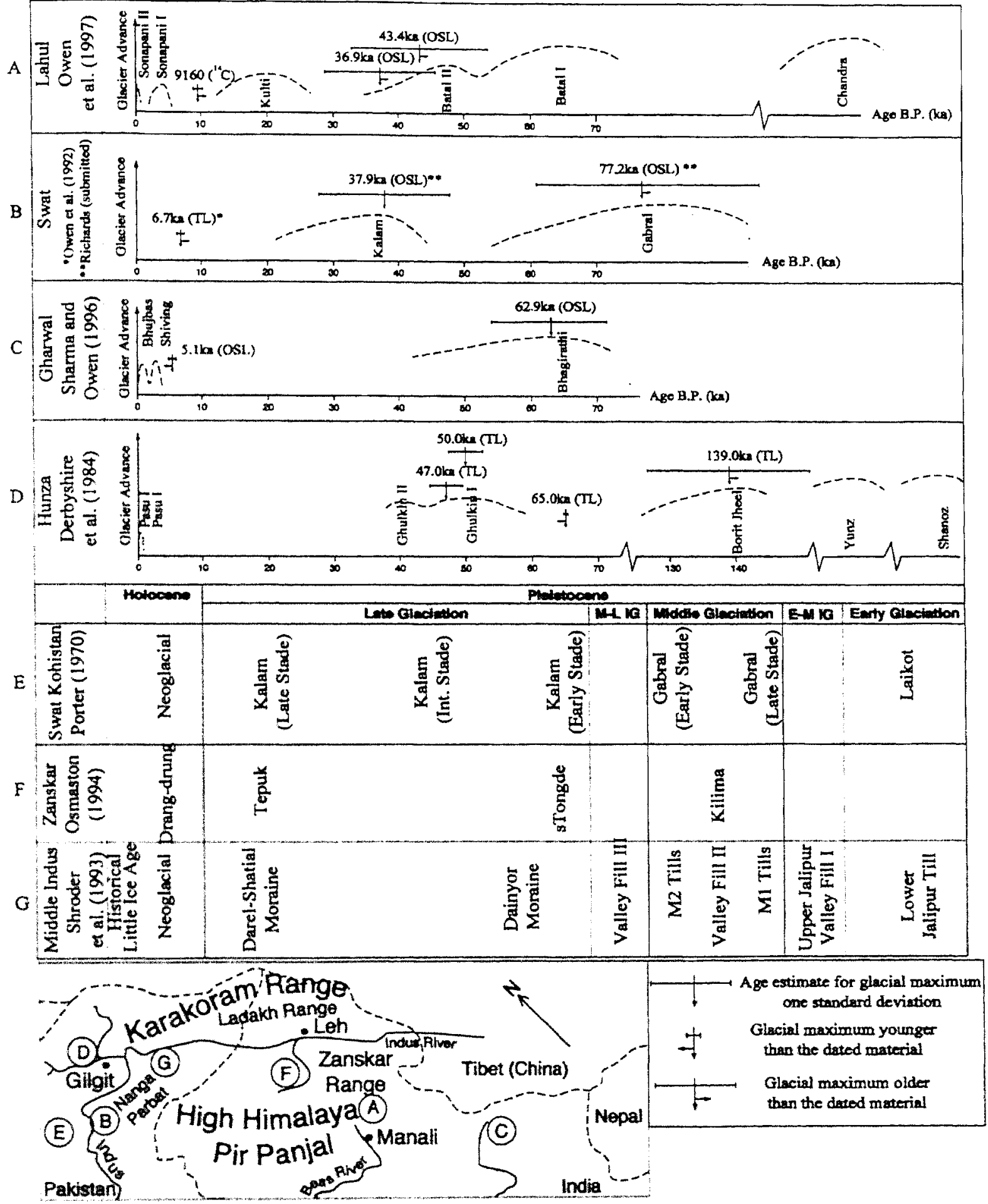

Figure 1.14 Glacial chronologies from the north-west Himalaya. Upper part of the table shows sequences with numerical age constraints and the lower part has those without numerical age estimates. Note that the TL dates for Hunza (D) are not considered safe and there is some doubt as to the reliability of the age estimates for Kalam Stage of Swat (see text). 
among the first to use Thermoluminescence (TL) dating on Himalayan glacial sediments, has been questioned (Shroder et al., 1993). Errors are unrealistically small and no explanation of the dating technique is available and, as such, TL dates from this paper should be viewed with caution. The reliability and interpretation of some of these dates are discussed in Chapter 6. In Lahul a similar glaciation, the Batal, is thought to have proceeded in two stages, both of which were at their maxima before deltaic sediments were deposited at $43.4 \pm 10.3 \mathrm{ka} \mathrm{BP}$ and $36.9 \pm 8.4 \mathrm{ka} \mathrm{BP}$ (Optically Stimulated Luminescence - OSL) (Owen et al., 1997). An age estimate from Namunani Peak, close to the western border of Nepal and India, places glaciation to before $41.1 \pm 1 \mathrm{ka}\left({ }^{14} \mathrm{C}\right.$ ) (Derbyshire et al., 1991), but no further information is given on the material dated or its association with the glacial sequence. Moraine ridges which represent maximum advances of the same style in Garhwal, Shiteral in the Middle Indus valley and Swat are dated to $62.9 \pm 8.6 \mathrm{ka} \mathrm{BP}$ (OSL) (Sharma and Owen, 1996), $59.1 \pm 8.5 \mathrm{ka}$ BP and $77.2 \pm 18 \mathrm{ka}$ BP (OSL) (Richards, 1999) respectively (Fig. 1.14). Based on the dates published from Garwal and Lahul, Benn and Owen (1998) suggest that this glacial event reached its maximum extent at $\sim 30-60 \mathrm{ka}$ BP (OIS 3 ) when the Indian monsoon was relatively strong.

A second less extensive valley glaciation has also been recognised in most areas, represented by a distinctive set of moraine ridges, but is equally poorly age constrained. In the Hunza valley there are three TL dates associated with a second advance within the present valleys, the Ghulkin I and Ghulkin II. Ghulkin I is dated to younger than $65.0 \pm 0.3 \mathrm{ka} \mathrm{BP}$ with two dates for a maximum of $50.0 \pm 2.5 \mathrm{ka} \mathrm{BP}$ and 47.0 $\pm 2.4 \mathrm{ka} \mathrm{BP}$ (Derbyshire et al., 1984). Unfortunately, as outlined above, these TL dates are unlikely to be accurate. Richards (1999) presents an OSL date of $37.9 \pm 10.0 \mathrm{ka}$ BP for a similar glacial advance in Swat, but questions the reliability of this age estimate as the dose-response curve shows considerable scatter. This date is not repeated and consequently is not considered to be reliable. $\mathrm{A}{ }^{14} \mathrm{C}$ date from peat in Lahul (Owen et al., 1997) implies that glaciation had ended by $9160 \pm 70 \mathrm{yr}$, but the peat overlies moraines of the older Batal Stage (Fig. 7b in Owen et al., 1997), saying 
little about the younger Kulti Stage (Fig. 1.14). No equivalent glaciation was found in the Garhwal (Sharma and Owen, 1996).

One or two Holocene advances are reported from the north-west Himalaya, recorded by sharp crested moraine ridges close to present glaciers. Only in the Hunza Valley are these moraine ridges dated, with ${ }^{14} \mathrm{C}$ dating of wood fragments giving age estimates of $830 \pm 80 \mathrm{yr}$ for an outer flank and $325 \pm 60 \mathrm{yr}$ for the proximal flank (Derbyshire et al., 1984).

To the north, ${ }^{14} \mathrm{C}$ dating of organics bracket moraines representing the maximum of the last glaciation from the West Kunlun Mountains to $22904 \pm 950 \mathrm{yr}-21046 \pm 716 \mathrm{yr}$ $\mathrm{BP}$ and $18250 \pm 625 \mathrm{yr}-16151 \pm 553 \mathrm{yr}$ BP (Derbyshire et al., 1991). In the northern Karakoram Mountains ${ }^{14} \mathrm{C}$ age estimates of $19045 \pm 365 \mathrm{yr}-24420 \pm 310 \mathrm{yr}$ BP have been obtained (Zhang and Shi, 1989 cited in Derbyshire et al., 1991) and material included in moraines from the Keriya Pass to the north-west of the Karakoram Mountains dates to $18140 \pm 319 \mathrm{yr}-15790 \pm 384 \mathrm{yr} \mathrm{BP}\left({ }^{14} \mathrm{C}\right.$ ) ( $\mathrm{Li}$ and Shi, 1992). The maximum advance of the last glaciation in the Kunlun Mountains and northern part of the Karakoram Mountains, therefore appears to coincide with the global LGM. This is out of step with the north-west Himalaya, unless older glacial limits assigned to the Middle Pleistocene (Zheng et al., 1990; Derbyshire et al., 1991) date to the early part of the last glaciation. A TL age estimate of $206 \pm 17 \mathrm{ka} \mathrm{BP}$ exists for this Middle Pleistocene glaciation from the Kunlun Mountains (Zheng et al., 1990), but no explanation of how the sample, a till, was exposed to light or details of the methodology are given, raising questions about its reliability.

A recent paper reinterprets fifteen landforms from the Karakoram Mountains, previously considered to be moraine limits, as catastrophic rock avalanches (Hewitt, 1999). Although not proposing an alternative chronology of glacial events, Hewitt (1999) questions existing interpretations based on these mass-movement deposits, particularly those which follow the pioneering work of Dainelli $(1914,1923)$, like the study by Shroder et al. (1993). 
Several studies from the central Nepal Himalaya have been published (sites 8, 9 and 10, in Fig. 1.8). Although two Middle Pleistocene extensive valley glaciations are reported (Zheng, 1988, 1989c; Burbank and Kang, 1991; Shiarawa and Wantanabe, 1991; Mann et al., 1996), as for the north-west Himalaya, no dating for these is available. The maximum of the last glaciation is dated to $\sim 18-20 \mathrm{ka} \mathrm{BP}$ by Benn and Owen (1998), who have two Infra-red Stimulated Luminescence (IRSL) age estimates of $18.3 \pm 4.5 \mathrm{ka} \mathrm{BP}$ and $18.7 \pm 2.4 \mathrm{ka} \mathrm{BP}$. A further seven OSL age estimates, all of which fit within one standard error, give an earlier maximum of $25-20 \mathrm{ka} B P$ (Richards, 1999). This is convincing evidence for the maximum advance of the last glaciation having been during OIS 2, close to the global LGM. A late glacial advance is described and dated, also using multiple OSL samples, to $\sim 10 \pm 2 \mathrm{ka}$ BP (Richards, 1999). Three Holocene advances, one of which dates from 3.6-3.0ka B.P $\left({ }^{14} \mathrm{C}\right)$ (Shiarawa and Wantanabe, 1991) with another dating to the Little Ice Age $\left({ }^{14} \mathrm{C}\right)$ (Fushimi, 1978), have also been reported.

Currently only a small proportion of the Himalaya as a whole has been investigated with regards to it glacial history ( $c f$. Owen et al., 1998). The studies undertaken show a similar number of glacial events of similar styles in the north-western Himalaya, but have poor age constraints. Although considered here as falling into three major glacial stages, it is possible that some of the advances belong to separate periods and do not correlate with those thought to be equivalent. The glacial story is further complicated by rapid Quaternary uplift of parts of the mountains, which may have altered the pattern of glaciation as discussed by Holmes (1993).

\section{The Zanskar Range}

Previous work in the Zanskar Range (Fort, 1982; Osmaston, 1994, in prep. a) recording three major glaciations and a minor advance, agrees with the above studies from other areas in the north-west Himalaya (Table 1.1). The former extent of ice in the southern part of the range has been reconstructed from field evidence and satellite 


\begin{tabular}{|c|c|c|c|c|c|c|}
\hline $\begin{array}{c}\text { Dainelli (1923) } \\
\text { Upper Indus }\end{array}$ & $\begin{array}{c}\text { Dainelli } \\
\text { (1923) } \\
\text { Zanskar }\end{array}$ & $\begin{array}{c}\text { De Terra and } \\
\text { Paterson (1939) } \\
\text { Unner Indus }\end{array}$ & $\begin{array}{l}\text { Fort (1983) } \\
\text { Upper Indus } \\
\text { and Markha }\end{array}$ & \multicolumn{2}{|c|}{$\begin{array}{c}\text { Osmaston (1994) } \\
\text { Zanskar }\end{array}$} & $\begin{array}{l}\text { Osmaston (in prep. } \\
\text { a) Markha, Gya }\end{array}$ \\
\hline $\begin{array}{c}\text { Small tributary } \\
\text { glaciers }\end{array}$ & Upti moraine & $\begin{array}{l}\text { Small moraines in } \\
\text { upper tributaries }\end{array}$ & $\begin{array}{l}\text { Frontal } \\
\text { moraines Kar } \\
\text { and Nimaling* }\end{array}$ & M4 & $\begin{array}{l}\text { Drung- } \\
\text { drung }\end{array}$ & Pulu (Leh valley) \\
\hline $\begin{array}{c}\text { Tributary } \\
\text { glaciers (no } \\
\text { Indus glacier) }\end{array}$ & sTongde & Tributary glaciers & $\begin{array}{c}\text { Leh and } \\
\text { Hankar* } \\
\text { moraine stages }\end{array}$ & M3 & Tepuk & $\begin{array}{c}\text { Leh (Leh gompa and } \\
\text { main Nyimaling } \\
\text { moraines) }\end{array}$ \\
\hline $\begin{array}{l}\text { Partial Indus } \\
\text { glaciation }\end{array}$ & & $\begin{array}{c}\text { Glacier in part of } \\
\text { the Indus }\end{array}$ & Indus* stage & $\mathrm{M} 2$ & sTongde & $\begin{array}{c}\text { Nimu and Hankar } \\
\text { moraines }\end{array}$ \\
\hline $\begin{array}{c}\text { Glacier fills the } \\
\text { Indus }\end{array}$ & & $\begin{array}{l}\text { Great Indus } \\
\text { glacier }\end{array}$ & $\begin{array}{l}\text { Possibly older } \\
\text { glaciations }\end{array}$ & M1 & Kilima & $\begin{array}{c}\text { Indus altiplano } \\
\text { moraines }\end{array}$ \\
\hline & & $\begin{array}{c}\text { High glacial } \\
\text { troughs (Kargil) }\end{array}$ & & & & \\
\hline
\end{tabular}

Table 1.1 Glacial Chronologies for the Zanskar Range, after Osmaston (1994). *No dates are suggested by Fort (1983) for these stages and they fit better with the other chronologies if moved down one place in the table. 


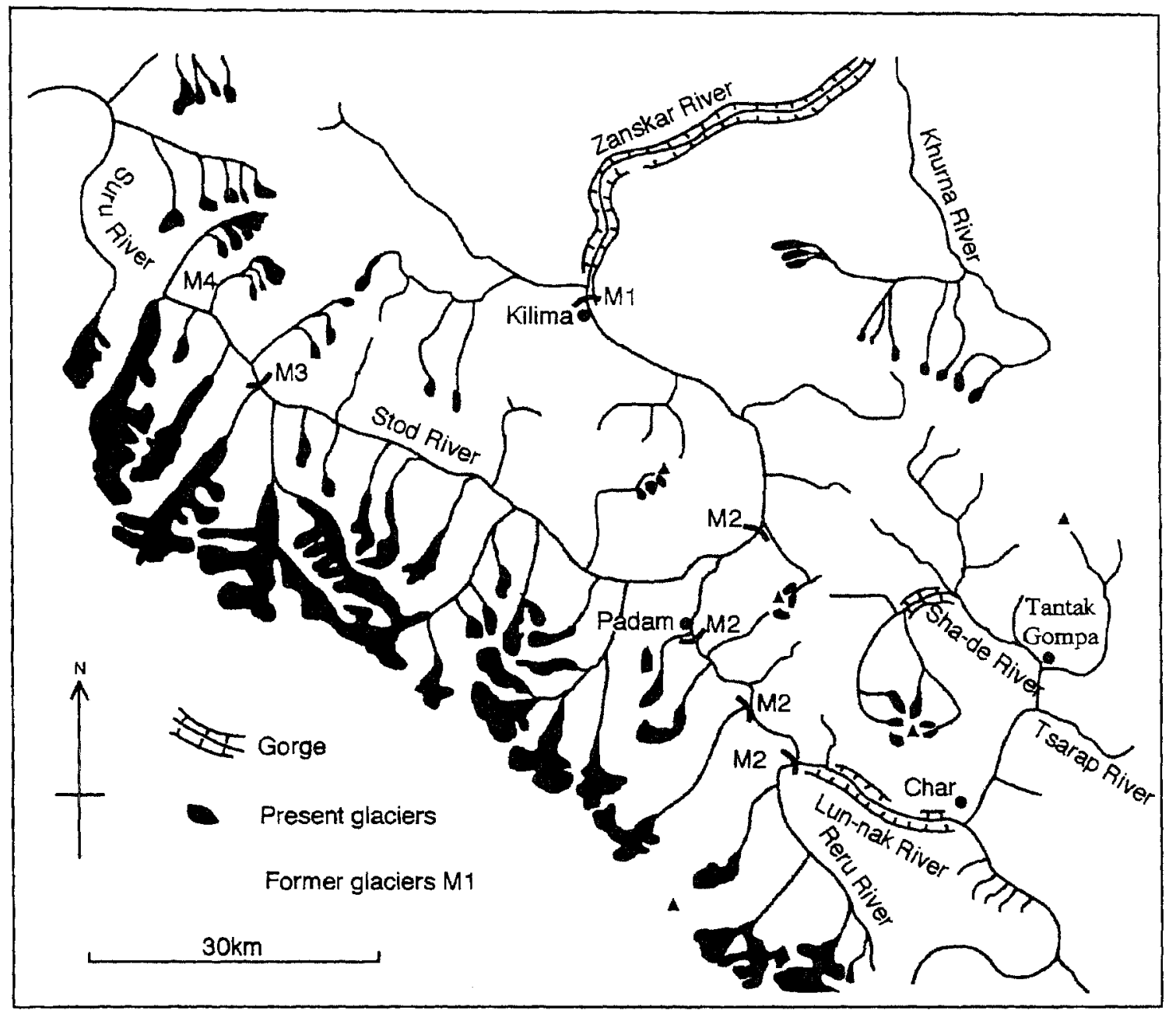

Figure 1.15 Limits of glaciation in the southern Zanskar Range (redrawn from Osmaston, 1994). This area lies to the south and east of the field area for this project, with the Tsarap-Lingti (Lun-nak), Tsarap and Khurna valleys in both study areas. 
imagery (Osmaston, 1994) (Fig. 1.15). Differing degrees of weathering have been used to distinguish between the moraines of each stage, particularly the development of tafoni on gneiss erratics carried into the Zanskar valley from the High Himalaya. The oldest and most extensive recognised glacial event (M1) is generally represented by high level erratics of gneiss reported from the Sha-de and Tsarap valleys and subdued moraine ridges close to river level in the Zanskar valley (Osmaston, 1994).

In other valleys, notably the Tsarap-Lingti (or Lung-nak), there is no evidence reported for ice of this age, although it is suggested as having occupied a higher former valley floor which has since been incised to form the present narrow gorge (Osmaston, 1994). The second reported glacial stage (M2) is represented by moraine ridges close to the river level in most major valleys often with a gorge section beyond the limit (e.g. Reru and Kurgiakh (Kargyak) valleys). The third stage (M3), thought to represent the global LGM, is represented by a distinctive group of moraine ridges and a minor advance (M4) is delimited by fresh moraines close to modern glaciers (Osmaston, 1994).

This sequence of glacial events is primarily based on evidence from the Stod/Zanskar valley. Three distinct moraine limits are recognized in this valley, from which the glacial stages get their names (Table 1.1; Fig. 1.15). Evidence for the oldest stage (M1) is absent in the Tsarap-Lingti (Lung-nak) valley, with only preservation of moraines attributed to the second oldest event (M2 in Table 1.1 and Fig. 1.15). Similarly, in the Sha-de and Tsarap systems (Fig. 1.15) limits are designated as M2 on the basis of weathering with an earlier stage (M1) inferred, followed by $>100 \mathrm{~m}$ of incision. Gneiss and schist erratics, reported from high on valley sides near Tantak Gompa (Fig. 1.15), present "a major problem" as no gneiss outcrops up-valley (Osmaston, 1994, p25). Although, unhappy on glaciological grounds about ice travelling so far up valley, Osmaston (1994, p25) finds this conclusion "inescapable". A tentative date of $70-40 \mathrm{ka}$ BP (TL) is put forward for silt deposits on the Padam Plain (H. Rendell, pers. comm, cited in Osmaston, 1994), suggesting that the 
moraines of M1 and M2 are older than this date. No details of the methodology are given and analysis is described as having been difficult.

Fort (1983) and Osmaston (in prep. a) find a similar pattern further to the north in the Markha valley of the Zanskar Range. They recognise moraine limits for two major glacial stages and a minor advance close to modern glaciers, with a third older event inferred on slight evidence. Damm (1997) also describes the moraine ridges reported by Fort (1983) and Osmaston (in prep. a), but recognises two more extensive glacial advances, one of which filled the valley to its mouth. These are delimited principally on geomorphological evidence for gross valley morphology including 'Mündungsstufe' or a junction/step in the valley and 'Schliffgrenze' or the border of glacial polishing (Damm, 1997). All four glacial events are assumed to have occurred since the LGM, although there are no numerical age estimates to support this supposition.

\section{Equilibrium Line Altitude (ELA) Values for Himalayan Glaciations}

The ELA of a glacier is the line where accumulation of snow is balanced by ablation. The ELA is closely linked to climate, especially precipitation of snow and air temperature, and as such ELA values calculated for former glaciers can provide a valuable indication of climate for that time (Sutherland, 1984). Snowlines, the altitude of snow on the glacier surface at the end of the ablation season, often approximate a glacier's ELA and, given the relative ease of measurement, is used as a surrogate from modern glaciers. Patterns of ELA and snowline values often mirror climatic gradients and consequently they are reviewed in the following section.

Past and present patterns of ELAs in the Himalaya reflect steep precipitation gradients (e.g. Williams, 1983; Holmes, 1993) and maximum depressions of ELA values vary considerably across the ranges of the Himalaya (Fig. 1.16 and Table 1.2). Modern climatic snowlines (von Wisseman, 1959) show a steep rise to the north-east and an increase from the west, corresponding to the monsoon and westerly climatic 
systems (Table 1.2). Values also increase from the interior, possibly representing the influence of cold northerly air, and the Karakoram Range has values that form a low in the overall trend (Fig. 16 and Table 1.2).

ELA depression for the southern part of the Zanskar Range is put at $400-600 \mathrm{~m}$ for the maximum of the last glaciation (Osmaston, 1994). Further north in the Gya and Markha systems of the same range two contrasting ELA depressions are presented, with Osmaston (in prep. a) and Damm (1997) giving values of $\sim 300 \mathrm{~m}$ and $>1000 \mathrm{~m}$ respectively. Neither study has an absolute chronology, however, and the former figure better fits the general pattern of modest depression. A depression of $500-600 \mathrm{~m}$ on the southern side of the upper Indus valley (the most northerly part of the Zanskar Range) compares with a depression of $900-1000 \mathrm{~m}$ for the north side of the valley (the southern part of the Ladakh Range) (Burbank and Fort, 1985). As the two flanks have similar climatic conditions and similarly located Neoglacial, late glacial and present glacier positions, Burbank and Fort (1985) attribute the limited depression in the northern slope of Zanskar Range to an unusual bedrock of vertical strata, which created a bulwark that is unfavourable for ice advances, rather than a climatic or tectonic control. Osmaston (in prep. b) presents a number of objections to this based on glaciological considerations and field evidence, which have been accepted by $M$. Fort (pers. comm. 1998). Low present snowlines (von Wisseman, 1959) and palaeoELA values for the Karakoram and Ladakh Ranges are not explained satisfactorily in the literature.

Synthesis of ELA data from the Himalaya is difficult for several reasons. Firstly, a variety of different methods have been employed to calculate palaeoELA values, with only a few studies of present ELA values or mass balance characteristics available (e.g. Kulkarni, 1992) on which to base such methods. Given the likely difference in style between past and present glaciation, especially in areas where current glaciers are now small avalanche fed types and past glaciers were large with thick debris covers, modern mass balance studies may not be applicable to palaeoglaciers. Values may not represent the climatic ELA, especially in areas of high relative relief (Benn 


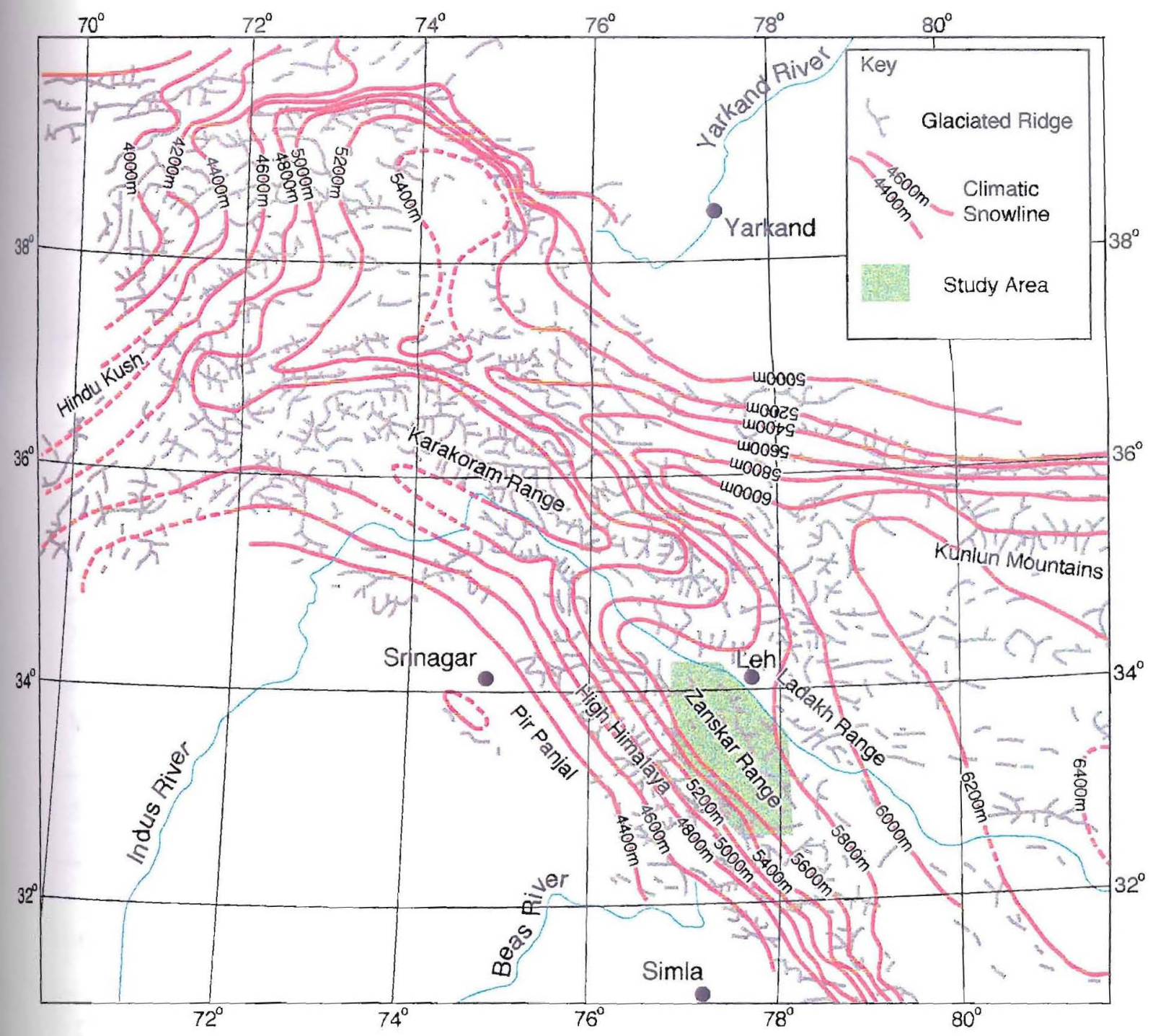

Figure 1.16 Modern climatic snowlines from the north-west Himalaya, after von Wissmann (1959). 


\begin{tabular}{|c|c|c|c|c|c|c|}
\hline Region & $\begin{array}{l}\text { Present } \\
\text { ELA (m) }\end{array}$ & $\begin{array}{c}\text { LGM ELA } \\
\text { (m) }\end{array}$ & $\begin{array}{l}\text { Depression } \\
\text { (m) }\end{array}$ & Method & $\begin{array}{l}\text { Dating } \\
\text { control }\end{array}$ & Source \\
\hline $\begin{array}{l}\text { Hindu } \\
\text { Kush }\end{array}$ & $4000-4600$ & $3000-3600$ & 1000 & AAR 0.6 & $\begin{array}{l}\text { Relative } \\
\text { dating }\end{array}$ & Porter, 1970 \\
\hline $\begin{array}{c}\text { Swat } \\
\text { Kohistan }\end{array}$ & $4100-4400$ & $300-3200$ & 1000 & AAR 0.6 & $\begin{array}{l}\text { Relative } \\
\text { dating }\end{array}$ & Porter, 1970 \\
\hline $\begin{array}{l}\text { Nanga } \\
\text { Parbat }\end{array}$ & $3750-5200$ & $3000-3700$ & $600-1200$ & - & & Scott, 1992 \\
\hline Kashmir & $3900-4300$ & $3200-3500$ & $700-800$ & - & & $\begin{array}{c}\text { Holmes and Street- } \\
\text { Perrott, } 1989\end{array}$ \\
\hline Ladakh & $5200-5400$ & 4300 & $900-1000$ & $\begin{array}{c}\text { THAR } \\
0.4\end{array}$ & $\begin{array}{l}\text { Relative } \\
\text { dating }\end{array}$ & $\begin{array}{c}\text { Burbank and Fort, } \\
1985\end{array}$ \\
\hline $\begin{array}{l}\text { Zanskar } \\
\text { (Indus) }\end{array}$ & $5200-5400$ & 4700 & $500-600$ & $\begin{array}{c}\text { THAR } \\
0.4\end{array}$ & $\begin{array}{l}\text { Relative } \\
\text { dating }\end{array}$ & $\begin{array}{c}\text { Burbank and Fort, } \\
1985\end{array}$ \\
\hline N Zanskar & $>5700$ & $4600-4800$ & $>1000$ & - & $\begin{array}{l}\text { Relative } \\
\text { dating }\end{array}$ & Damm (1997) \\
\hline N Zanskar & $5500-5550$ & $5100-5400$ & 300 & $\begin{array}{c}\text { THAR } \\
0.4\end{array}$ & $\begin{array}{l}\text { Relative } \\
\text { dating }\end{array}$ & $\begin{array}{c}\text { Osmaston, in prep. } \\
\text { a }\end{array}$ \\
\hline S Zanskar & $5200-5500$ & 4900 & $400-600$ & $\begin{array}{l}\text { THAR } \\
0.4\end{array}$ & $\begin{array}{l}\text { Relative } \\
\text { dating }\end{array}$ & Osmaston, 1994 \\
\hline $\begin{array}{c}\text { NW } \\
\text { Garhwal }\end{array}$ & $4500-5400$ & 4300 & 650 & $\begin{array}{c}\text { AAR } 0.6 \\
\text { THAR } \\
0.4\end{array}$ & OSL & $\begin{array}{c}\text { Sharma and Owen, } \\
1996\end{array}$ \\
\hline S Everest & 5200 & 4300 & 900 & $\begin{array}{c}\text { MELM } \\
\text { AAR } 0.6\end{array}$ & $\begin{array}{l}\text { Relative } \\
\text { dating }\end{array}$ & Williams, 1983 \\
\hline N Everest & 5800 & 5500 & 300 & $\begin{array}{l}\text { MELM } \\
\text { AAR } 0.6\end{array}$ & $\begin{array}{l}\text { Relative } \\
\text { dating }\end{array}$ & Williams, 1983 \\
\hline N Everest & 5800 & 5600 & 200 & $\begin{array}{l}\text { AAR } \\
0.57\end{array}$ & $\begin{array}{l}\text { Relative } \\
\text { dating }\end{array}$ & Mann et al., 1996 \\
\hline N Everest & 5800 & 5350 & 450 & $\begin{array}{c}\text { THAR } \\
(+)\end{array}$ & $\begin{array}{l}\text { Relative } \\
\text { dating }\end{array}$ & $\begin{array}{c}\text { Burbank and Kang, } \\
1991\end{array}$ \\
\hline C Nepal & $5000-5200$ & $4600-4450$ & $500-650$ & $\begin{array}{l}\text { THAR } \\
0.5\end{array}$ & ${ }^{14} \mathrm{C}$ & Duncan et al., 1998 \\
\hline
\end{tabular}

Table 1.2 Present and LGM ELAs from the Himalayan region (modified from Sharma and Owen, 1996). 
and Lehmkuhl, in press), but they are still a useful way of characterising glaciers as a single number to show climatic trends. Glacial evidence on which palaeoglacier limits and hence ELA values are based may have undergone uplift, in which case the calculated ELA depression would be smaller than the true value (Holmes, 1993). As tectonic data over glacial time periods are inadequately known (Section 1.6), correction for uplift is difficult. Finally, comparison of ELA values from studies with poor or no dating control presents the problem of whether the same periods are being compared, particularly given the emerging asynchronous maximum during the last glaciation (Benn and Owen, 1998; Owen et al., 1998).

\subsection{An lce-sheet on the Tibetan Plateau?}

It has been proposed that an ice-sheet occupied the Tibetan Plateau and environs during the LGM (Kuhle, 1985, 1987, 1990, 1991, 1998; Kuhle et al., 1989). This hypothesis, although strongly opposed (e.g. Osmaston, 1989; Zheng, 1989a, 1989b; Burbank and Kang, 1991; Derbyshire et al., 1991; Gupta et al., 1992a; Shi et al., 1992a, 1992b; Lehmkuhl and Liu, 1994; Lehmkuhl, 1998a; Zheng and Rutter, 1998), is persistent in the literature (e.g. Emeis, 1995; Kaufmann and Lambeck, 1997; Kulhe, 1998) and has implications both regionally and for the glaciation of the Zanskar Range.

Debate surrounding the existence and extent and timing of a Tibetan ice-sheet has continued for a century ( $c f$. Zheng, 1989b). Among earlier work is that of Hedin (1899-1902) who considered the plateau to be too dry for the development of an icesheet and Trinkler (1930) who was in favour of a Tibetan wide ice cover.

Proposed global implications of a LGM ice-sheet of $1 \mathrm{~km}$ thickness, covering an area of 2-3 $\times 10^{6} \mathrm{~km}^{2}$ and occupying a volume of $3 \times 10^{6} \mathrm{~km}^{3}$, are a $7-8 \mathrm{~m}$ lowering of sea level and a $0.1 \%$ change in the $\delta^{18} \mathrm{O}$ record of the oceans (Kulhe, 1998). Furthermore, to achieve wastage by the Holocene, the average rate of melting must 
have been $>200 \mathrm{~km}^{3}$ per year (Gupta et al., 1992a). Modelling by Gupta et al. (1992b) highlights the potential influence that this would have had on Indian Ocean sedimentary records, demonstrating that only a $10 \%$ increase in present discharge of the catchment rivers of the Bay of Bengal, would lead to a change of $>1 \%$ in the $\delta^{18} \mathrm{O}$ records. In addition, a Tibetan wide ice-sheet with high albedo would have an effect on the large scale weather patterns, with the SAH being weaker or even failing to form (Ye and Gao, 1981).

The proposed LGM ice cover also has major implications for the study area. It is described as having inundated the Ladakh and Zanskar Ranges draining over northwest India as a series of $\sim 1000 \mathrm{~m}$ thick glaciers interconnected via transfluence passes in a similar manner to the Jötunheimen area of Scandinavia (Kuhle, 1998, p88). This is of particular relevance to this project because, if the hypothesis is accepted, the glacial record of the Zanskar Range will be post LGM and will not record multiple Pleistocene glaciations.

Critical to Kuhle's ice-sheet hypothesis is the depression of ELAs to between $1100 \mathrm{~m}$ and $1600 \mathrm{~m}$ along the margins of the Tibetan Plateau giving an ELA below the mean altitude of the plateau surface and consequently causing ice-sheet build up (Kuhle, 1998). Former glacial margins on which these ELAs are calculated are largely delimited by diamicts (Kuhle, 1988), although these are often difficult to identify generically (Derbyshire and Owen, 1990). Criteria used for ELA calculation are based on those devised by van Hofer (1879) with later modification (see Kuhle, 1988, p458) and include mean altitude of crest frames, or the highest summit where avalanching is pre-eminent, lowest location of ice margins, the superficial extent of accumulation and ablation areas and the difference in angle between the average slope of the accumulation and ablation areas. No critical evaluation of alternative and often contradictory interpretations of the geological evidence which give smaller ELA depressions is presented by Kuhle $(1988,1998)$. 
Few well dated glacial chronologies exist for the Himalaya or Tibetan Plateau. However, those emerging dates show valley glaciations older than the global LGM (e.g. Sharma and Owen, 1996; Owen et al., 1997, 1998). The only numerical dating evidence submitted in Kuhle's 1998 review paper is improperly interpreted with discernible problems ignored. ${ }^{14} \mathrm{C}$ dated wood fragments from horizons within an $80 \mathrm{~m}$ section through ice-dammed lake sediments from the Tsangpo depression, range from $495 \pm 85 \mathrm{yr}$ BP to $48580 \pm 4660 \mathrm{yr} \mathrm{BP}$ (Kuhle, 1998). The age estimates are not, however, in chronological order, disobeying the fundamental geological law of superposition. The basal age estimate of $9820 \pm 350$ years $B P$ is cited in spite of there being three age estimates of $\sim 45 \mathrm{ka}$ BP from a higher horizon, all of which lie within each other's error margins. ${ }^{14} \mathrm{C}$ age estimates for peat and TL/OSL dates for loess overlying moraines often give Holocene ages, but many of these represent the onset of humid conditions which facilitated vegetation growth for peat production and the entrapment of loessic material (Hovermann, 1987; Lehmkuhl, 1998a, 1998b).

Almost all the geological evidence for glaciation is located in or near mountain ranges with little evidence for occupation of ice on the intermontane parts of the plateau (Derbyshire et al., 1991). Kuhle (1987) explains this through loss of depositional evidence owing to high present-day erosion rates and the lack of erosional evidence due to the ice having been cold-based.

Reconstructed multiple glacial sequences have been reported from parts of the Himalaya where LGM ice-sheet outlet glaciers have been proposed (cf. Zheng, 1988; Burbank and Kang, 1991; Mann et al., 1996; Owen et al., 1998). Many of these glacial chronologies claim to record one or two Middle Pleistocene glaciations and produce Late Pleistocene ELA depressions smaller than those required by the icesheet hypothesis (Williams, 1983; Shi et al., 1992a, 1992b). In addition, all the Himalayan studies provide convincing evidence for locally nourished LGM valley glaciers, without input from a Tibetan Plateau ice-sheet. 
Recent observations of streamlined landforms, erratics and till in the source area of the Yellow River, and troughs near Garing Lake (Zhou and $\mathrm{Li}$, reported in Rutter, 1995; Zheng and Rutter, 1998), suggest the existence of a large ice-sheet predating the last glaciation. This is based on dating of periglacial landforms, one of which gives an age of $135 \pm 10.5 \mathrm{ka} B P(T L)$. Although the area is not as elevated as other parts of the plateau, it does receive higher precipitation (300-400 $\left.\mathrm{mma}^{-1}\right)$, and would have had low temperatures supplied by the North Mongolian High Pressure (Rutter, 1995).

The LGM Tibetan-wide ice sheet hypothesis is generally rejected, with contradicting geological evidence independently produced from many regions ( $c f$. Derbyshire et al., 1991). Consequently, the Zanskar Range is likely to hold a multiple glacial record extending beyond the LGM.

\subsection{Conclusions}

The Zanskar Range, which is located in the north-west Indian Himalaya forms an important area for palaeoclimatic study as it lies in an area thought to be influenced by both monsoon and westerly circulation. This project aims to reconstruct palaeoglacier limits through detailed geomorphological mapping, create a chronology for these events using OSL dating methods, draw palaeoclimatic inferences from these dated limits and compare the record with previous studies from the region. The area is semi-arid with only small glaciers in high corries and valley heads, but holds a record of multiple glaciation (Osmaston, 1994).

The evolution of the Zanskar Range is intimately connected with the collision of the Indian and Asian continents, as expressed in the intensely folded rocks which represent the northem Indian crust, shelf sediments and ISZ. Late Pleistocene rates of uplift, which may have implications for glaciation, are inadequately known for the 
Zanskar Range and surrounding mountains over the time-scale appropriate to glacial studies.

Proxy indicators for fluctuations in the monsoon and westerly climatic systems, which may have affected palaeoglacier timing and extent, are reviewed. Biogeochemical proxy climatic indicators of monsoon strength from ocean, lake and ice cores record fluctuations in the Indian summer monsoon. In spite of variations between records of the different indicators, they show low intensity monsoon circulation resulting in relative aridity in the north-west Himalaya during the global LGM, with relatively strong monsoons and hence humidity at 9,50 and $123 \mathrm{ka} \mathrm{BP}$ (Clemens et al., 1991). High resolution complex records show short term fluctuations over decades and millennia, which correlate with high latitude records. There is a paucity of data regarding fluctuations of the westerly climatic system, although climatic modeling suggests that they may have been relatively strong at the LGM (Kutzbach et al. 1998).

Previous glacial studies typically show preservation of three major Pleistocene glaciations with a general consensus that no ice-sheet covered the Tibetan Plateau and Himalaya (e.g. Derbyshire et al., 1991), as has been proposed by M. Kuhle (Kuhle, 1998). The timing of Himalayan glaciations is based on a few widely spaced age estimates, many of which have considerable errors. Nevertheless, the last glaciation is reported as having had its maximum in OIS 3 in the north-western Himalaya at $-30-60 \mathrm{ka} \mathrm{BP}$, whereas in the central and eastern Himalaya this was in OIS 2 at $\sim 25$ 18ka BP (Benn and Owen, 1998). Comparison of ELA values presents many problems, including differences in methodologies and a lack of dated limits for comparison, but overall trends reflect summer monsoon and winter westerly precipitation patterns.

Investigation into the style and timing of glaciation of the Zanskar Range may help to clarify the relative roles of the monsoon and westerly climatic systems. In addition, the Zanskar Range presents an area in which to test the timing of the maximum 
Chapter 1, Introduction

glaciation in the north-west Himalaya, which is presently based on only three age estimates. 


\section{Methodology}

Reconstruction of glacial sequences requires detailed mapping of former glacial margins. Once delimited, these margins need to be dated so that a chronology of events can be created and related to other climatic records. From reconstructed palaeoglaciers altitudinal indexes can be calculated, usually approximating the Equilibrium line Altitude (ELA) and therefore relating to former climate. These are useful for between glacier and regional comparison. Methods chosen to fulfil these requirements are described and justified.

\subsection{Geomorphological Mapping}

Much of the literature on the technique of geomorphological mapping, which forms the basis of fieldwork for this project, is written from the perspective of application to environmental management and planning (e.g. Cooke and Doornkamp, 1974; Embleton and Verstappen, 1988), with guidelines for detailed mapping to those ends (cf. Demek, 1972). Geomorphological mapping investigates the morphology, genesis and age of the relief and is usually employed as a means of data collection for a specific geomorphological problem (Embleton and Verstappen, 1988), which in this case is the delimitation of former glacial extents. No single system has been proposed for this purpose, although the detailed geomorphological mapping technique pioneered by J. B. Sissons (e.g. Sissons, 1974) for reconstruction of British Loch Lomond Stadial glaciers has been adopted and refined by many later workers (e.g. Ballantyne, 1989; Bennett and Boulton, 1993) and employed in recent palaeoglacier reconstructions in the Himalaya (e.g. Owen et al.,1996).

Landforms have to be recognised genetically during the mapping process and the technique, therefore, relies on the ability, knowledge, experience and training of the 
interpreter (Cooke and Doornkamp, 1974) leading to potential conflicting interpretation between geomorphologists. The environmental setting, which aids in the interpretation of morphologically similar landforms, must be considered and the mapping system should be flexible (Mitchell, 1991).

An element of subjectivity surrounds the location of landform boundaries (Cooke and Doornkamp, 1974), particularly where cultural references (like field boundaries) are sparse. In the absence of suitable base maps and air photographs to provide topographic and cultural references, landforms are plotted relative to each other directly on to squared paper and referenced to the Earth's surface with a Global Positioning System (GPS) which is more than accurate enough for this purpose. Distances are measured along compass bearings through pacing and by triangulation, and altitudes are recorded using a Thommen altimeter, which is calibrated at the few points of known altitude. The vastness of the area studied, its inaccessibility, the poor quality of topographic data and time constraints preclude the construction of a continuous geomorphological map, with detailed mapping reserved for areas deemed to be of particular significance for the history of glaciation. The actual routes taken and time spent at each area are dictated by the terrain and the need to arrive at areas of grazing for pack animals and non-glacial water for drinking.

Symbols adopted for this study are shown in Figure 2.1 and are largely based on those of C. K. Ballantyne (e.g. Ballantyne, 1989) and W. A. Mitchell (e.g. Mitchell, 1991). Landforms that delimit lateral and vertical extents of former ice include glacial versus non-glacial valley form, end and lateral moraines, drift against drift free slopes, periglacial trimlines and relict periglacial features which in particular circumstances can indicate areas that remained ice free. Other landforms including erratics, striae, roches moutonneés and streamlined drift give former direction of ice flow. 


\begin{tabular}{|c|c|c|}
\hline Symbol & Short explanation & Long explanation \\
\hline & Fiver & Aiver \\
\hline & Dry river & Ephemeral Stream \\
\hline & Palaeochannel & Former channel in which water no longer flows \\
\hline & Aliuvial Fan / Debris cone & Debris cone often grading into an alluvial fan \\
\hline & Terrace & Fluviaf terrace \\
\hline 6 & Moraine ridge & $\begin{array}{l}\text { Moraine ridge - dashed line shows the crest and the highest point } \\
\text { is marked with a cross }\end{array}$ \\
\hline$n$ & Moraine hummock & Hummocks of till usually a fow lens of metres across \\
\hline$m$ & Undulating dritt & Undulating and disected dritt \\
\hline RM & Re-sedimented moraine & Re-sedimented morainic sediment \\
\hline$F$ & Fiutes & Fluted moraines \\
\hline ow & Out-wash & Out-wash \\
\hline k & Kettle lake & Kettle hole with a lake \\
\hline 6 & Landstide ridge & $\begin{array}{l}\text { Landslide ridges - dashed line shows the crest and the highest point } \\
\text { is marked with a cross }\end{array}$ \\
\hline$\nabla \nabla$ & Drit limit & Limit of drift against dritt tree areas \\
\hline RG & Fock glacier & Rock glacier \\
\hline & Front scarp of a RG & Front active scarp of a rock glacier \\
\hline WWW & Fluvially cut stope & Fluvially eroded stope cut into drift \\
\hline $\mathrm{b} \pi$ & Bedrock & Bedrock \\
\hline E & Bedrock cliff & Bedrock clitt \\
\hline & Talus & Talus siope \\
\hline $\mathfrak{\imath}$ & ice-moulded bedrock & Undifferentiated ice-moulded bedrock \\
\hline$M$ & Frost shattered bedrock & Frast shattered bedrock \\
\hline$y_{135}$ & Roches moutonnees & Roches moutonnees with the orientation in degrees \\
\hline $270 \div$ & Striae & Striae with the orientation in degrees \\
\hline L & Lake & Lake \\
\hline & Lake sediments & Lake sediments \\
\hline 4530 & Metres a.s! & Altitude in metres above sea level and location of GPS data \\
\hline
\end{tabular}

Figure 2.1 Geomorphological mapping symbols adapted from those employed by C. K. Ballantyne and W. A. Mitchell. 


\section{$2.2 \quad$ Dating}

\subsubsection{Justification for Choosing the OSL Dating Method}

Optically Stimulated Luminescence (OSL) dating is the method with the greatest potential for the production of a dated glacial chronology in the Zanskar Range. Although alternative methods have been successfully employed in the Himalaya, most of these have serious problems and limitations. The lack of organic material in this semi-arid environment precludes the widespread use of radiocarbon dating, although this has been employed in other areas with higher precipitation (e.g. Lahul, Owen et al., 1997). In addition, there is the problem of association, with organics on moraines in north-east Tibet representing the onset of climatic conditions favourable for vegetation, following a lag time, rather than the age of the underlying landforms (Lehmkuhl, 1997). Similarly, the lack of shells prevents the use of Uranium Series and Amino-acid Racemization dating. Palaeomagnetic methods have been used in northern Pakistan (Cronin et al., 1989), although the validity of this particular example is challenged on grounds of glaciotectonics (Owen and Derbyshire, 1988) and, more generally, the method provides only broad age ranges and requires exceptionally thick sequences for its application. Cosmogenic isotope dating of exposed rock surfaces has been successful for fluvially eroded landforms in the Middle Indus valley, the results of which have been used to calculation an erosion rate (Burbank et al., 1996). This method has potential for the dating ice-scoured bedrock and erratic boulders, but has yet to be tested for the Himalaya, although research to this end is under way (Benn, pers. comm.).

Two of the greatest advantages of OSL dating are the ability to date clastic sediments directly and the ubiquity of potential samples. An additional advantage over radiocarbon dating is that OSL dating has a longer time range, which although 
dependent on the individual properties of the site and sample is in the order of $100 \mathrm{ka}$ (Duller, 1996; Aitken, 1998).

OSL dating has been widely applied to aeolian sediments with their advantages of having been very well bleached and having high luminescence sensitivities. Recent OSL work has successfully dated fluvial (Perkins and Rhodes, 1994), coastal (Wood, 1994) and colluvial (Rees-Jones, 1995) sediments. Application of luminescence dating to fluvioglacial sediments, however, shows recurring problems of incomplete bleaching, low luminescence sensitivity and difficulties in the acquisition of pure quartz (Gemmell, 1988; 1994; 1997; Hütt and Junger, 1992; Rhodes and Pownall, 1994; Rhodes and Bailey, 1997). Several of these potential problems are of reduced importance or not directly applicable due to the latitude of the region, the use of OSL rather than Thermoluminescence (TL) and innovations in the preparation technique (Richards, 1999). Dates considered as reliable have been produced from Himalayan fluvioglacial sediments (Sharma and Owen, 1996; Owen et al., 1997; Richards, 1999).

\subsubsection{Principles of Luminescence Dating}

Certain naturally occurring minerals (principally quartz and feldspar) act as dosimeters by recording their exposure to environmental radiation. In some crystalline solids electrons reside in the lowest possible energy configuration, which under normal conditions is the valance band (Fig. 2.2). An input of energy from ionizing radiation can remove the electron to the conduction band (a in Fig. 2.2) creating a hole in the valance band. It may then recombine with the hole causing the release of a photon; alternatively the hole or electron may become trapped within the 'forbidden gap' at a metastable trap site ( $b$ and $f$ ). A small input of energy may release the electron (c) returning it to the conduction band from where it may reconnect with the hole (e), releasing a photon of light. It is this luminescence signal that is measured. 


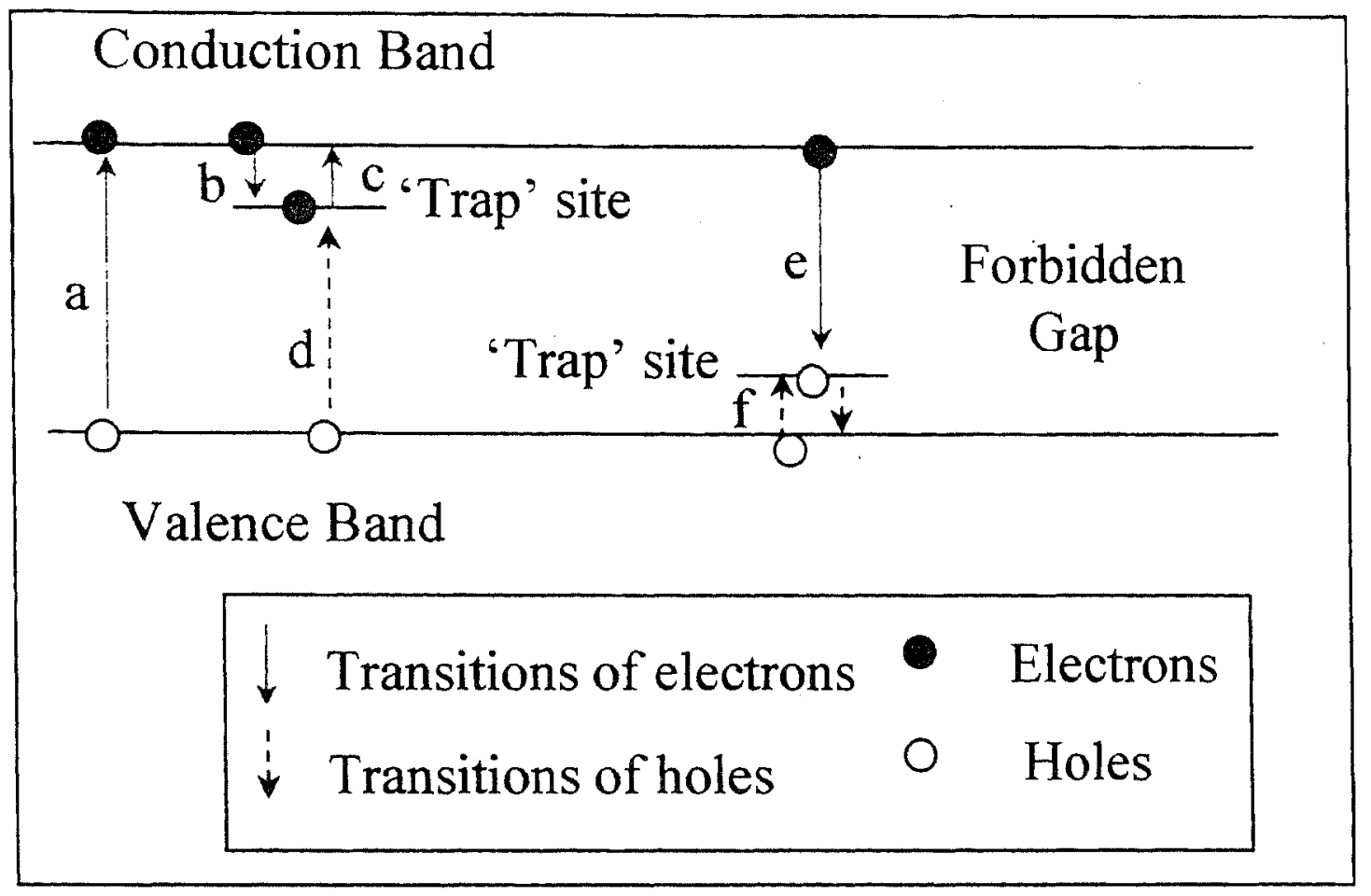

Figure 2.2 Energy band model (after Duller, 1996)

An input of heat or light energy can be sufficient to empty some of a mineral's trapped charge. In the case of sediments, this resetting energy is exposure to light during transport and deposition, with the accumulation of charge following sedimentation. A second input of energy under controlled conditions releases the trapped electrons giving off a measurable luminescence signal.

As the number of trapped electrons is dependent on the amount of radiation received since deposition, an age can be calculated provided that the total radiation dose received since the resetting event (the equivalent dose, $D_{E}$ ) and the annual environmental dose rate can be determined (below). Both these parameters can be found through independent measurements, and therefore the following equation can be written (Gy (Grey) is the unit of radiation):

$$
\text { Age }(k a)=\frac{\text { Equivalent dose }\left(D_{E}\right)(G y)}{\text { Dose Rate }(G y / k a)}
$$




\section{Thermoluminescence Dating}

Thermoluminescence (TL), from which OSL developed, employs heat energy to release the luminescence signal and was initially developed for the archaeological dating of pottery heated by firing during manufacture (Fleming, 1979). The artefacts, having been zeroed by firing, accumulate electrons in trap sites during burial. This trapped charge is measured through heating the sample, causing the release of the luminescence signal, which is recorded using a photomultiplier tube (PMT). TL dating has also been adapted to naturally occurring sediments zeroed by sunlight (Wintle and Huntley, 1980). The heating process, however, releases not only the charge that has accumulated since exposure, but also a proportion from nonbleachable traps. The signal produced from these non-bleachable traps has to be determined experimentally, adding to the uncertainty of the resultant age estimates, especially for young samples or those which have experienced only brief daylight exposures.

\section{Optically Stimulated Luminescence (OSL) Dating}

Huntley et al. (1985) first used light as the stimulant for the production of a luminescence signal for dating, with the advantage that, in principle, only those traps sensitive to light are sampled. Preliminary experiments showed some encouraging results with increasing amounts of OSL produced from sets of samples of increasing depth from two sites and an age which related to a pre-existing radiocarbon date, although other experiments showed problems (Huntley et al., 1985).

A number of methods exist for the calculation of $D_{E}$ values, with various advantages and disadvantages ( $c f$. Duller, 1996). Two of the most widely used procedures are the Regeneration Method and the Additive Dose Method. The Regeneration Method involves the measurement of the natural luminescence signal (with no artificial dose) from a number of aliquots and bleaching of the remaining aliquots. These then receive various radiation doses and have their luminescence measured to produce a 
response curve. The dose that produces a luminescence signal of the same size as the natural signal can be read from this graph (Fig. 2.3a). This is the equivalent dose that the sample would have received during its burial time.

The Additive Dose Method characterises the growth of the luminescence signal by giving increasing high radiation doses to different groups of aliquots, but leaving one set natural without an artificial dose. A function is fitted to the data and extrapolated to find the dose from the time of deposition (zero luminescence signal) to the present (natural dose) (Fig. 2.3b).

The Regeneration Method does not require extrapolation beyond a data set and is therefore analytically preferable to the additive dose method. Exposure to light during the Regeneration Method may, however, cause changes in luminescence sensitivity (Duller, 1996) and as such the Additive Dose Method is adopted for this study. Duller (1996) advocates the Australian Slide Method (Prescott et al., 1993), which employs data sets from both of the above methods. This technique requires the preparation of considerably more aliquots than the chosen method and is therefore not feasible for this study on the grounds of time and finance.

There have been many developments in luminescence dating since its conception, some of which are discussed in Duller (1996) and Aitken (1998).

\subsubsection{Site Selection and Sample Collection}

Once a suitable sediment type has been found, which for this methodology is fine sand or silt containing quartz grains (Section 2.2.4), two criteria must be considered for each sample site :

(1) Association. How does the sediment relate to the glacial sequence of events? 


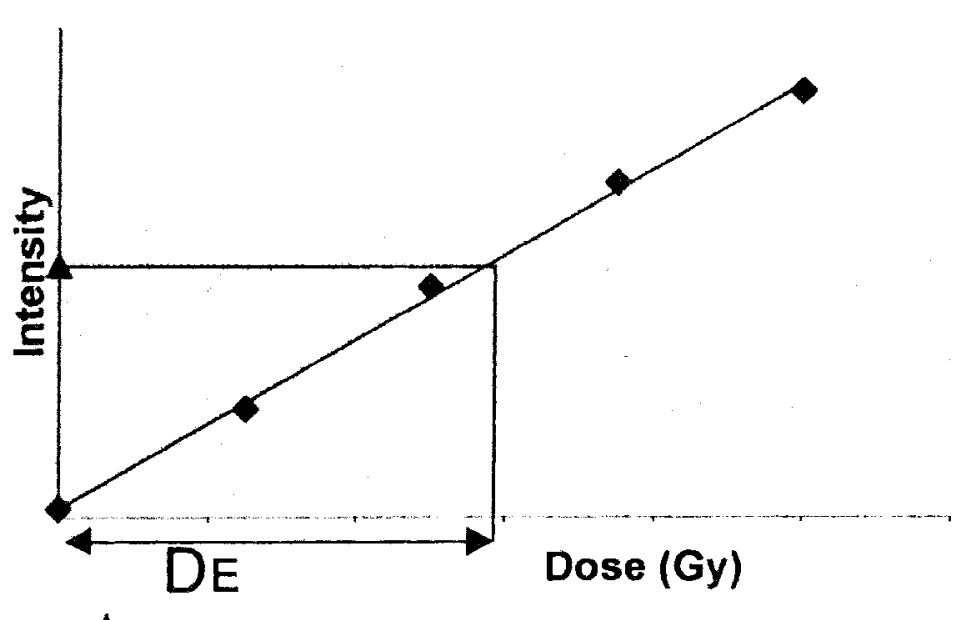

A

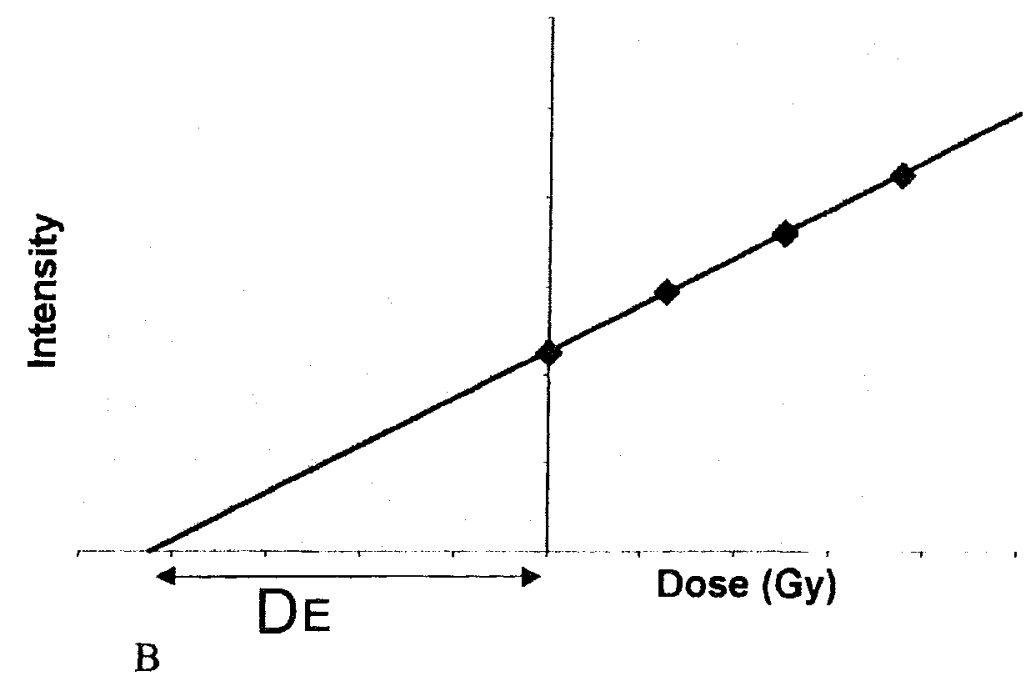

B

Figure 2.3 Methods for the calculation of the Equivalent Dose. a) Regeneration Method, the triangle represents the natural signal and the diamonds that regenerated following bleaching. b) Additive Dose Method, the first point represents the natural signal with the other points representing the signal from an artificially added dose. 
(2) Zeroing. What is the likelihood that the sediment was exposed to sunlight at or shortly before deposition?

Detailed geomorphological mapping and sedimentology are employed to determine the relationship of the deposit to the sequence of events to be constrained. Clearly, those sediments with the closest association to former maximum ice margins are most desirable for dating.

Zeroing of pro-glacial sediments has been investigated by Gemmell (1988, 1994, 1997) for the TL and Infra-Red Stimulated Luminescence (IRSL) signal and by Rhodes and Pownall (1994) and Rhodes and Bailey (1997) for the OSL signal. Sediment transported subglacially is unlikely to have been zeroed and consequently is avoided. The dominant debris transport path for many modern Himalayan glaciers is supraglacial (Scott, 1992) and as such subglacial sediment may be rare. However, samples should not be collected from areas with geomorphological and sedimentological evidence for subglacial deposition (e.g. drumlinised areas, Owen et al., 1996), as these deposits may not be bleached. Glaciolacustrine and fiuvioglacial systems are often turbid, which reduces the rate of bleaching of grains (Gemmell, 1997) and light intensity decreases with water depth, nevertheless, Rendell et al. (1994) have shown that after 3 hours quartz at a depth of $14 \mathrm{~m}$ is zeroed. As there is a chance that deposition occurred at night, which would not zero grains (Gemmell, 1997), sediment that is likely to have undergone multiple cycles of transport and those having travelled further from the former glacier are favourable. As fluvioglacial sediments are deposited from strongly diurnal flow regimes (Ferguson, 1984; Collins, 1996), they are likely to have experienced multiple cycles of deposition and are therefore likely to have been bleached (Gemmell, 1997; Rhodes and Bailey, 1997).

For the above reasons, fluvioglacial sediments which have an unambiguous relation to former ice margins are considered as the most suitable potential samples. In practice, however, sites are limited by additional factors such as accessibility and 
safety, the latter especially where silt/sand lenses from within unstable diamicton faces of several tens of metres are concerned.

Once silt or fine sand that meets the requirements of association and bleaching is identified, a sample can be collected from a cleaned face at least $300 \mathrm{~mm}$ from clasts greater than sand sized so that the Neutron Activation Analysis (NNA) determination of $\mathrm{U}, \mathrm{Th}$ and $\mathrm{K}$ concentration is not compromised. For consolidated sediments a block of sides at least $100 \mathrm{~mm}$ is cut, wrapped in strong tape for protection and placed in double light proof bags. Unconsolidated sediments are collected by hammering opaque plastic tubes into a cleaned face, the ends of which are then taped, and stored in double light proof bags.

\subsubsection{Preparation of Aliquots}

The methodology used for the preparation and measurement of aliquots is based on standard methods employed at the luminescence laboratory at Royal Holloway, University of London, which at the time was run by Edward Rhodes. Modification of this method is the result of work on the OSL dating of fluvioglacial sediments by Richards (1999).

\section{Choice of Mineral and Grain Size}

A wide range of luminescence techniques exist. Mineralogy and grain size are important in the decision as to which sub-method to employ. Of the two major mineral groups, quartz is chosen over feldspar for several reasons. Feldspar generally has a greater luminescence emitted per unit dose (luminescence sensitivity (Stokes, 1992) - often referred to as the 'brightness' of a sample), which makes it easier to measure than quartz (Godfrey-Smith et al., 1988). Outweighing this advantage of feldspar, however, is the quicker bleaching time of the OSL signal in quartz (Godfrey-Smith et al., 1988) increasing the likelihood of zeroing, and the longevity 
of the quartz signal. The latter is estimated at $>10^{8}$ years (Rhodes, 1990), whereas certain feldspars have been shown to 'fade' anomalously over periods relative to those being dated, due to thermal instability of the signal used (Spooner, 1992, 1994).

Grain size determines dosimetry and the preparation method used to manufacture aliquots. Approximately the outer $20 \mu \mathrm{m}$ of each grain has a luminescence signal due to natural external alpha radiation, which it receives during burial. For 'coarse' grains, which in this study are of $90-125 \mu \mathrm{m}$ diameter, the affected outer layer is etched off using hydrofluoric acid (HF) and this component can be ignored, whereas for 'fine' grains, which are of $4-11 \mu \mathrm{m}$ diameter, the entire grain is affected and an alpha efficiency value can be employed (Aitken, 1985). Grains of intermediate sizes are not suited to either method and are therefore not used.

Although fine grained aliquots are more easily damaged during transfer between measuring and irradiation machines and are of lower sensitivity due to there being a smaller mass on each disc, they have several advantages over coarse grained aliquots. Firstly, the method of attachment to discs produces a more consistent cover with the consequence of reducing disc to disc variation (Richards, 1999). Secondly, fine particles are likely to have been transported in suspension rather than as bedload and as such have a higher probability of having been effectively bleached. Thirdly, the preparation, especially if multiple samples are processed simultaneously, is less time consuming. Finally, the need to use extremely hazardous HF is removed.

For the above reasons fine grained quartz (FGQ) is the preferred sub-method. However, where too few fine grains can be produced from a sample, coarse grained quartz (CGQ) is used, and where feldspar contamination cannot be reduced to an acceptable level fine grained polymineral (FGPM) aliquots are prepared. 


\section{FGQ Preparation}

All laboratory preparation is done under safe light conditions - a dark room lit by a low pressure sodium lamp $(588 \mathrm{~nm}$, filtered with a LEE 101 celluloid filter (Smith, 1988)). Samples are weighed regularly during the dry stages of preparation and great care is taken to prevent contamination between samples.

Cohesive blocks are sprayed black and once dry are scraped to a depth of $10-20 \mathrm{~mm}$, the paint ensuring that no part of the exposed surface is missed. The remaining sediment is gently crushed to granules and $\sim 12 \mathrm{~g}$ are removed for Neutron Activation Analysis (NAA). Tubes of unconsolidated material are opened and $\sim 20 \mathrm{~mm}$ from each exposed end is removed, $\sim 12 \mathrm{~g}$ of which provides an NAA sample. In each case the material which has not been exposed is dried at $50-60^{\circ} \mathrm{C}$ for 24 hours and the difference in weight recorded to determine water content.

The samples are then sieved using Endecotts test sieves with apertures of 90, 125, 180,250 and $500 \mu \mathrm{m}$. Where there is $>30 \mathrm{~g}$ of grains finer than $90 \mu \mathrm{m}$ the FGQ procedure is adopted, if not then the $90-125 \mu \mathrm{m}$ fraction is used for a CGQ procedure.

The adopted FGQ procedure of Richards (1999) is presented in summary in Figure 2.4. The sample is put through a series of rinses, each one being stirred vigorously and left for 24 hours. Three rinses in 10-20\% hydrochloric acid ( $\mathrm{HCl})$, with further rinses if reaction persists, removes carbonate. Following three rinses in distilled water $\left(\mathrm{dH}_{2} \mathrm{O}\right)$, the sample is put through three rinses in hydrogen peroxide $\left(\mathrm{H}_{2} \mathrm{O}_{2}\right)$ to remove any organic material. Four further washes in $\mathrm{dH}_{2} \mathrm{O}$ are followed by two in methanol and two in acetone to prevent coagulation of grains. The sample is then dried and settled in acetone for 20 mins 15 secs, keeping the material remaining in suspension after each of five repetitions, which is then settled in acetone for 20 minutes twice, giving a sediment of $4-11 \mu \mathrm{m}$ diameter. The sample is again dried and then rinsed in flurosilicic acid $\left(\mathrm{H}_{2} \mathrm{SiF}_{6}\right)$ for 7 days to remove non-quartz grains. This 
step is not performed for FGPM samples. Five rinses in $\mathrm{dH}_{2} \mathrm{O}$, two in methanol and two in acetone follow, then $1 \mathrm{ml}$ is pipetted from a $2 \mathrm{mgml}^{-1}$ suspension maintained using a magnetic stirrer into glass tubes with aluminium discs in the base. The grains settle onto the discs and the acetone is allowed to evaporate over a minimum of 2 days.

\section{CGQ Preparation}

Preparation of CGQ aliquots follows the method of Richards (1999) which is based on that of Rhodes (1988). Initial rinses with $\mathrm{HCl}$ are as for FGQ. Minerals less dense than $2.62 \mathrm{gcm}^{-3}$ are separated in a centrifuge using a sodium polytungstate solution of that density. Minerals of a density greater than $2.68 \mathrm{gcm}^{-3}$ are removed similarly, with the remaining quartz treated for 40 minutes in continuously agitated $40 \% \mathrm{HF}$ to etch $10 \mu \mathrm{m}$ from the outer layer (given an error of $\pm 10 \mu \mathrm{m}$ in calculations) and remove any surviving non-quartz minerals. The sample is then re-sieved to remove particles that have become too small.

The centres of aluminium discs are coated with viscose silicone oil (Dow Corning $60,000)$ and placed oil-side-down on a pile of prepared quartz grains. Loose grains are removed by lightly tapping the discs to produce a monolayer.

\subsubsection{Measurement}

(see appendix $\mathrm{C}$ for a worked example)

Luminescence measurements are made on a TL-DA-12 automated Riso reader, which holds 24 discs. Infra-red stimulation is produced by infra-red diodes (TSHA 6205) delivering approximately $5 \mathrm{mWcm}^{-2}$ at $880 \pm 80 \mathrm{~nm}$ (Botter-Jensen and Duller, 1992). Green light stimulation of $420-560 \mathrm{~nm}$ is produced by a filtered $75 \mathrm{~W}$ halogen lamp of $12 \mathrm{mWm}^{-2}$ at $2.21-2.95 \mathrm{eV}$. A heat absorbing filter, three GG420s and a broad band interface filter are used. The Riso machine has a facility for heating samples to up to $500^{\circ} \mathrm{C}$ and irradiating them using a beta irradiator at $\sim 1.3 \mathrm{Gymin}^{-1}$. Emissions are 


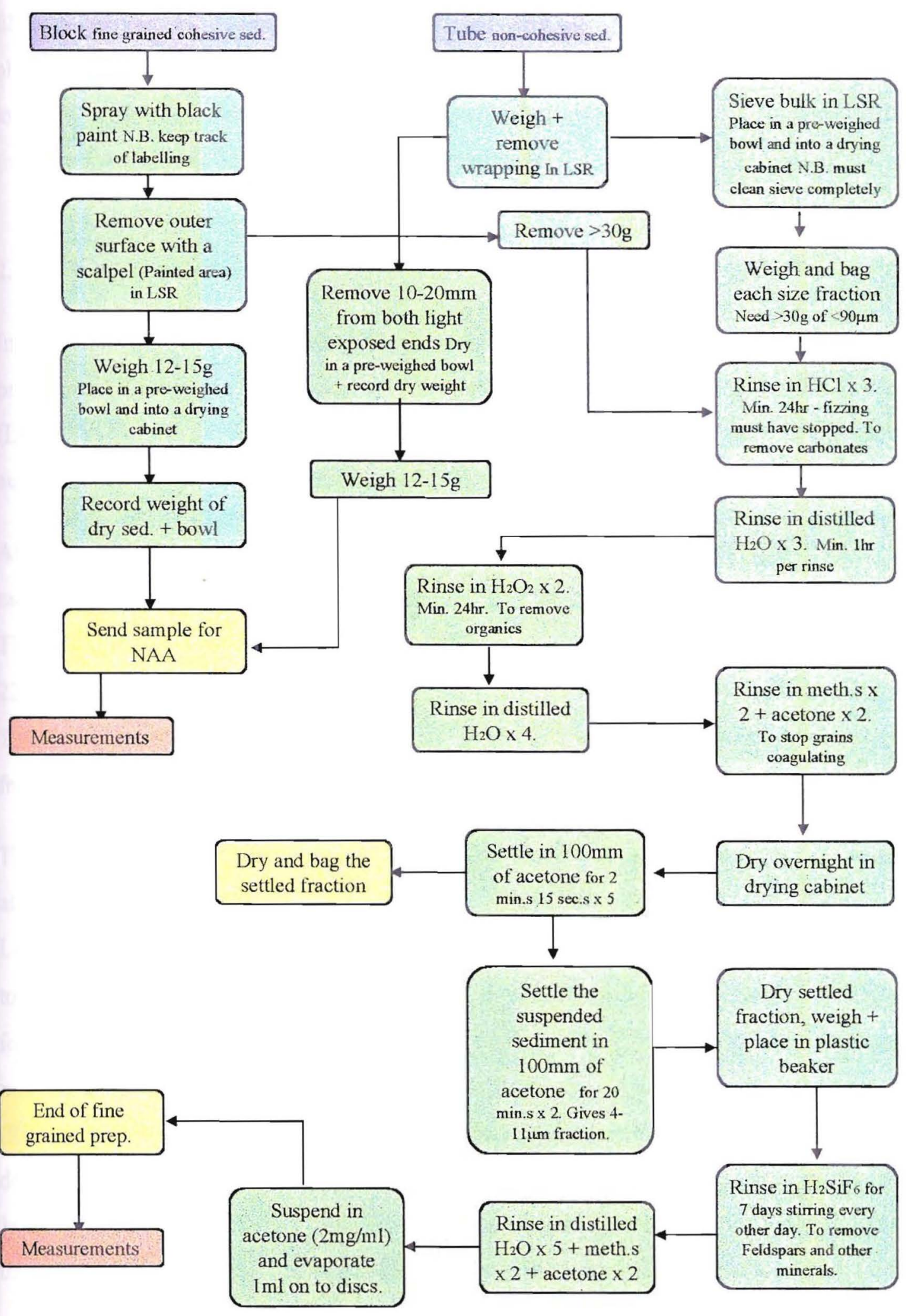

Figure 2.4 FGQ methodology 
filtered with two U340 and a 1mm BG39 filter, and an EM1963QA Bialkai cathode photomultiplier tube (PMT) detects the signal. All discs are numbered on their bases to guard against accidental changes in order, particularly as the Riso and Elsec (irradiator) machines have different loading patterns.

\subsubsection{Initial Measurements : LISA Tests}

Information on sample composition, sensitivity and sensitivity changes, and preliminary $D_{E}$ values are given by the Luminescence Initial Sample Assessment (LISA) developed by Richards (1999) (Fig. 2.5). The test uses six discs and is fully automatic taking $\sim 6$ hours running time in the Riso machine.

All discs are given $1 \mathrm{~s}$ of infra-red stimulation, then disc 2 receives $20 \mathrm{~Gy}$ of beta radiation and discs 1 and 2 are heated to $500^{\circ} \mathrm{C}$ at $2^{\circ} \mathrm{Cs}^{-1}$ to measure the shape of the TL glow curves. Discs 1 and 2 receive $20 \mathrm{~Gy}$ of beta radiation and are preheated to $220^{\circ} \mathrm{C}$ for 5 minutes and while held at $160^{\circ} \mathrm{C}$ are exposed to green light for 1000 s. This information is displayed in two parts, $0-50$ s to show the initial rapid decay and from 50-1000s to show any further long-term decay (Fig. 2.6).

The remaining four discs are used to provide two $D_{E}$ determinations using single aliquot techniques (Duller, 1991, 1995). The natural Green Light Stimulated Luminescence (GLSL) signal is measured for $1 \mathrm{~s}$ for discs 3-6, then 5 and 6 are dosed to $47 \mathrm{~Gy}$ in five increasing steps and between dosing discs 3-6 are preheated to $220^{\circ} \mathrm{C}$ for 5 minutes and 1s of GLSL is measured. Such a long shine (1s) for single aliquot measurement is required due to the dimness of many of the fluvioglacial samples (Richards, 1999). Discs 3 and 4 receive preheats and measurement, but no additional dose to provide data with which the single aliquot $D_{E}$ calculations can be corrected. 1s of Infra-Red Stimulated Luminescence (IRSL) is measured to monitor any signal that may have developed following irradiation. GLSL and IRSL data are fed into an 


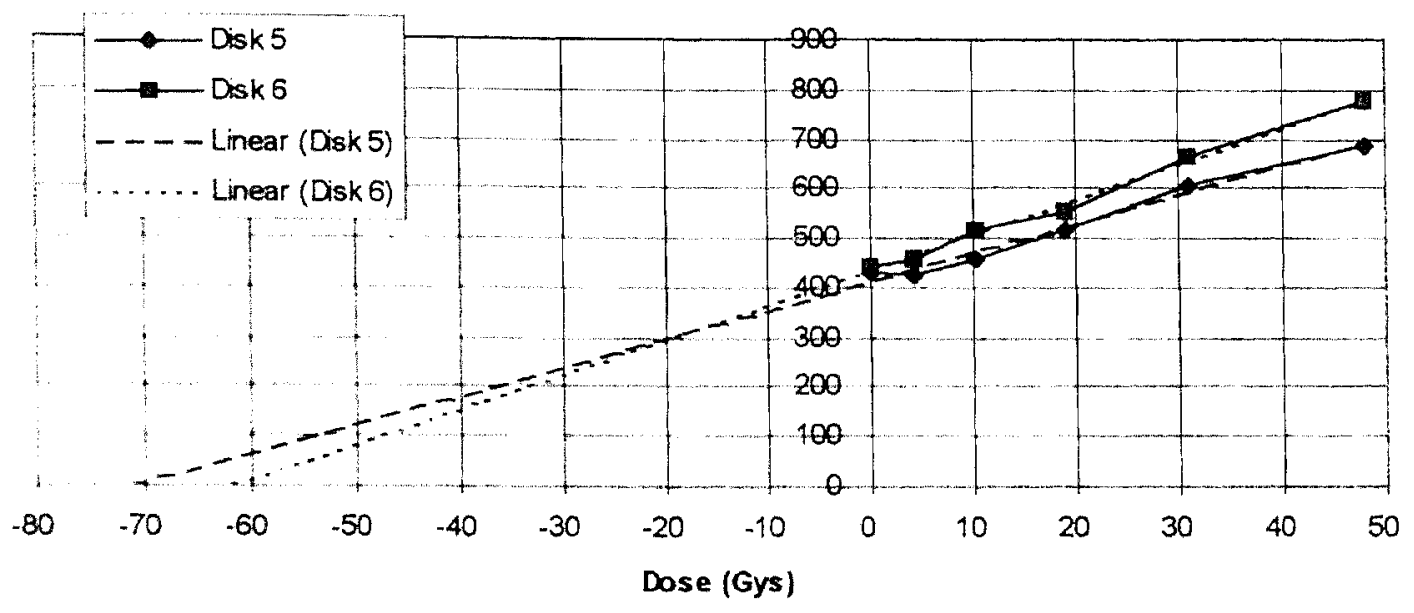

Figure 2.5 An example of $D_{\mathrm{E}}$ values from the LISA test from sample V053

Excel spreadsheet programme written by Richards (1999), which subtracts background (PMT dark noise) and calculates two single aliquot $\mathrm{D}_{\mathrm{E}}$ values. TL glow curves (Fig. 2.7) and raised temperature GLSL shine-down curves (Fig. 2.6) are printed from the Riso sottware.

These graphs show various characteristics belonging to quartz and feldspar and as such can be used to determine whether the sample is suitable for further measurement. The magnitude of the natural GLSL signal indicates the sensitivity of the sample. $D_{k}$, values are derived using three variations of the luminescence correction method' (Duller, 1991). These results are not necessarily an accurate estimate of the $D_{\mathrm{F}}$ value, but give a means of estimating the amount of additive dose to give the sample, which should ideally be five times the $D_{\mathrm{E}}$ (Grün and Rhodes, 1991). Without this initial measure and with no existing information on the age of the sample or dose rate (the NAA results not being complete at this stage in the 
(a)
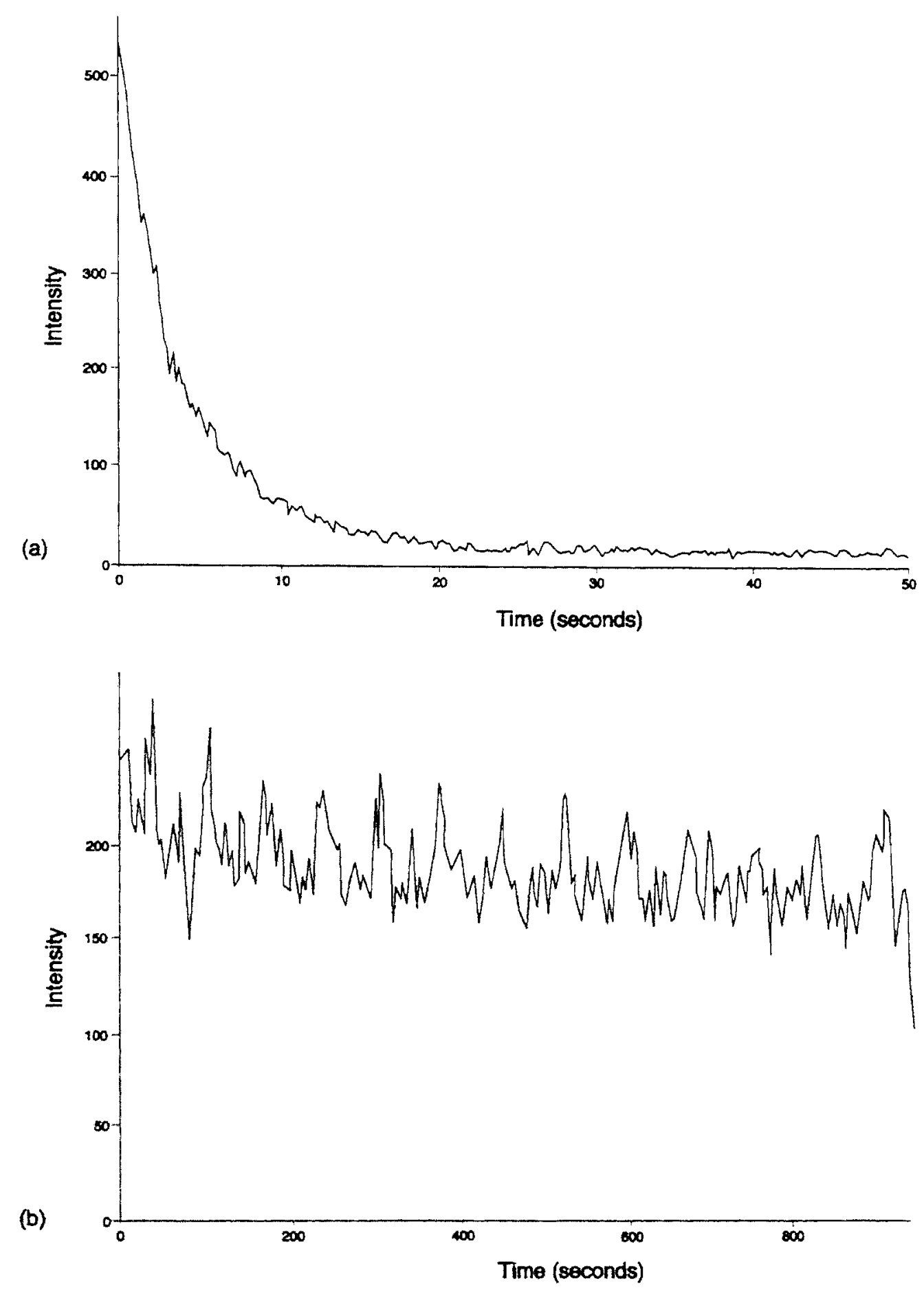

Figure 2.6 Shine down curves from sample V053, (a) short-term curve from 0$50 \mathrm{~s}$, (b) long-term curve from $0-1000$ s (the scatter on this second curve is due to the low signal strengh). 
(a)
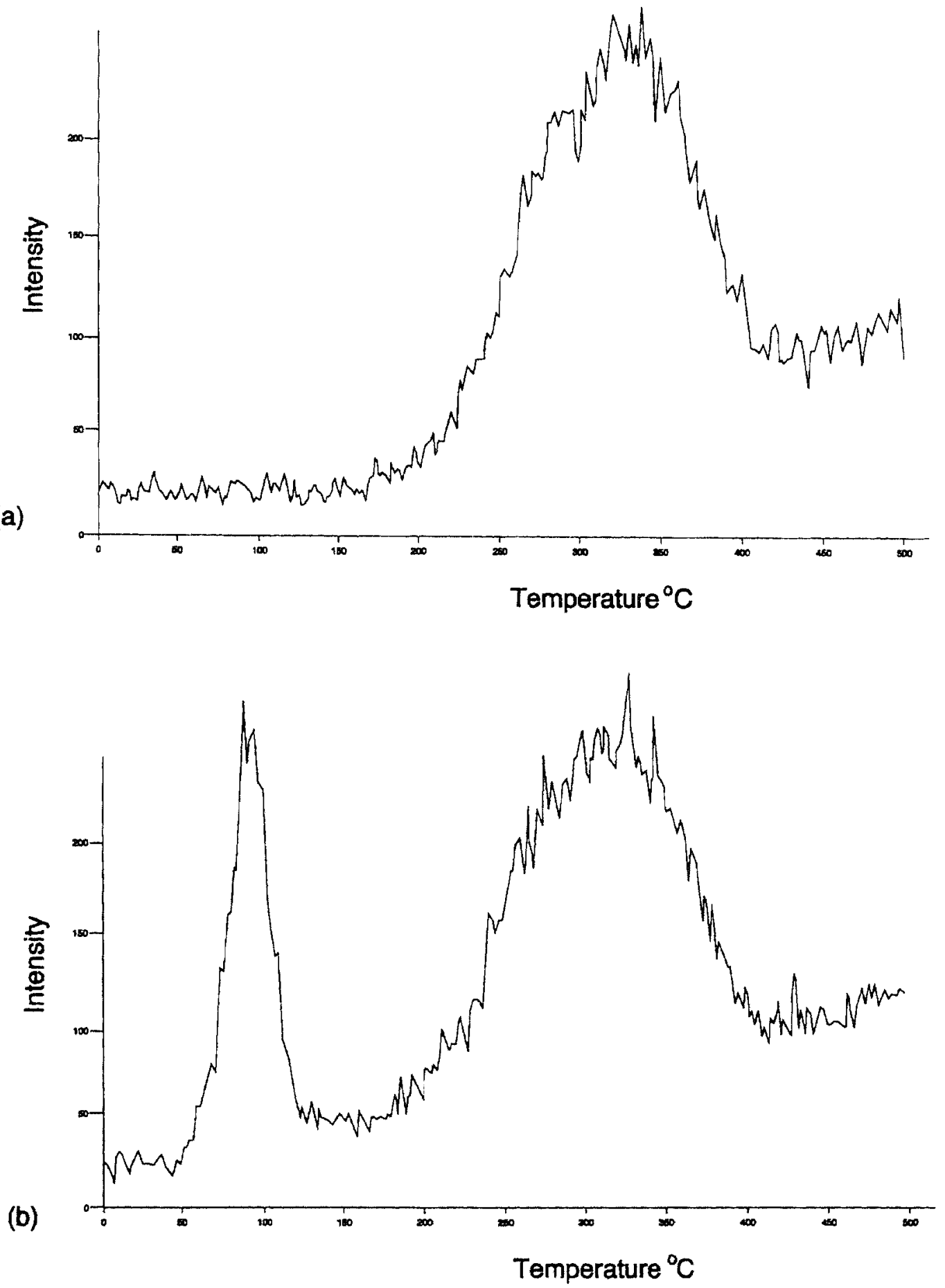

Figure 2.7 TL glow curves from sample V053, (a) natural, (b) natural plus $\beta$ dose. 
procedure), the amount of additive dose would have to be guessed, resulting in a needless reduction in the precision of the $D_{E}$ estimate.

\subsubsection{Main Measurements}

\section{Natural Normalisation}

A problem encountered with OSL dating is the scatter from disc to disc (e.g. Rhodes, 1990 , Huntley and Berger, 1995), especially for fluvioglacial samples ( $c f$. Rhodes and Pownall, 1994). Richards (1999) suggests as possible reasons for this, sample inhomogeneity, feldspar contamination, inhomogeneous bleaching of grains in the sediment owing to non-uniform pre-depositional histories, partial bleaching of sediments, contamination on the aluminium discs and variation of the in situ microdosimetry and water content of different grains.

To overcome this scatter, $0.3 \mathrm{~s}$ of GLSL is measured for each disc. This data, which shows the relative brightness of each disc, is used to normalise the post-dosing measurements. The luminescence of each disc is depleted by a small amount, but not enough to affect the later measurements (Rhodes, 1988). 1s of IRSL is also measured to indicate whether there is feldspar contamination (Stokes, 1992) and optical microscopy is used on a small sub-sample to check for non-quartz grains.

\section{Dosing}

To produce an additive dose response graph, 40 of the 48 discs were given increasing radioactive doses from a beta irradiator made by Elsec at a dose rate of $3.9 \mathrm{Gymin}^{-1}$, with the remainder left as 'natural'. 


\section{Preheating}

During the dosing, trap sites that are not stable for the order of time being dated are occupied. A $220^{\circ} \mathrm{C}$ preheat for 5 minutes (Rhodes, 1990) removes this unstable charge for quartz samples, with a longer preheat of 5 days at $100^{\circ} \mathrm{C}$ and then 4 hours at $160^{\circ} \mathrm{C}$ for polymineral samples (Richards, 1999).

\section{Main Measurement}

IRSL and GLSL measurements are made in the Riso machine for 50 s at $50^{\circ} \mathrm{C} .48$ discs are measured rather than 24 to provide greater precision. Subtraction of the background signal is done by taking away the last integral of the shine-down curve (Aitken and Xie, 1992).

\section{Curve Fitting}

A single saturated exponential function is fitted to the data to give the $D_{E}$ using a programme called Fit-sim (Grün and Brumby, 1994). Two curves are displayed by the programme, one of which attributes equal status to all points, while the other employs a weighting inversely proportional to the square of intensity to take greater account of lower intensity points (Fig. 2.8).

\section{Environmental Dose Rate Calculation}

A sub-sample of sediment from each sample is sent to Becquerel Laboratories, Lucas Heights, Australia for Neutron Activation Analysis (NAA) to determine the radiation flux experienced by the grains. Gamma spectroscopy, which may give more representative measures, is not used due principally to the fragility of such instruments, which would not survive transport by pack animal in the field area. 


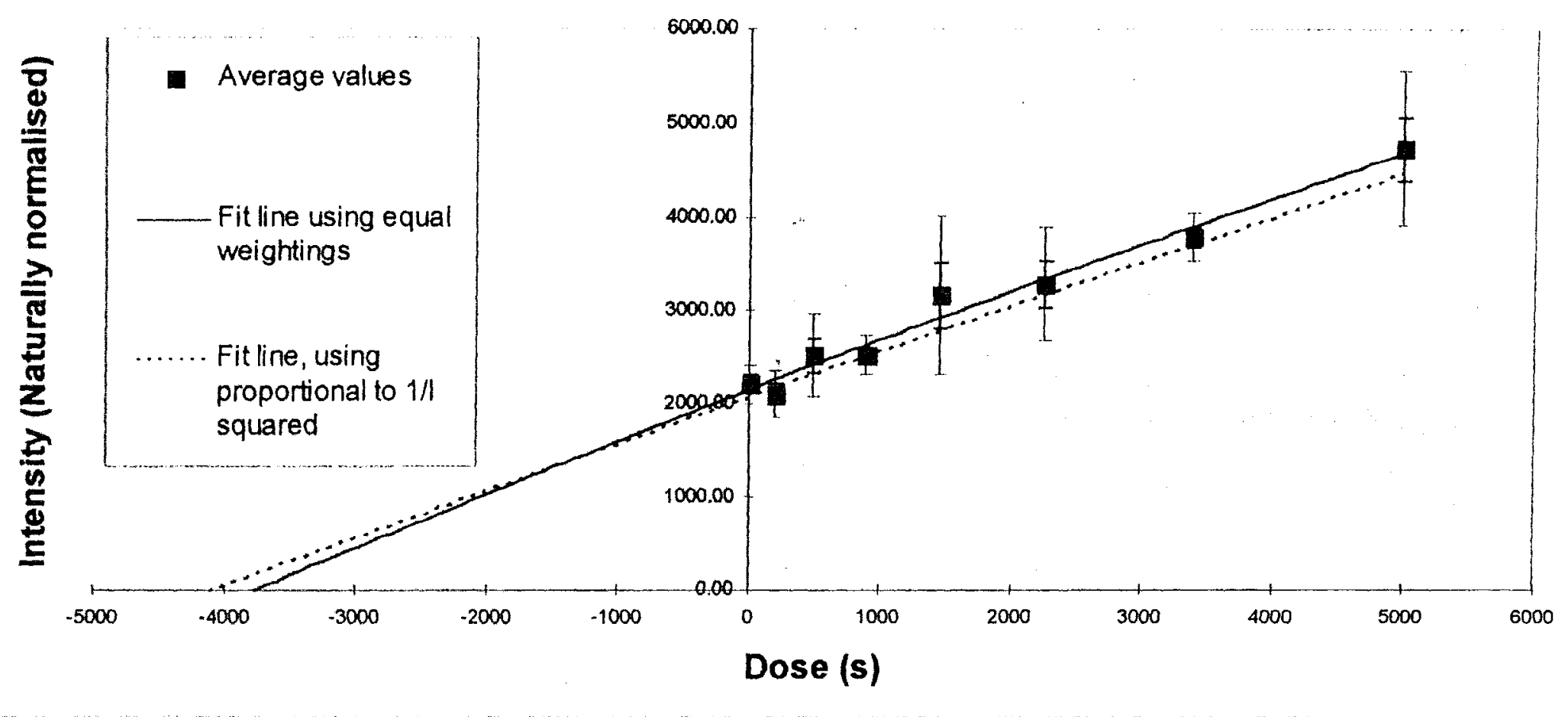

Figure 2.8 Additive Dose response curve from V053, best fit line with equal weights and inversely proportional to intensity squared. 
Water content, which effects the environmental dose rate, is measured by loss of mass after drying at $50-60^{\circ} \mathrm{C}$. Samples are usually from free faces and as such may not represent the hydrological history for much of the burial time, however this is unlikely to be a problem in semi-arid regions like the Zanskar Range where water content is liable to have been low anyway.

The cosmic dose rate is calculated using the longitude, latitude and altitude of each site (Prescott and Hutton, 1994) as well as the depth of overburden. Results are given errors of $\pm 20 \%$ to account for uncertainties in the palaeo-depth of burial and shielding effects of mountains in high relief areas (Richards, 1999).

\subsubsection{Age Determination}

Age estimates are determined using a program written by Grün from the $D_{E}$, NAA and cosmic dose data. The layer removed for CGQ is assumed to be $10 \mu \mathrm{m}$ and given a liberal error of $\pm 10 \mu \mathrm{m}$ and the alpha efficiency for FGQ is given as $0.04 \pm 0.01$.

\subsection{Palaeoclimatic Reconstruction}

The relationship between glaciers and climate is a major source of palaeoclimatic evidence (Sutherland, 1984). Consequently, palaeoglacier reconstruction can be used in the examination of regional climatic conditions for the period of time when ice bodies were at that limit (Sutherland, 1984; Bradley, 1985; Locke, 1990; Lowe and Walker, 1997).

The equilibrium line altitude (ELA), the height of the line that separates the upper zone of net accumulation from the lower zone of net ablation on a glacier, has been used in climate reconstructions (e.g. Sissons and Sutherland, 1976; Williams, 1983; Sutherland, 1984; Burbank and Fort, 1985; Ballantyne, 1989; Locke, 1990; Holmes, 1993 ), on the basis of present day mass balance studies which show a critical link 
between ELA and climate (Sutherland, 1984; Kuhn, 1984; Ohmura et al., 1992). The ELA will decrease with increased snowfall and/or a decrease in the frequency of positive air temperatures. As the ELA is sensitive to perturbations in either of these variables, reconstructed ice limits do not provide an unequivocal climatic representation, but require additional palaeoclimatic data for one variable in order to calculate or model overall climate (Bradley, 1985). Thus, studies of ELA values must be viewed in conjunction with palaeoclimatic proxy data from independent sources.

Former ELAs provide a potential method of quantifying palaeoclimates. Regional trends of ELA values have been used to show former precipitation gradients, allowing moisture sources and atmospheric circulation patterns to be reconstructed (e.g. von Wisseman, 1959; Sissons and Sutherland, 1976; Meierding, 1982; Williams, 1983; Ballantyne, 1989; Burbank and Kang, 1991; Holmes, 1993; Lehmkuhl, 1995, 1998b; Lehmkuhl et al., 1998).

There are, however, problems with the use of ELAs in palaeoclimatic reconstruction (cf. Benn and Lehmkuhl, in press). Indices calculated for palaeoglaciers do not always have a clear relationship with former climate and as such palaeoclimatic studies based on these indicators may be imprecise or misleading. In high relief mountain environments, the relationship between climate and glacier distribution is complicated by the influence of avalanching and debris cover on glacier mass balance, and where terrain attributes result in complex glacier morphologies. Benn and Lehmkuhl (in press) discuss in detail the estimation of former ELA values and some of the problems peculiar to high mountain environments. Nevertheless, a comparative study of methods has shown that while altitudes vary between methods, the reconstructed trends are similar (Meierding, 1982). 


\section{Methods of ELA Calculation}

To determine steady-state ELAs for modern glaciers, mass balance observations have to be made over several years. Mass balance characteristics are not known for the study area and the remit of this project does not extend to the extensive measurements required to gain such data (e.g. Kulkarni, 1992). Furthermore, mass balance characteristics of modern and palaeo-glaciers may be significantly different, such that indices describing modern ELAs may not be applicable for palaeoglaciers.

PalaeoELAs cannot be directly measured, so a number of surrogate indices have been employed to approximate these values, some of which are evaluated by Osmaston (1975), Meierding (1982), Locke (1990), Torsnes et al. (1993) and Benn and Lehmkuhl (in press). These methods vary widely in their sophistication, reliability, ease of use and demand on ice margin reconstruction, topographic and mass balance data.

The Maximum Elevation of Lateral Moraines (MELM) (Liechtenecker, 1938; Visser, 1938) is the only direct evidence for former ELA, as deposition of these landforms can only occur in the ablation zone. In comparison studies, however, this method was found to be the least reliable (Meierding, 1982; Locke, 1990). Meierding (1982) found that identification of lateral moraines from air photographs could be difficult. Englacial debris may not reach the glacier surface at the ELA with the moraine being deposited some distance down valley and slow continuous retreat of ice may produce overprinted lateral moraines up-slope (Benn and Lehmkuhl, in press). Furthermore, side slopes in many valleys of the Zanskar Range are too steep for deposition or the preservation of lateral moraines.

The altitude of corrie floors (e.g. Charlesworth, 1957; Flint, 1971) is inapplicable due to the scarcity of these landforms. Although the method is simple and data can be rapidly obtained from topographic maps, Meierding (1982) reports on the difficulties of dating such features, particularly as they are likely to be composite landforms eroded over several glacial periods. He also highlights the subjectiveness of 
identification, especially when at the lower end of their altitudinal range, where they are not well developed. This problem is exacerbated by the poor quality of available topographic data from the field area. Results from a comparison of methods found that those based on small former glaciers, such as this one, gave variable results compared to those based on larger glaciers, due to greater influence of local topography and climate on small ice bodies (Meierding, 1982).

The average altitude between the lowermost glacier clad mountain and the uppermost ice free summit (excluding unsuitably shaped peaks), the Glaciation Threshold - GT (e.g. Charlesworth, 1957; Østrem, 1966; Flint, 1971; Porter, 1977), parallels ELA trends. The regional GT for the Kashmir Basin (Holmes, 1993) shows a good correlation with the ELA trend, but with values $200-300 \mathrm{~m}$ higher. Nevertheless, insufficient data for small palaeoglaciers of a given age are available for calculation of the GT for the Zanskar Range and glacial evidence in high marginal areas is often equivocal (Kuhle, 1988).

Two more commonly implemented methods of ELA approximation, requiring reconstruction of the former glacier surface, are the Accumulation Area Ratio (AAR), which assumes that a certain ratio of the glacier surface lies within the accumulation area (Porter, 1970), and the Area Weighted Mean, which assumes that the amount of ablation decreases linearly with height (Sissons, 1974). Neither of these methods could be applied to palaeoglaciers from Zanskar as constraints on time and accessibility prevented the reconstruction of continuous glacial margins, and topographic data are unreliable. In addition, ablation is unlikely to have decreased linearly with height for what were probably debris covered avalanche fed glaciers with mass balance curves showing a maximum ablation up-glacier from the snout ( $c f$. Khumbu Glacier - Inoue, 1977) and an accumulation maximum down-glacier from the uppermost reaches ( $c f$. Benn and Lehmkuhl, in press).

The Balance Ratios (BR) method (Furbish and Andrews, 1984) is also based on linear accumulation and ablation gradients and as such suffers the same problems for debris 
covered and avalanche fed glaciers. In addition to information on glacier hypsometery, requiring good topographic maps, this method uses mass balance gradients, data that are unavailable to this study.

Various ratios of the vertical distance between glacier termini and upper limits of ice (taken as a two thirds up the headwall) have been proposed as an approximation for ELA values (e.g. Charlesworth, 1957). This method (the Toe Headwall Altitude Ratio - THAR) has been shown to be reasonable for some areas (Meierding, 1982; Locke, 1990), in spite of the AAR method having "a more satisfactory physical basis than the THAR method because it integrates surface area, absolute elevation and gradients of ice accumulation and ablation..." (Meierding, 1982, p306). As the THAR bears no relationship to the concept of steady-state ELA, Benn and Lehmkuhl (in press) recommend that it be referred to as a 'Glacier Elevation Index' (GEI) rather than an ELA.

Delimitation of the headwall and estimation of two-thirds of its height are subjective. This is partly overcome by using the maximum altitude in the catchment as an alternative. Gross et al. (1976) produced ELA values $\sim 100 \mathrm{~m}$ too high using this method (ratio of 0.5), although Lehmkuhl (1998b) found it to be representative for the Turgen-Khariraa, the northernmost range of the Mongolian Alti. The use of the highest peak is likely to be problematical for catchments where that summit is not representative and contributes little to the accumulation of the glacier (Benn and Lehmkuhl, in press). Although the method is crude and does not consider glacier mass balance, but rather summarises the gross morphology of the glaciated catchment, it is rapid and can be applied in areas with poor topographic maps.

A THAR of 0.4 , derived from a comparative study of methods (Meierding, 1982), has been adopted, mainly to allow direct comparison with adjacent studies which employ the same methodology (Burbank and Fort, 1985; Holmes 1988, 1993; Sharma and Owen, 1996; Osmaston, in prep. a). It is acknowledged that the mass balance dynamics of former glaciers in the Zanskar Range are likely to have been different 
from that of the Colorado Front Range (USA), where the ratio was derived, and may not be representative. Indeed, contemporary Himalayan glaciers to the south of the study area have been shown to have an AAR of 0.44, differing from that used in Europe and North America (Kulkarni, 1992) and Sharma and Owen (1996) have shown a THAR of 0.5 to be more appropriate for the Garhwal Himalaya. With modern glaciers mainly small, clean ice, avalanche fed types, the empirical determination of a THAR would not be representative for large palaeoglaciers, which were probably debris covered.

Headwalls are steep and inaccessible and as such their altitudes are estimated from topographic maps. Since the decisions as to what constitutes the headwall slope and the estimation of two thirds of its height are subjective and the coarseness of topographic data with contours at intervals of $152 \mathrm{~m}$ hinders interpretation, the maximum summit altitude method is also used. Toe altitudes are recorded from maps and altimeter readings. Points of known altitude for calibration of the altimeter are scarce, leading to errors as weather conditions change. The readings are, however, more reliable than those calculated by the GPS which vary wildly, or from the topographic map which often bear little resemblance to the gross morphology of the area.

A THAR of 0.4 (using a headwall estimate) and of 0.5 (using the maximum summit altitude) are used in this thesis, the former allowing direct comparison with existing studies and the latter providing data for the correlation program for High Asia (Lehmkuhl, pers. comm.). Toe, headwall and summit altitude data are also provided in the event of future ratios based on more rigid mass balance investigations of appropriate glaciers becoming available. 


\subsection{Conclusions}

The following methodology is employed to address the aims of the project :

(1) Geomorphological mapping based on methods employed by previous glacial reconstruction will form the basis of fieldwork for this project, delimiting former glacier margins.

(2) A geochronology will be established using OSL dating, chiefly using FGQ. Recent developments have reduced some of the problems often associated with OSL dating of fluvioglacial sediments (Richards, 1999) and few alternative methods are applicable in such arid regions.

(3) GEI values will be calculated from mapped limits using a THAR of 0.4 , so that direct comparison can be made with data from adjacent areas derived using the same method. Data calculated with a ratio of 0.5 using the maximum summit altitude in the catchment will also be presented. Although not related directly to the concept of steady-state ELA (Benn and Lehmkuhl, in press) such glacier altitude indices are useful guides where more robust palaeoclimatic indices cannot be used. Furthermore, the reconstructed trend will mirror that for ELA values. 


\section{Field Evidence for Glaciation}

\subsection{Introduction}

This chapter describes the geomorphological and sedimentological evidence for glaciation. The field area is divided into eight sections, which are described in turn from south to north. Names of rivers, valleys and villages are taken from the available maps to avoid confusion, although it is acknowledged that many of these are not recognised locally. Many of the names used are followed with the words 'chu', 'la' and 'gompa', which translate as 'river', 'pass' and 'monastery' respectively. Six figure grid references in the text relate to a location map, which has been split into southern (Fig. 3.1) and northern (Fig. 3.34) sections, and enlargements of this map that correspond to each described section.

\subsection{Baralacha La to the Phirtse Chu}

(Fig. 3.2)

Evidence from the southernmost section of the field area is presented. The Yunan (upper Tsarap) valley is traced down river from the Baralacha La in the south before following the Lingti valley west to the Phirtse La and into the Phirtse valley (Fig. $3.2)$.

The Baralacha La (071011) occupies a broad basin of $\sim 5000 \mathrm{~m}$ a.s.l. (above sea level) at the head of three valley systems, the Bhaga, the Chandra and the Yunan. Largely vegetation-free rock and talus mantled slopes lead from the basin to high snow covered peaks. Several small glaciers can be observed in the distance and there is abundant evidence of former glaciation. At the head of the Bhaga valley, a $10-30 \mathrm{~m}$ 


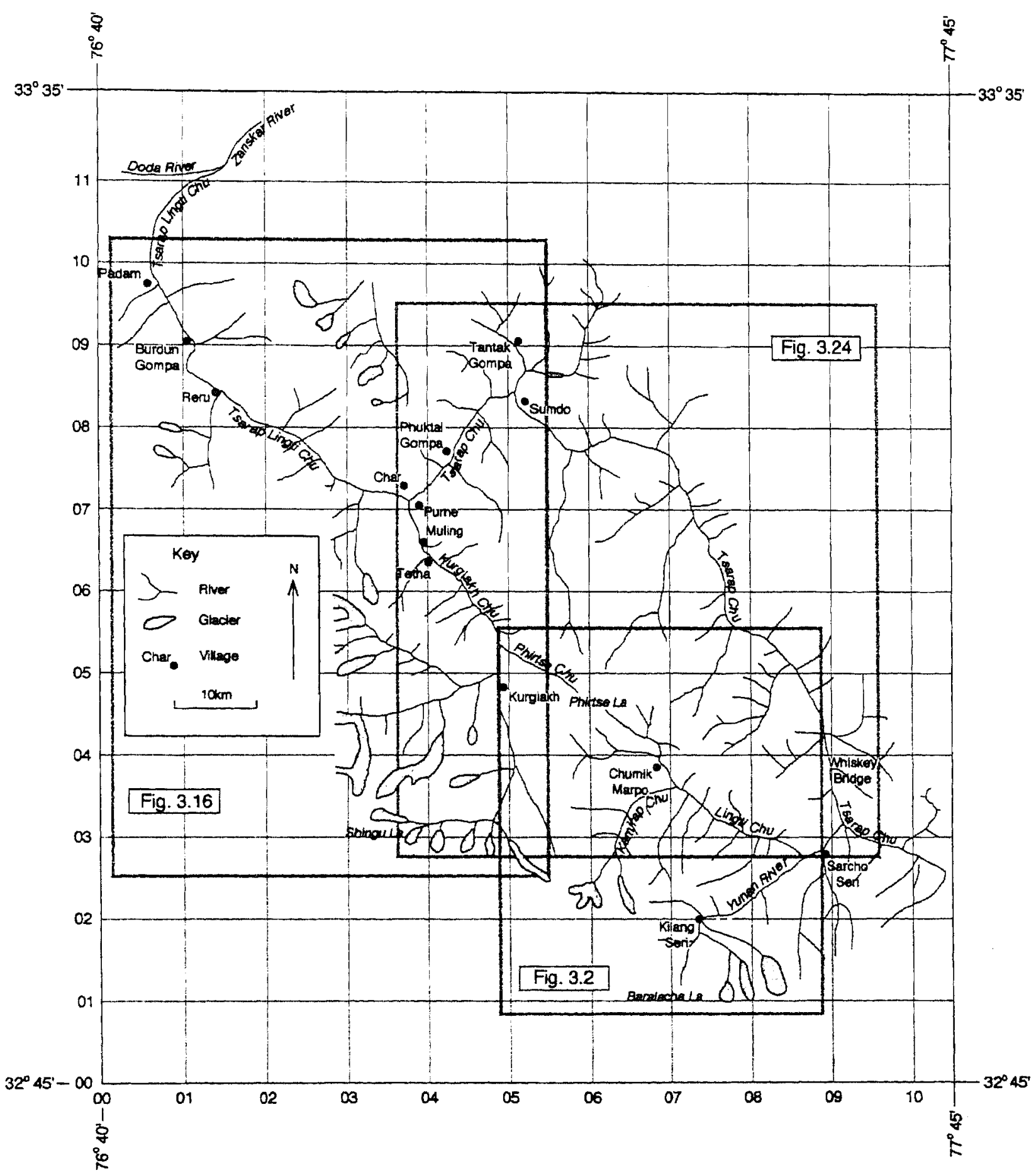

Figure 3.1 Location map for Sections 3.2, 3.3 and 3.4 showing the Tsarap-Lingti, Kurgiakh and Tsarap river systems. 


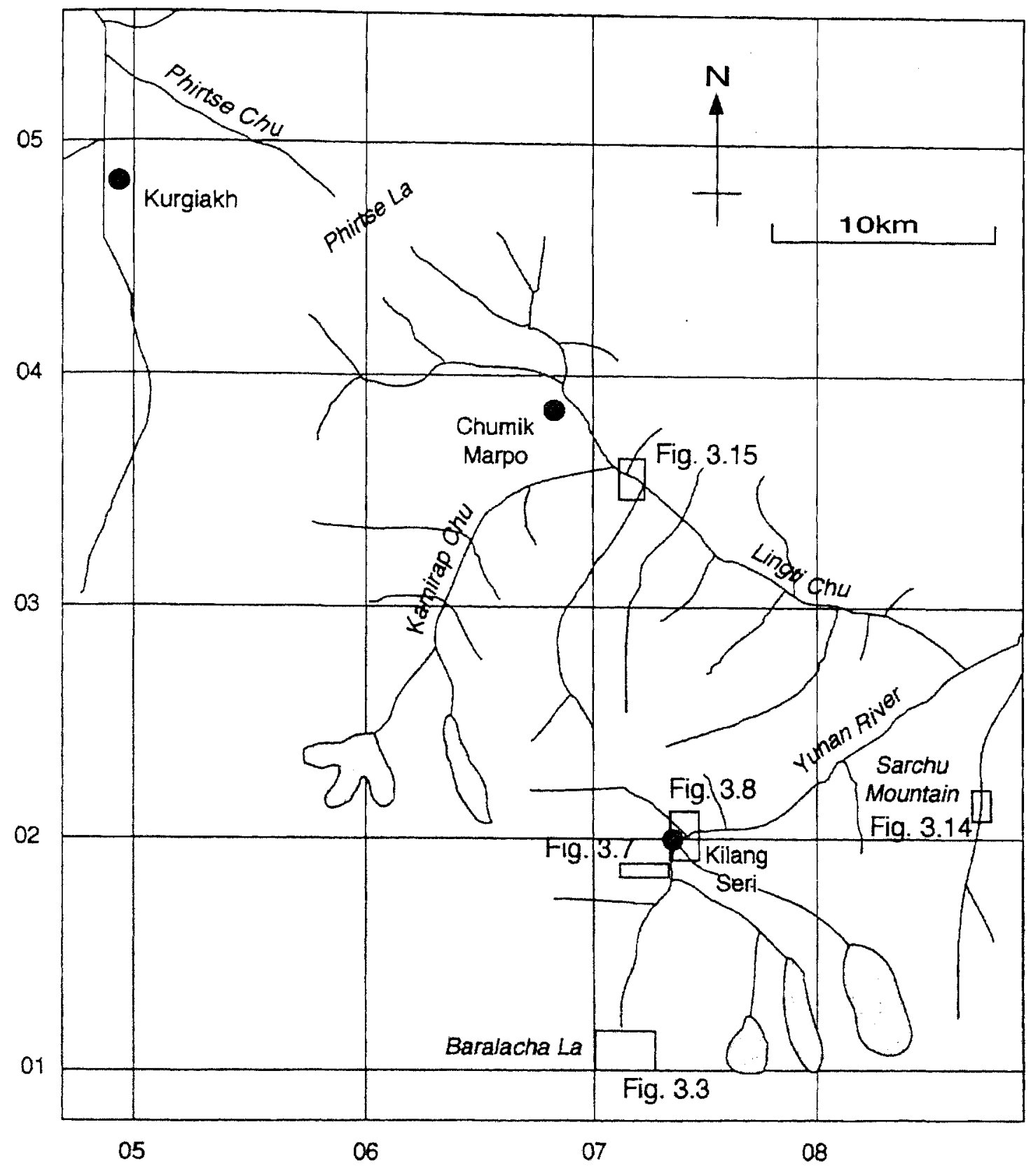

Figure 3.2 Location map for Section 3.2, enlarged from Figure 3.1, showing the Yunan, Lingti and Phirtse rivers. 


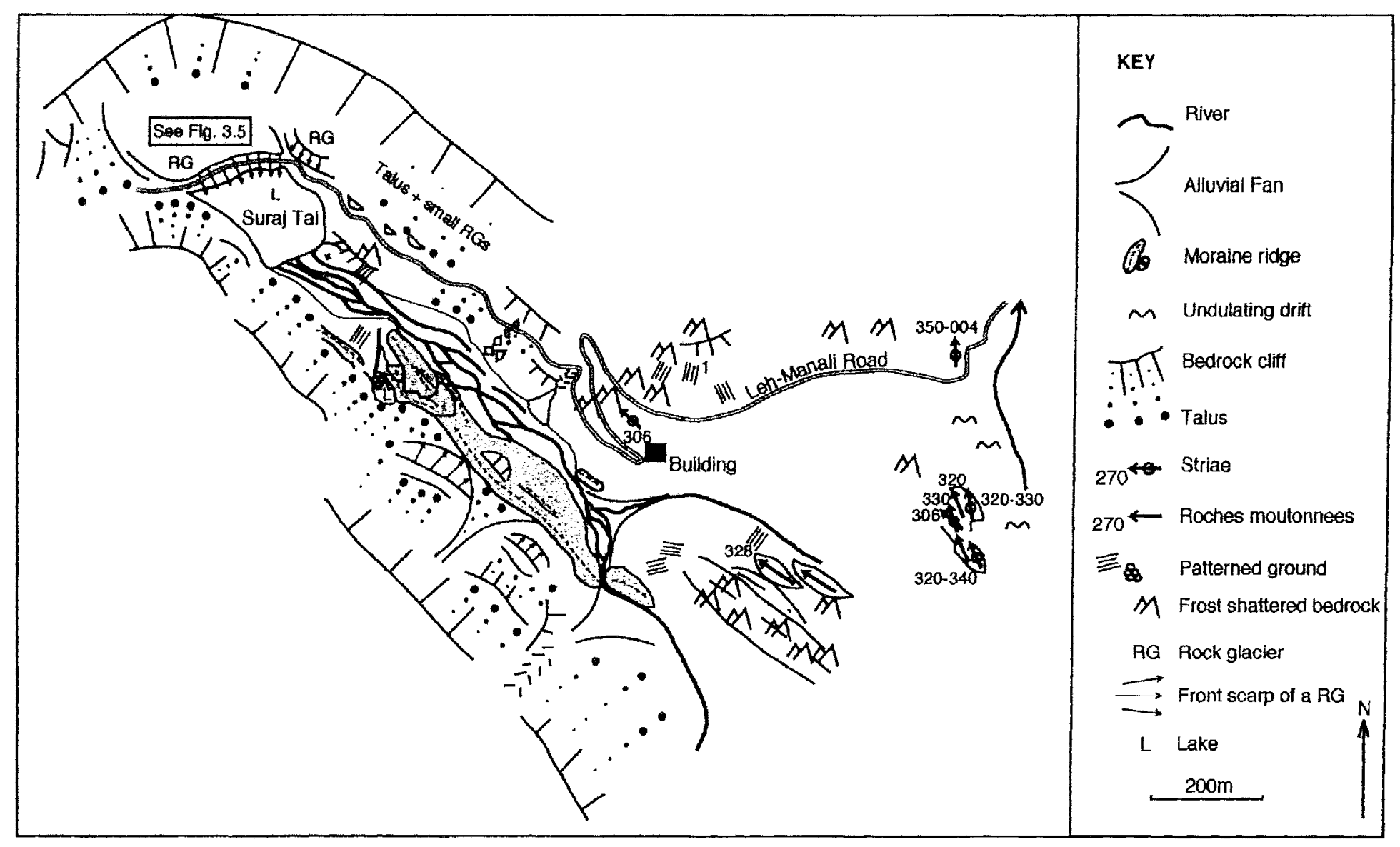

Figure 3.3 Geomorphological map of the Baralacha La. See Fig. 3.2 for location. 
high moraine ridge extends for $7700 \mathrm{~m}$ along the south-western slope at the foot of a rock glacier modified talus slope (Fig. 3.3). Rock outcrops generally have a streamlined gross morphology, but heavily frost shattered, desert varnished faces. A few notable exceptions have well developed roches moutonneés and cross-cutting striae, with orientations into the Bhaga and Yunan valleys (Fig. 3.3) indicating that the basin formed an accumulation area for ice at some time.

Active periglacial processes currently dominate the geomorphology of the pass and have produced sorted patterned ground in the form of circles of $1 \mathrm{~m}$ diameter on flat saturated ground and, more commonly, as stripes with a spacing of $1-1.5 \mathrm{~m}$ on slopes of $10-20^{\circ}$ (Fig. 3.4). The active protalus rock glacier shown in Figure 3.5 is $\sim 300 \mathrm{~m}$ from the back wall to the snout, $\sim 300 \mathrm{~m}$ across and has a complex morphology of lateral, longitudinal and frontal transverse ridges of a few metres to $>50 \mathrm{~m}$ width. A continuous permanent snow patch fills the depression between the rock glacier and the back wall, with numerous rock falls on its surface. The western part is relict with a secondary active scarp developed $\sim 75 \mathrm{~m}$ from the margin. The feature has moved against rock glacier modified talus to dam the lake of Suraj Tal (Figs. 3.5 and 3.6).

Outcrops of diamictite observed by Mitchell et al. (1996) were interpreted as evidence of an early Pleistocene glacial period. Subsequent investigation in late summer, when much of the late lying snow which previously obscured the ground had melted, revealed that the diamictite occurs only as boulders and is more likely to be of Permian age, although no record has been found of this diamictite from geological mapping.

Present glaciers occupy positions close to the highest peaks at the head of the Yunan valley, with lowermost altitudes of $\sim 5300 \mathrm{~m}$ and head walls of $\sim 5800 \mathrm{~m}$. Large moraines are deforming as rock glaciers at the lips of the corries. 

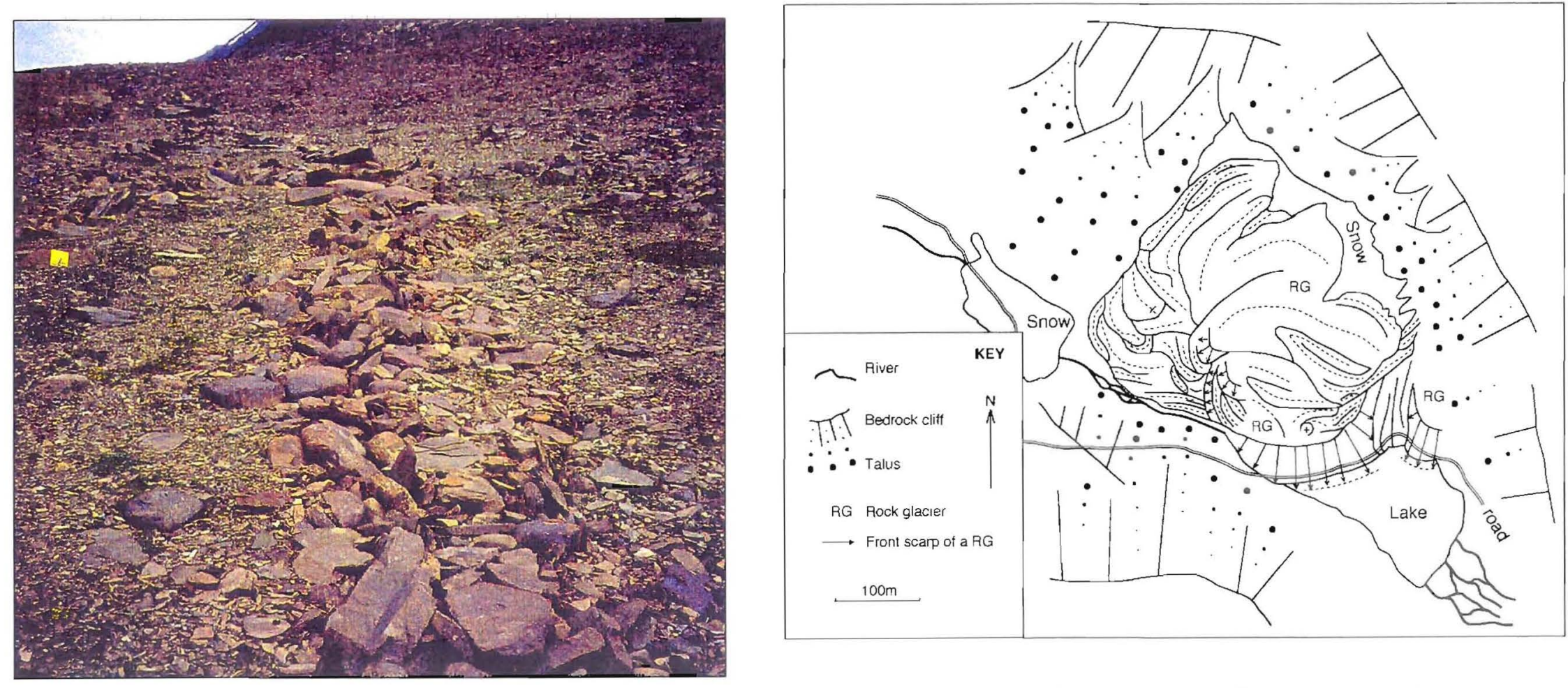

Tigure 3.5 Geomorphological map of a rock glacier,

Figure 3.4 Sorted stripes at the Baralacha La $(200 \mathrm{~mm}$ notebook for scale). 071011 in Fig. 3.2, looking north-west. which dams the Suraj Tal (Tal E Lake), at the Baralacha La. See Fig. 3.2 for location. 


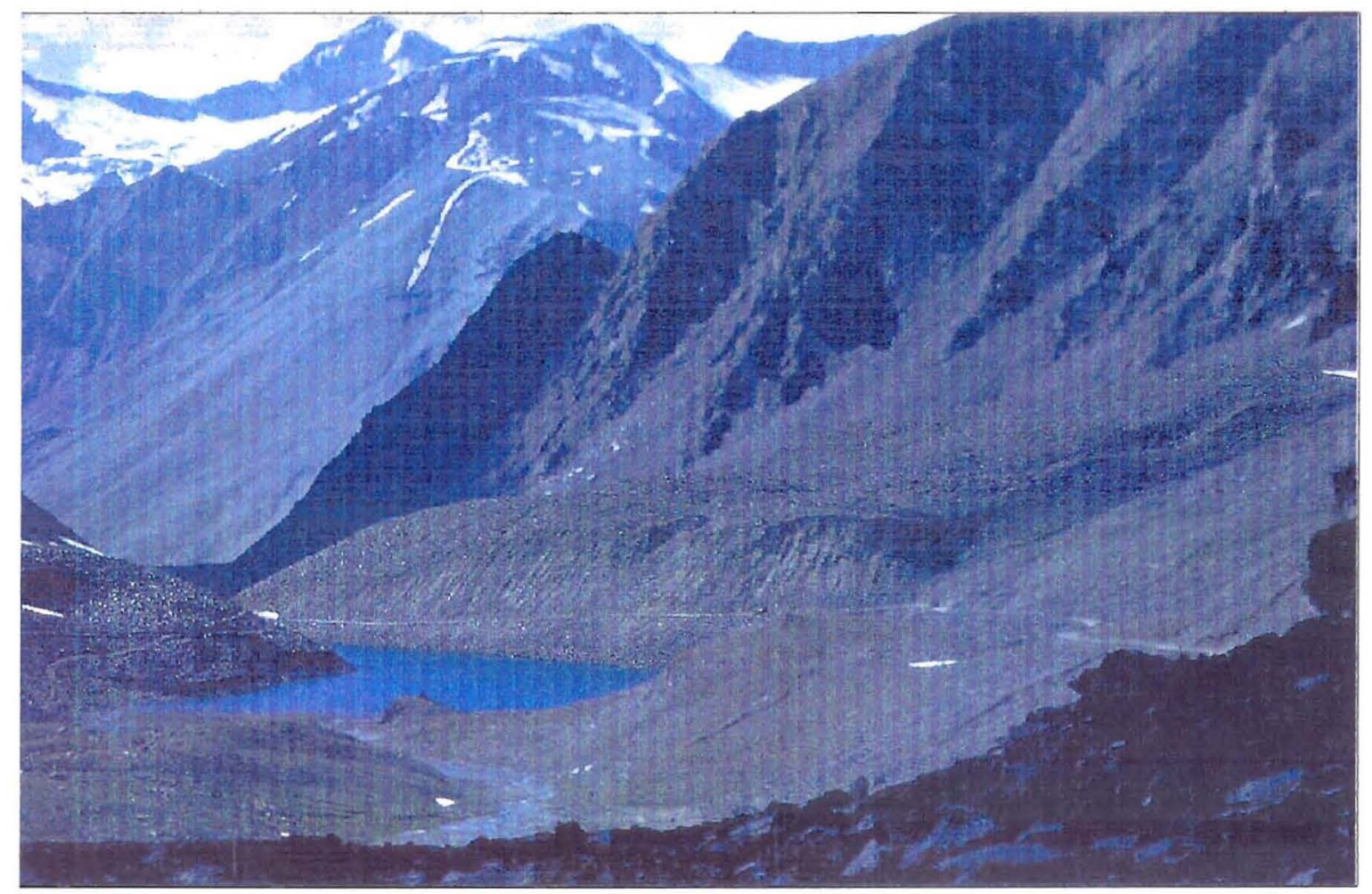

Figure 3.6 General view of the rock glacier and talus slopes of the upper Bhaga valley looking north-west from the Baralacha La. The rock glacier mapped in Figure $3.5 \mathrm{can}$ be seen damming the drainage. Note the road crossing the $40-50 \mathrm{~m}$ high active scarp. 
Chapter 3, Field Evidence for Glaciation

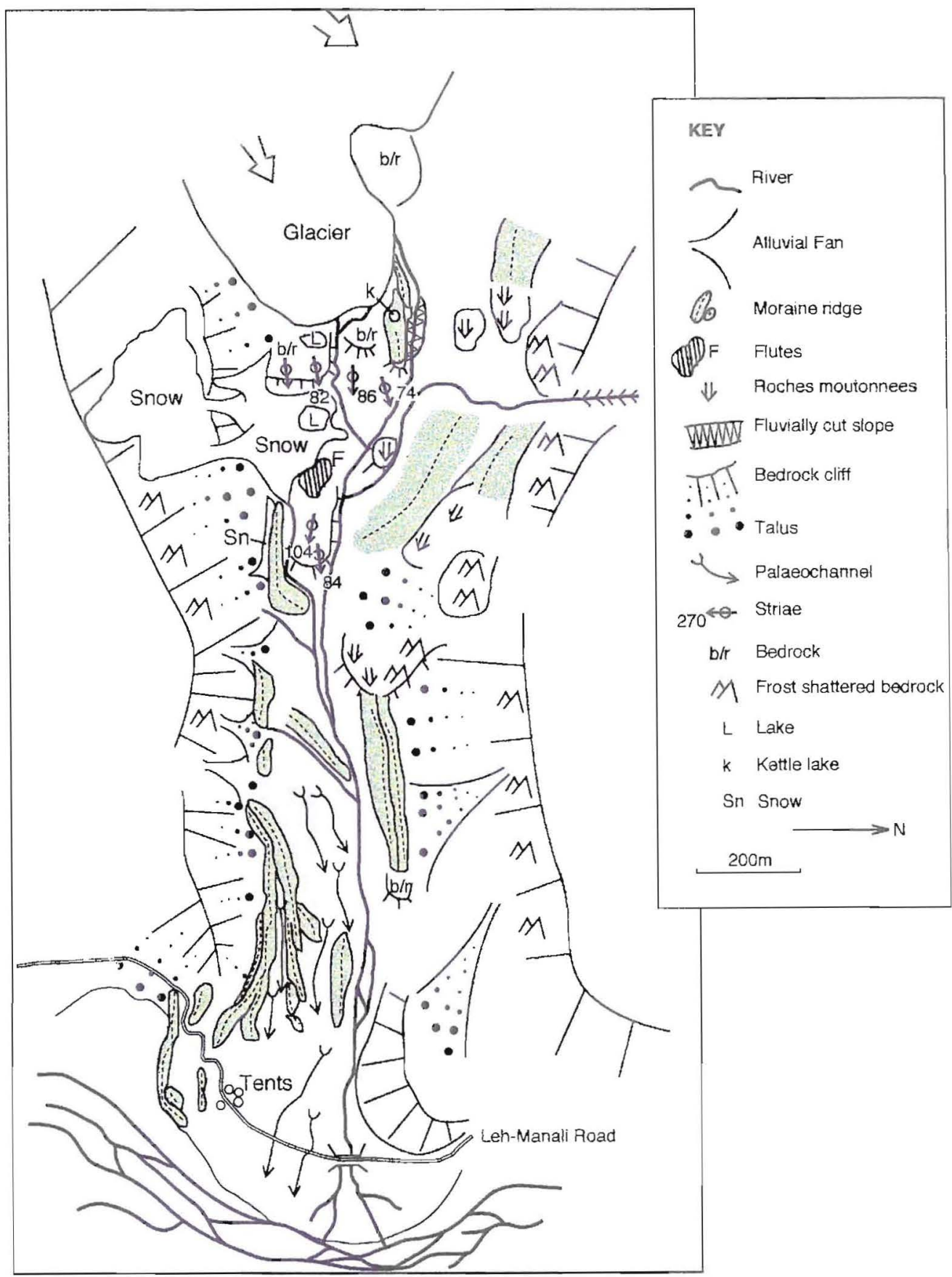

Figure 3.7 Geomorphological map of the western tributary of the Yunan valley, $4 \mathrm{~km}$ up-river from Kelang Seri, showing a suite of glacial landforms including sharp crested moraine ridges. See Fig. 3.2 for location. 
The Yunan River, a major north flowing tributary of the Tsarap Chu, has a broad floor of $\sim 1.5 \mathrm{~km}$ width with steep valley walls characterised by bedrock cliffs that feed talus cones and rock glaciers. Towards the river, these cones of debris are reworked as alluvial fans and terraces. The largest of these (073017) emanates from an unnamed tributary valley to the west, partially burying a suite of sharp crested moraine ridges of $5-10 \mathrm{~m}$ height, $10-20 \mathrm{~m}$ width and several hundred metres length. A small glacier occupies the head of this tributary, $<2 \mathrm{~km}$ from the Yunan valley (Fig. 3.7). The glacier snout is largely debris free with a low angle suggesting current retreat. Striae and roches moutonneés adorn bedrock outcrops beyond the glacier snout and an area of fluted moraine is also preserved (Fig. 3.7).

Further down the main valley (074020), the river is deeply entrenched by $\sim 40-60 \mathrm{~m}$ where it cuts through landslide material in the southern part of the mapped area, but reverts to a braided form down stream. The area mapped in Figure 3.8 shows a suite of moraine ridges and hummocks, a catastrophic rock avalanche deposit and lake sediments. The rock avalanche forms ridges composed of an open work of angular blocks of up to $5 \mathrm{~m}$ diameter, of the same low grade metamorphosed sandstones and limestones that makes up the bedrock. The deposit clearly travelled across the valley where it is banked against and onto the $50 \mathrm{~m}$ front scarp of a protalus rock glacier (074020). This caused a lake to be dammed up-stream, the deposits of which having been incised by the river leaving a sharp terrace (L2 in Fig. 3.8). A sample for OSL dating from this lake deposit (laboratory code, V067; Chapter 4) has been collected by Edward Rhodes. Given the ridge morphology and extensive area of run-out of the mass movement, it is classed as a catastrophic rock avalanche or sturtzstrom.

Some of the moraine ridges and mounds that extend down-valley are buried by the sturtzstrom. Moraine mounds vary greatly in size from $\sim 5 \mathrm{~m}$ to $\sim 40 \mathrm{~m}$ height and from $-20 \mathrm{~m}$ to several hundred metres length. Clasts are mainly of sub-rounded to subangular sandstone and range in size from $>1 \mathrm{~m}$ down to a fine sandy matrix; the proportion of sandstone to limestone in the moraines is difficult to access as when desert varnished they have a similar appearance. A sparse heavily grazed vegetation 


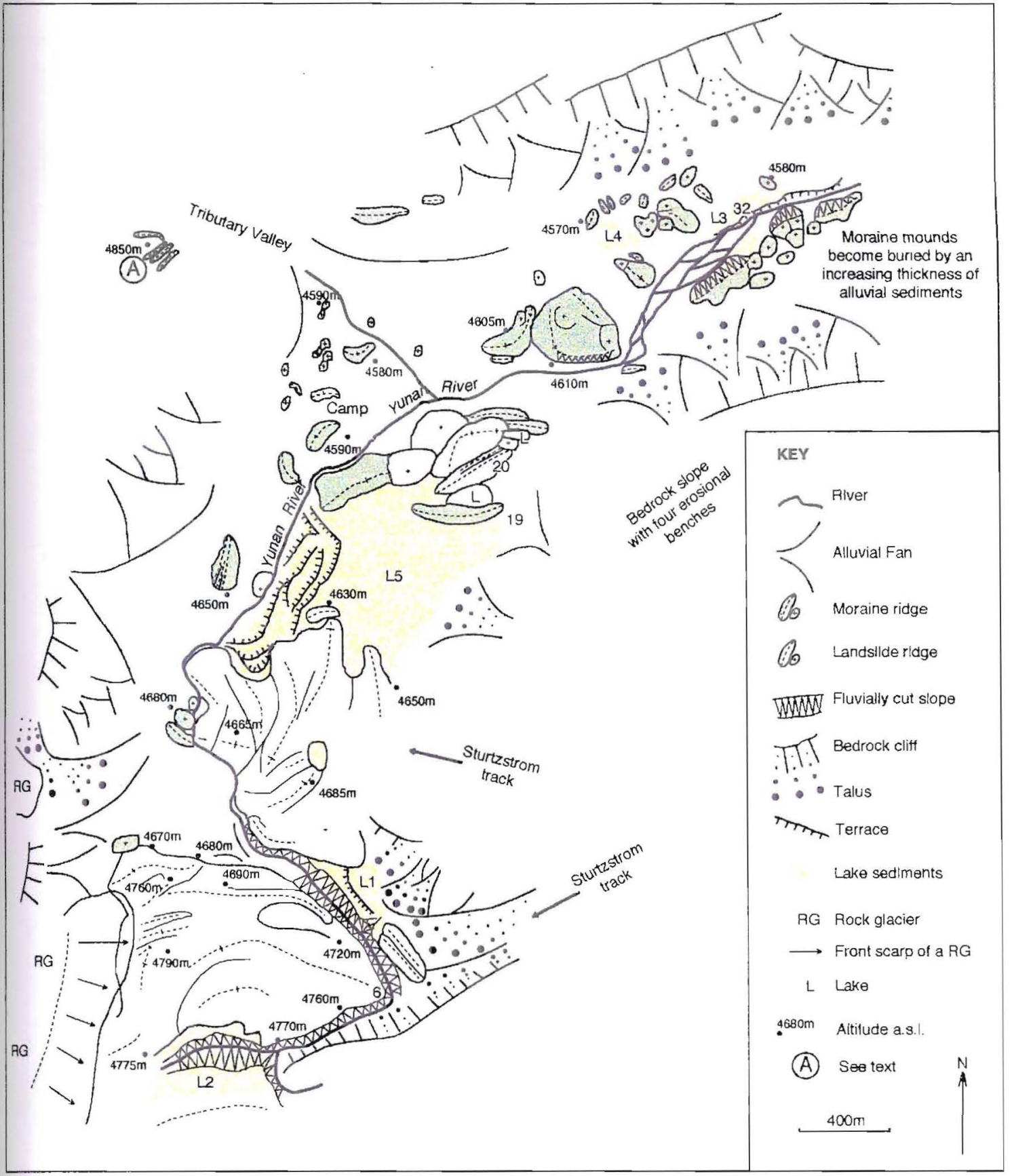

Figure 3.8 Geomorphological map of the Yunan valley around Kelang Seri camping ground. Large moraine mounds with overlying landslide ridges have terraces of lacustrine sediment up-valley. See Fig. 3.2 for location. 


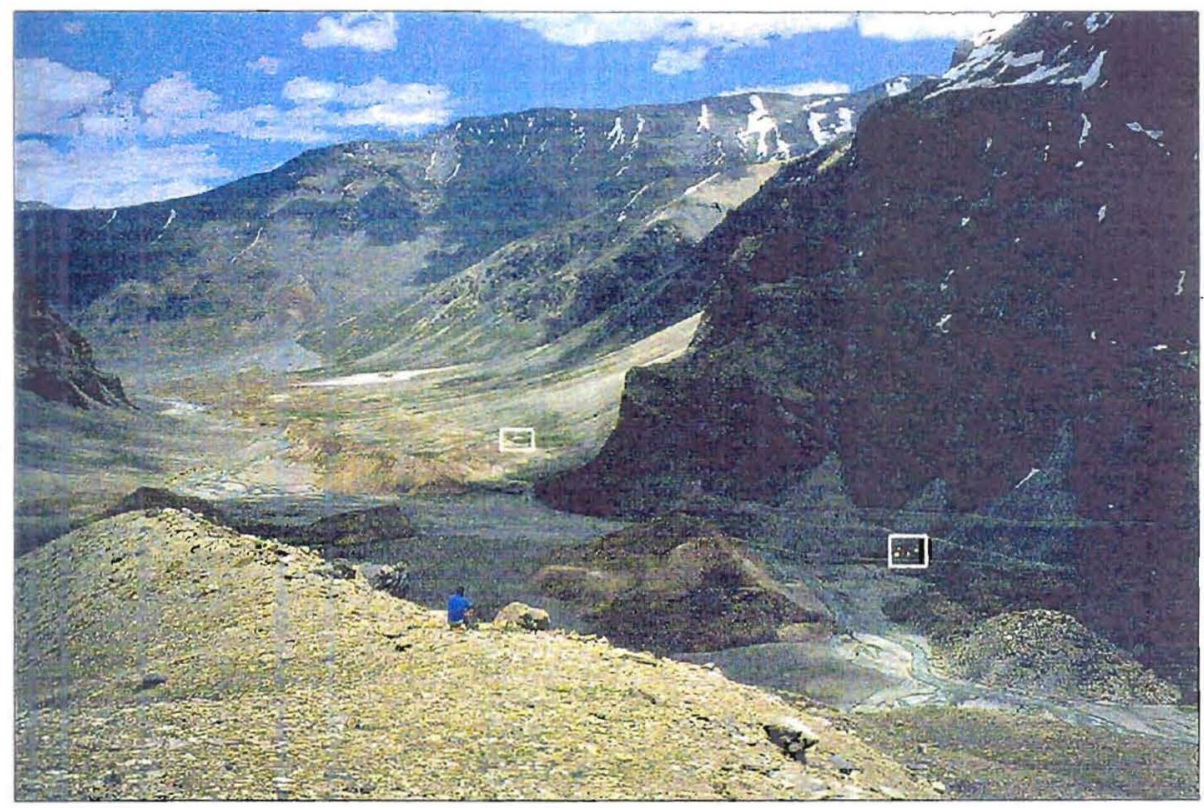

Figure 3.9 Lateral moraine ridge in the Yunan valley, 'A' in Figure 3.8 (person for scale). Large moraine mounds can be seen in the valley floor (tents in white box for scale). 073020 in Fig. 3.2, looking east.

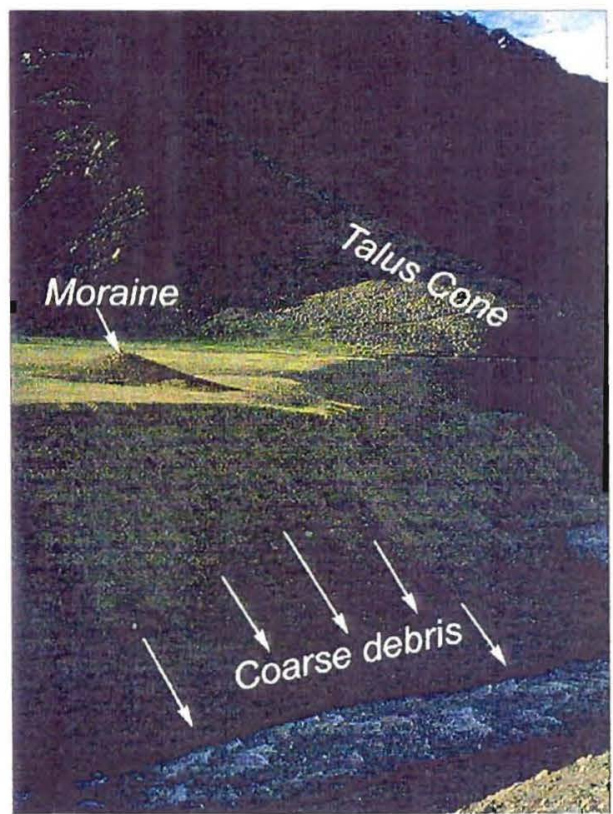

Figure 3.10 Moraine mound buried under sandur deposits. Note the coarse sediment being liberated where the river is cutting through the till. 078021 in Fig. 3.2 looking south. 
covers the moraines, but rarely the landslide, which is probably a reflection of the lack of near-surface matrix of the latter rather than being a function of age. The primary spatial pattern of the moraine ridges has been lost due to fluvial erosion and partial burial by alluvial fans. It is not immediately clear whether the landforms are recessional moraines from a glaciation of the Yunan valley, or represent later ice advancing from tributary valleys. Evidence for several former lakes can be seen among the moraine hummocks (Fig. 3.8) potentially providing samples for dating. However, these may not have been dammed solely by them, but may have been blocked only after deposition of the sturtzstrom.

Four sub-parallel lateral moraines of $\sim 200 \mathrm{~m}$ length and $\sim 20 \mathrm{~m}$ width (Fig. 3.9), oriented parallel to the valley axis at an altitude of $\sim 4850 \mathrm{~m}(\sim 300 \mathrm{~m}$ a.r.l. - above river level), are preserved on a relatively stable spur on the north-west wall of the main valley (A in Fig. 3.8). The clasts are medium grained red sandstone (40\%), dolerite (25\%), a dark metamorphic rock (10\%) and others including hornfels. Sub-angular boulders cover $\sim 60 \%$ of the surface with the remainder consisting of a sandy matrix. A few clasts have faceted edges and striae. A steeply sloping lateral moraine on the tributary valley side of the ridge meets the others at the crest, indicating a higher icesurface in the tributary valley. In this moraine there are fewer sandstone clasts $(\sim 15 \%)$, a high proportion of schist $(\sim 20 \%)$ and a silt rich matrix. This matrix is thought to represent sedimentation within a former marginal water body, and as such, a sample (V059) was taken with the aim of obtaining a date through OSL methods. From these lateral moraines, lower level moraines can be seen to the north extending from the tributary where talus build up has been relatively modest.

A spur across the main valley (to the East) has four erosional benches at $\sim 4675 \mathrm{~m}$, $\sim 4770 \mathrm{~m}, \sim 4815 \mathrm{~m}$ and $\sim 4955 \mathrm{~m}$. The upper bench supporting a pronival rampart or small rock glacier beneath a talus slope.

Beyond the area covered in Figure 3.8 the valley widens to $3-4 \mathrm{~km}$ breadth and moraines become progressively buried as the thickness of alluvial fill increases (Figs. 


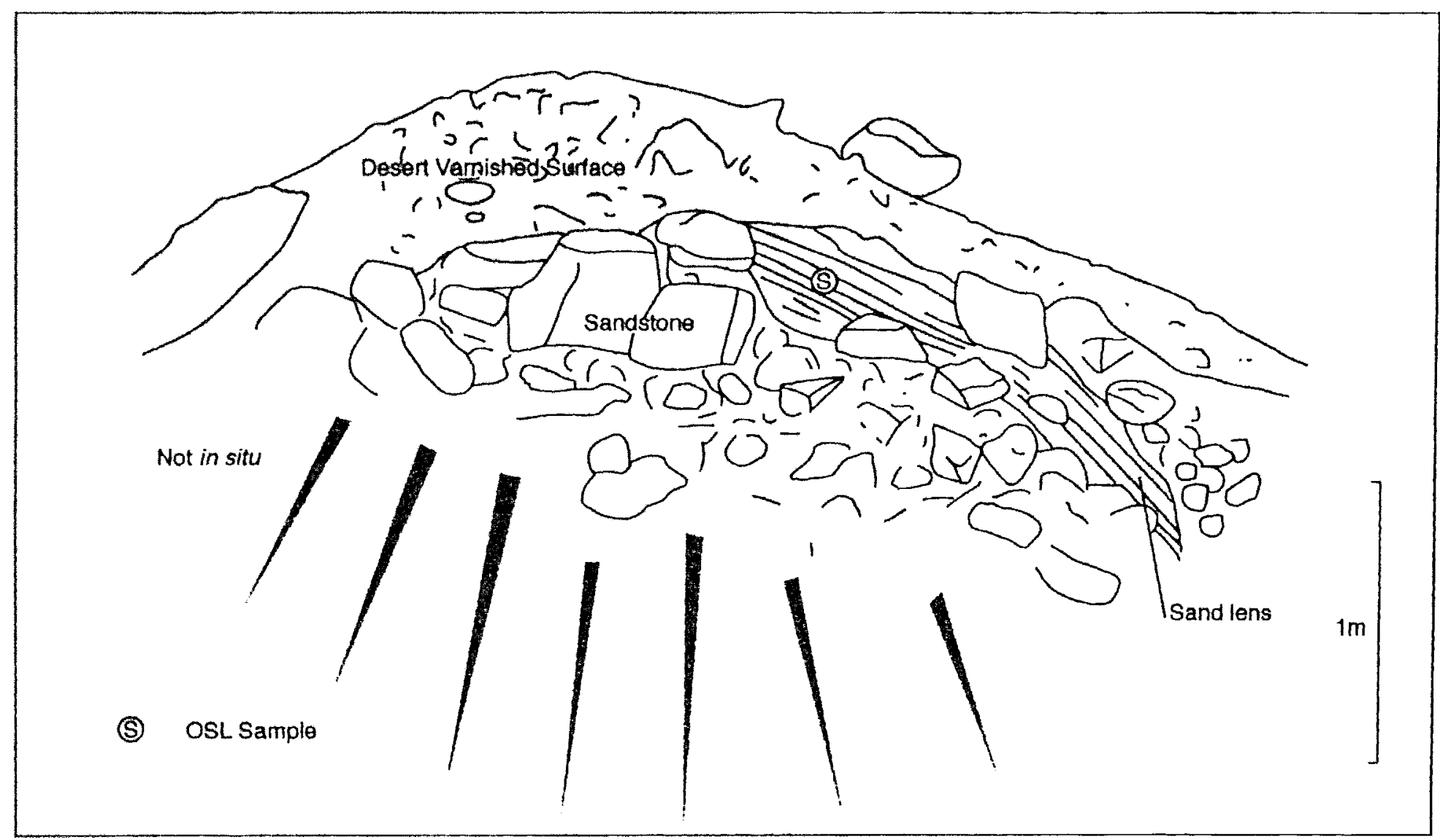

Figure 3.11 An exposed section in the protruding part of a moraine hummock buried in outwash, with the location of dating sample tubes. 080023 in Fig. 3.2. 

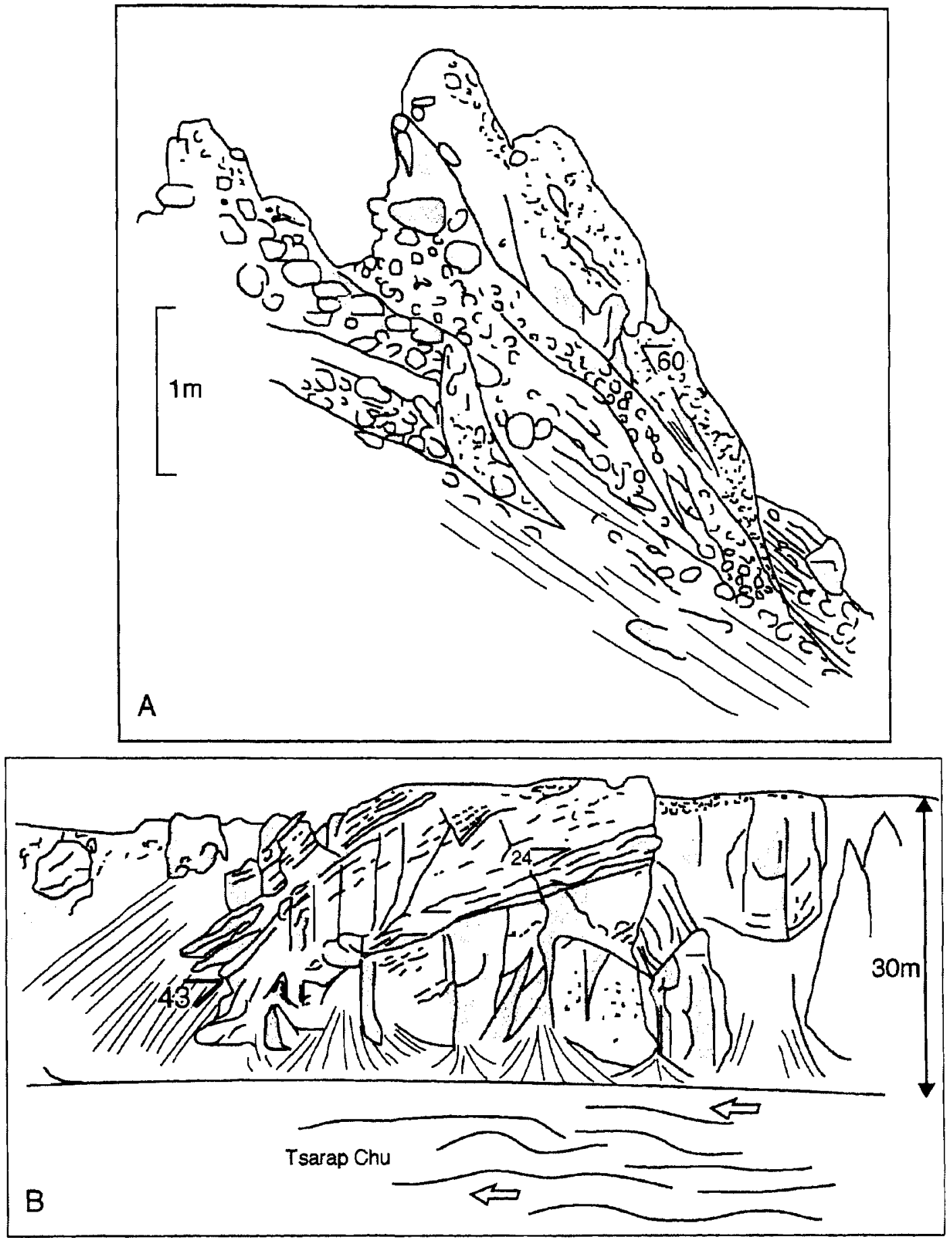

Figure 3.12 Ice contact sedimentation from the Sarchu Plain sandur, exposed as a series of earth pillars. The angle of bedding varies often exceeding $30^{\circ}$. (A) is the south-east bank and (B) the north-west bank (viewed from across the river). 089029 in Fig. 3.2. 
3.8 and 3.10). The summit of a mound can clearly be seen in Figure 3.10 above the main alluvial terrace, with coarse sediment being eroded from the exposed portion of the moraine. A sand lens was identified in a section through the protruding part of another mound (Fig. 3.11) and two samples were collected for OSL dating (V062).

Deposition of this alluvial fill was contemporaneous with ice retreat as demonstrated by ice contact sedimentation with diagnostic bedding of $>30^{\circ}$ (087028, Fig. 3.12), and as such the surface is interpreted as a sandur. Large open folds of an uncertain origin were also observed. The sandur deposit is incised to $>40 \mathrm{~m}$, forming a series of erosional terraces and spectacular earth pillars.

A single cubic block of augen gneiss, with $2 \mathrm{~m}$ edges, was observed on the sandur surface, $\sim 4.5 \mathrm{~km}$ up-valley from Sarchu $(083024)$, in a situation that suggests a rockfall origin (Fig. 3.13a). Sarchu Nala (Nala $\equiv$ valley), a tributary with its head high on the mountain from which the erratic pictured in Figure 3.13a must have emanated, was investigated. Several similar high grade metamorphic erratics, with their distinctive $100 \mathrm{~mm}$ long orthoclase feldspar porphroblasts with Carlsbad twinning, were observed as rockfalls on the floor of the Sarchu Nala. They form an abundant scatter on the wide undulating palaeosuface that forms the upper slopes of the mountain between the main valley and the tributary (085022) (Fig. 3.13b). Occasional striated sandstone clasts with well developed desert varnish were also observed in situ. Geological maps (e.g. Searle et al., 1997) show gneiss cropping out to the south-west of Zanskar Normal Fault in the upper part of the Kamirap Chu tributary valley (062026) which enters the main valley down river from the palaeosurface on the opposite side of the trunk valley, but nowhere else in the drainage basin. The provenance of these erratics and their implications for glaciation are discussed in Chapter 5 .

In the Sarch Nala tributary, a rock avalanche deposit has failed from the eastern slope with boulders deposited to a height of $30 \mathrm{~m}$ up the opposite slope. Up-river at (088022) moraines represent a former glacial limit (Fig. 3.14). Two well-formed 
terminal/lateral moraine ridges lie close to the centre of the valley with an area of hummocky moraine/undulating drift to the west. This may represent ice narrowing, becoming confined within lateral moraines, with the marginal area abandoned as dead ice.

On the north-west of the trunk valley the western tributary of the Lingti Chu has an unusually straight low ridge across its mouth. Lake sediments are exposed in sections up-river from this ridge and, as such, this feature is interpreted as an aqueous ice marginal moraine, which held back a lake at a time when ice was no longer confluent between the two valleys. In the floor of the valley, up-stream from the ice-front, alluvial fans extend from the north-east side confining the river, ice-dammed lake sediments and fluvioglacial outwash to the south-west. The fans, which have been incised by ephemeral streams to expose sections in deep gullies, are of $\sim 90 \%$ finemedium arkosic sandstone, $\sim 10 \%$ low grade metamorphic rocks and have some vein quartz, with no foreign clasts. This dominant input of coarse sediment from the north-east reflects the direction of dip of the sandstone bedrock. The south-western valley side cuts the bedding at a high angle to give a relatively stable slope, whereas the opposite side slopes close to the angle of dip, creating a relatively weak slope.

The terraces of alluvial fan, lacustrine and fluvioglacial deposits extend up the Lingti valley with granite and high grade metamorphic clasts becoming more abundant. Distinctive evidence for glaciation can be observed at 072035 , with a former ice margin clearly defined by moraine ridges of $\sim 10 \mathrm{~m}$ height and an area of hummocky moraine up valiey (Fig. 3.15). Beyond this area, at the confluence of the Lingti Chu and Kamirap Chu (071036) on the western shoulder, there is a $60 \mathrm{~m}$ rock glacier modified lateral moraine with several sub-parallel ridges (070036), with a granite clast content of $\sim 30 \%$. In the Kamirap Chu valley, a sandur extends for $>10 \mathrm{~km}$ towards the present glaciers, which were viewed distantly.

In the broad glacially modified Lingti Chu valley, a moraine mound with $40 \%$ granite clasts is preserved where the river is controlled in a bedrock section (070037). A few 

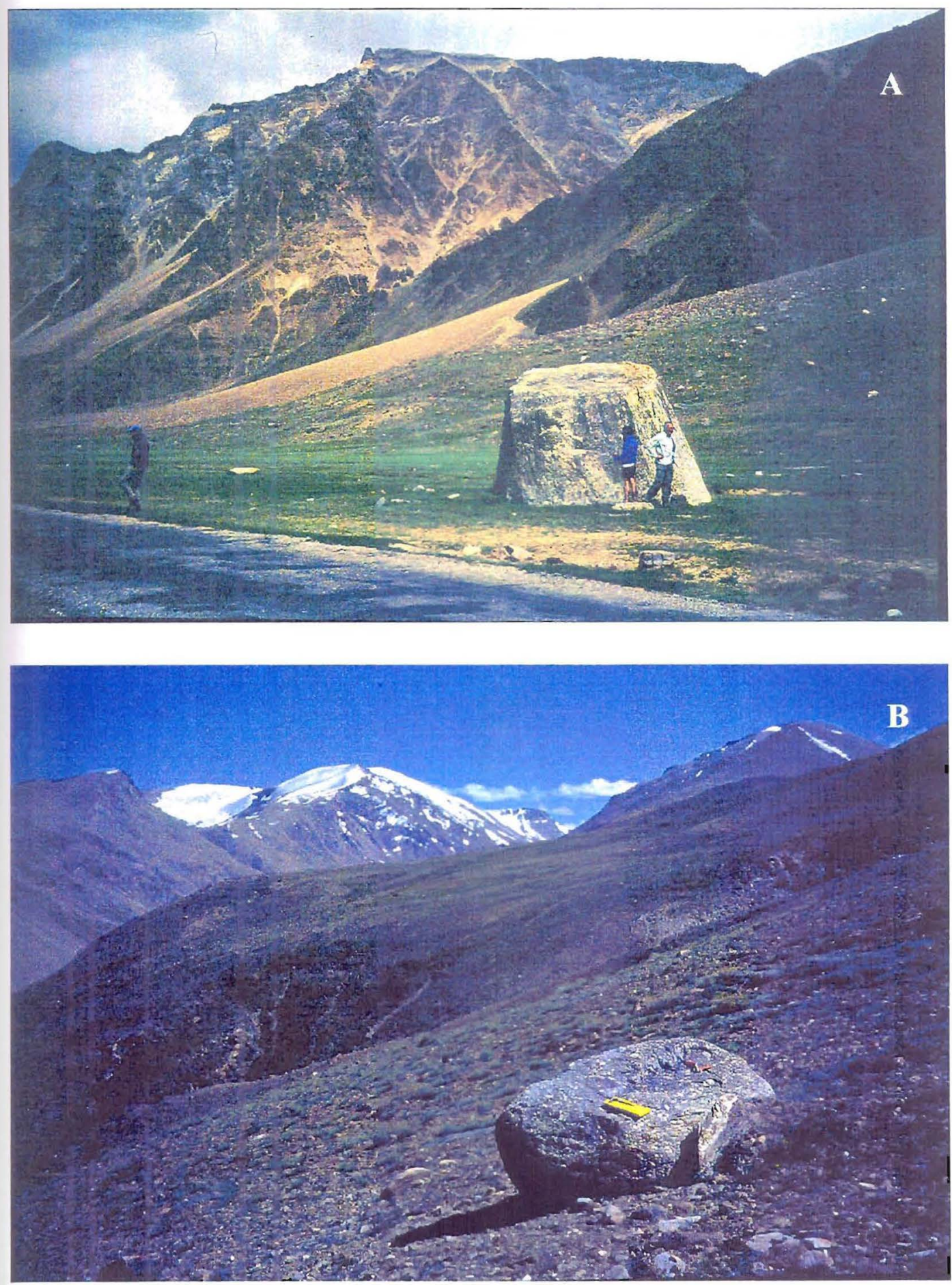

Figure 3.13 Gneiss erratics from the Yunan valley. (a) Augen gneiss block on the Sarchu sandur between Sarchu Seri and Kelang Seri (figures for scale), 084025 in Fig. 3.2, looking south-west. (b) Palaeosurface on Mount Sarchu (300m a.r.l.) with gneiss erratic in the foreground (200mm notebook for scale). 086021 in Fig. 3.2, looking south 


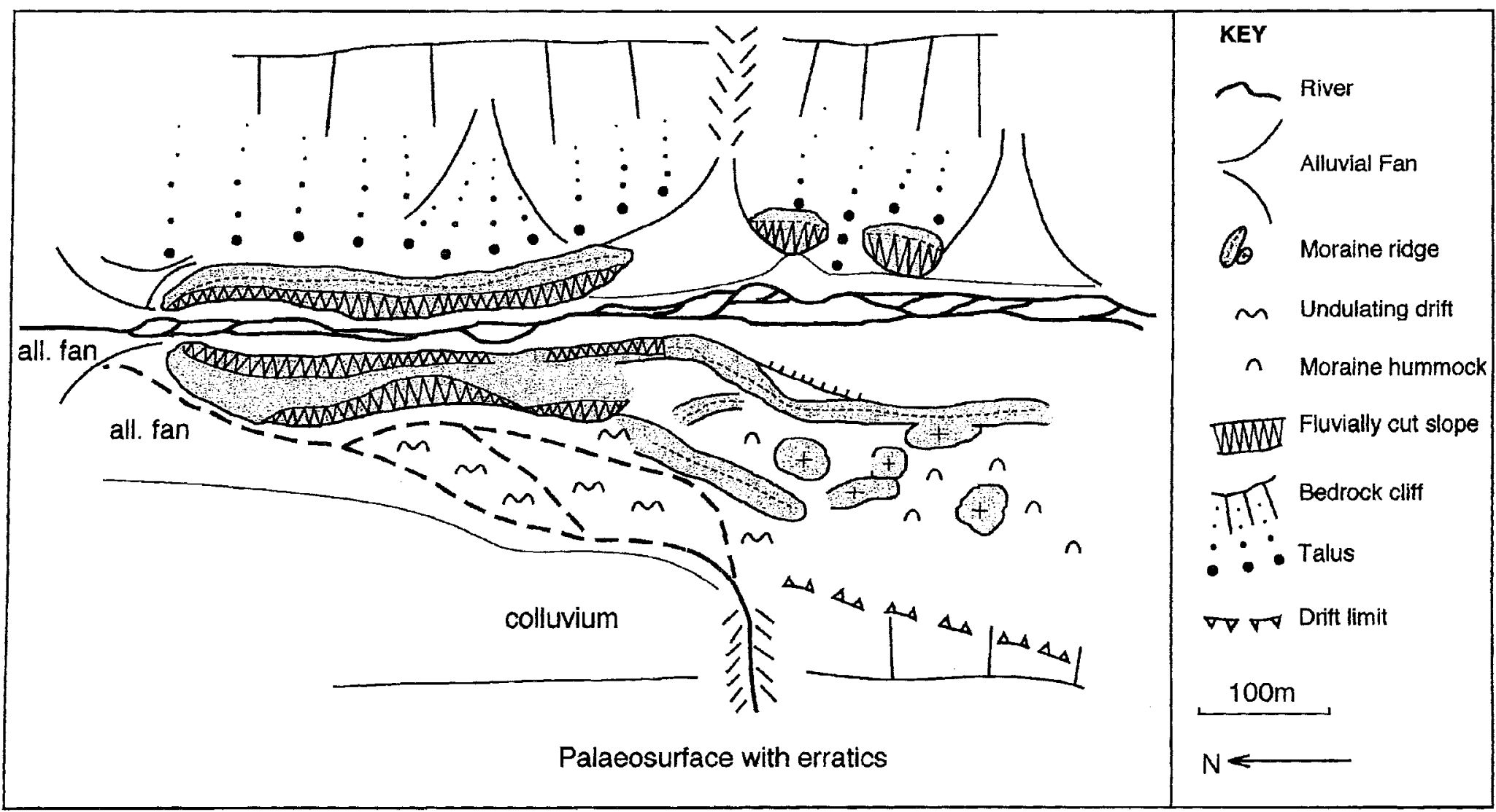

Figure 3.14 Geomorphological sketch map of moraine ridges in the Sarchu Nala, drawn from the western moraine and western slope. Two well-formed ridges represent a former glacial margin with an area of undulating drift to the west. See Fig. 3.2 for location. 


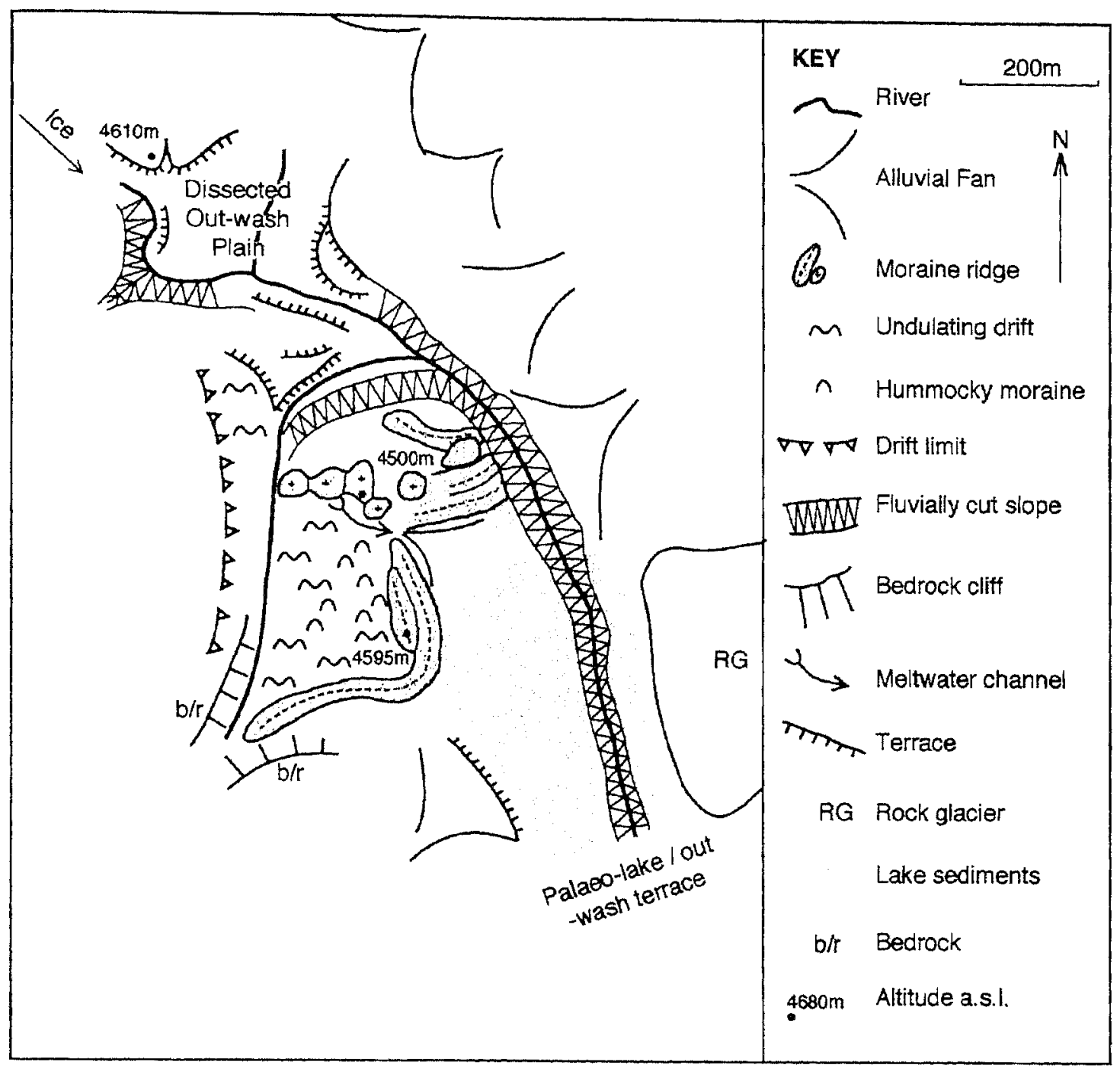

Figure 3.15 Geomorphological map of moraines in the Lingti valley. See Fig. 3.2 for location. 
clasts are bullet shaped, many have faceted edges and some of those that are fine or medium grained and have developed a desert varnish are striated. A lateral moraine extends for $\sim 400 \mathrm{~m}$ on the north-eastern valley side at $\sim 200 \mathrm{~m}$ above the valley floor, $\sim 1 \mathrm{~km}$ down valley from Chumik Marpo (068039). In the upper reaches of the valley rock glaciers are dominant. Nevertheless, a small area of fine grained basic igneous bedrock (069039) preserves a glacially moulded surface with striae striking down valley, where the surface has not been broken by frost action. On the east slope above Chumik Marpo, till forms a ridge at a similar altitude to the lateral moraine described above.

The Phirtse La $(5435 \mathrm{~m})$ is a broad interfluve, which shows no evidence of glaciation other than for the former presence of small corrie glaciers on the north-west side (060047). The slopes are strewn with periglacial detritus and colluvium of local origin and foreign clasts such as granite are notably absent (Mitchell et al., 1999). Diamicts were observed and are interpreted as mass movement deposits given that they only contain clasts of local lithologies and have down-slope fabrics. Gentle slopes support regolith arranged into sorted stripes and outcrops are shattered and angular. On the northern side of the pass are two corries, one of which has a small rock glacier at its head. $\sim 300 \mathrm{~m}$ from the back wall are two arcuate moraine ridges, with the proximal one of $3 \mathrm{~m}$ height, $5 \mathrm{~m}$ width and $>100 \mathrm{~m}$ length. The distal ridge is broken and is deforming as a rock glacier.

The Phirtse Chu valley heads west from the pass as a deep narrow gorge, particularly at its mouth, locally widened where major slope failure has occurred (055051). Although some mass movement deposits resemble moraines, the orientation of their ridges and sedimentology discount this interpretation. There is no evidence for glaciation within the Phirtse valley until the confluence with the broad deep Kurgiakh valley (049054), where granite erratics at $\sim 4570 \mathrm{~m}$ a.s.l. ( $\sim 400 \mathrm{~m}$ a.r.1.) mark the upper limit of a former glacier. 


\subsection{Shingu La to the Village of Padam}

(Fig. 3.16)

Evidence from the Kurgiakh and Tsarap-Lingti (Lung-nak) valleys in the south-west of the field area is described from the Shingu La down-river to the village of Padam (Fig. 3.16).

The Shingu La (035030) has at least four corrie glaciers descending to within $100 \mathrm{~m}$ of the $5000 \mathrm{~m}$ pass. Late lying snow obscured much of the area at the time of observation. Nevertheless, several sets of moraine ridges of $<5 \mathrm{~m}$ height were observed. These are sharp crested arcs consisting of angular clasts of local origin.

Down-river from the Shingu $\mathrm{La}$ on the north side, a moraine ridge is preserved on a spur, which separates this tributary from main Kurgiakh valley (048032). The tributary valley narrows at this point forming a favourable topographic site for a stillstand of a retreating glacier and, in the absence of any evidence for a separate advance, the ridge is treated as a recessional moraine. Additional recessional ridges in less favourable situations are likely to have been buried or eroded, as can be observed in the Yunan and other valleys. At the head of the Kurgiakh Chu valley a large glacier/pro-glacial rock glacier was viewed at a distance.

The Kurgiakh valley has a typically glacial shape with a broad flat floor and deep, steep valley sides. $\sim 10 \mathrm{~km}$ up-valley from Kurgiakh Village the granite mountain of Gumberanjon has been eroded to a huge monolith (051038). The mineralogy of this granite matches that of the erratics that are abundant in the moraines, reworked glacial deposits and outwash that mantle the valley floor and walls. A recent slab failure/rock avalanche narrows the flood plain, demonstrating the on-going sediment supply to the valley floor from this lithology.

Near Kurgiakh Village (049048) is a suite of moraine ridges of $<10 \mathrm{~m}$ height and $<100 \mathrm{~m}$ length (Fig. 3.17). Large areas of diamict are preserved in favourable locations such as on spurs and where landslides have partially covered them. However, the moraine ridges in the valley floor are an order of magnitude smaller and 
have a clear pattern of inset chevrons. The difference in size and location suggests that they represent a distinct ice limit. The landslide ridges, which consist only of very angular blocks of local lithology, located on a steep valley side slope, are easily distinguishable from the moraine ridges, which are composed mainly of sub-rounded granite boulders in a sandy matrix and occupy valley floor locations.

Only one side of the chevron pattern can be clearly seen (Fig. 3.17), as alluvial fans and talus cones have been effective in building out from the steep rocky eastern side of the valley. The western slope is more gentle, supporting a more complete drift and vegetation cover, which suggests greater stability. As a result there has been less geomorphic action on that side and the moraines to the west are buried to a lesser degree.

Lateral terraces of $\sim 30 \mathrm{~m}$ height extend down valley to the Phirtse Chu (049054). The sediments are weakly stratified suggesting a fluvioglacial origin, or re-sedimentation of a lateral till. The less stable eastern slope has buried these terraces in rock glacier modified talus. However, these features are better preserved on the opposite slope and into a major tributary to the west. At the convergence of the Phirtse valley and the main valley (049054), granite clasts mantle slopes, where erosion has failed to remove them, to a maximum altitude of $\sim 4570 \mathrm{~m}$ a.s. 1 .

Lateral moraines and a limit of granite erratics, were examined on the south-west slope of the main valley at $-4440 \mathrm{~m}$ ( $450 \mathrm{~m}$ a.r.1.) near the village of Tetha (041063). Constituent clasts are mostly of local lithologies with only occasional granite erratics. An active rock glacier extends down to $-4645 \mathrm{~m}$ in the tributary valley to the west of Tetha, above which is a moraine at $\sim 5000 \mathrm{~m}$ and a comice capped headwall $\sim 800 \mathrm{~m}$ above, although these were only viewed at a distance.

Near the village of Muling, $-25 \mathrm{~km}$ from the previous moraine limit, a large diamict ridge to the east of the Kurgiakh Chu extends down-valley from a drift limit at $-4300 \mathrm{~m}$ to the river at $-3950 \mathrm{~m}$ (Fig. 3.18). There is no corresponding moraine on the westem valley side, although there is much evidence of mass-movement 


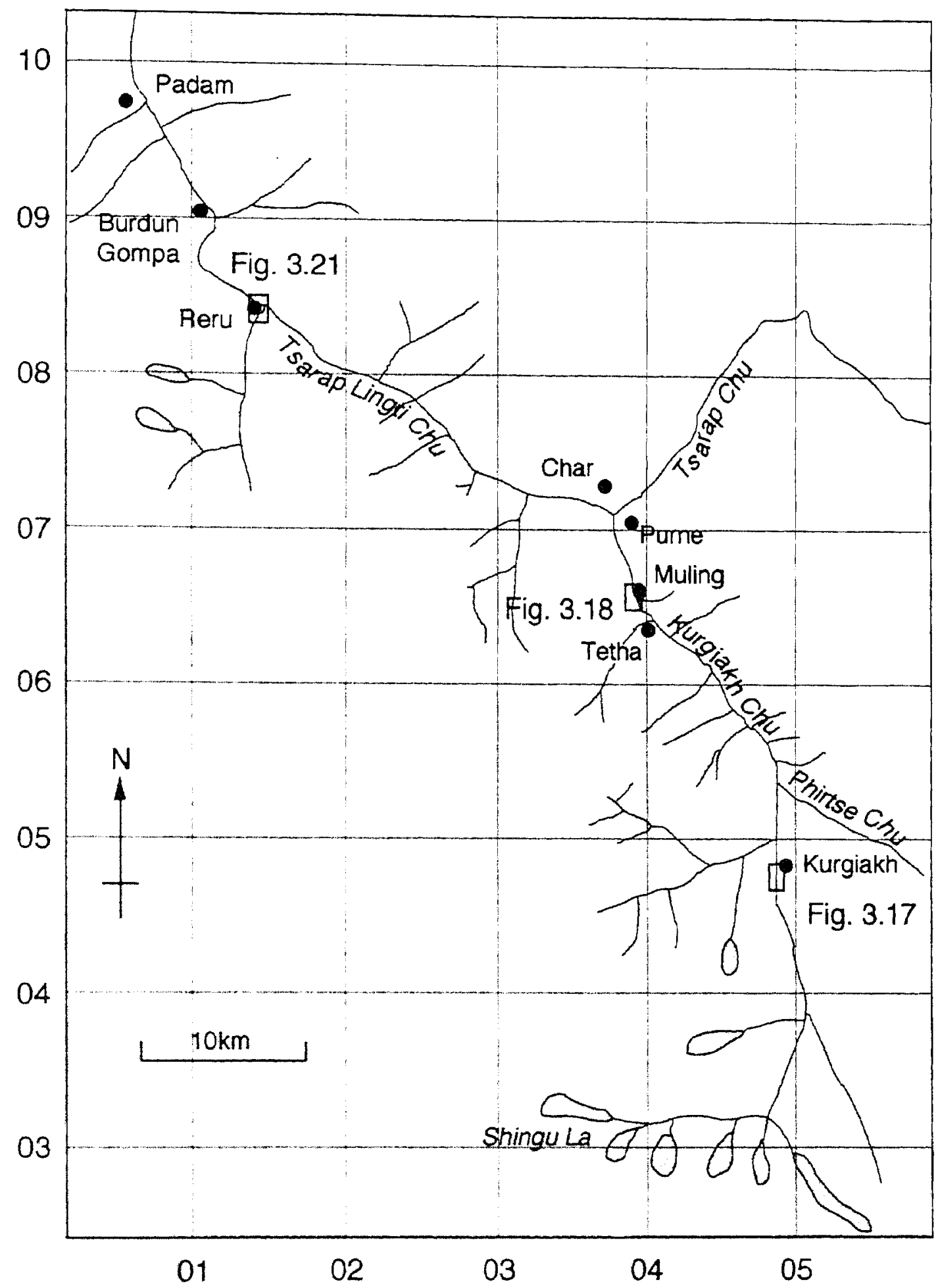

Figure 3.16 Location map for Section 3.3, showing the Kurgiakh and TsarapLingti valleys. 


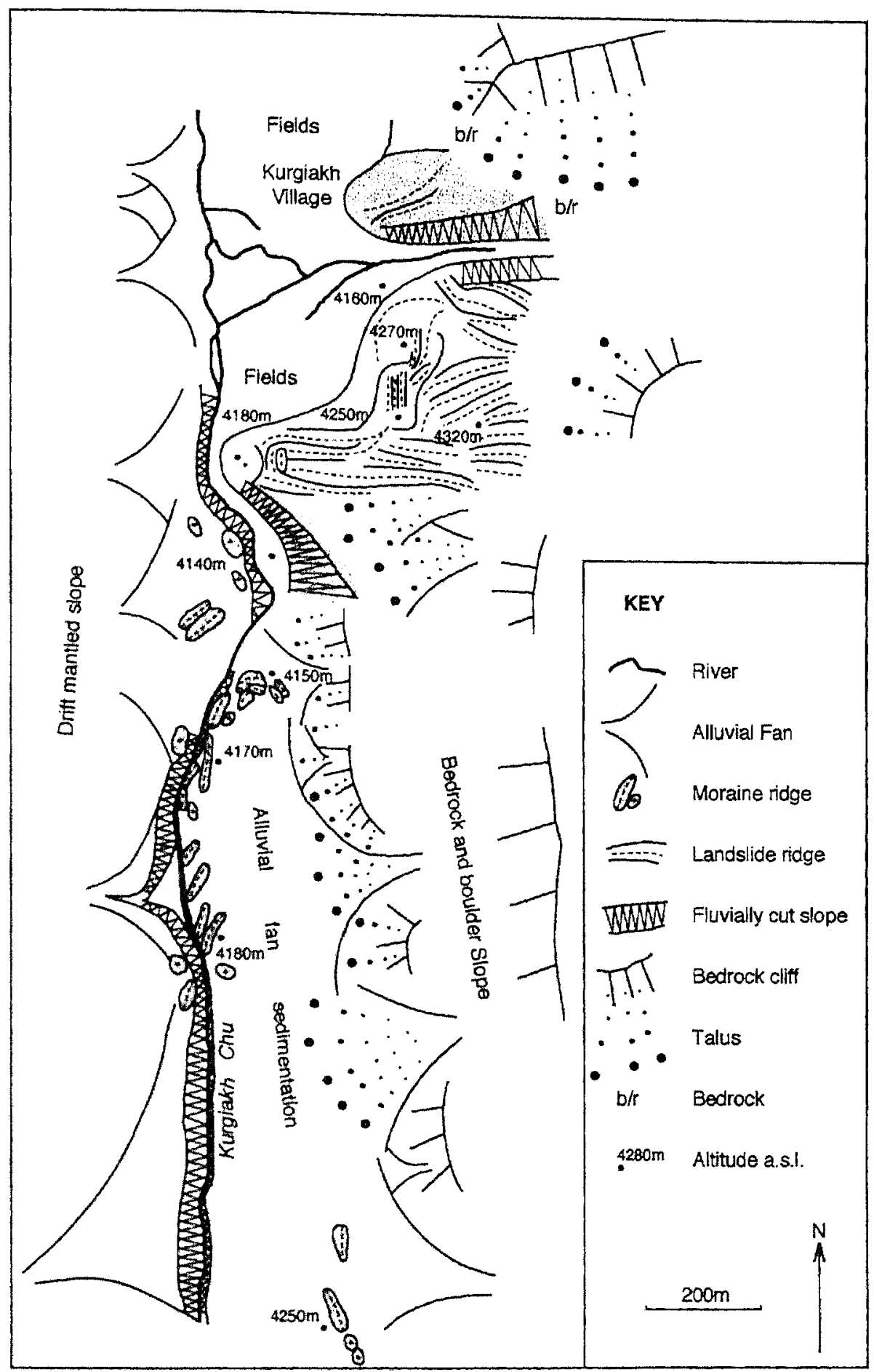

Figure 3.17 Geomorphological map of the area around the village of Kurgiakh in the Kurgiakh valley. Note the partial burial of the inset moraine ridges by alluvial fans, particularly on the eastern side, See Fig. 3.16 for location. 


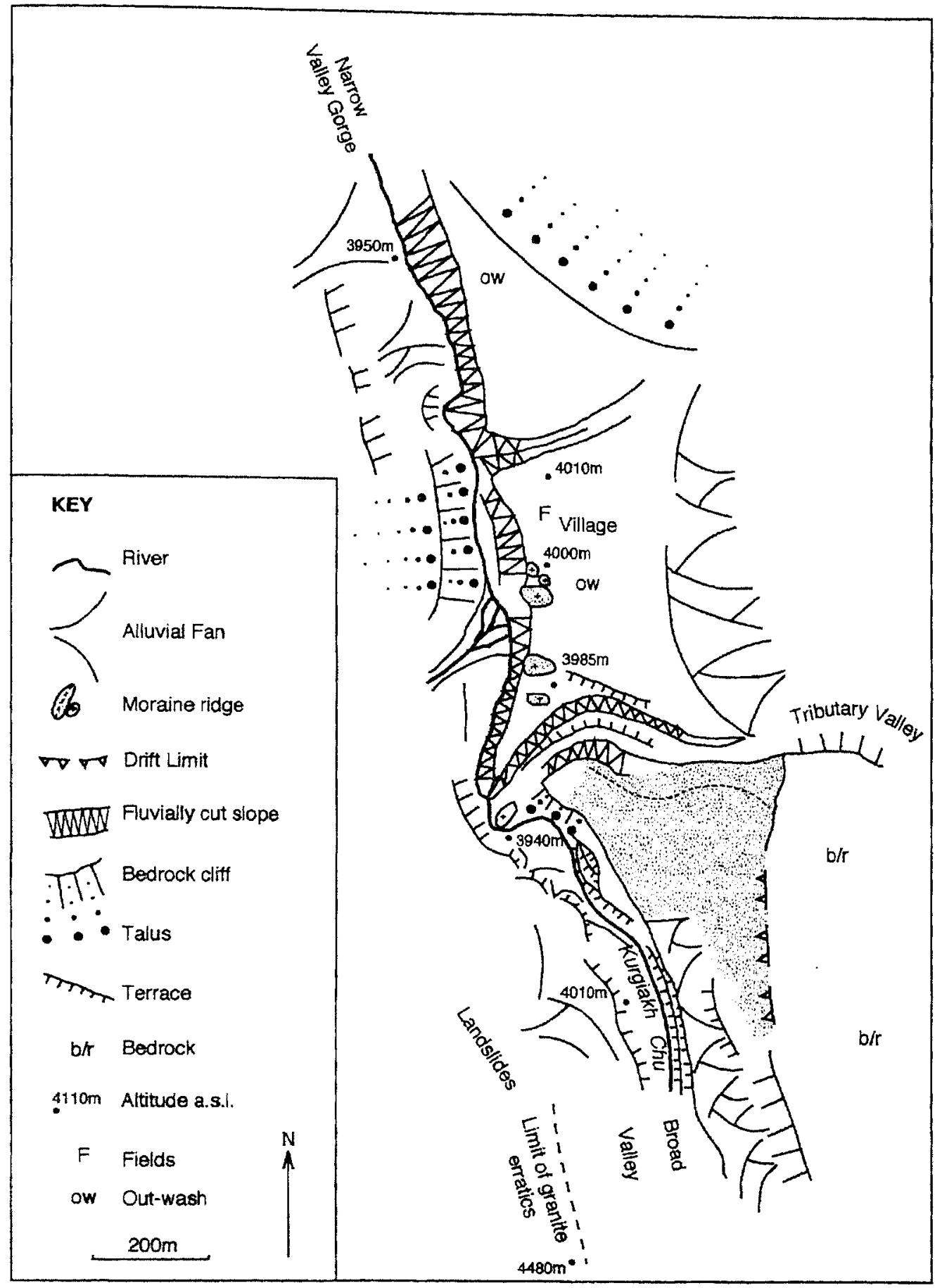

Figure 3.18 Geomorphological map of the area around the village of Muling in the Kurgiakh valley. Note the large moraine ridges and drift limit on the eastern side of the river compared with the western side, which has multiple slope failures. See Fig. 3.16 for location. 
suggesting the reworking of a former moraine. Lateral moraines and a limit of granite erratics at $\sim 400 \mathrm{~m}$ a.r.l. are preserved on this side a few kilometres up valley. Down-river from the moraine, granite boulders which make up the ridge are abundant within the outwash sediment. There is little difference in clast shape to distinguish the depositional process on either side of the limit as the reworked granite clasts have not been transported far and were already sub-rounded with a high degree of sphericity. The fluvial sediment is predominantly well stratified, but can also be poorly bedded or massive where re-deposited as debris flows or other mass movement deposits. Clasts are occasionally faceted, but are too coarse to record striae.

Beyond this glacial limit, at the village of Muling (039067), the valley narrows from its broad U-shape to become a steep bedrock gorge. The Kurgiakh Chu is joined from the north-east by the Tsarap Chu to become the Tsarap-Lingti (or Lung-nak) $\mathrm{Chu}$, which continues flowing to the north-west in a deep bedrock gorge. The inaccessible slopes above this gorge are undulating resembling moraines, although alternatively they could be topographic expression of the highly deformed schistose bedrock. A large gneiss erratic of $>4 \mathrm{~m}$ diameter appears to have come from these upper slopes.

Remnants of alluvial fill can be observed on the gorge walls to $\sim 200 \mathrm{~m}$ a.r.l. along the gorge from the village of Char (037073) to the Reru valley (014084). The river has incised through this fill and cut into the former valley floor, leaving a rock bench at $\sim 30 \mathrm{~m}$. At the village of Char a new rock gorge has been eroded, leaving a $1-2 \mathrm{~km}$ stretch of valley fill in the abandoned gorge section. Gravels, sands and silts can be observed across the present river from the village of Purne (Fig. 3.19), while palaeochannels, trough bedding and related sedimentary structures can be seen, again from the opposite bank, in the gravels of the down-river exposure.

On the north-east wall of the valley are two $\sim 20 \mathrm{~m}$ thick roughly cubic blocks of horizontally bedded silt and fine sand at an altitude of $\sim 4040 \mathrm{~m}(180 \mathrm{~m}$ a.r. 1.$)$. These 
blocks (Fig. 3.20) cap the valley fill, with no alluvial sediments or granite clasts above, and are at an altitude which relates to the down-valley ice damming of the valley at Reru. Granite dropstones of $\sim 100 \mathrm{~mm}$ diameter further suggest ice contact sedimentation. A sample (V055) was collected for OSL dating.

Around the village of Reru (014084) the valley widens where tributary ice has entered from the south-west (Fig. 3.21). The Tsarap-Lingti Chu, has been forced to the north-east by the palaeoglacier, where it now occupies a $30-40 \mathrm{~m}$ deep bedrock gorge on the eastern edge of the valley floor, leaving well preserved inset moraine ridges composed of gneiss boulders (up to $5 \mathrm{~m}$ in diameter) which display well developed tafoni (Fig. 3.22). These ridges are several hundred metres long and $\sim 10$ $30 \mathrm{~m}$ high, the inner moraines enclosing lake sediments (Fig. 3.21). At its maximum extent the former glacier dammed the trunk valley and remnants of lake sediments and alluvial gravels remain on some slopes from $30-200 \mathrm{~m}$ a.r.l. The pattern of some of the moraine ridges, with younger moraines cutting older ridges (A in Fig. 3.21), show that the palaeoglacier readvanced, or at least underwent marginal fluctuations.

Glacier ice reached into the Tsarap-Lingti valley from the south-west via two further tributaries leaving evidence near Burdun Gompa (011090) and to the north in the form of moraine ridges of $\sim 50 \mathrm{~m}$ height. The till which makes up these moraines is matrix supported with clasts almost exclusively of gneiss, whereas diamicts in the main valley associated with outwash and re-worked sediment are clast supported and contain granite from a prominent up valley source (Mount Gumburanjon).

Towards Padam village, the Tsarap-Lingti Chu is confined in a narrow gorge cut into $30 \mathrm{~m}$ of alluvial fill, which is locally thicker where debris cones and alluvial fans enter the valley. Boulders of up to $1.5 \mathrm{~m}$ diameter lie on the former flood plain, suggesting that the final depositional event was a high magnitude flood (possibly as an up-valley ice-dam failed). The village of Padam (005098), the older part of which is built on moraine mounds, lies in a broad plain where the Stod River and Tsarap-Lingti Chu 


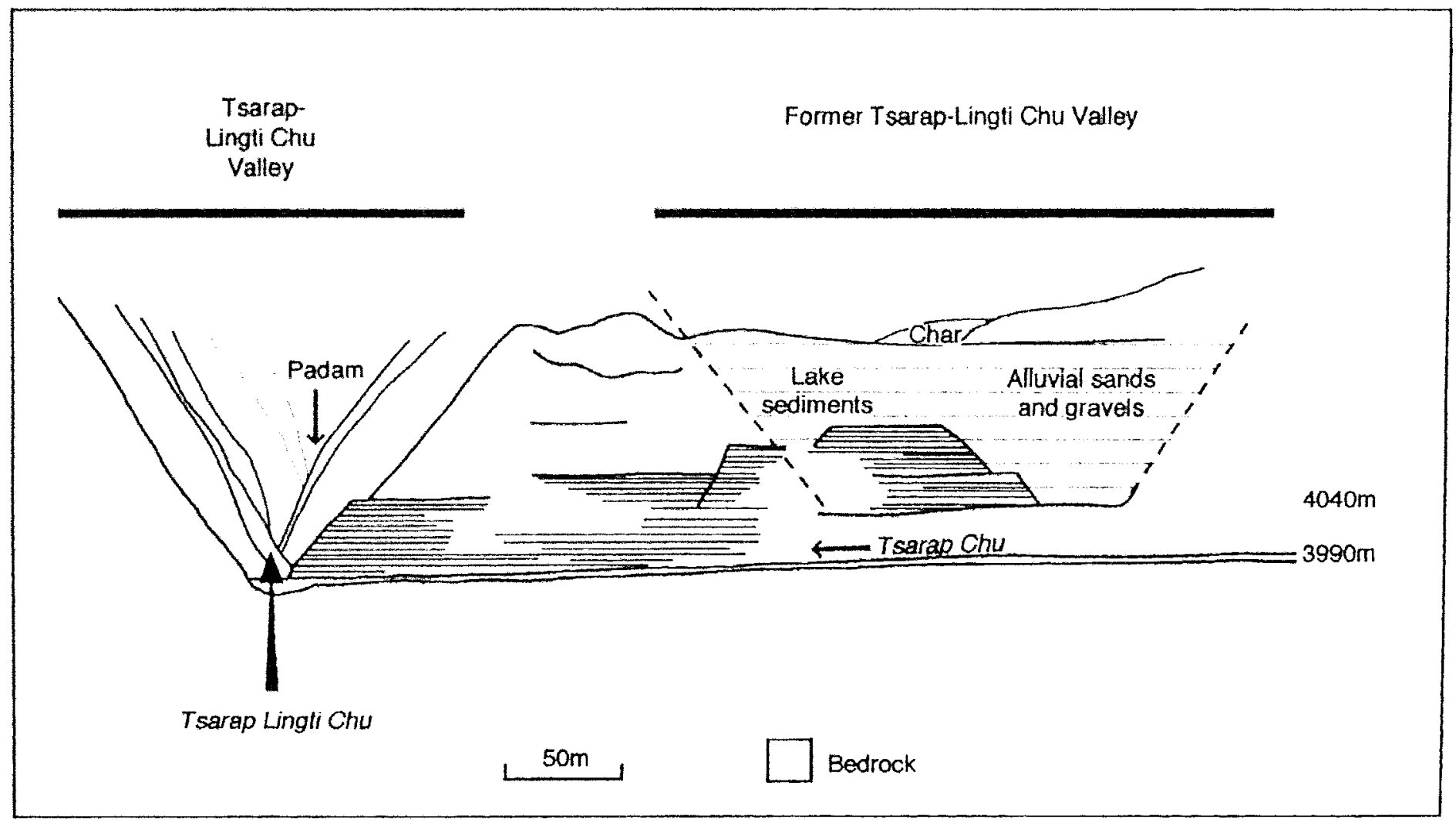

Figure 3.19 Valley fill in an abandoned section of gorge near the village of Char at the head of the Tsarap-Lingti gorge, viewed from Purne village. 039070 in Fig. 3.16, looking north-west. 

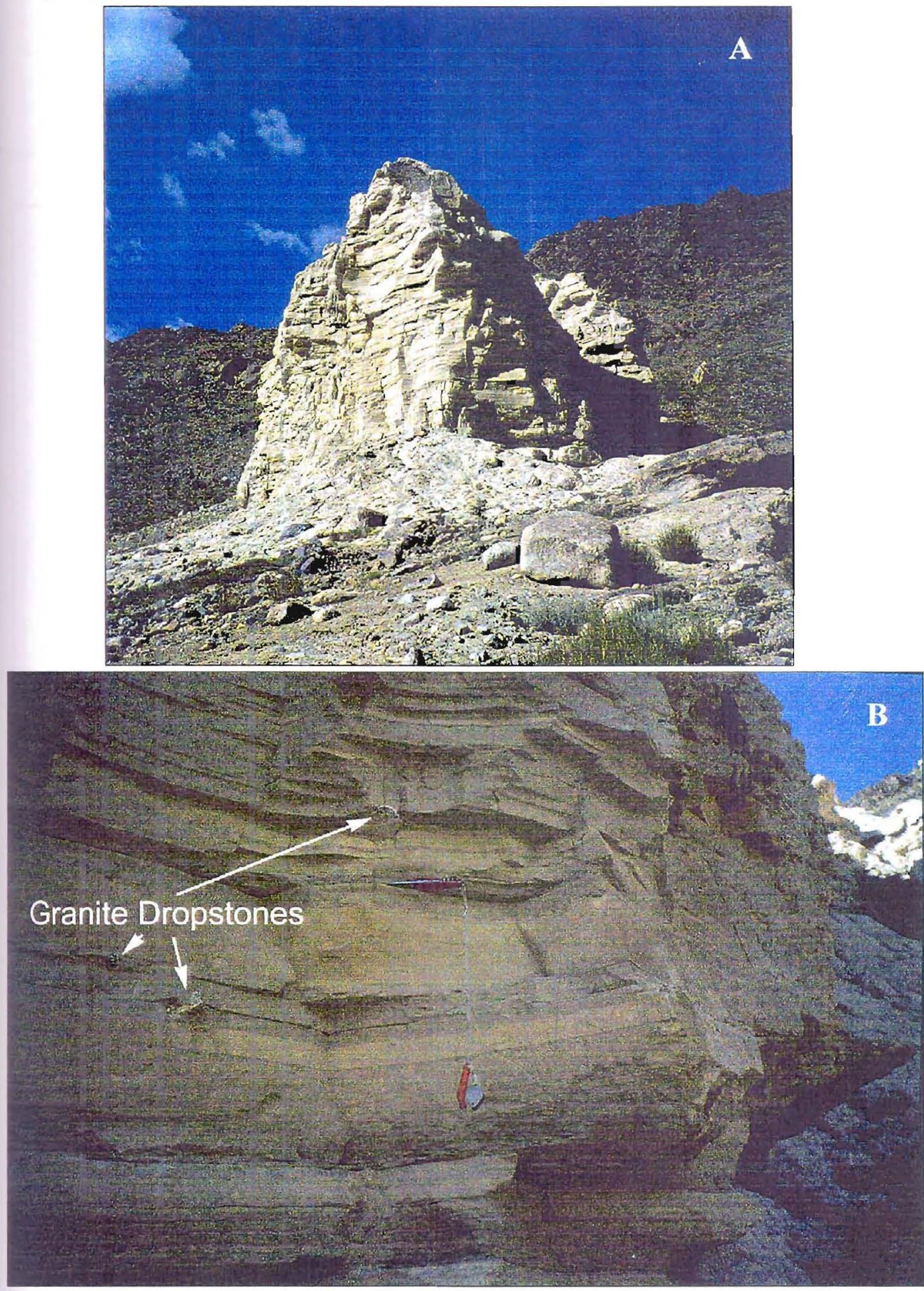

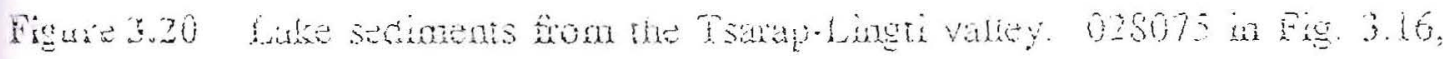

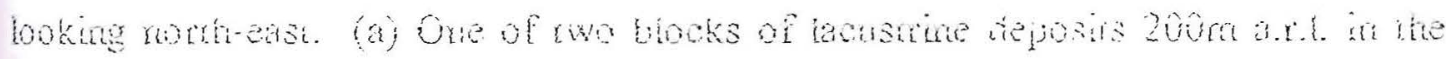

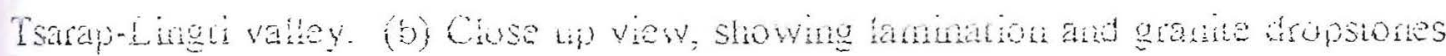
(penkitile fur saie). 
Chapter 3, Field Evidence for Glaciation

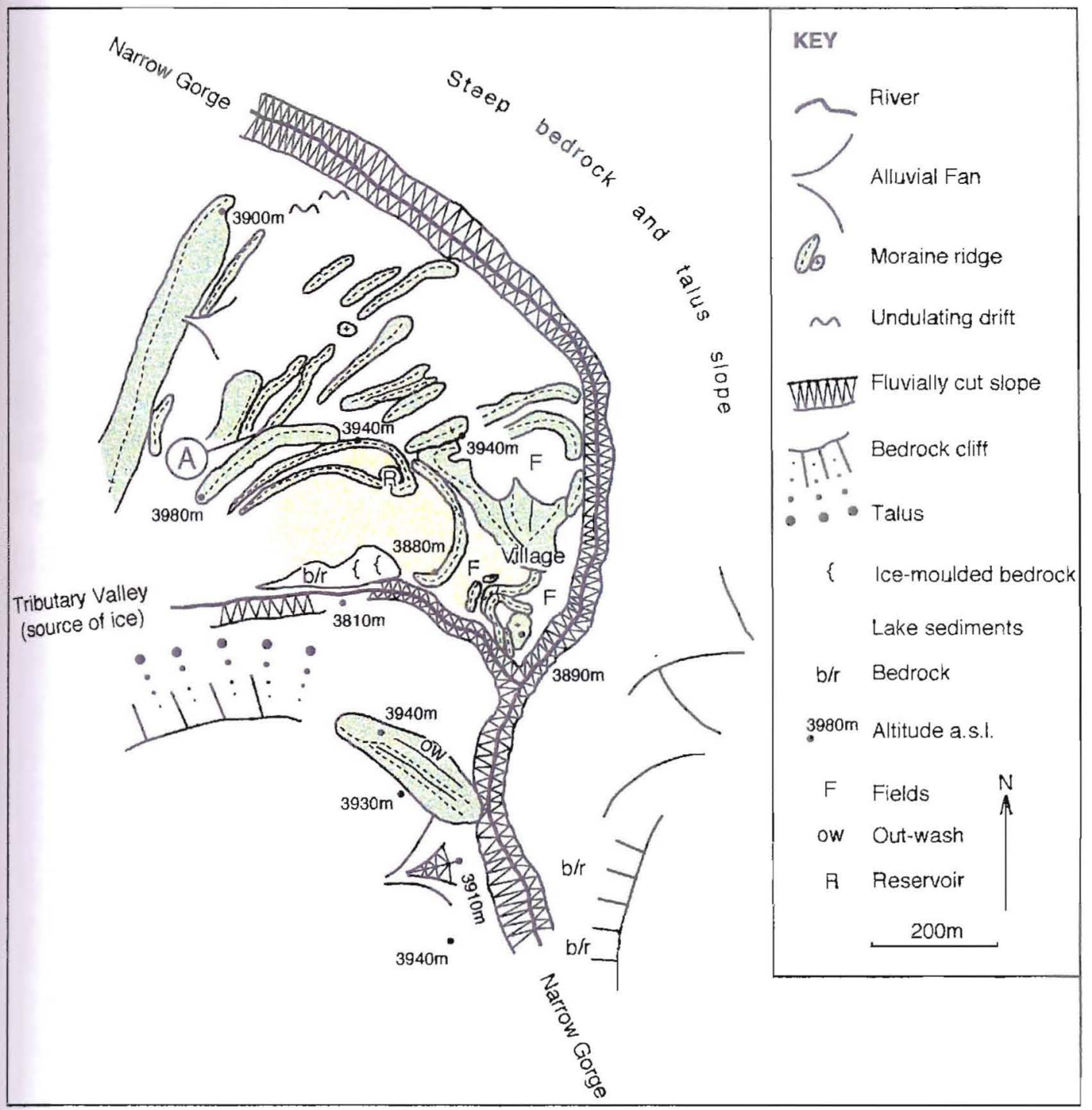

Figure 3.21 Geomorphological map of the moraine ridges around the village of Reru in the Reru valley. Note the younger ridges cutting older forms in the northern part of the mapped area (A). See Fig. 3.16 for location. 


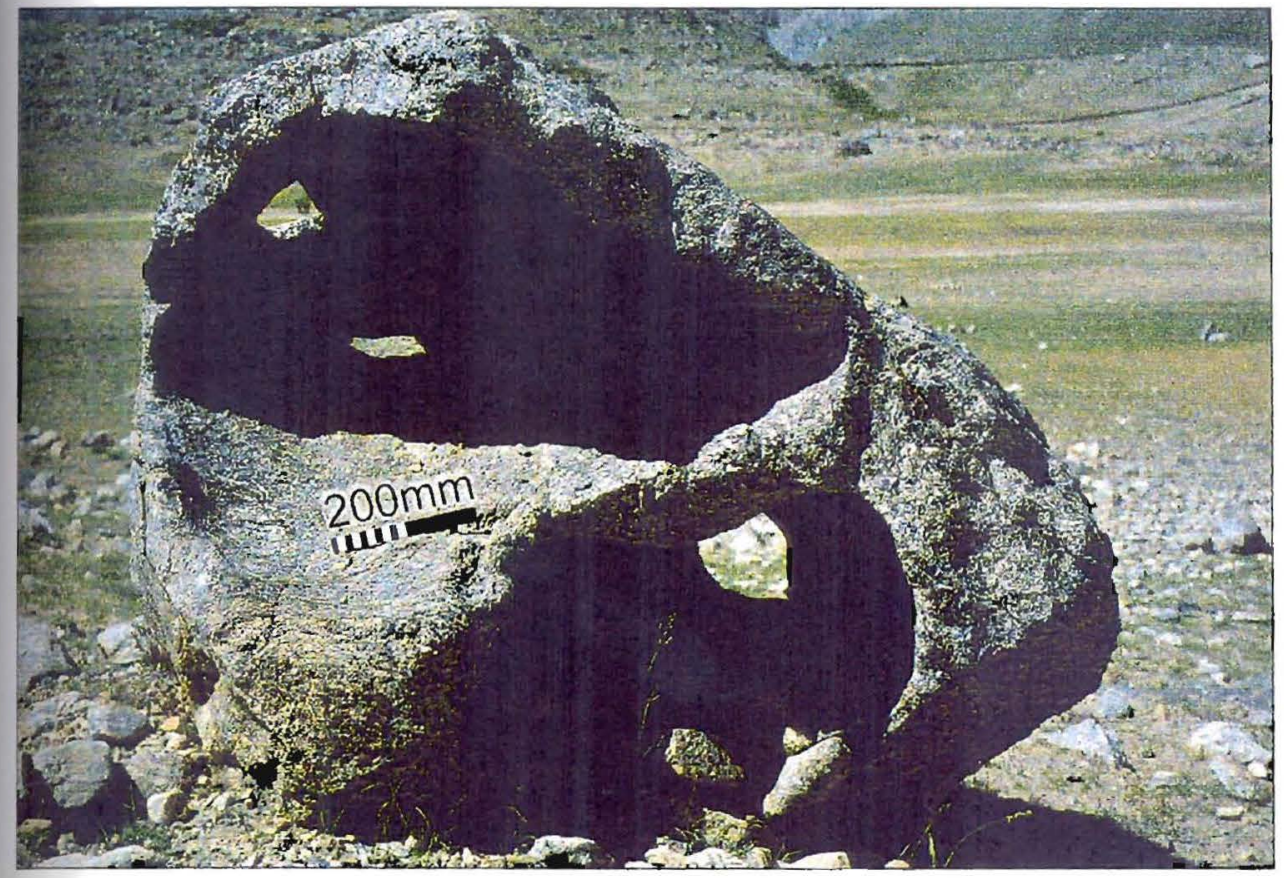

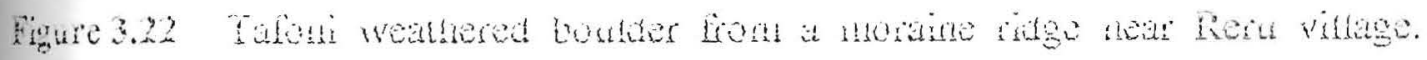
015084 in Fis. 3.16.

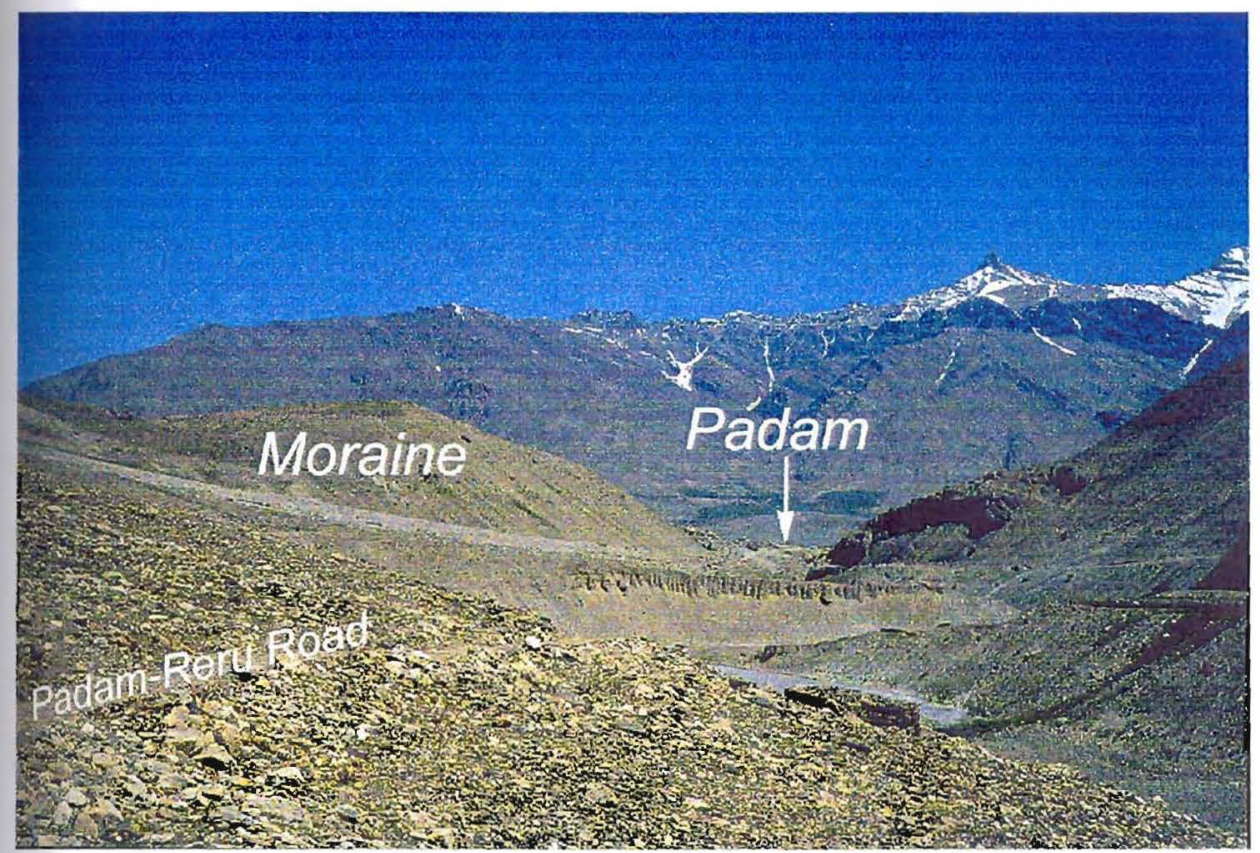

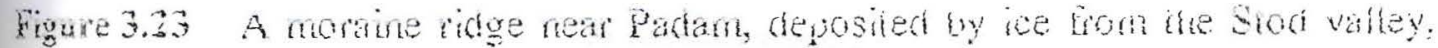

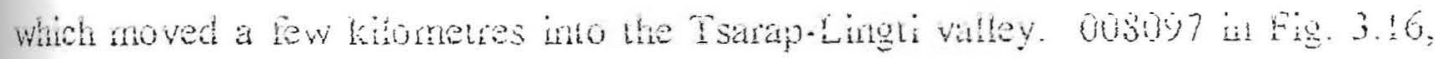
looking nomin-wesi. 
meet to become the Zanskar River. Kame terraces and other evidence clearly indicate that ice extended into this area from the Stod valley and a short distance into the Tsarap-Lingti valley (cf. Osmaston, 1994). $\sim 1 \mathrm{~km}$ up-river from the village, a moraine on the western side of the river marks this former ice limit (Fig. 3.23), which must have dammed the drainage, although no evidence of lake sediments was found.

\subsection{Sarchu Seri to Purne}

(Fig. 3.24)

The following section describes field evidence from the Tsarap valley, from the police check-point at Sarchu Seri down the generally steep sided narrow poorly populated gorge, to its confluence with the Kargiakh system (Fig. 3.24).

At Sarchu Seri (089028) three lateral moraines occupy the eastern flank of the broad U-shaped Yunan valley. The crest of the moraine nearest the river is $60 \mathrm{~m}$ above the general land surface, but till extends a further $25 \mathrm{~m}$ down-slope into a gorge (Fig. 3.25). Although granite clasts are abundant in the river terraces, the lateral moraines are of local lithologies (15\% psammite, 35\% limestone, 15\% other low grade metamorphics, $<10 \%$ vein quartz, $15 \%$ conglomerate and $10 \%$ others) as would be expected of ice marginal deposits receiving debris from side slopes. Boulders with characteristics indicative of active glacial transport are rare on the lateral ridges, but more common in a lower part of the moraine, which contains striated and edge rounded faceted clasts with a maximum clast diameter of $\sim 400 \mathrm{~mm}$, decreasing to a sand/silt matrix. Towards the valley centre, outwash or re-sedimented till has distinct sand lenses that have been deformed into open folds and tight diapir-like structures (Fig. 3.26). These fluvioglacial deposits may have been deformed by glacier ice or by the weight of overlying sediment. They are closely related to the till and hence the former ice margin and, as such, a sample of fine sand was collected for dating analysis (V060). 


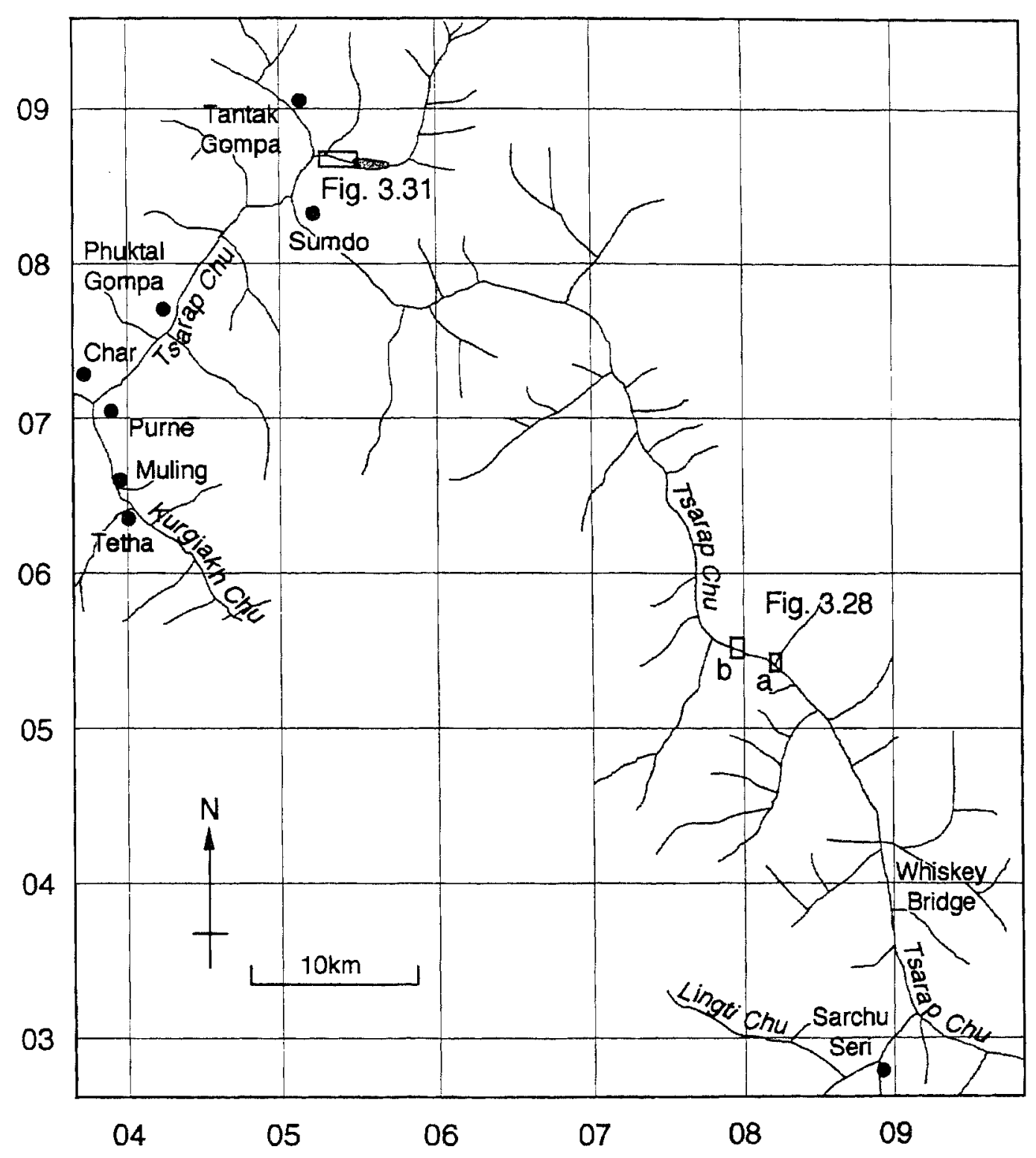

Figure 3.24 Location map for Section 3.4, showing the Tsarap valley. 


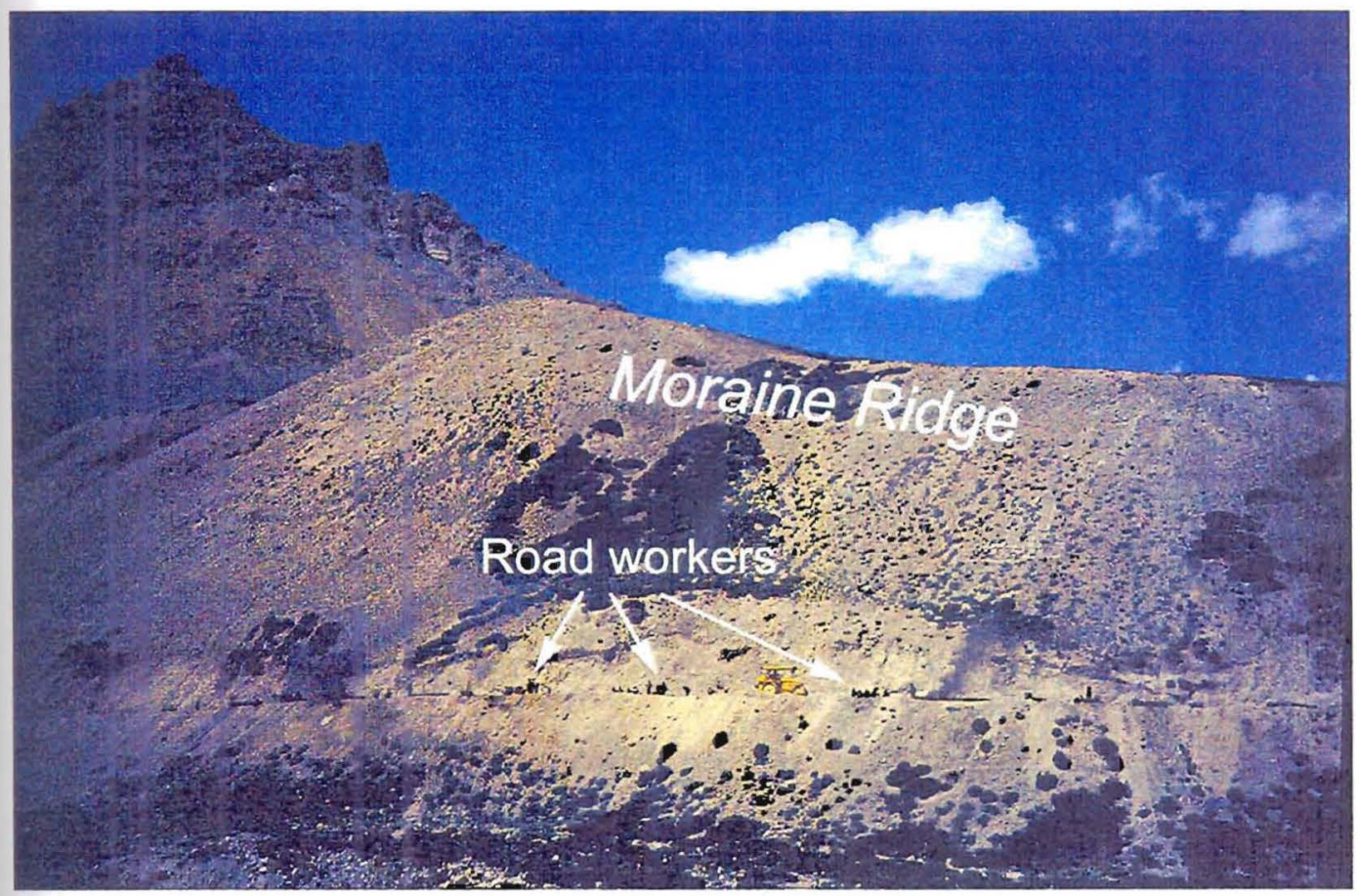

Figme 3.25 Moraine ridge at Sarchu Seri police check-post (bulldozer and road workers for scale). 089028 in Fig. 3.24, looking south-west. 


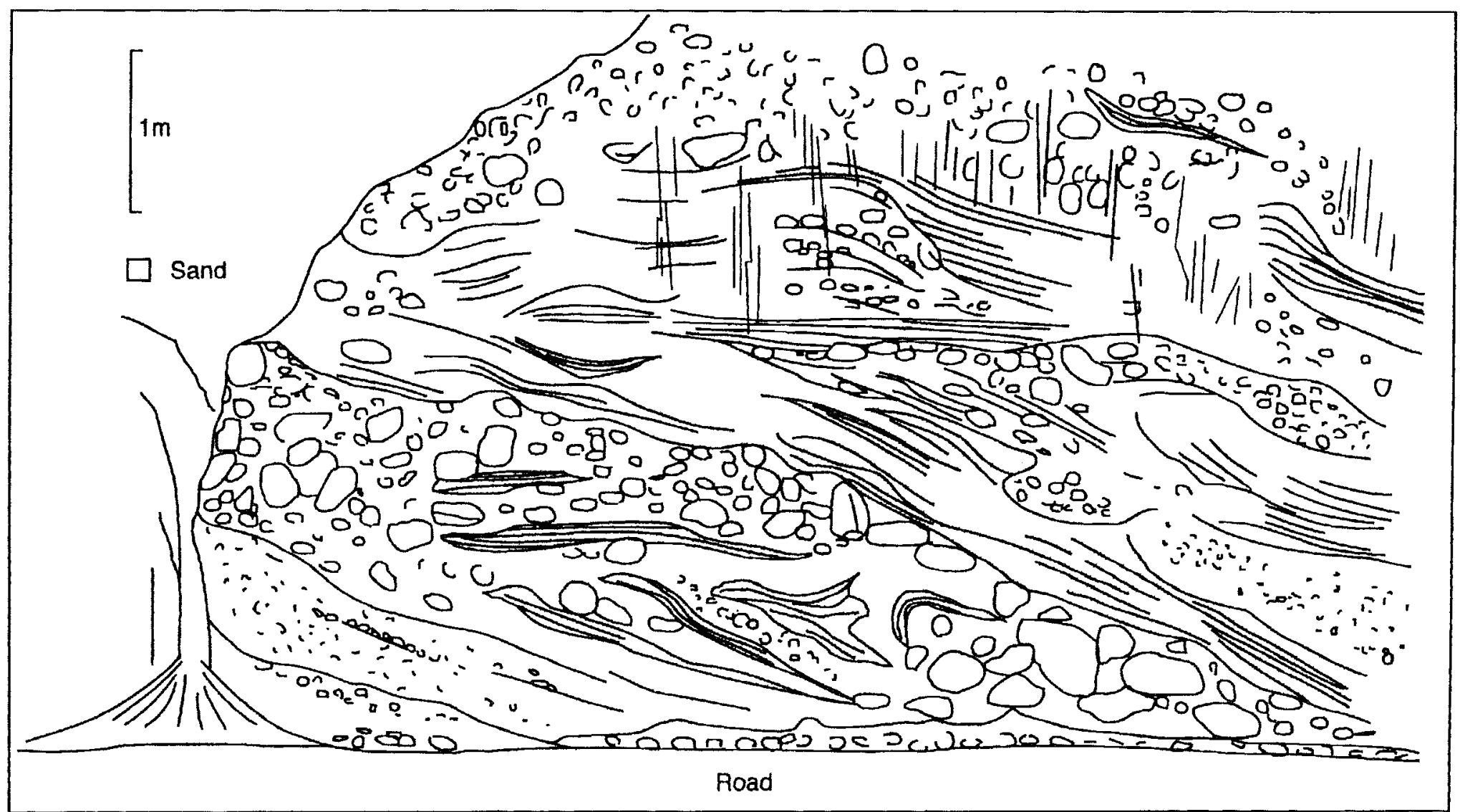

Figure 3.26 Road cut sections in fluvioglacial deposits near Sarch Seri police check-post. Note the deformation of fine grained horizons. 089028 in Fig. 3.24. 
A lateral moraine with its crest $\sim 100 \mathrm{~m}$ a.r.l. can be traced for a few kilometres up the western side of the tributary valley to the south of Sarchu Seri (089028). Periglacial and mass movement processes dominate the steeper eastern flank. Gullies have eroded sections through the moraine, exposing a massive poorly sorted matrix supported diamicton, with limestone, sandstone and schist clasts which vary from sand and gravel to $\sim 500 \mathrm{~mm}$ diameter boulders. Between this moraine and its equivalent in the main valley are remnants of a $70 \mathrm{~m}$ thick well bedded alluvial fill with clasts of $<200 \mathrm{~mm}$ diameter. Similar moraine ridges can be observed $1 \mathrm{~km}$ downvalley, where they are typically several hundred metres long, $50-150 \mathrm{~m}$ wide, $10-50 \mathrm{~m}$ high and trend sub-parallel to the valley axis. A large proportion of these ridges is buried by the sandur deposit, which is $>50 \mathrm{~m}$ thick. Morphologically similar landslides ridges and eroded roots of alluvial fans/debris cones can be distinguished in some cases on the grounds of sedimentology.

At the confluence with the Tsarap Chu (092031) the overall glacial valley form continues down-river from the Yunan valley, but the upper Tsarap Chu has a narrow non-glacial appearance, with a $20-30 \mathrm{~m}$ wide, $30 \mathrm{~m}$ deep bedrock gorge in its floor. Valley sides are steep rock slopes with avalanche modified talus and a number of alluvial terraces up to $\sim 80 \mathrm{~m}$ a.r.l., where debris cones from side gullies have built into the main valley. These high terraces may relate to a time when ice restricted drainage at the gorge mouth. The most continuous terrace level, cut both into alluvium and bedrock, is at $\sim 30 \mathrm{~m}$ a.r.1., which is coincident with the sandur of the main valley. Sorted stone polygons of up to $1.5 \mathrm{~m}$ diameter cover a small area of a terrace at $\sim 40 \mathrm{~m}$ a.r.l. at 096029 (Fig. 3.27). These features, which are $800 \mathrm{~m}$ lower than similar patterned ground from the Baralacha La, are largely unvegetated due to the aridity and appear in comparison with them to be relict.

Ice moulded bedrock can be observed on the eastern side of the $2-3 \mathrm{~km}$ wide valley floor down-river from the confluence of the Upper Tsarap and Yunan valleys (092032). Ridges on the opposite side of the river from the route-way have the 


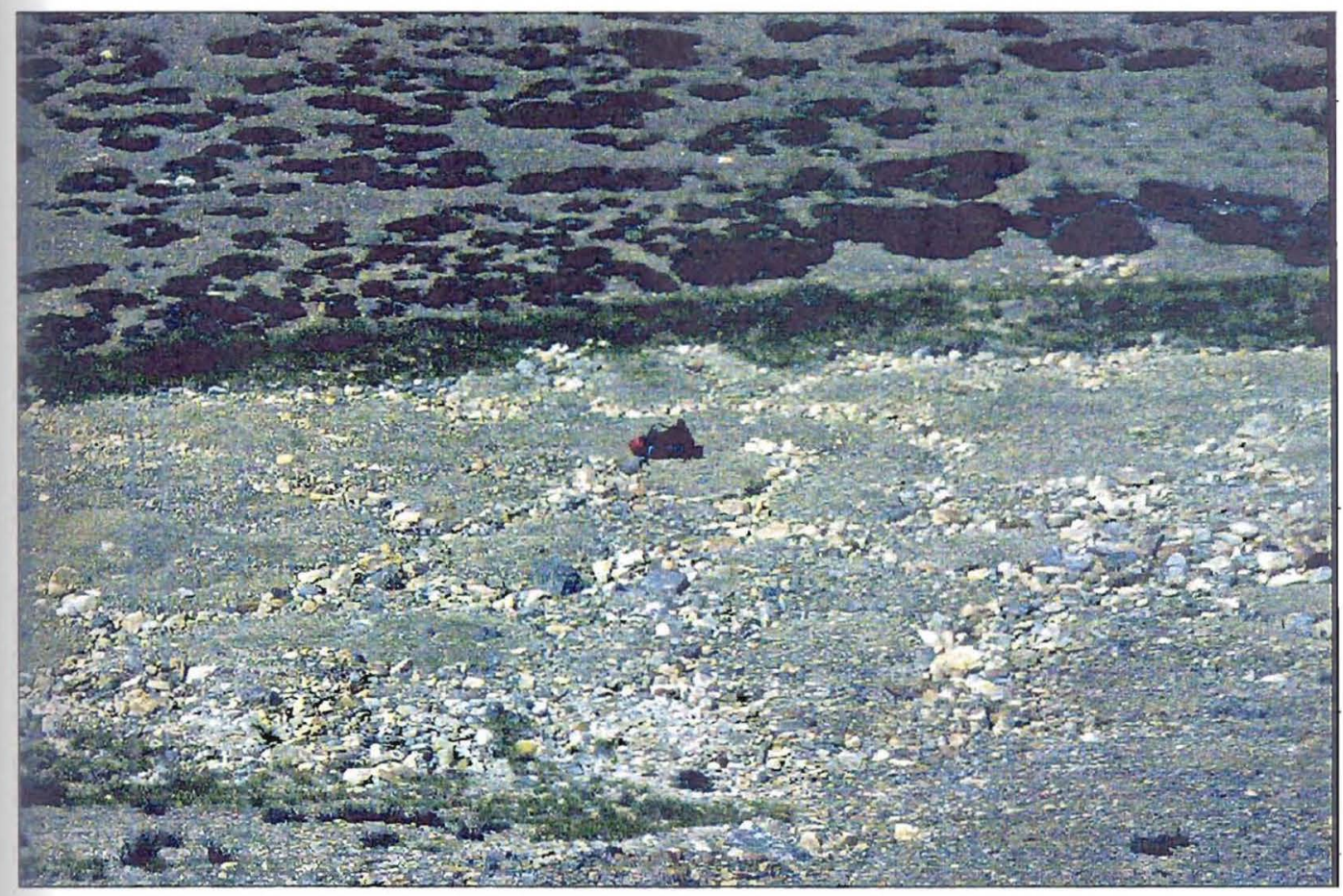

Figure 3.27 Sorted polygons on a terrace in the upper Tsarap Chu gorge (large rucksack for scale). 092031 in Fig. 3.24. 


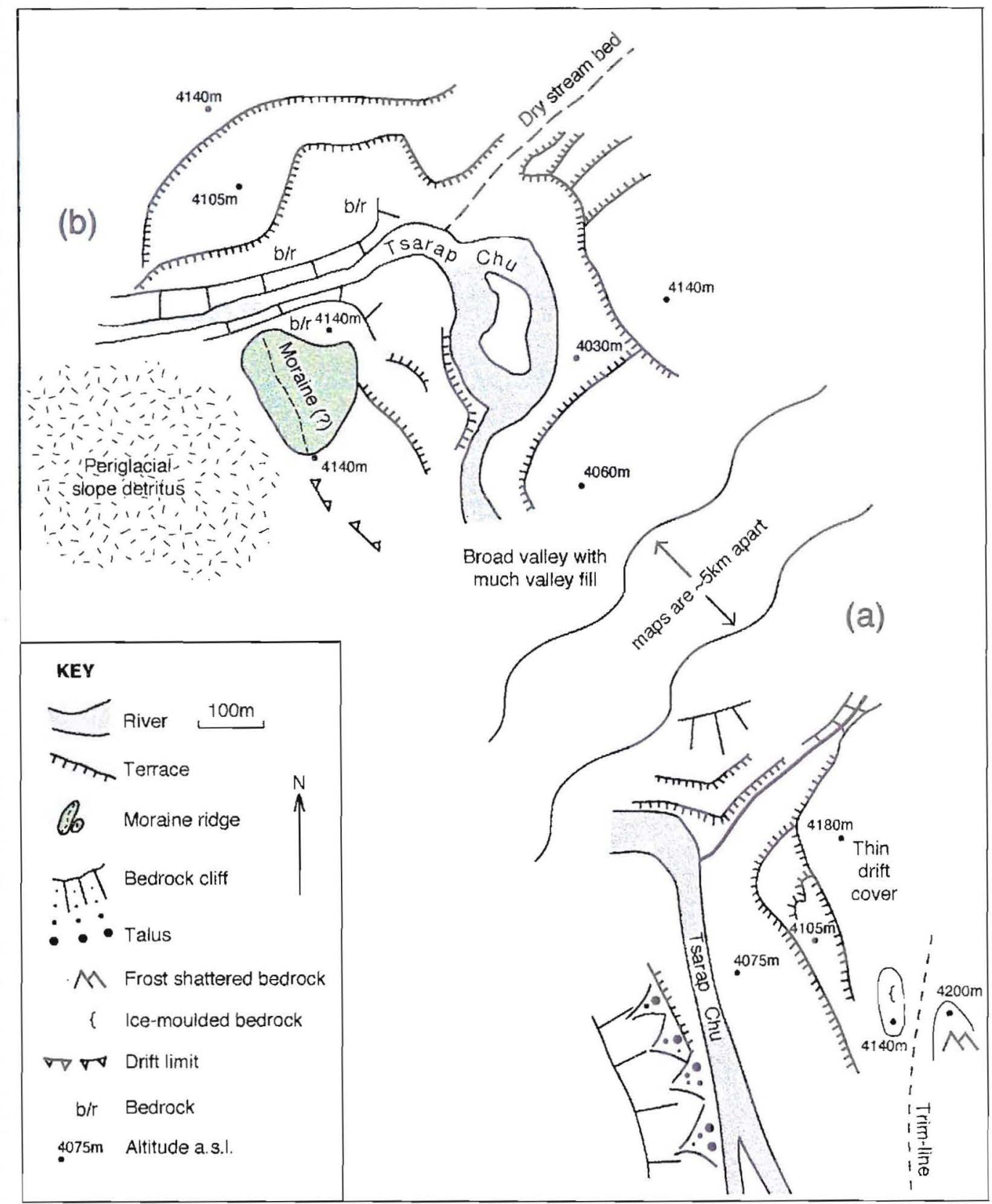

Figure 3.28 Geomorphological sketch maps of glacial evidence from the Tsarap valley. (a) $5 \mathrm{~km}$ up-river from the limit of glaciation, showing trim-line evidence. (b) Limit of glaciation. See Fig. 3.24 for location. 


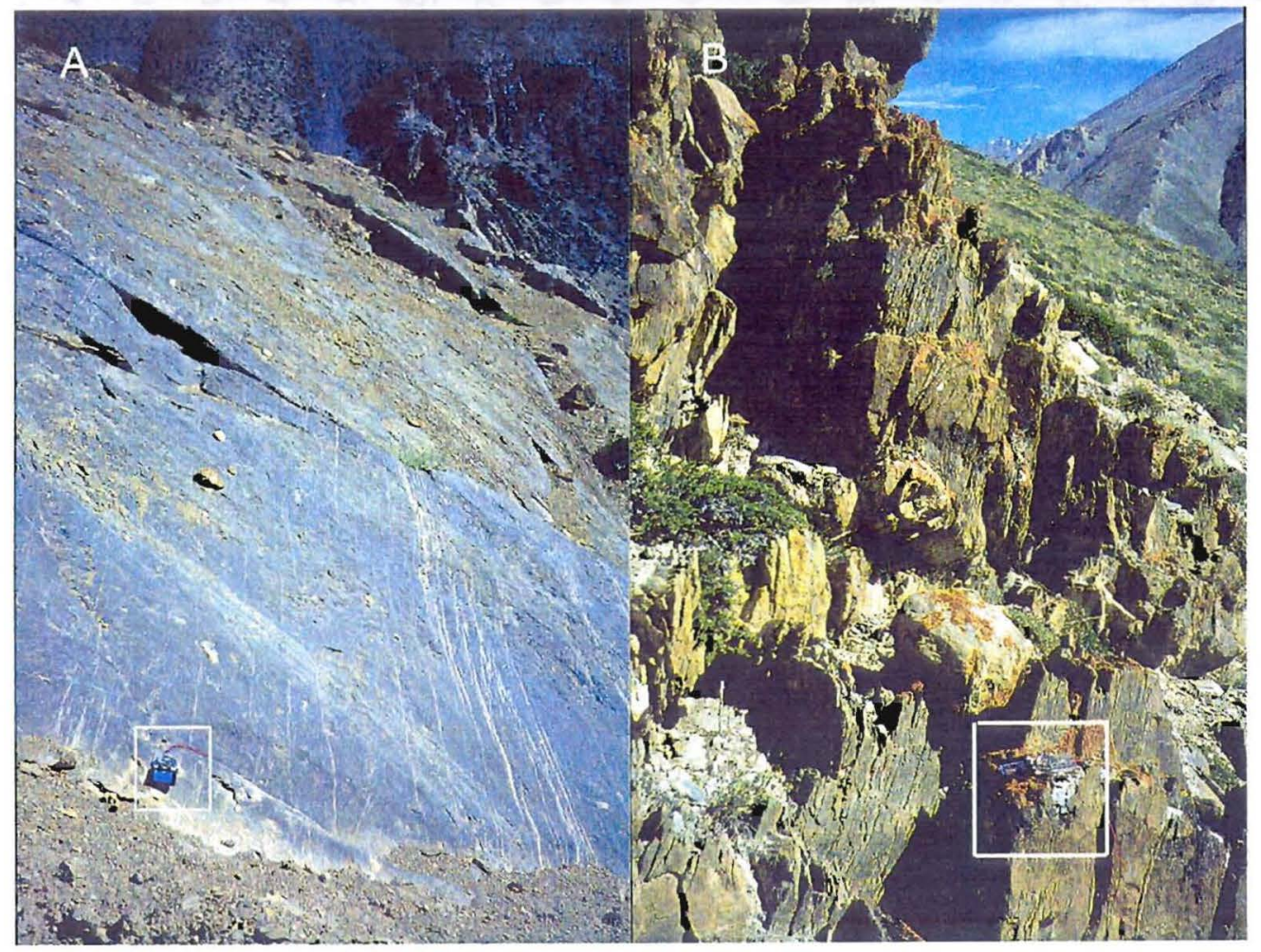

Figure 3.29 A trimline from the Tsarap valley. (a) Ice-moulded bedrock (compass in white box) and (b) frost shattered bedrock from $10 \mathrm{~m}$ above $3.29 \mathrm{a}$. Both outcrops are limestone with similar joint orientations and spacing, and are of similar appearance in fresh section. 082054 in Fig. 3.24, looking south. 
appearance of lateral moraines, but could equally be remnants of alluvial fans. Nevertheless, the valley has a well developed glacial shape.

Figure 3.28a (083054) shows a set of terraces on either side of the Tsarap Chu. Granite erratics, possibly from the head of the Kamirap valley, are abundant in the bed load of the river and can be traced on the eastern slope up to an altitude of $4200 \mathrm{~m}$ a.s.1. ( $\sim 120 \mathrm{~m}$ a.r.1.), although they become scarce. Above these terraces bedrock is exposed at $95 \mathrm{~m}$ a.r.l. and above $125 \mathrm{~m}$ a.r.l. The lower limestone is not striated, but is clearly ice-moulded (Fig. 3.29a), whereas the upper outcrop, which has a similar near vertical dip and is of the same appearance in fresh faces, is angular, frost shattered and has a well developed desert varnish (Fig. 3.29b). To the north of this trim-line the slope becomes gentler and supports a thin veneer of drift. Of the few clasts that are exposed at the surface ( $10 \%$ of the area), fewer than $10 \%$ are granite and some are edge-rounded and faceted, whereas those of the terraces are more rounded and have a high sphericity.

Down-river at 079055 the valley form undergoes a dramatic change from a broad Ushape, with an active often braided river channel and a thick sequences of terraces, to a narrow V-shaped gorge with remnants of fill only locally thick where alluvial fans and debris cones have built from side gullies (Fig. 3.30). The moraine shown in Figure $3.28 \mathrm{~b}$ (079055) was only observed from the opposite side of the river and consequently is interpreted on morphology alone. Beyond the moraine, an area of periglacial detritus and steep valley slopes, which are probably controlled by landsliding, can be observed. Although granite clasts continue down the valley as outwash, this change in morphology is interpreted as the limit of glaciation within the current valley system.

Down-valley from the ice-limit the Tsarap Chu occupies a deep gorge. On an interfluve $370 \mathrm{~m}$ a.r.l. is an area of periglacial detritus and a 'tor' of conglomerate with associated rock falls. The conglomerate is unconformable on the underlying limestones with sub-rounded to sub-angular pebbles of low to medium sphericity, 


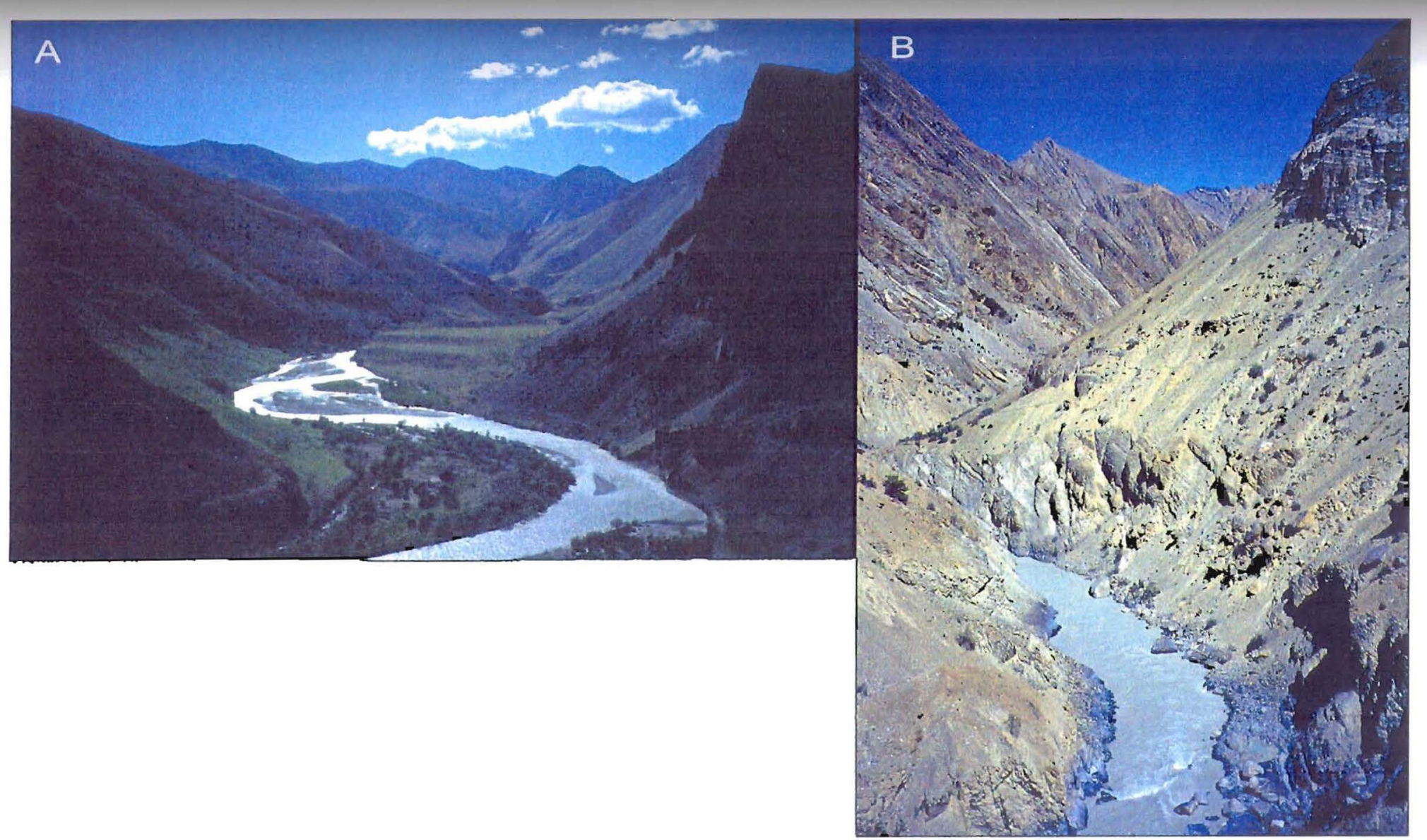

Figure 3.30 Valley cross-sectional form in the Tsarap Chu. (a) Broad U-shaped valley up-valley from the proposed limit of glaciation. 081055 in Fig. 3.24, looking north-west. (b) Narrow V-shaped bedrock gorge down-valley from the proposed limit of glaciation. 078056 in Fig. 3.24, looking north-west. 
which range from $<10 \mathrm{~mm}$ to $300 \mathrm{~mm}$ in diameter with an average of $\sim 100 \mathrm{~mm}$ and are of local lithologies. The rock is bedded and clast supported indicating a fluvial origin, and although now a high point, this sediment must have been laid down in a valley floor situation.

Gneiss boulders can be observed in the current river sediment, the largest of which being of $700 \mathrm{~mm}$ diameter and well rounded (074066). Much of the gorge section is inaccessible with few opportunities to leave the precarious path to descend to the river or view the upper slopes and, as such, observations are limited. River sediments consist of $\sim 90 \%$ limestone, $\sim 5 \%$ granite and $\sim 5 \%$ others (including pebbles of conglomerate and gneiss) and remnants of this alluvial fill are well lithified in the lower $10-15 \mathrm{~m}$ of the terraces. Sections show areas of cross-bedding and at least one large flood event is recorded by a horizon of clasts $>1 \mathrm{~m}$ in diameter. Sub-angular gneiss boulders of $>1 \mathrm{~m}$ diameter are situated in a steep stream gully $\sim 1 \mathrm{~km}$ to the north. These rocks can only have come from an upper palaeosurface as observed upvalley on Mount Sarchu and down-valley, as described below.

At Sumdo (053083) a rock bench has been cut on both sides of the valley at $\sim 40 \mathrm{~m}$ a.r.l., the same height as the sandur terrace level. These benches continue down the Tsarap Chu and up the tributary towards Tantak Gompa, with some exposures of the limestone bearing macro-fluvial erosional forms although sharp with runnels.

Figure 3.31 covers an area to the north of Sumdo (054087) where a former ice-limit can be identified. The narrow valley with near vertical rock walls of $>300 \mathrm{~m}$ height (Fig. 3.31) contains undulating drift and hummocky moraine which is composed of local limestone with some blocks of $>10 \mathrm{~m}$ diameter. There are no fines at the surface and clasts are angular, suggesting periglacial alteration, a passive transport through the glacier or an alternative origin such as mass movement.

Further down this tributary valley there is more convincing evidence for glaciation, with a moraine in front of a large rock glacier and other debris cones/alluvial fans that appear to be re-sedimented till. Clasts are sub-angular to sub-rounded, have faceted 


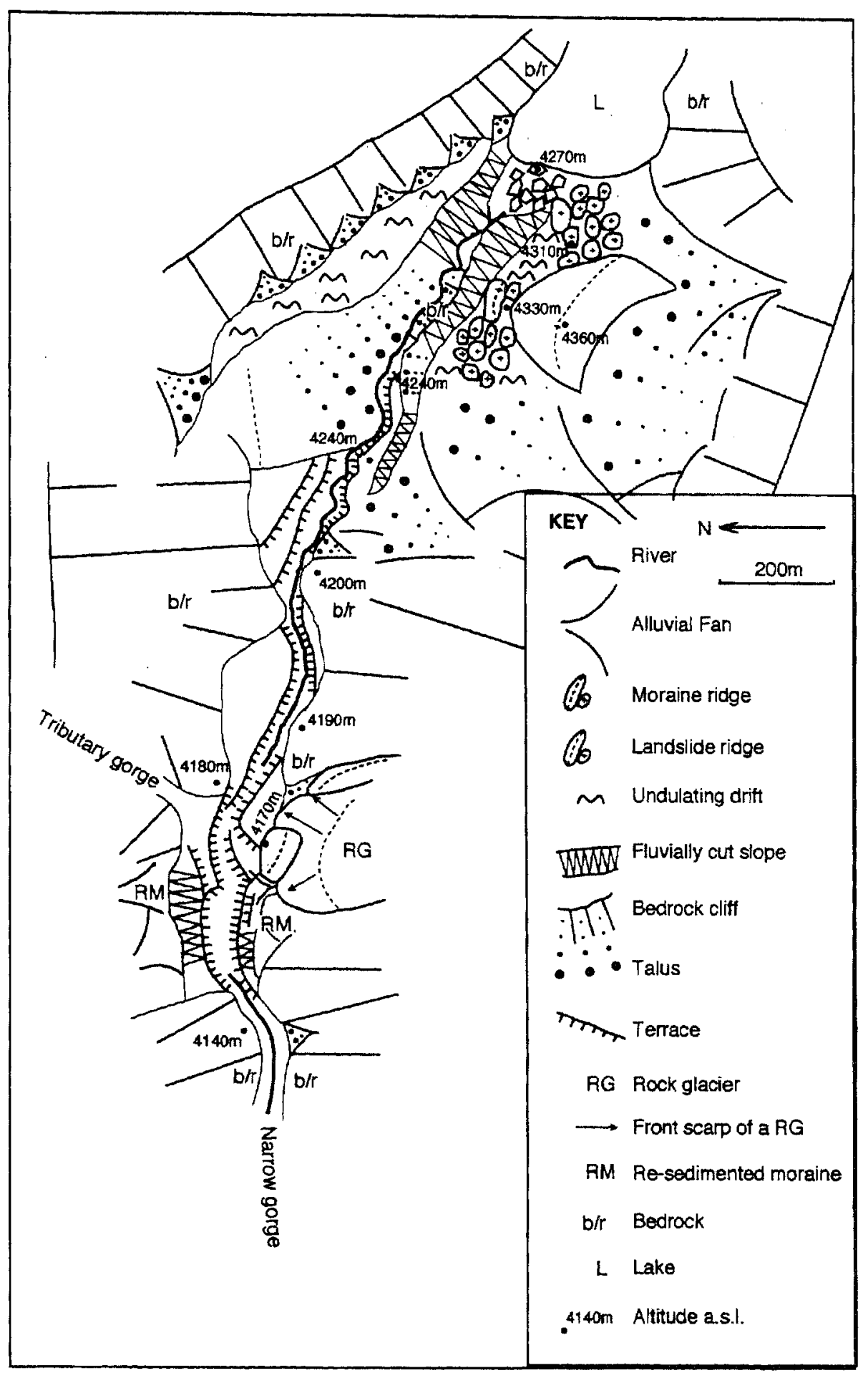

Figure 3.31 Geomorphological map of the lower Tok valley. See Fig. 3.24 for location. 
edges, vary in size from sand and gravel to $\sim 0.5 \mathrm{~m}$, and are not solely of limestone, but also contains $\sim 20 \%$ sandstone. Underlying the down-valley side of the western re-sedimented moraine are remnants of a conglomerate of sub-rounded clasts ranging from $10-150 \mathrm{~mm}$ diameter (also of $80 \%$ limestone and $20 \%$ sandstone). Immediately down-stream from these sediments the narrow valley becomes a more restricted gorge with little fill, although in a few places remnants of the well lithified conglomerate which is $\sim 30 \mathrm{~m}$ a.r.l. remain. This fluvially lain sediment may be outwash from the former glacier, or river sediments that pre-date the glacial event. No gneiss or schist erratics were observed, although Osmaston (1994) describes these high on valley sides up-river near Tantak Gompa (051090).

$\sim 280 \mathrm{~m}$ above the Tsarap Chu, on the north-west side, $\sim 5 \mathrm{~km}$ down-river from Sumdo (049084), a large ice-moulded bedrock outcrop/whaleback occupies a 200-300m wide gently sloping surface. Gneiss boulders are exposed on this palaeosurface and a weathered diamictite is exposed in two places. The gneiss boulders are relatively abundant, possibly due to their chemical stability compared to the other rocks within the drift, particularly limestone which shows highly evolved weathering. Nevertheless, well developed tafoni forms in the gneiss were not observed, possibly indicating an advanced state of weathering, with the collapse of tafoni hollows, although no direct evidence for this was observed. The poorly sorted diamictite is mainly limestone (>95\%), but also contains occasional gneiss and granite, with clasts ranging in size from $\sim 1 \mathrm{~m}$ down to gravel (Fig. 3.32). Boulders are sub-angular and some have faceted edges. Unlike the fluvial conglomerate of the 'tor' described above, this outcrop has no obvious fabric and is not entirely of local lithologies. The rock is highly weathered with many of the limestone clasts reduced to a brittle honeycomb that is indistinguishable from the weathered calcite cemented matrix, something that makes examination difficult, with only single clasts of other lithologies liberated when the rock is repeatedly struck. This diamictite is tentatively classed as a tillite. Although it may be a debris flow deposit, the parent material with its erratic content must have been of glacial origin. 


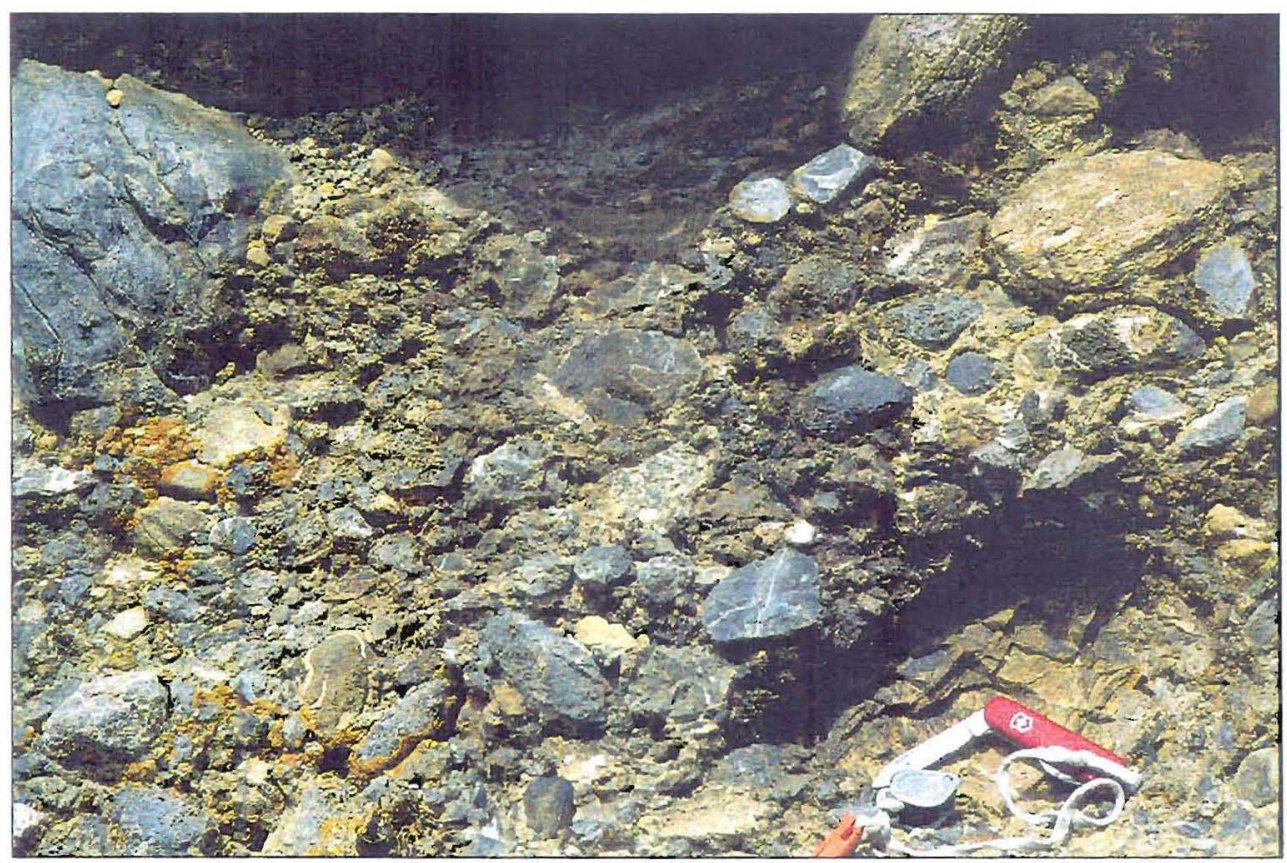

Figure 3.32 Diamictite (tillite?) above the Tsarap Chu gorge (penknife for scale). 049084 in Fig. 3.24.

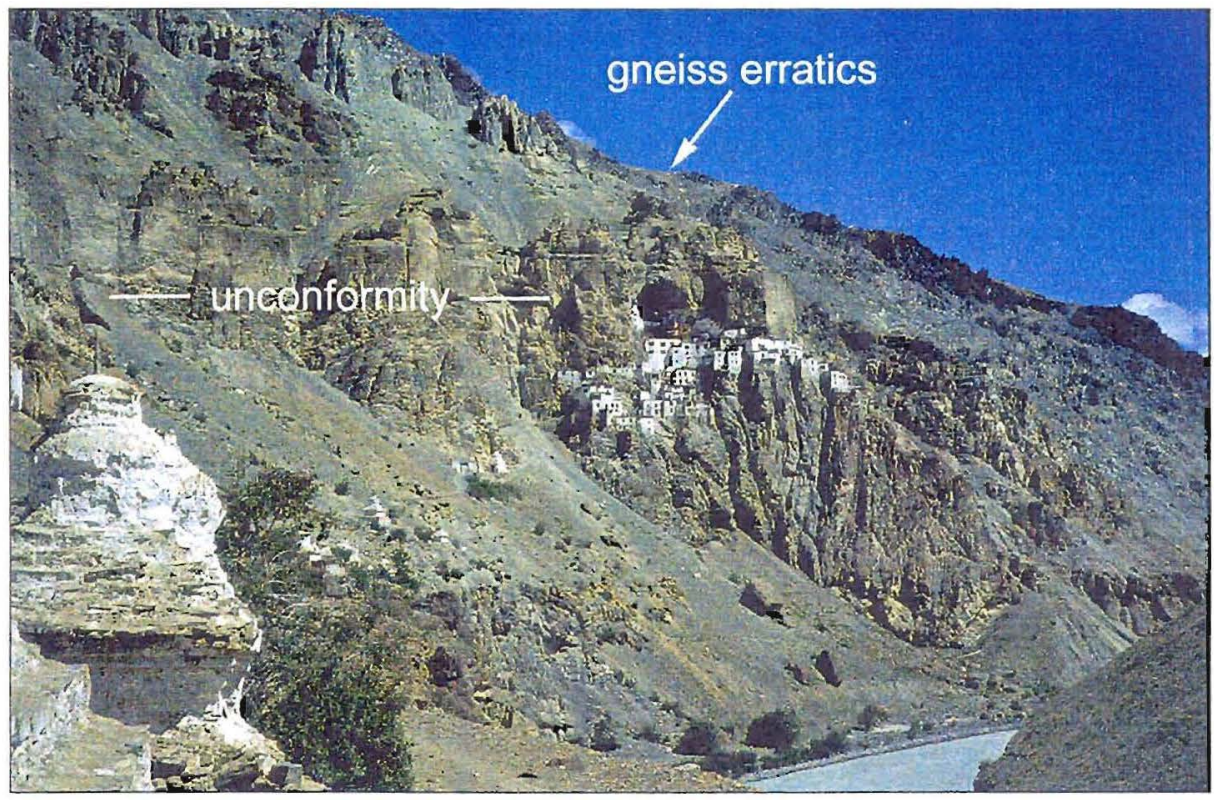

Figure 3.33 Phuktal Gompa with fluvial conglomerate unconformably on limestone and gneiss erratics on upper slopes. 043077 in Fig 3.24, looking north. 
A few kilometres up-river from Phuktal Gompa (044079) the valley widens, with thick fill in the form of fluvial terraces and fans eroded into earth pillars. Phuktal Gompa is built into a cave in a $\sim 150 \mathrm{~m}$ cliff of conglomerate, which is unconformable on limestone bedrock (Fig. 3.33). Fallen blocks of the conglomerate allowed examination, which revealed sub-rounded to rounded fluvial clasts. No gneiss was observed in the conglomerate, although gneiss clasts can be found on upper slopes.

\subsection{Whiskey Nala to Mare Plains}

Evidence from the eastern segment of the field area is presented from the Whiskey Nala, a tributary of the Tsarap Chu, up-river to the Lachalung La and out of the Tsarap catchment, down its northern flank, to the camping ground of Pang. The broad dry Mare Plain to the north and the west flowing Sumkhel Lungpa are then described (Figs. 3.34 and 3.35).

Whisky Nala (091043) joins the Tsarap Chu valley as a narrow, $5 \mathrm{~km}$ long, $150-200 \mathrm{~m}$ deep gorge. On the eastern shoulder of the valley an undulating rock bench has the appearance of a glacial erosional surface, however, no positive evidence for glaciation could be found and the sub-horizontal aspect of the bedding in the limestone seems to erode to this form through periglacial and fluvial processes. Above the gorge section, the river resides in a broad basin with a $500 \mathrm{~m}$ wide floor, again with no evidence for glaciation and valley sides are mantled for several hundred metres with talus and periglacial detritus and are backed by limestone cliffs. This pattern continues over the $5065 \mathrm{~m}$ Lachulunga La (094092), where a braided stream occupies a $200 \mathrm{~m}$ wide valley floor beneath $400-500 \mathrm{~m}$ of frost-shattered limestone cliffs and solifluction modified talus.

In the valley, which becomes a gorge, $70-80 \mathrm{~m}$ of gravel fill is preserved in discontinuous remnant terraces of lithified conglomerate, with sporadic rockfalls 


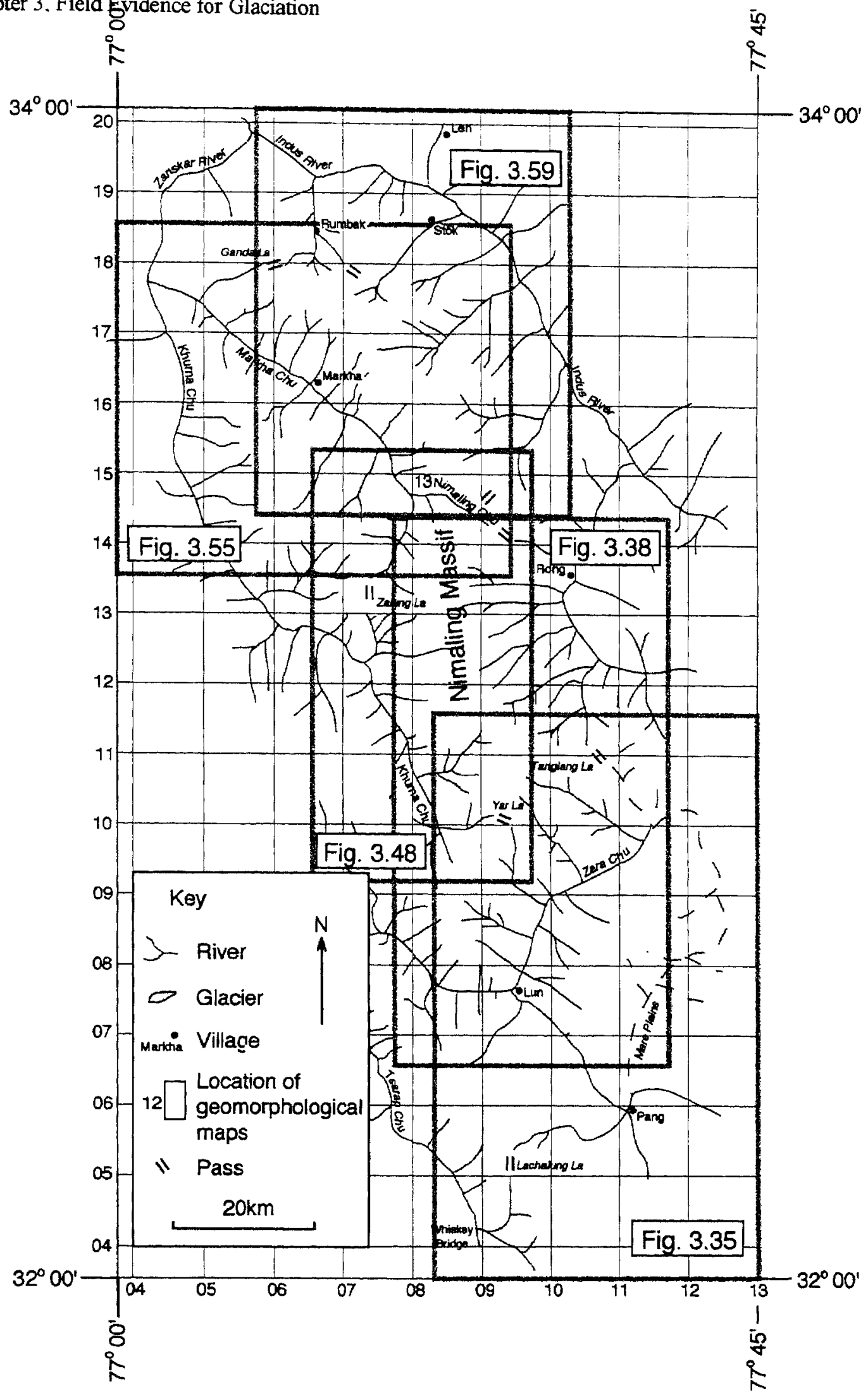

Figure 3.34 Location map for Sections 3.5 to 3.9 in the north of the field area. 


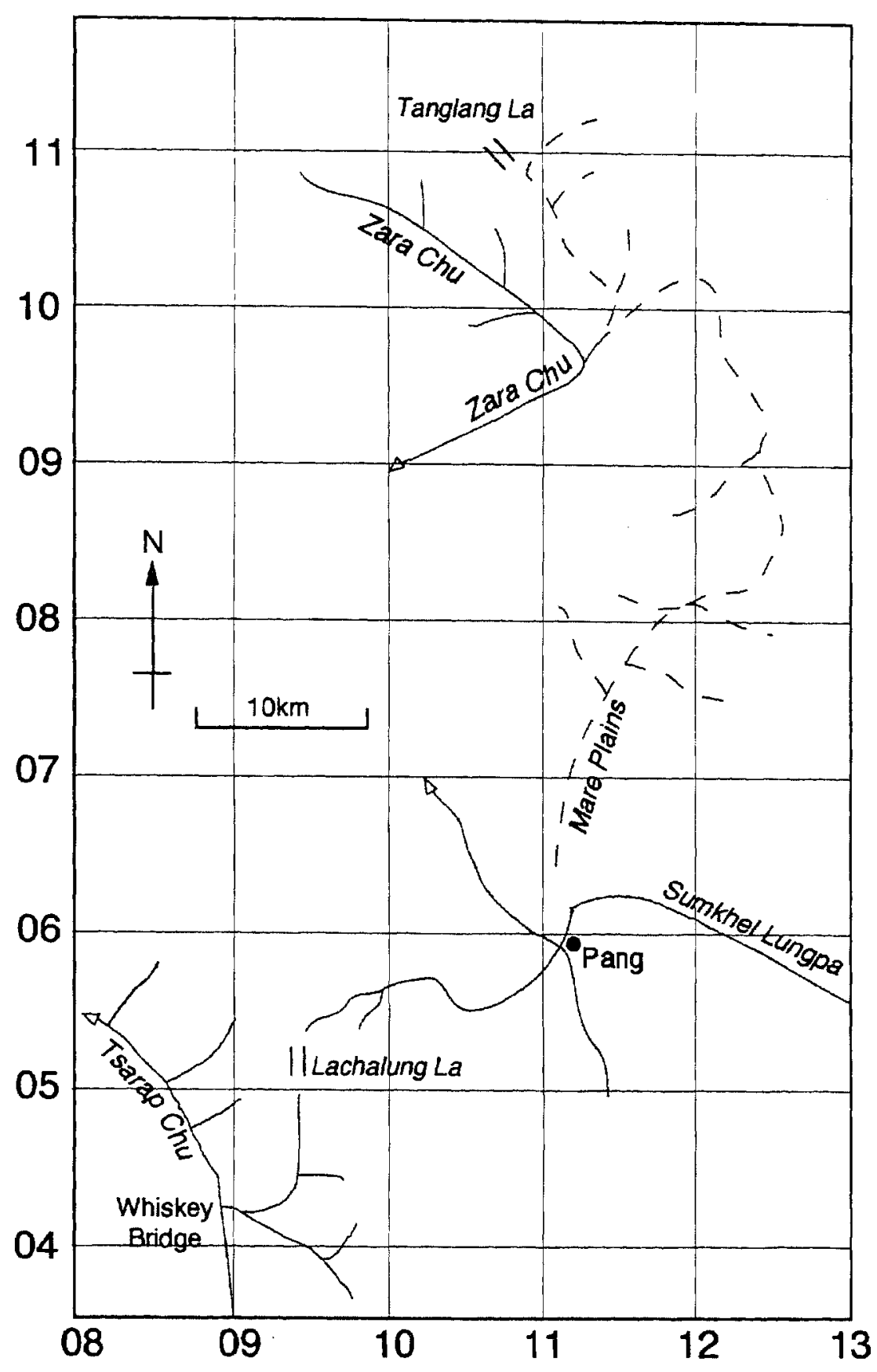

Figure 3.35 Location map for Section 3.5, showing Whiskey Nala and the valleys surrounding Pang. 
'floating' within the sediment (103057). Younger unconsolidated remnants were also observed and, like the older deposits, they appear to have been deposited when the narrow gorge was blocked by rockfalls, as is the case with the present flood plain which extends up-valley from a rock avalanche. Down valley from this blockage the bedrock gorge is $>300 \mathrm{~m}$ deep with no valley fill except rockfalls. Towards the camping ground of Pang (112059) the river substitutes its bedrock walls for $200 \mathrm{~m}$ of horizontally bedded gravels, resting on $15 \mathrm{~m}$ of folded bedrock, forming a gently undulating to flat surface of which the Mare Plains (112072) forms the greatest part. These sediments were examined at a number of sites and altitudes around the camping ground of Pang and were found to be weakly lithified in places, moderately well sorted and clast supported, with sub-rounded limestone clasts of up to $200 \mathrm{~mm}$ diameter (Fig. 3.36).

In contrast to available topographic maps, which show the broad Mare Plain sloping to both the north and the south, the plain and associated high terraces around Pang and in the Sumkhel Lungpa valley slope to the north. Altitude readings taken periodically from the top of the $240 \mathrm{~m}$ conglomerate cliff near Pang (113062) (Fig. 3.37 ) along the surface to the north give a gradient of $\sim 10^{\circ}$. Although the small scale morphology of dry channels and alluvial fans reflect recent processes, the overall slope and sedimentology suggest that the plain was deposited by a braided river system, which flowed from the Lachalung La (094052) and Sumkhle Lungpa (125055) to the Zara Chu in the north (115097). This former flood plain has since been abandoned with the Sumkhle Lungpa having been captured by another tributary of the Zara Chu, which has since cut $240 \mathrm{~m}$ into the alluvium (Fig. 3.37). Alluvial fans have modified the plain damming the ephemeral drainage such that a large lake forms in early spring (Robert Newbury, pers. comm.).

The lowermost few metres of the $240 \mathrm{~m}$ exposure in the Sumkhle Lungpa valley was examined, revealing an immature gravel consisting of predominantly dises and blades which are sub-angular to sub-rounded and of $\sim 100 \mathrm{~mm}$ diameter with a maximum of $\sim 200 \mathrm{~mm}$. The gravel deposits are well bedded, but show few additional sedimentary 

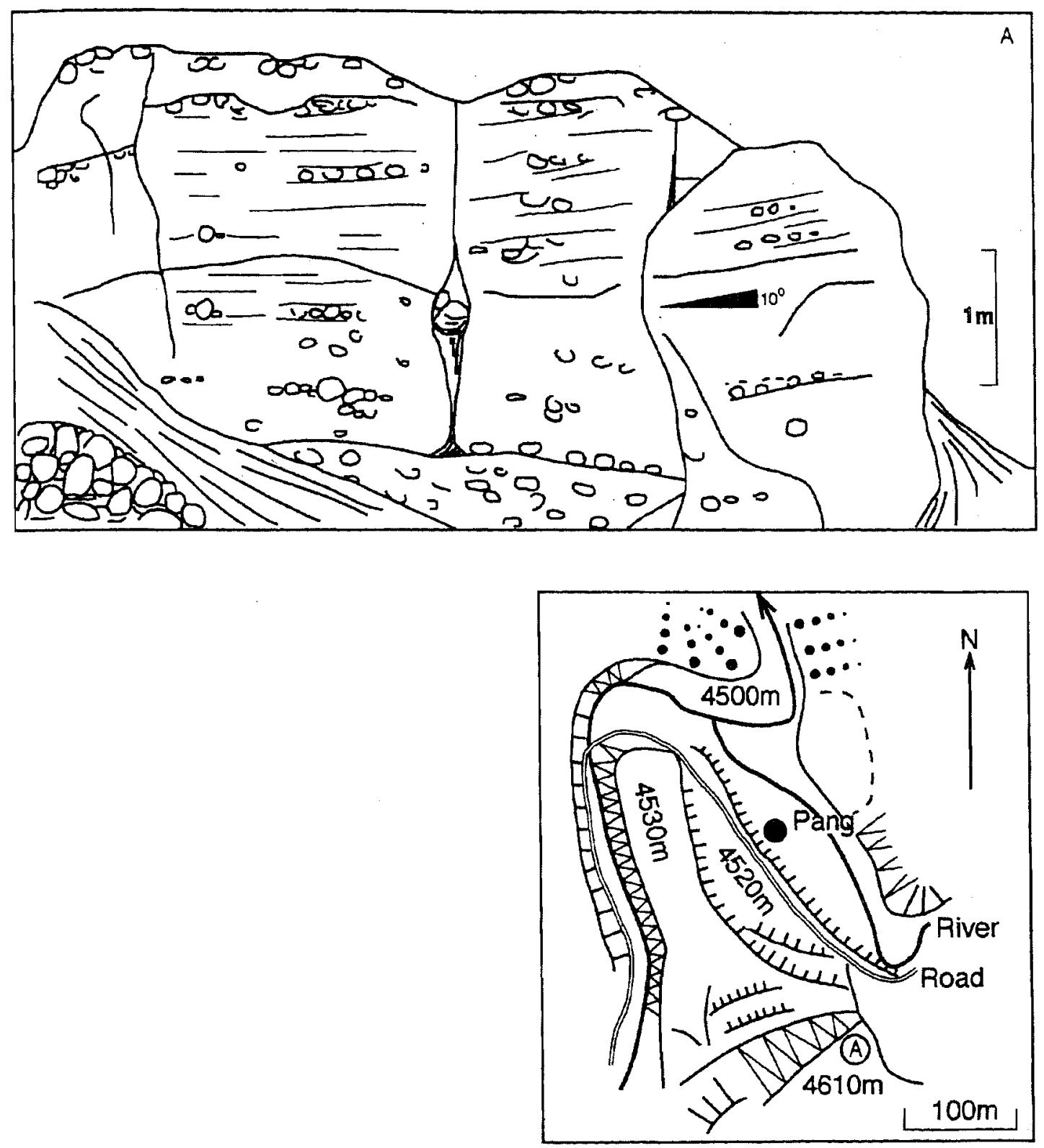

Figure 3.36 Fluvial conglomerates and gravels around the camping ground of Pang The location of the section (A) is shown in the geomorphological sketch map. 112059 in Fig. 3.35. 


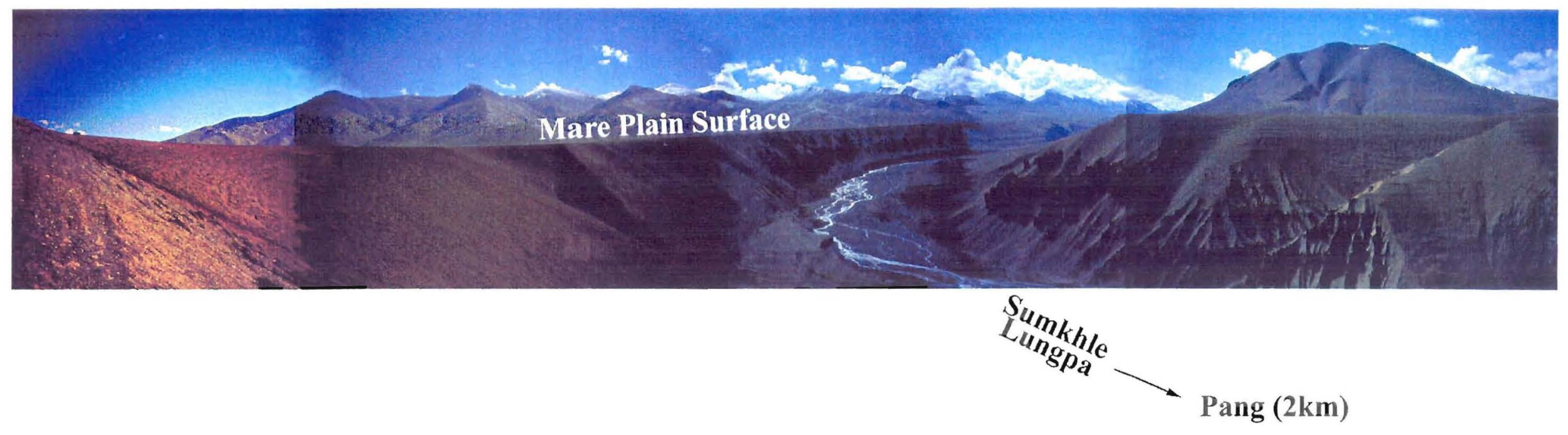

Figure 3.37 Mare Plain with a $240 \mathrm{~m}$ cliff to the Sumkhle Lungpa. From 110062, looking north-east 
structures. A $1 \mathrm{~m}$ thick horizon of coarse material (of $300 \mathrm{~mm}$ diameter) forms a slight convex up curve dipping away from the centre at $\sim 5^{\circ}$, possibly reflecting a flood event. A sample for OSL dating (V064) was obtained from the lowermost exposure in this Mare Plain conglomerate (121061).

The Sumkhle Lungpa is now confined in a $20-50 \mathrm{~m}$ wide bedrock gorge up-river from 130051 , which becomes $80-100 \mathrm{~m}$ deep with a further $100 \mathrm{~m}$ of the Mare Plain gravels above. Down-stream from this bedrock section conspicuous white granite boulders of 1-3m diameter form a lag deposit on the present flood surface and are occasionally in the alluvium cliffs on either side. A potential source area for these boulders has not be found, although they may have been reworked from an older possibly glaciated surface, as observed in the Tsarap system.

\subsection{Lun (Zara Chu) to Rong (Gya Valley) (Fig. 3.38)}

The north-eastern area of investigation is described from the camping ground of Lun in the Zara valley, up-river to the Tanglang La and down the Gya valley to the village of Rong (Fig. 3.38). These two valleys form the eastern side of the crystalline rock of the Nimaling Massif.

To the south of the camping ground of Lun (096072) dry valleys are eroded into alluvial sediments similar to those described for the neighbouring Mare Plain. This undulating surface slopes steeply to the Zara Chu, which on its north-western side, is flanked by a $150 \mathrm{~m}$ sub-vertical cliff of well lithified alluvial conglomerate, forming a deep narrow valley. Clasts from the cliff are sub-angular limestone with minor vein quartz and are on average $50 \mathrm{~mm}$ in diameter, forming a well bedded, moderately well sorted, clast supported fluvial conglomerate, with cross and trough bedding. All clasts are derived from locallithologies with no foreign clasts observed.

At the base of this conglomerate cliff, terraces of up to $60 \mathrm{~m}$ height occupy the $100-$ $200 \mathrm{~m}$ wide valley floor. In contrast to the older valley fill described above, these 


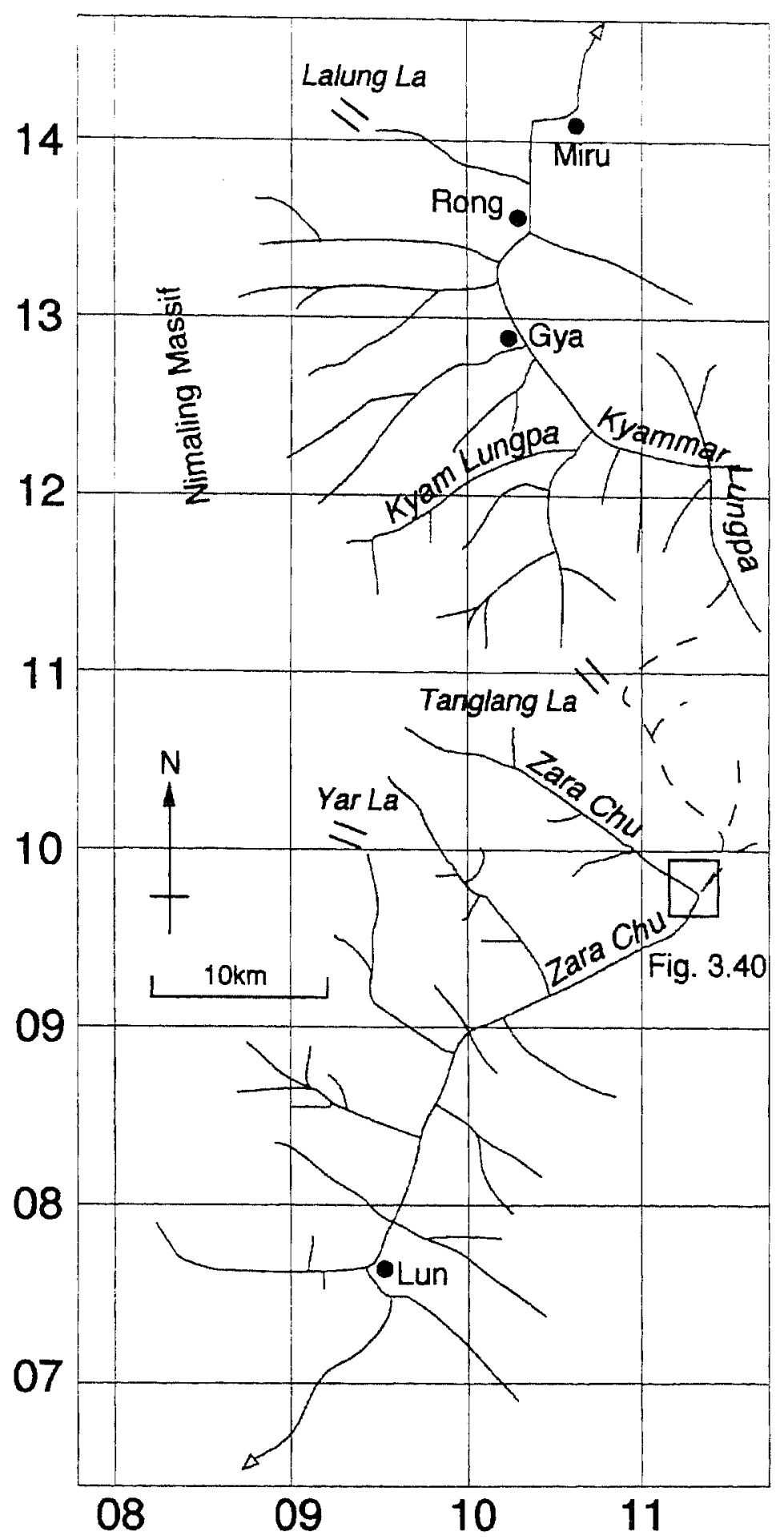

Figure 3.38 Location map for Section 3.6, showing the Zara and Gya systems, which form the eastern boarder of the $6000 \mathrm{~m}$ plus Nimaling Massif. 
Chapter 3, Field Evidence for Glaciation

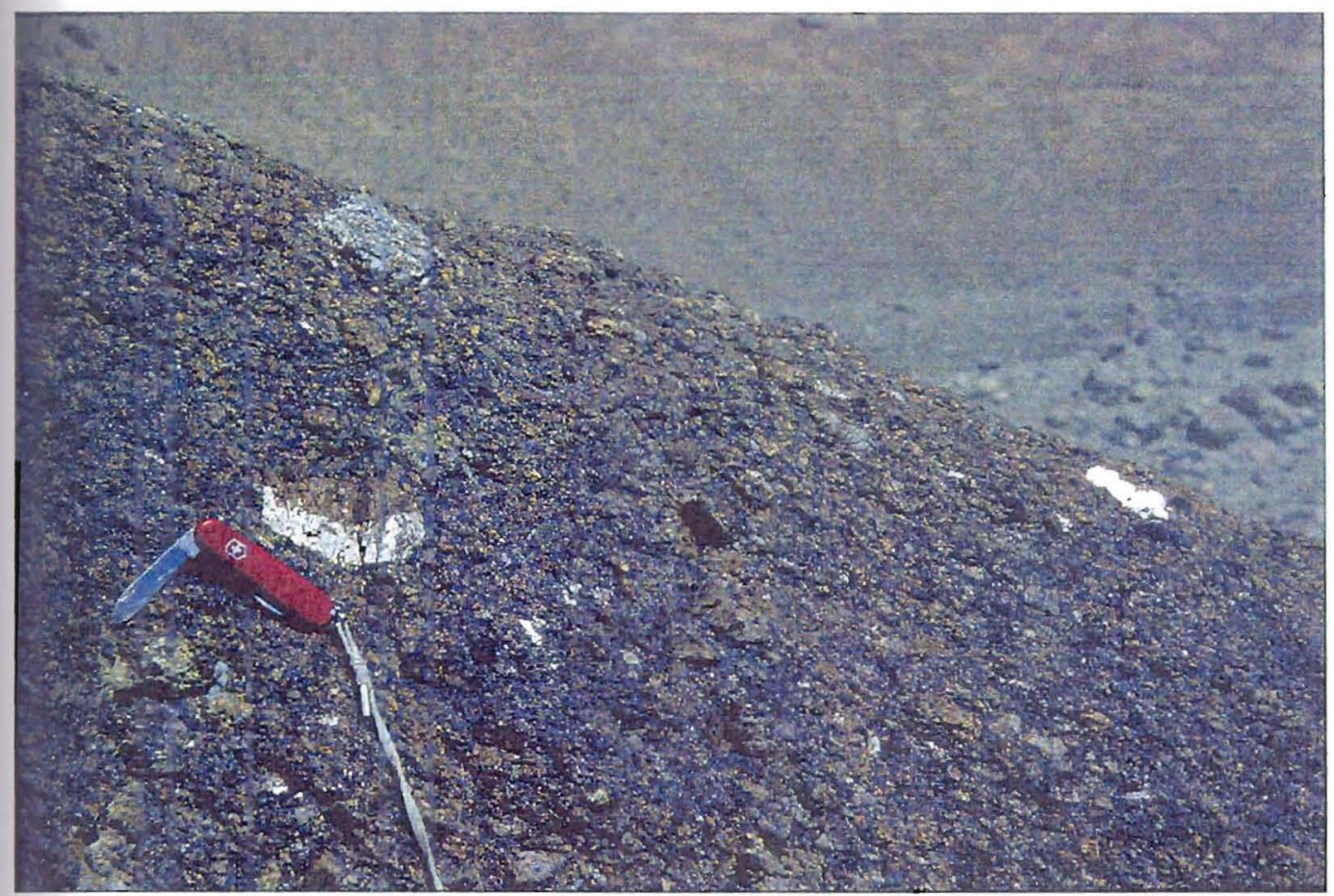

Figure 3.39 Close up of a granite erratic from the Zara Chu. Above the penknife a large porphyroblast of albite feldspar can be seen with one twin plane reflecting sunlight. 098084 in Fig. 3.38. 
deposits only consist of $40 \%$ limestone clasts (which are well rounded with low sphericity), but have $45 \%$ granite and high grade metamorphic clasts (which are well rounded with high sphericity) and occasional clasts of gabbro and vein quartz. To account for this difference in clast lithology, there could have been a change in drainage source area, or alternatively an unroofing of the erratic source rock, the Rupshu granite (which is now exposed at the head of the Zara Chu) between the two depositional events.

Up-valley at 099088 large granite erratics of up to $4 \mathrm{~m}$ diameter punctuate the river terraces (Fig. 3.39), whereas down valley from this point only clasts $\leq 1 \mathrm{~m}$ in diameter are found. These erratics must have been transported by glacial ice, as they are not in the size fraction recorded in the fluvial record of river terraces. The Rupshu granite (Brethelsen, 1953) has distinctive euhedral phenocrysts of K-feldspar of up to $120 \mathrm{~mm}$ by $60 \mathrm{~mm}$ and well know boundaries, which make it a useful indicator erratic. Any moraines that may have existed on this confined flood plain have since been reworked into alluvial terraces with only a lag deposit of the largest boulders marking the maximum limit of glaciation. Additional evidence includes up-valley increases in the width of the valley floor from $200 \mathrm{~m}$ to $500 \mathrm{~m}$ and in the angle of the conglomerate cliff which changes from sub-vertical to $40-50^{\circ}$. To the north-west near the Yar La (093101) a series of west facing corries, which would have been a source for the palaeoglacier, can be observed.

Convincing evidence for the glaciation of the Zara valley presents itself where the river makes a $90^{\circ}$ turn from the south-east to the south-west (114098). A large moraine complex on the convex side is preserved due to the favourable situation of being on the broad valley floor of the Mare Plain and Debring valley, with their small ephemeral streams (Figs. 3.40 and 3.41). This is in contrast to the glacial limit in the narrow Zara valley with its permanent river. The eastern lateral moraine has several sub-parallel ridges making up the $>80 \mathrm{~m}$ thick deposit and a complex morphology where ice has locally overtopped the moraine (Fig. 3.40). The western lateral 


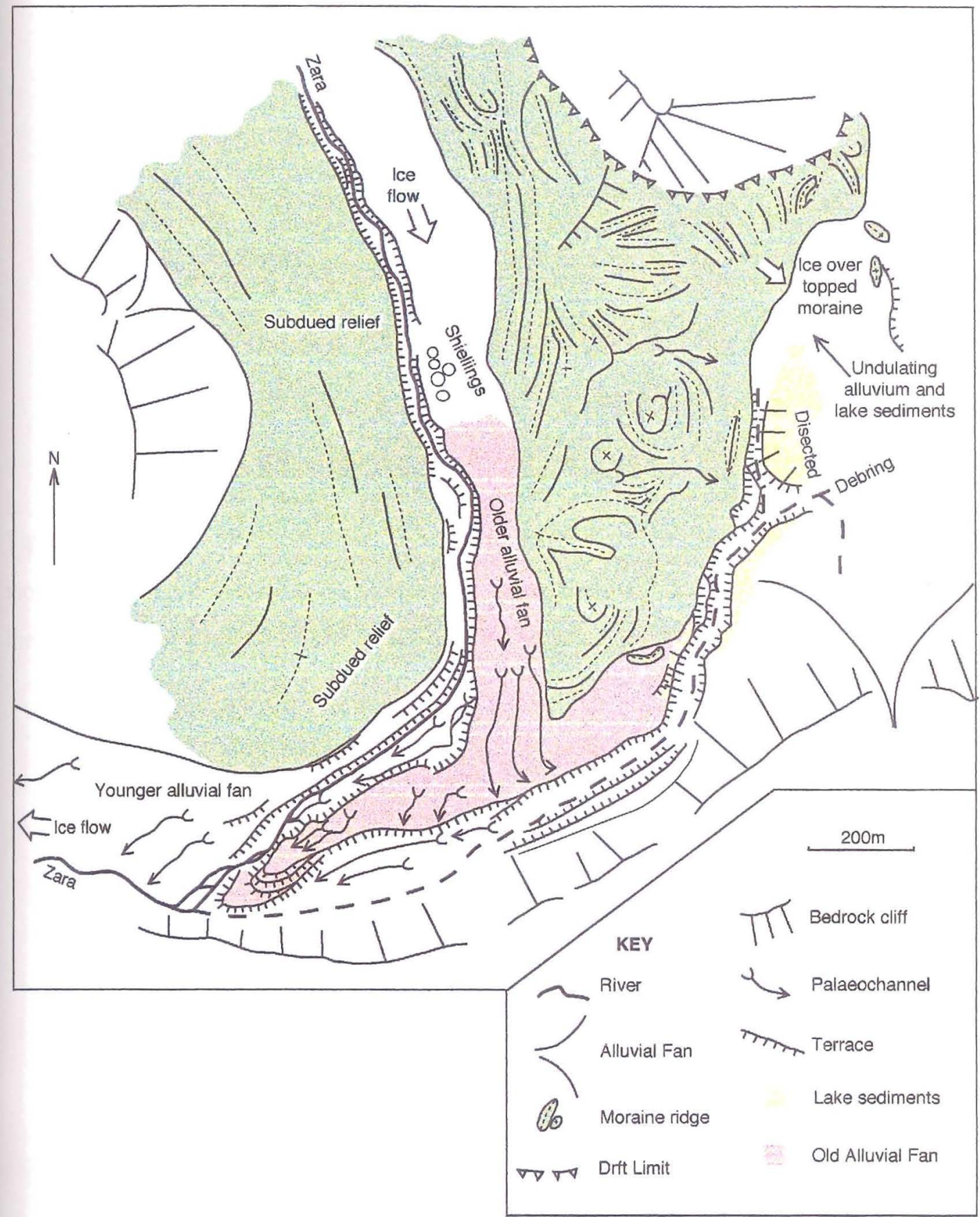

Figure 3.40 Geomorphological map of the Zara valley at its confluence with the broad, dry Debring valley and Mare Plain. See Fig. 3.38 for location. 


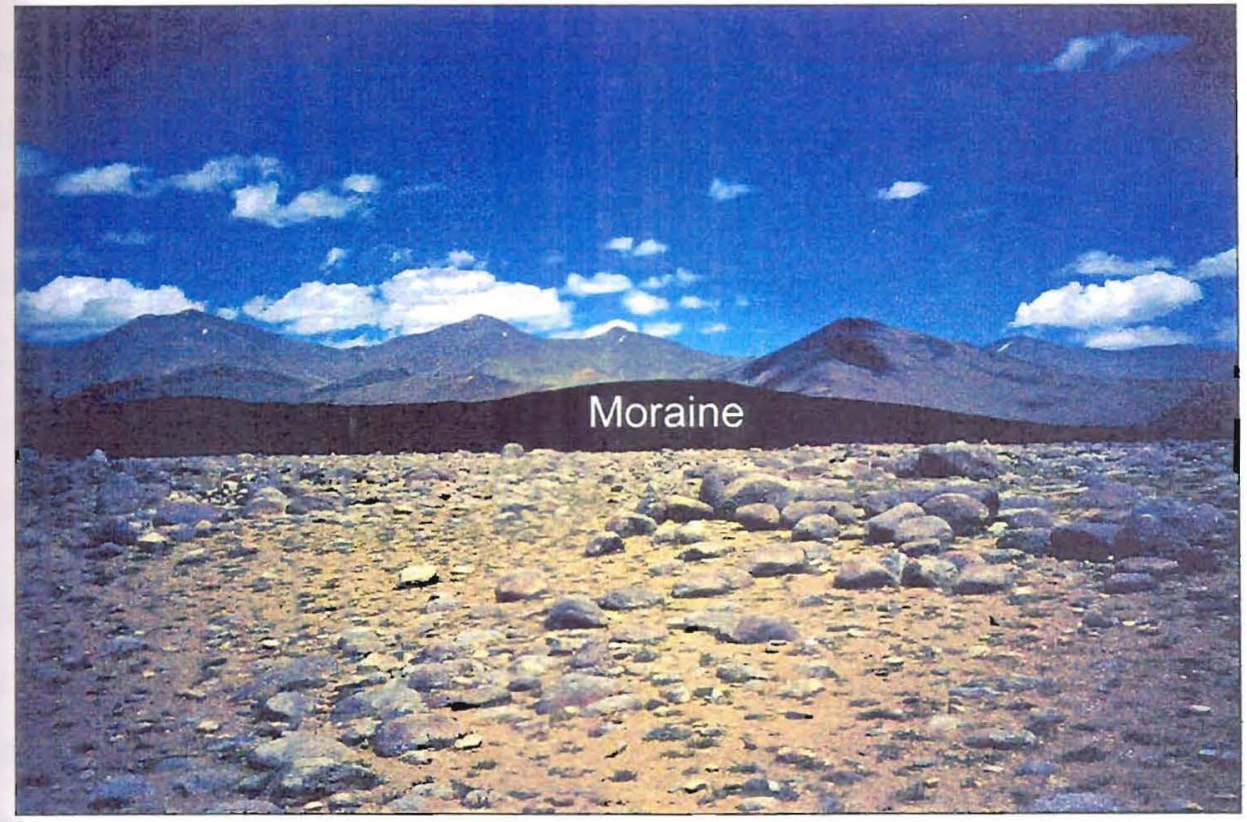

Figure 3.41 Moraine ridge in the upper Zara valley, looking north-east. The moraine ridge is in shadow and the upper of two alluvial fan surfaces can be seen in the foreground. $1.1309 \mathrm{~s}$ in Fig. 3.38, looking north-east.

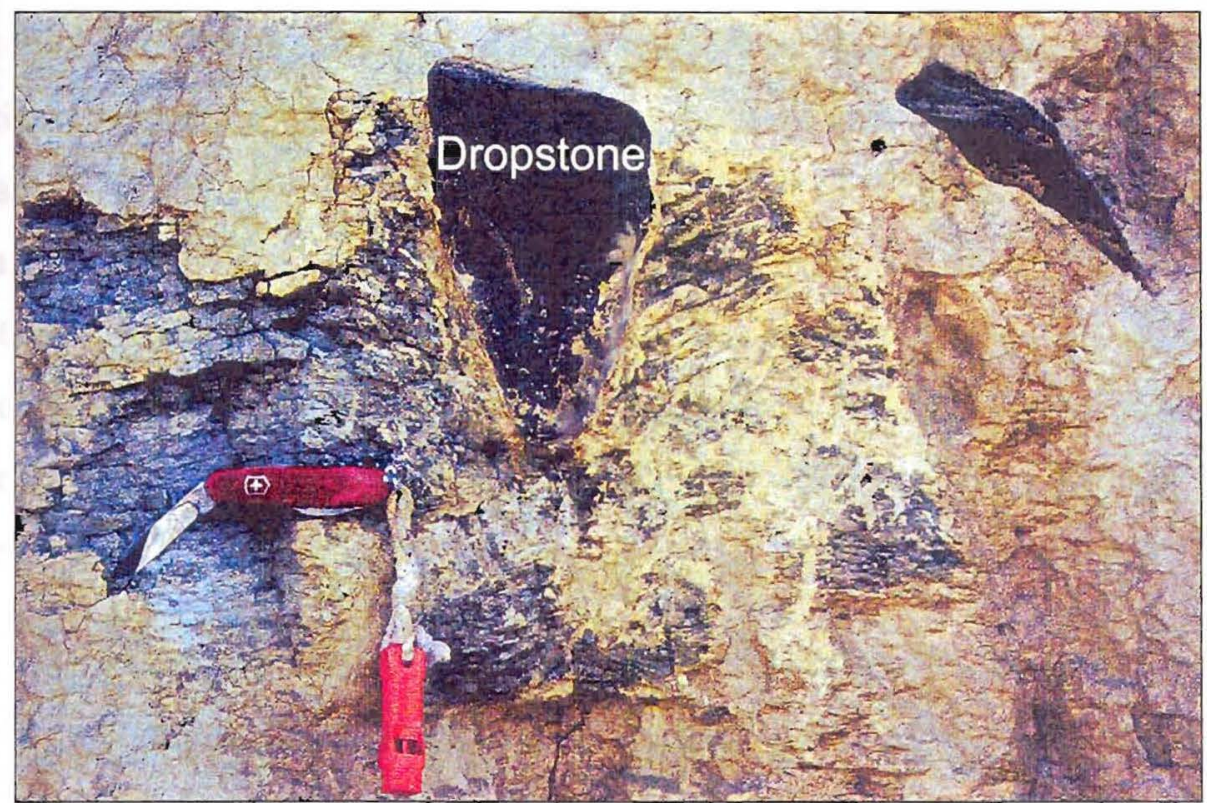

Figure 3.42 A dropstone in ice dammed lake sediments from the Zara-Debring confluence. Note the orientation of the clast with its long axis vertical and the deformation of the sediments. Penknife for scale. 113098 in Fig. 3.38. 
moraine has a more subdued topography due to ice having overridden it as the former glacier flowed round the $90^{\circ}$ bend. The older of the two alluvial fan surfaces shown in Figure 3.40 may represent sedimentation during deglaciation and/or paraglacial adjustment. West of the moraines, laminated lake sediments with dropstones (Fig. 3.42) abut the moraine, indicating that the ice blocked the Debring and Mare Plain systems to form an ice-dammed lake. As these silts lie on the Mare Plain sediments, the glaciation of the Zara valley must post-date capture of the Mare Plain system.

In the alluvial fan dominated Debring valley there is little evidence for glaciation with only the broad valley shape to suggest glacial modification. No erratics were found although foreign rocks have been imported as road markers. The meta-sedimentary bedrock has a high mica content and is susceptible to frost weathering and consequently is not conducive to the preservation of glacial erosional evidence. The resultant detritus also exhibits a high degree of frost susceptibility with many tabular clasts turned on their edges.

The 5376m a.s.1. Tanglang La (107110) lies between snow clad peaks, with one small glacier observed on the north-west side, although this was only viewed from a distance. To the north in a deep parabolic valley (105114) granite erratics from the Nimaling Massif are again found. A large bedrock-cored medial moraine ridge of $>100 \mathrm{~m}$ height extends down-valley from a spur between this and the Kyam Lungpa valley (104122). Clasts on this ridge, which are $90 \%$ granite and $10 \%$ limestone, have an average diameter of $200 \mathrm{~mm}$ (maximum $2 \mathrm{~m}$ ), and exhibit a well developed desert varnish.

A similar moraine ridge extends from the spur between the Kyammar Lungpa and Upper Gya valleys (107123) forming a narrow ridge, which becomes three wedge shaped terraces towards its apex. Related terraces cut into a large fan, which covers much of the main valley around 107124. The fan terraces are made of granite boulders of $\sim 0.5 \mathrm{~m}$ to a maximum of $\sim 1 \mathrm{~m}$ diameter, and are clast supported and often have stone pavement surfaces (Fig. 3.43a). Sections near the Kyammar Lungpa 


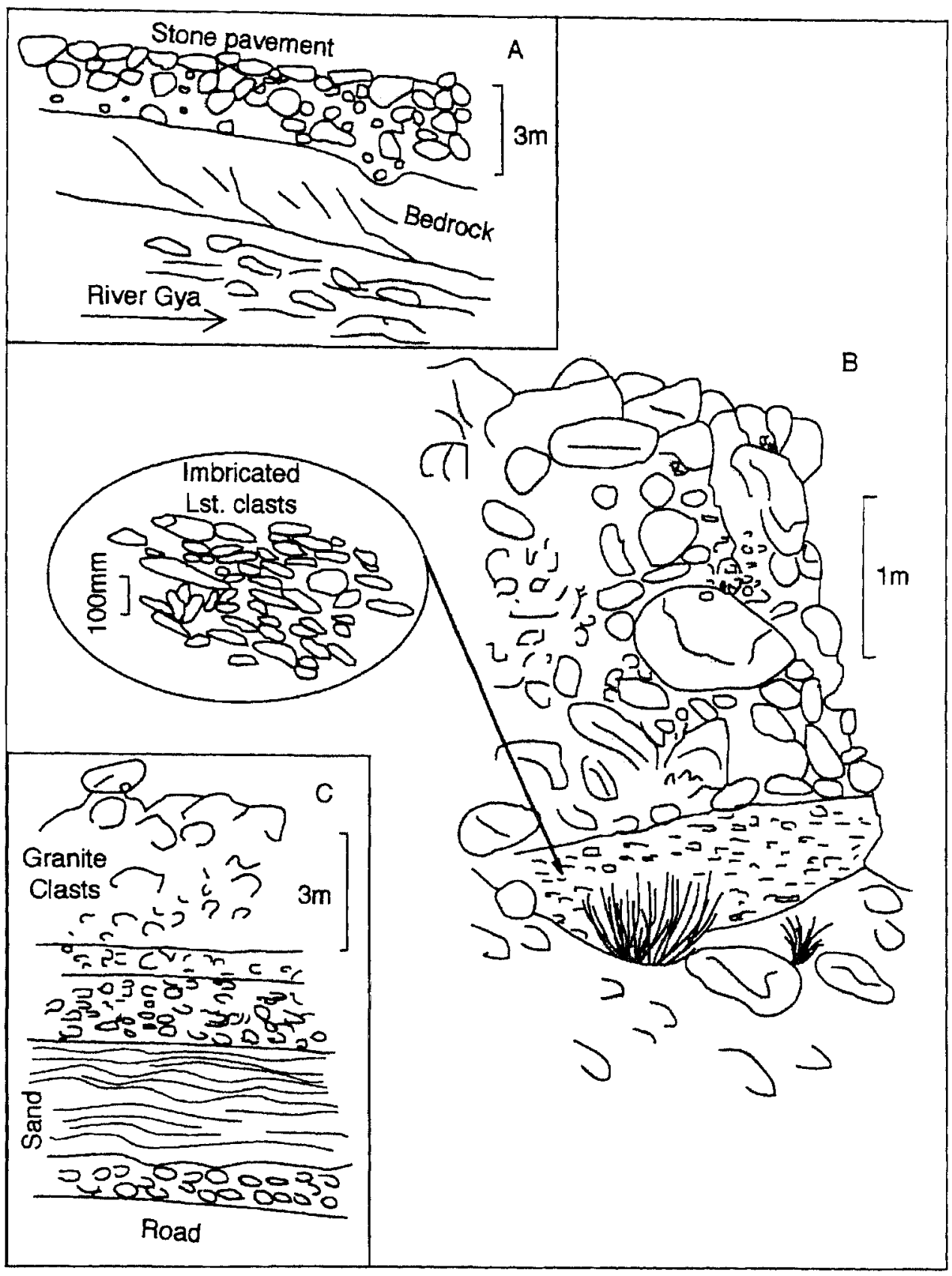

Figure 3.43 Sections from alluvial fans in the Gya valley. (a) showing the stone pavement surface of some terraces, (b) fan material overlying locally derived fluvial sediments, and (c) a complex sequence within a fan terrace. 107123 in Fig. 3.38. 


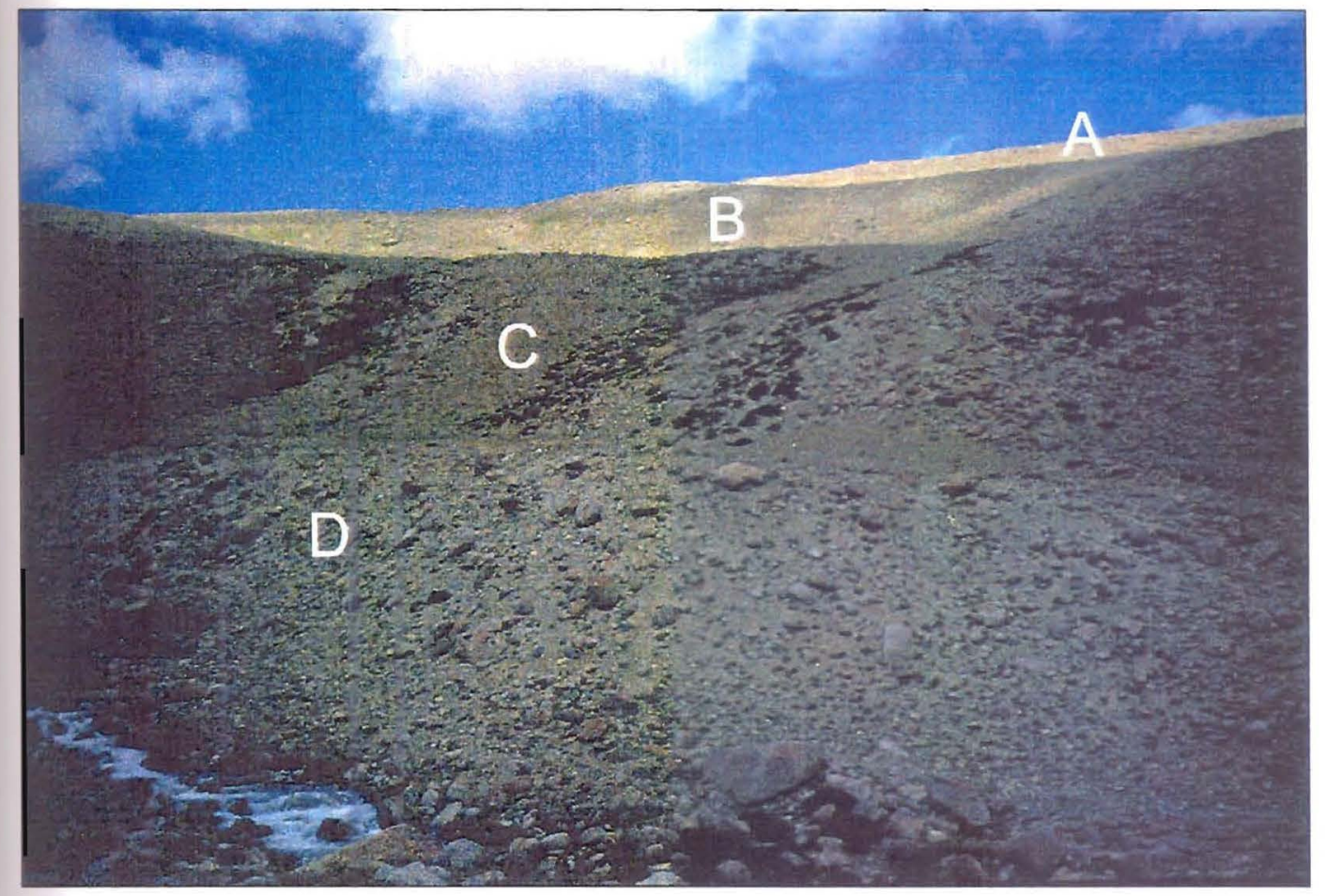

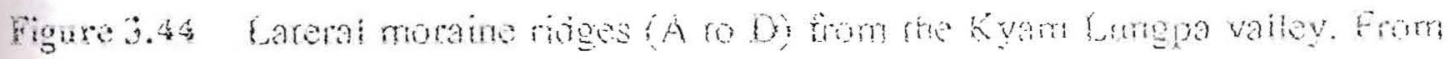

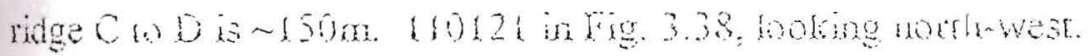

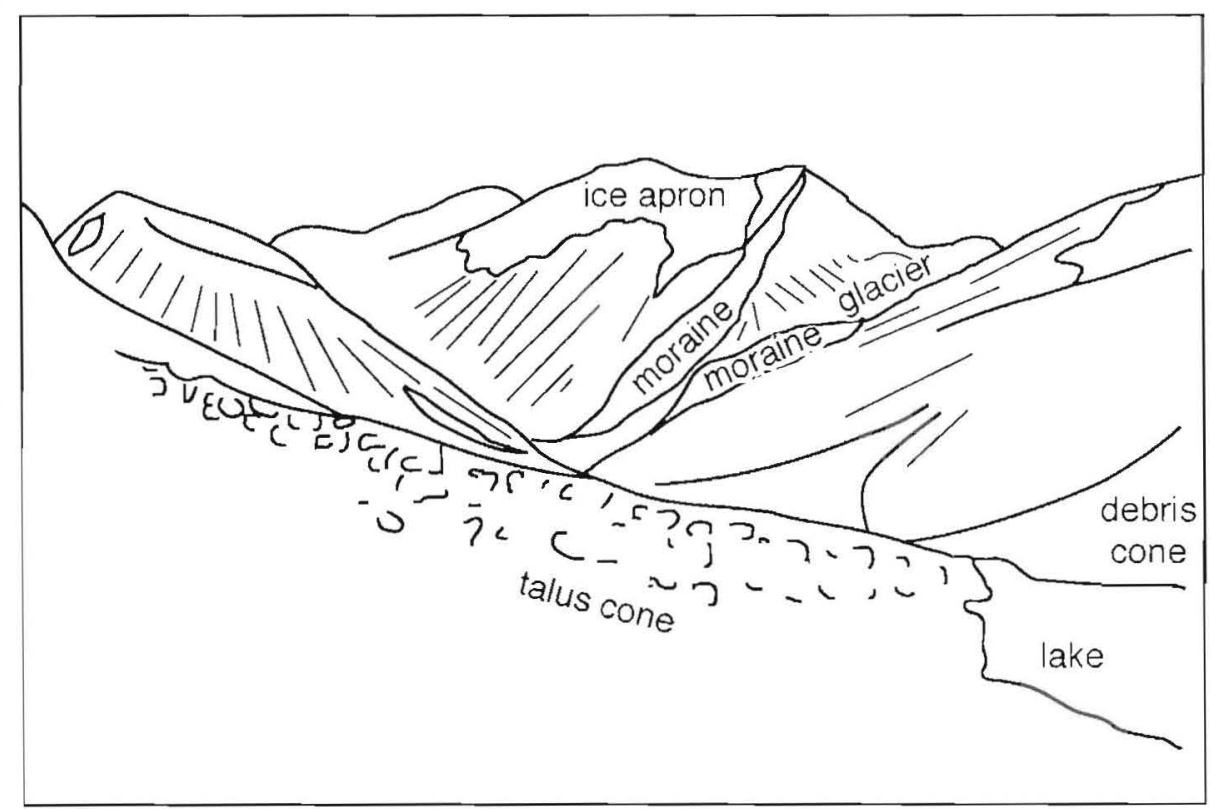

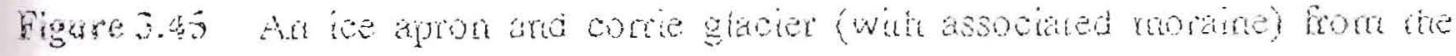

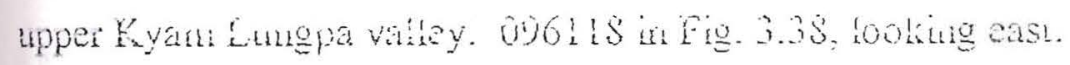


confluence show the granite clasts, which are from the Nimaling Massif to the west, overlying locally derived fluvial sediments, which are predominantly strongly imbricated limestone blades of $\sim 100 \mathrm{~mm}$ length forming a compact layer of $>1 \mathrm{~m}$ thickness (Fig. 3.43b), however, the sequence in other sections is more complex (Fig. $3.43 \mathrm{c})$.

Moraines composed entirely of granite clasts, some of which have well defined tafoni, extend up the Kyam Lungpa (100121) towards the Nimaling massif source area. Several lateral ridges can be identified (Fig. 3.44), but it is unclear whether these represent distinct ice limits or recessional stages of a major advance. Due to the effects of altitude and constraints of time, only brief investigation of the upper Kyam Lungpa (094117) was made. A small lake is dammed by debris cones, which are one of the dominant landforms in this high valley area. An ice apron and small corrie glacier with an associated moraine ridge were viewed from a distance (Fig. 3.45). Unfortunately both GPS and altimeter were not functioning, however, the moraine is estimated as being $>5200 \mathrm{~m}$ a.s. 1 .

A drift limit of light coloured granite boulders against the dark schist bedrock can be seen extending across the northern valley side in Figure 3.46a (104124), indicating that some of the spurs, although surrounded, remained as nunataks above the ice during the maximum ice extent. To the north (103127), a large alluvial fan has built into the main valley and is of predominantly imbricated, very angular to angular, schist blades of $\sim 100 \mathrm{~mm}$ across, with occasional granite boulders of up to $1 \mathrm{~m}$ diameter. Granite clasts are common on the slopes above the fan and can be traced up slope to a drift limit that descends to the north-west (Fig. 3.46b).

At the village of Gya (103128) a 3-4m thick alluvial fan deposit of mostly granite clasts with a surface of $5-10^{\circ}$ lies over $\sim 40 \mathrm{~m}$ of horizontally bedded lacustrine silts (Fig. 3.47). These silts have frequent dropstones forming a rainout diamict such that a suitable 'clean' sample of sand/silt away from larger clasts could not be obtained for OSL dating. There is evidence for ice having entered the Gya valley from western 

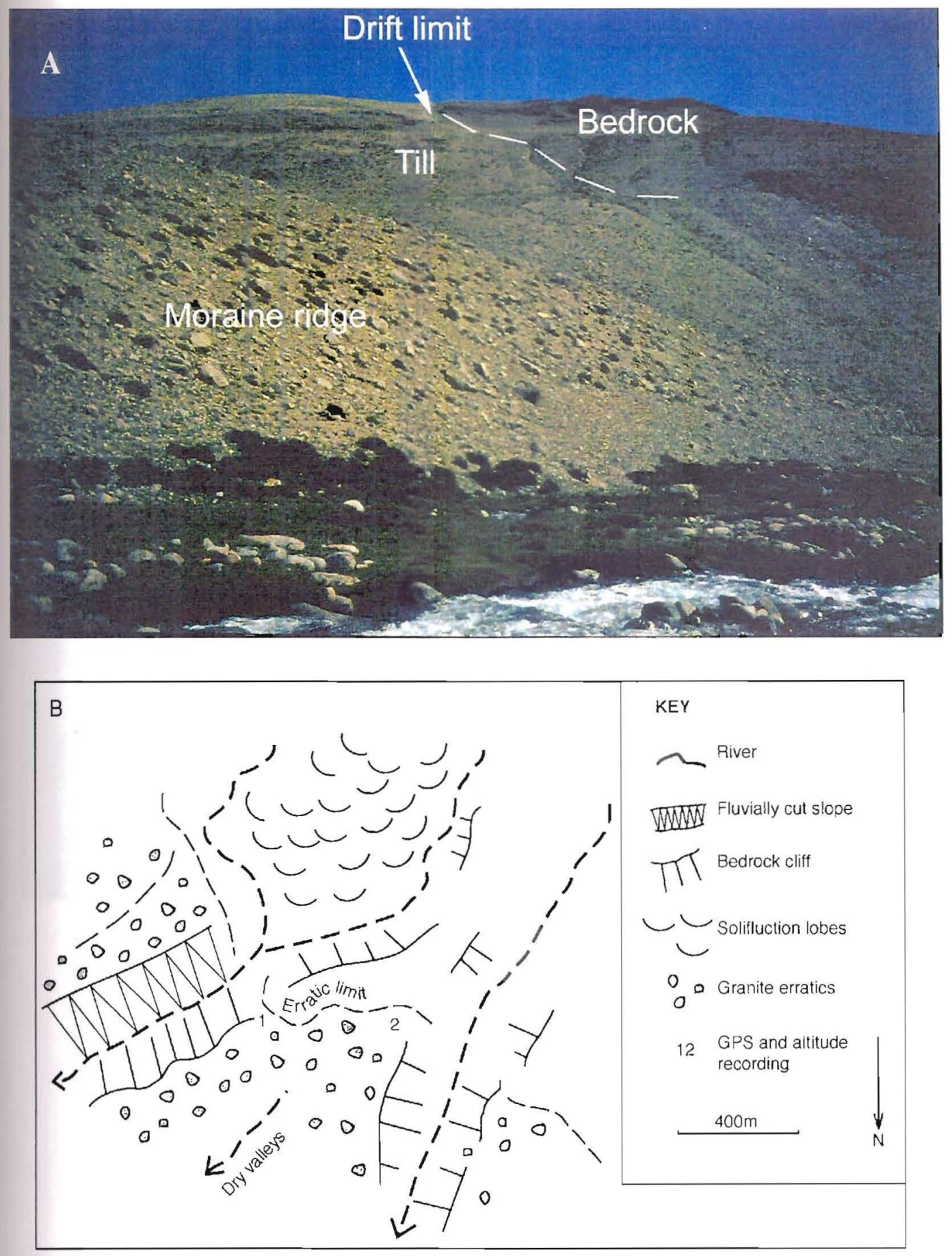

Figure 3.46 Former ice limits fjom the Gya valley. (a) A drift limit of granite boulders on a western spur leading into the Gya valley. 104122 in Fig. 3.38, looking north-noth-east. (b) Geomorphological sketch map showing a limit of granite erratics in the Gya valley. 103125 in Fig. 3.38. 
Chapter 3, Field Evidence for Glaciation

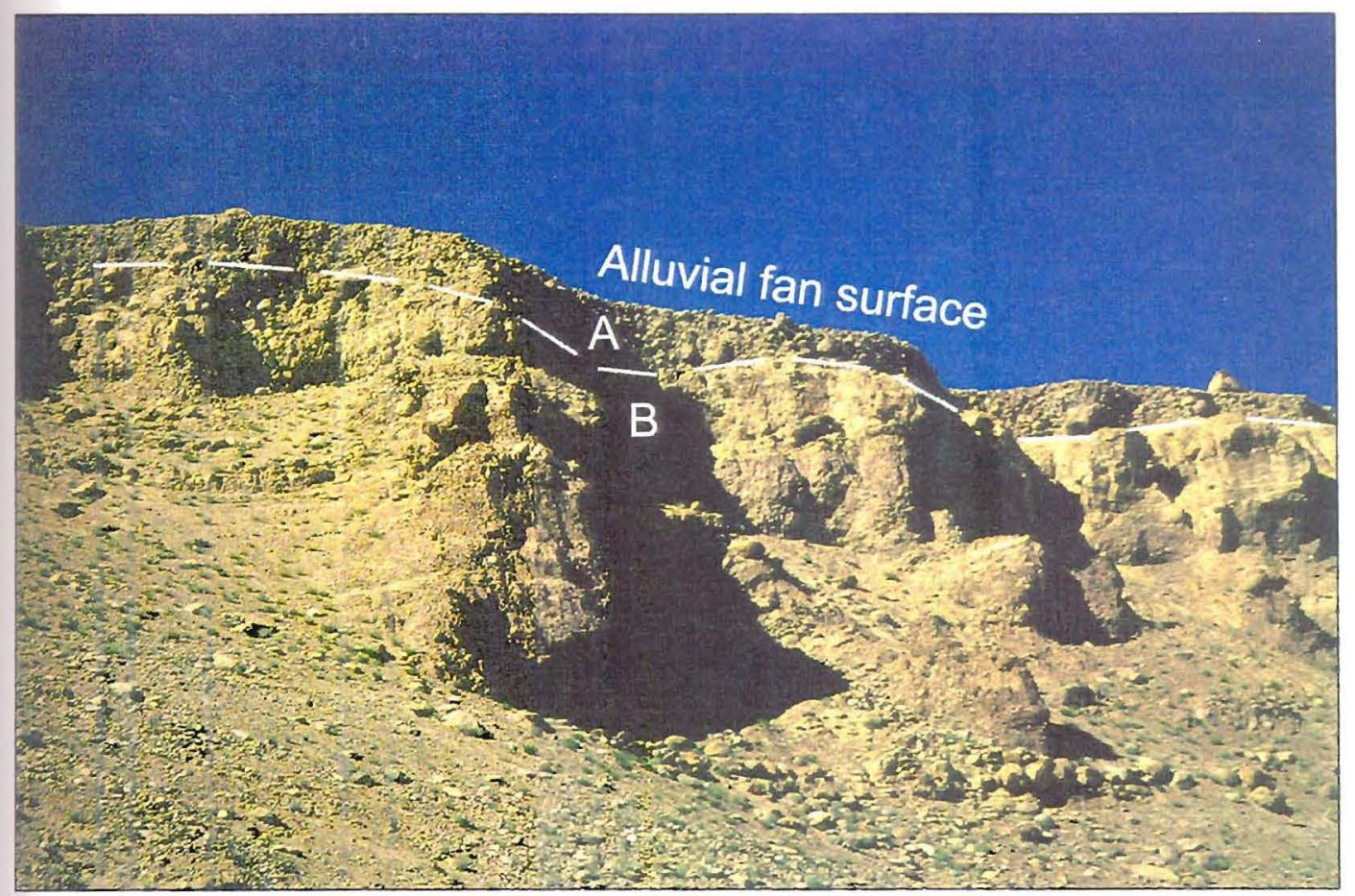

Figure 3.47 Alluvial fan sediments (A) overlying lake sediments with abundant dropstones (rainout diamict) (B). 102128 in Fig. 3.38, looking north. 
tributaries around the village of Rong (103136), which would have provided an ice dam allowing the deposition of these lacustrine sediments. It is not clear from the surviving moraines, whether ice in the Gya valley was confluent with the tributary ice, damming an ice marginal lake, or if the lake existed between ice in the upper valley and a tributary ice dam.

Beyond the village of Rong (103136) the valley narrows from its broad glacial form to a narrow bedrock gorge. This possibly represents the maximum extent of glaciation, although it is suggested (Osmaston, in prep.) that a thin tongue of ice may have extended further (to Miru, 107141), although this ice may have come form a side valley.

\subsection{Yar La (Khurna) to Kurma to Lungtung}

(Fig. 3.48)

The central portion of the area of investigation is described from the Yar La at the head of the Khurna valley, following the valley for $30 \mathrm{~km}$ down-river, before evidence from the tributary valleys of the Kurma and Lungtung to the north is outlined (Fig. 3.48). These valleys form the western side of the crystalline Nimaling Massif, which reaches an altitude of $\sim 6400 \mathrm{~m}$.

The south-east side and summit of the Yar La (091101) are dominated by fluvial and periglacial processes with no direct evidence for glaciation. The north-west side, at the head of the Khurna valley, has a long curved scarp of $5 \mathrm{~m}$ backing a regolith of rock debris with longitudinal flow lines on the surface (Fig. 3.49). The lower portion of the feature has been eroded by ephemeral streams and a $15 \mathrm{~m}$ high ridge with the form of a recessional moraine (A - Fig. 3.49) is in fact a remnant of a fluvial deposit, the conglomerate being clast supported, moderately sorted and well bedded. The feature is interpreted as a cryoplanation surface on the basis of its morphology ( $c f$. Nelson, 1989; Czudak, 1995). A drift limit marks the north-eastern valley side (Fig. 3.49), indicating that ice once occupied this valley head. 


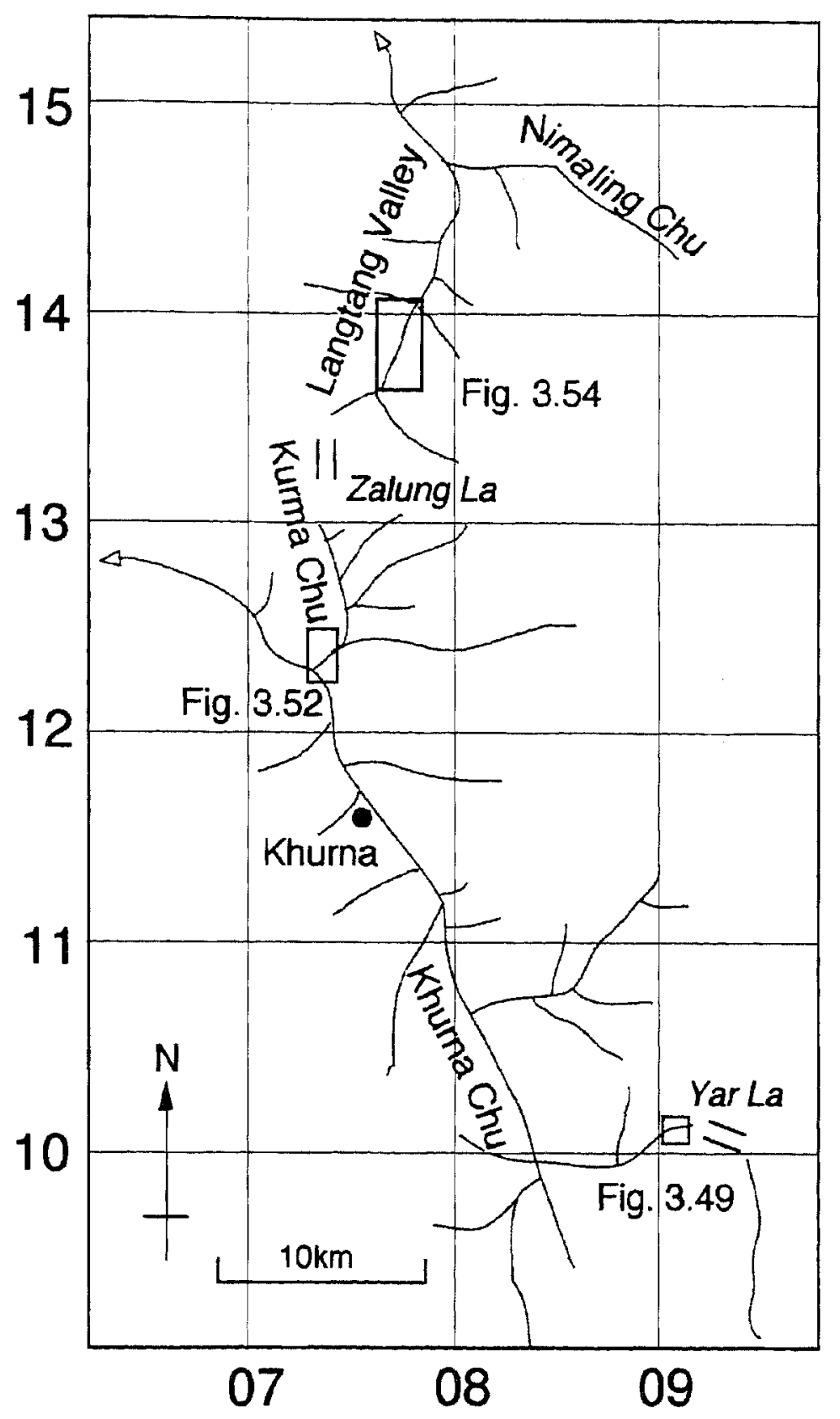

Figure 3.48 Location map for Section 3.7, showing the Khurna, Kurma and Lungtung valleys. 


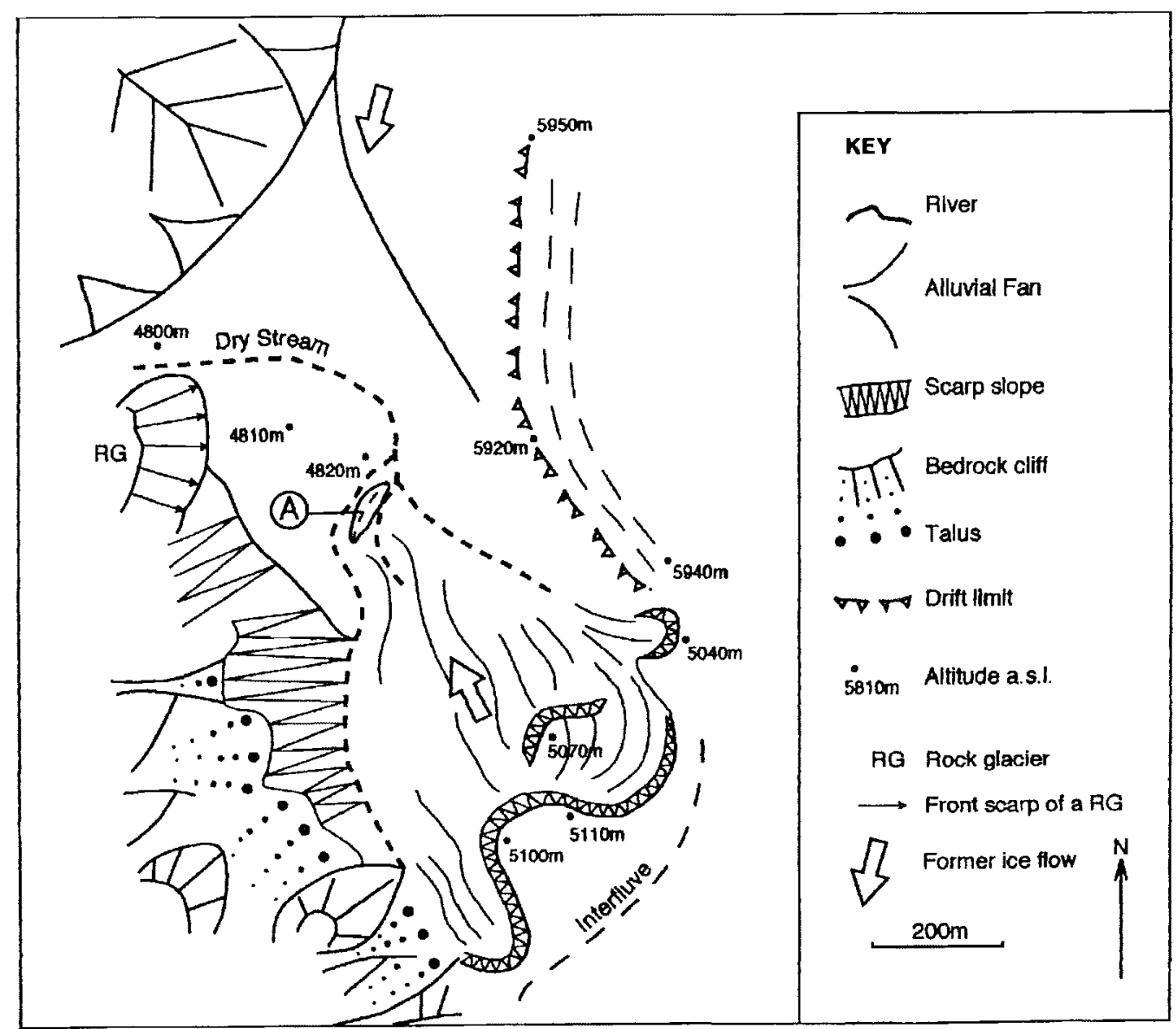

Figure 3.49 Geomorphological map of the upper Khurna valley, showing a cryoplanation surface and drift limit. See Fig. 3.48 for location. 


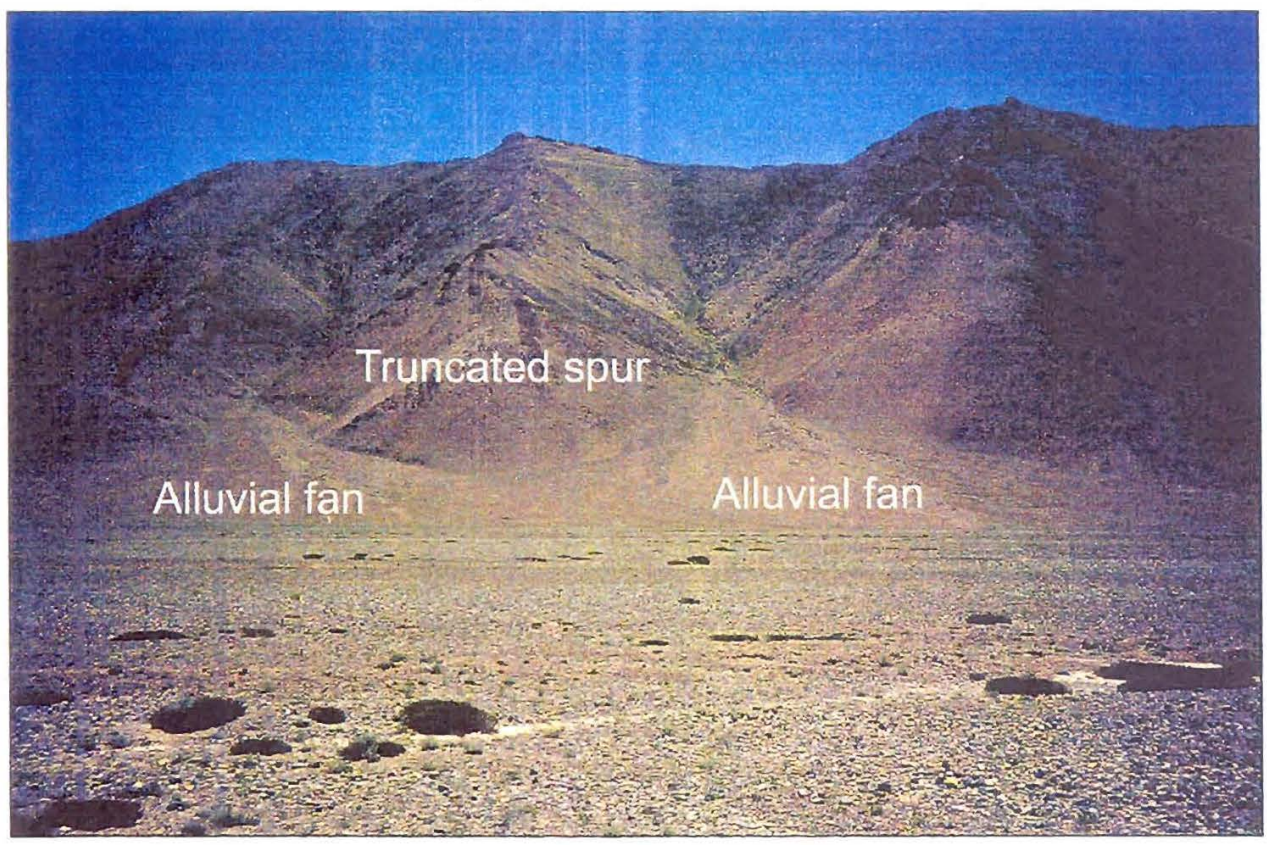

Figure 3.39 Trumeated spurs and alluvial tans from the brond, dry upper Khuma valley. 080110 in Fig. 3.48, looking south-west.

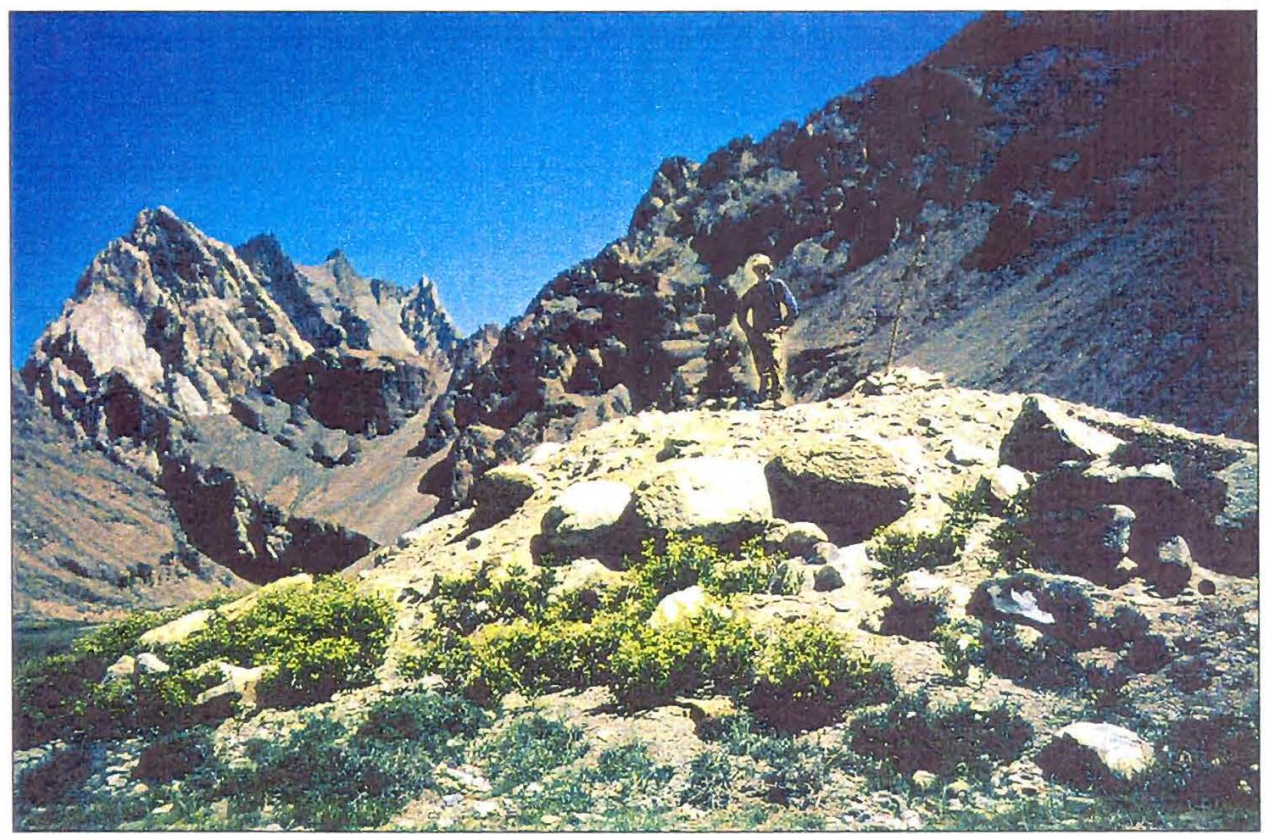

Figne 3.51 An extmed movane mound in the Khura valtey. Enatics are nigh grade metamophics and graite fom the Nmalng Massin (Tgure or sode). 07418 in Fig. 3.48, bokigg nontheast. 
The broad flat-floored Khurna valley has only ephemeral streams in its upper section with coalescing alluvial fans cut into terraces issuing from gullies separated by truncated spurs (Fig. 3.50). To the west of Khurna Village (076116), where the valley starts to narrow and surface water flows (observed in mid July), two tributaries supplied ice to the main valley - eroding the ridge between them to an arête. Ice from a third tributary (from the east) has deposited granite erratics from the Nimaling Massif and formed a moraine mound (074118; Fig. 3.51), providing direct evidence for former glacial ice. The moraine, which comprises $60 \%$ granite, $40 \%$ limestone, minor vein quartz and gabbro clasts is $15 \mathrm{~m}$ in diameter and is exposed to $5 \mathrm{~m}$ above the current flood plain (Fig. 3.51). It is likely that much of the original till has been eroded - liberating the numerous granite erratics of $>1 \mathrm{~m}$ diameter that litter the valley floor. The moraine has been buried by fluvial sediments and later exhumed, the river having been sufficiently powerful to erode the $100 \mathrm{~mm}$ diameter clasts of the alluvium back to a $10 \mathrm{~m}$ high terrace $100 \mathrm{~m}$ away, but having been unable to completely destroy the moraine with its clasts of $>1 \mathrm{~m}$ width. Granite erratics are also perched on icemoulded bedrock slopes where the valley narrows further to $<50 \mathrm{~m}$ width at $\sim 074120$. This is the lowest evidence for glaciation in the Khurna valley at $4280 \mathrm{~m}$ a.s.l. Downriver the valley becomes an impressive gorge with walls several hundred metres high and a floor often only a few tens of metres wide, and numerous rock fall deposits. The river erodes alternate rock walls forcing numerous crossings, eventually preventing further investigation (navigation only becomes possible in late September).

Where the Kurma valley enters the Khurna valley (073123), a $20 \mathrm{~m}$ high terrace composed of both granite and limestone clasts of $>1 \mathrm{~m}$ diameter stands on either side of the tributary (Fig. 3.52). This landform, interpreted as a moraine, is structureless on the proximal side becoming weakly stratified on the distal side where it merges with well bedded alluvium, and is thought to mark the maximum glacial advance in this valley. 


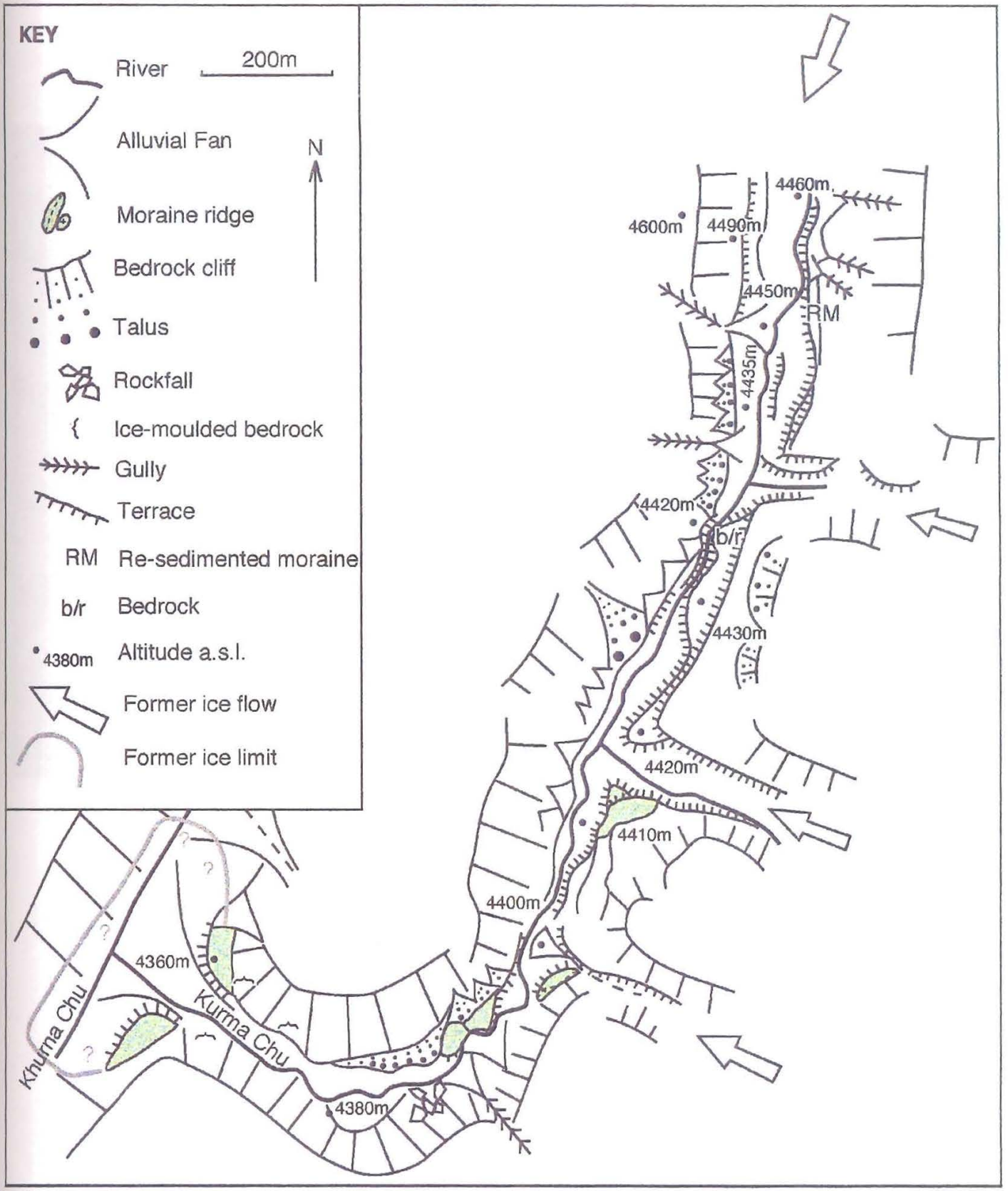

Figure 3.52 Geomorphological map of the lower Kurma valley. See Fig. 3.48 for location. 
Chapter 3, Fiend Evidence is Giaciation

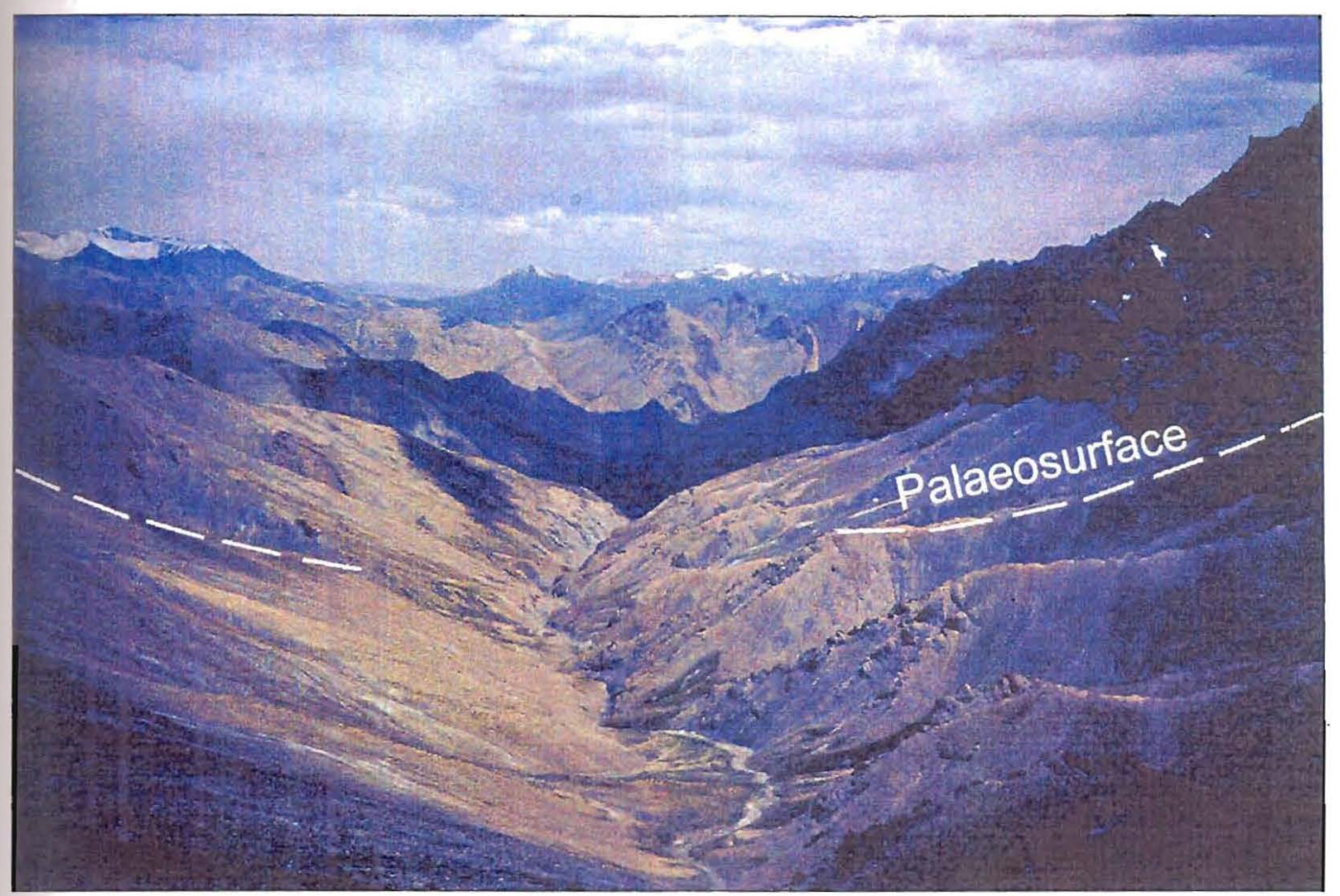

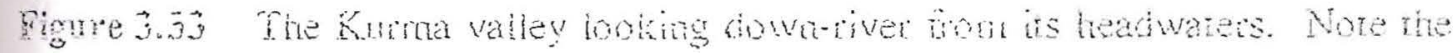
palacosmace bench un the spurs or the valey, which can be seen on botn hanks. 074121 in Fin. 3.48 , lekking sowit. 
The Kurma valley widens up valley from its narrow rock walled mouth of $\sim 60 \mathrm{~m}$ width to a broad glacial form. Granite erratics of up to $4 \mathrm{~m}$ diameter are common near the former ice limit, becoming less so up-valley and till which appears to have been re-sedimented as debris flow deposits mantles some lower slopes. The present river occupies a flood plain, with a middle gorge section, both of which are cut $\sim 5 \mathrm{~m}$ into the former glacial surface (Fig. 3.52). A bench cut into the spurs of the valley (Fig. 3.53) represents an older former valley surface, although on this no direct evidence for glaciation was found. There is little evidence for glaciation in the upper part of the valley, where fluvial and periglacial processes dominate. The importance of aspect on snow/ice distribution is highlighted at the Zalung Kurpo La (074133) where snow is absent from the Kurma side, but exists on the northwest facing Lungtung side (observed in late July).

The distribution of moraine ridges and erratics in the Lungtung valley is shown in Figure 3.54. These moraine ridges have been heavily eroded with many reworked as debris cones or buried by sedimentation from neighbouring slopes. Three former ice margins are distinguished, one which was fed by Lungtung ice and two which emanated from side valleys. Down valley from the ice limits alluvial fans are large and mature (B in Fig. 3.54), fluvially eroded back to $40 \mathrm{~m}$ cliffs in places, contrasting with the smaller immature forms within the limit which are trimmed to form terraces of $<10 \mathrm{~m}$ ( $\mathrm{A}$ in Fig. 3.54. The Lungtung valley continues as a broad glacial trough to its confluence with the Nimaling valley (080147), where the two become the Markha valley.

\subsection{Markha}

(Fig. 3.55)

Evidence from the central valley of the Markha is described from the head of the Nimaling Chu in the south-east to the village of Skio in the north-west (Fig. 3.55). 


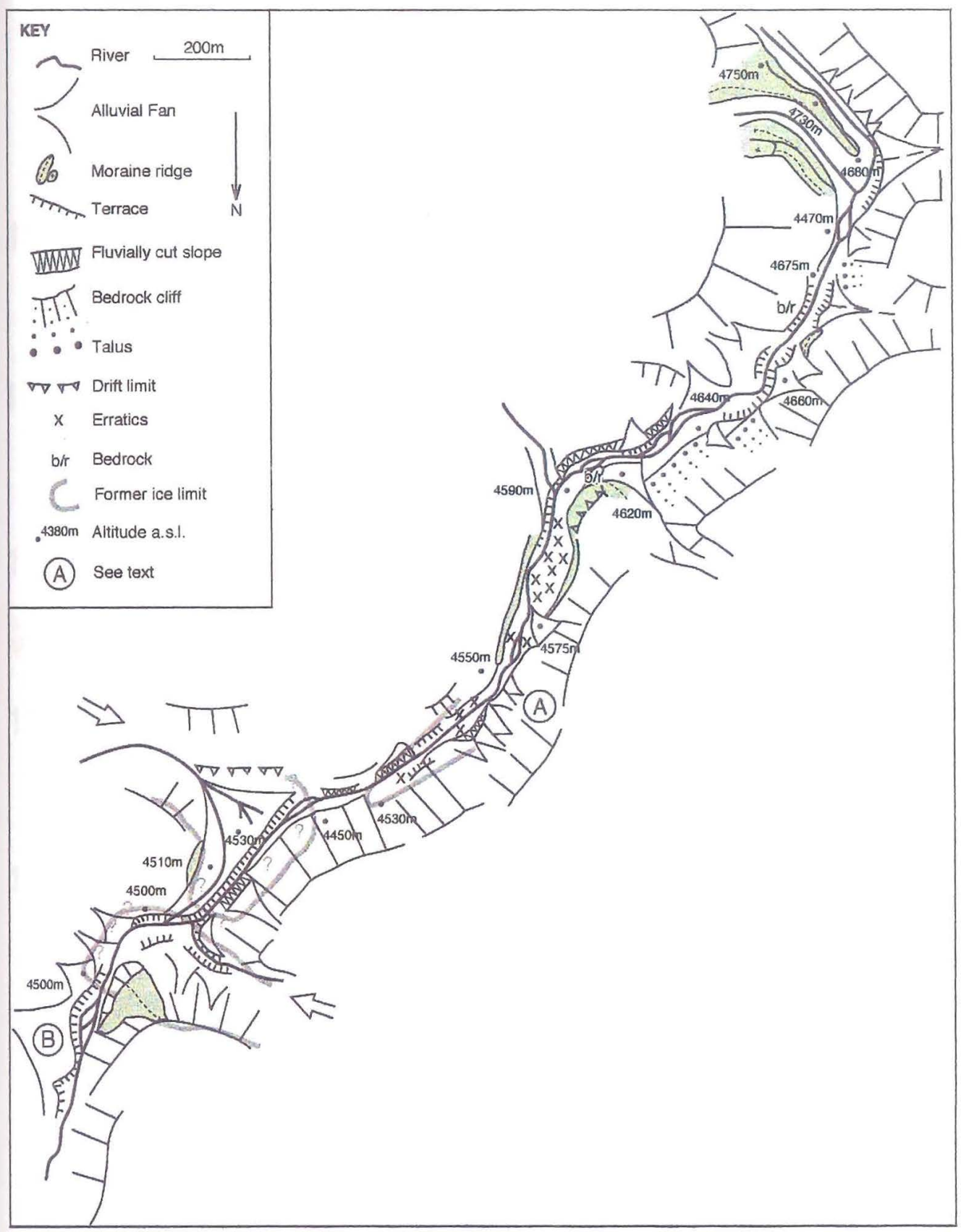

Figure 3.54 Geomorphological map of the Lungtung valley, showing moraine ridges and erratics representing the positions of three former glaciers. Note the size difference between debris cones $\mathrm{A}$ and $\mathrm{B}$ from within and outside the proposed limit. See Fig. 3.48 for location. 


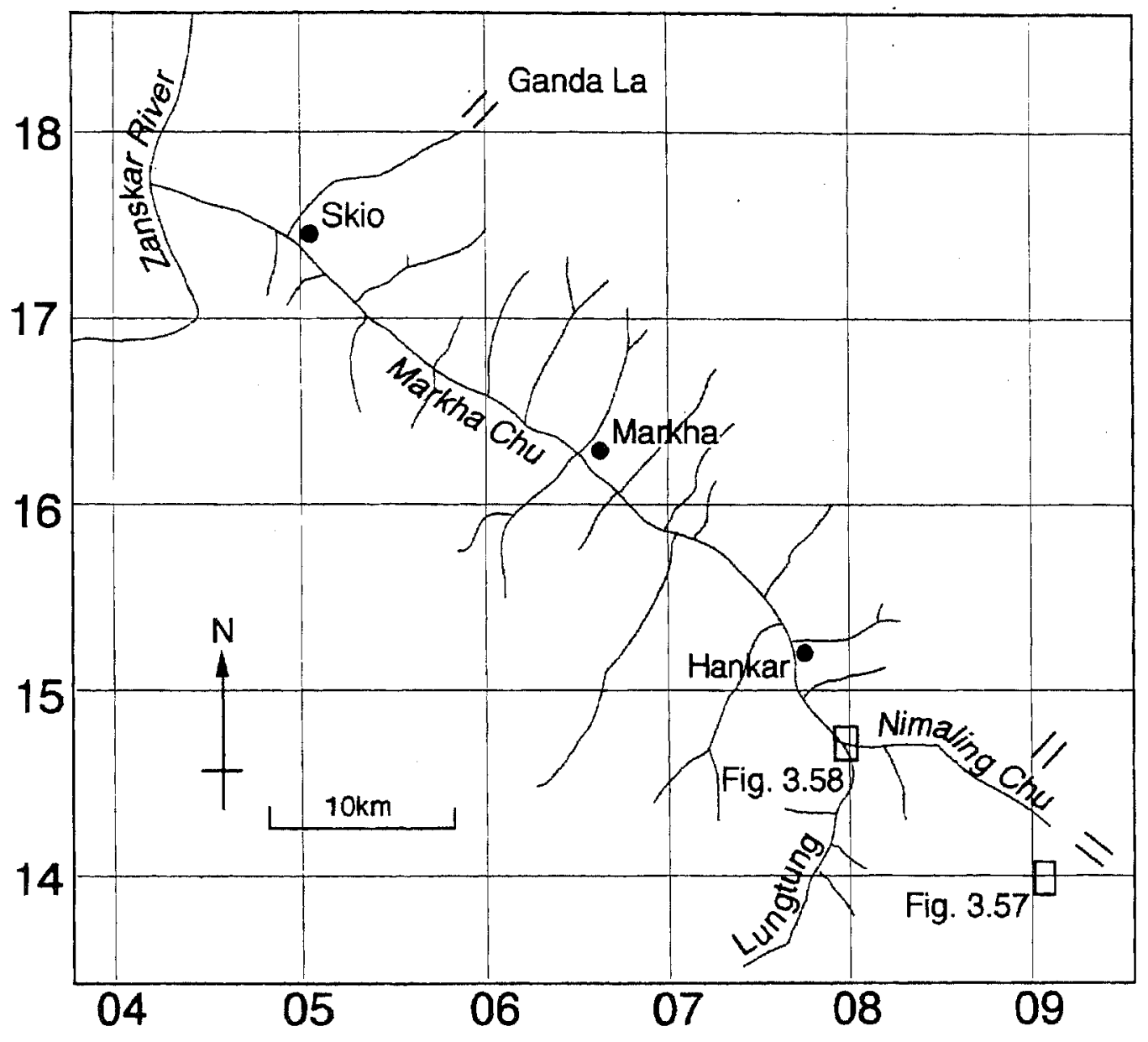

Figure 3.55 Location map for Section 3.8, showing the Markha valley. 

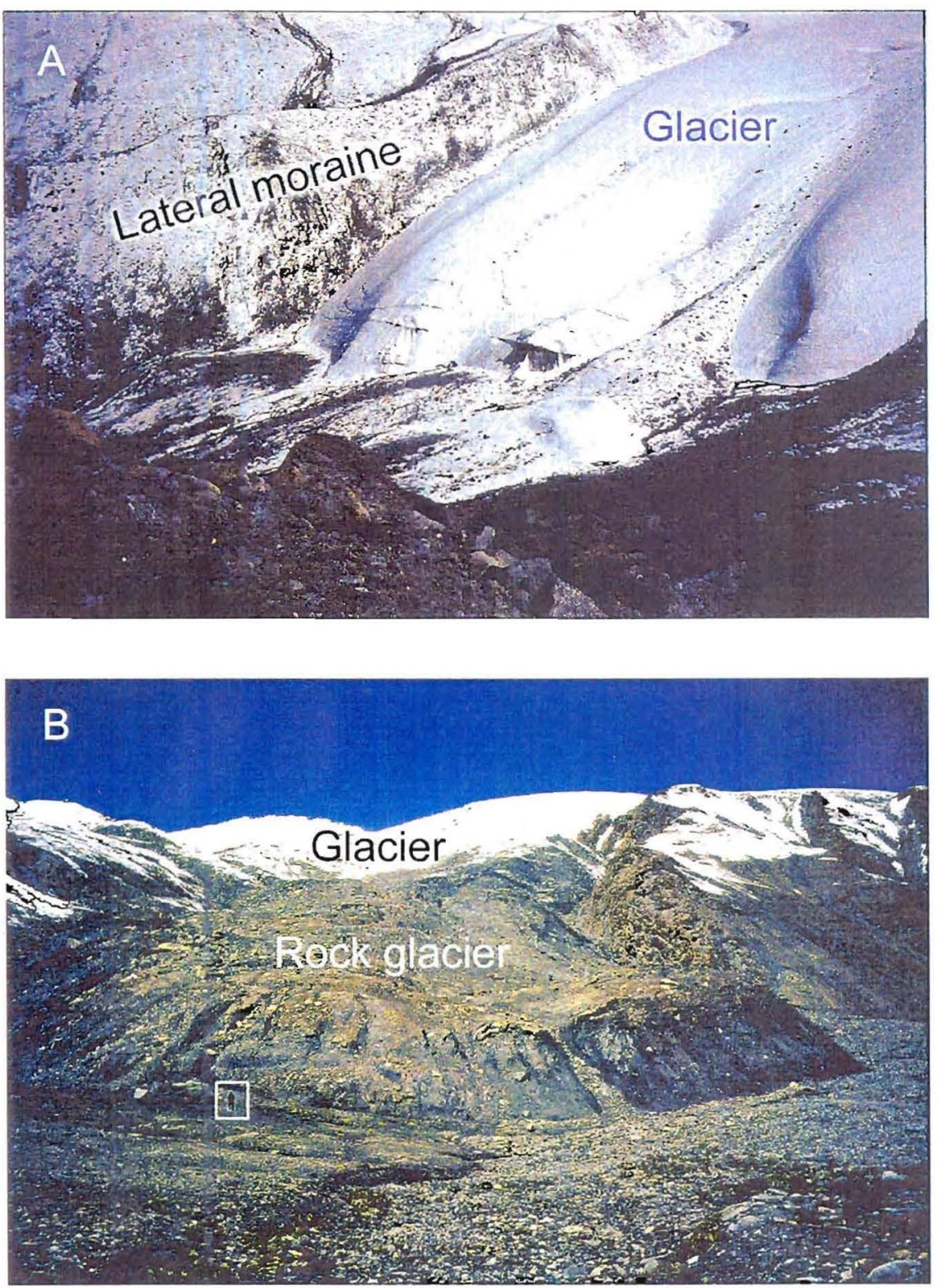

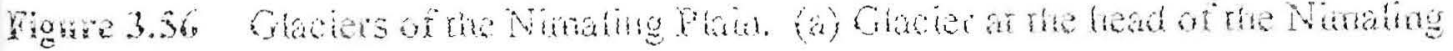

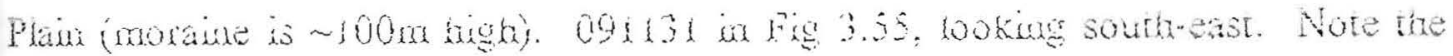

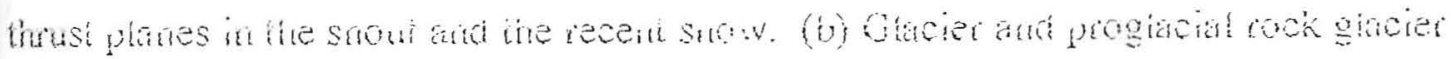

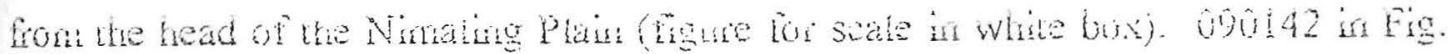
3.55 , hinitige west. 


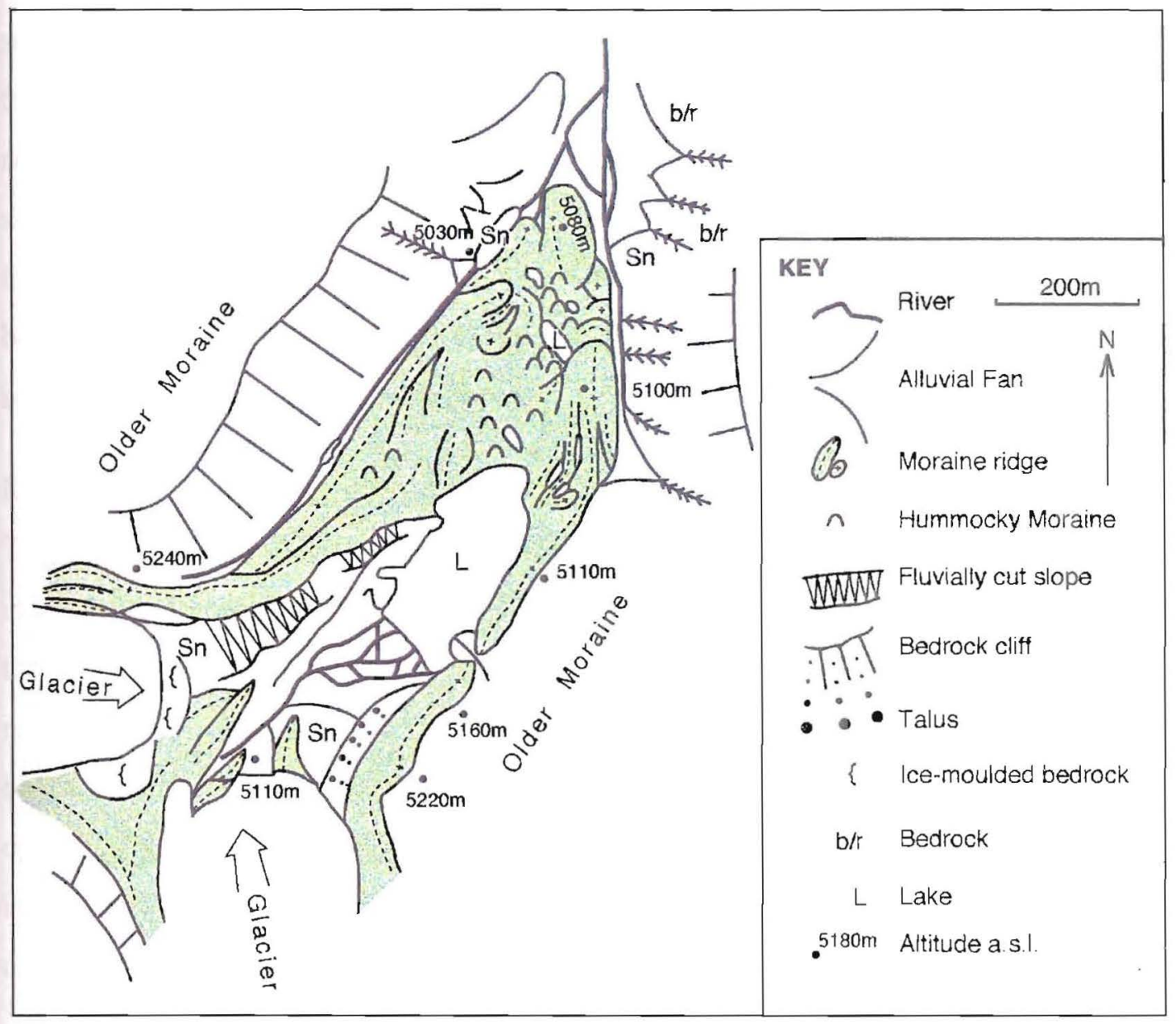

Figure 3.57 Geomorphological map of the upper Nimaling Plain, with a moraine complex, kettle holes and a moraine dammed lake. See Fig. 3.55 for location. 
At the head of the Markha valley (the Nimaling Plain) five small glaciers, with snouts between $5050 \mathrm{~m}$ and $5220 \mathrm{~m}$ a.s.l., can be observed on the north and east facing slopes of the Nimaling Massif (085144) (Fig. 3.56). At the time of observation (late August) the ice-bodies and the surrounding slopes were covered with $\sim 200 \mathrm{~mm}$ of snow which had fallen four days previously, and which prevented surface ablation at the snout for the four days of observation and probably for several days more. In addition fresh scars were observed on high slopes, indicating accumulation of avalanche snow, highlighting the importance of the sporadic summer precipitation in the mass balance of present glacier systems. These glaciers may be intermediate between the summer accumulation type of Nepal (Ageta and Kadota, 1992) and those solely supplied by winter precipitation.

Recent well formed moraine ridges can be observed in front of the glacier snouts. The best example is the suite of lateral and recessional ridges, kettle holes and moraine dammed lakes that extend for $1 \mathrm{~km}$ beyond two small glaciers at the head of the valley (Fig. 3.57). The lateral ridges are $\sim 100 \mathrm{~m}$ high and almost exclusively of metasediments and granite, although the proportions vary considerably, and they may be ice-cored. No large sections were found, with the consequence that there was no opportunity for collection of an OSL dating sample, the small streams having had insufficient time and power to erode through the deposits. Several of these moraines are deforming as small proglacial rock glaciers (Fig. 3.56b).

The Nimaling Plain, which in fact has moderate undulating upper slopes with a central glacial trough, is mantled to $240 \mathrm{~m}$ a.r.l. by a till of mainly granite and high grade metamorphic clasts, with occasional striated limestone clasts. This blanket of till can be traced over the north-east watershed into the Gya system and down-valley in the Nimaling valley.

Where the Nimaling Plain meets the Lungtung valley the trough narrows, with till to $>100 \mathrm{~m}$ on each side. At this confluence a $20 \mathrm{~m}$ high moraine/terrace of $70 \%$ granite/high grade metamorphics, $25 \%$ limestone and $5 \%$ other clasts marks the 

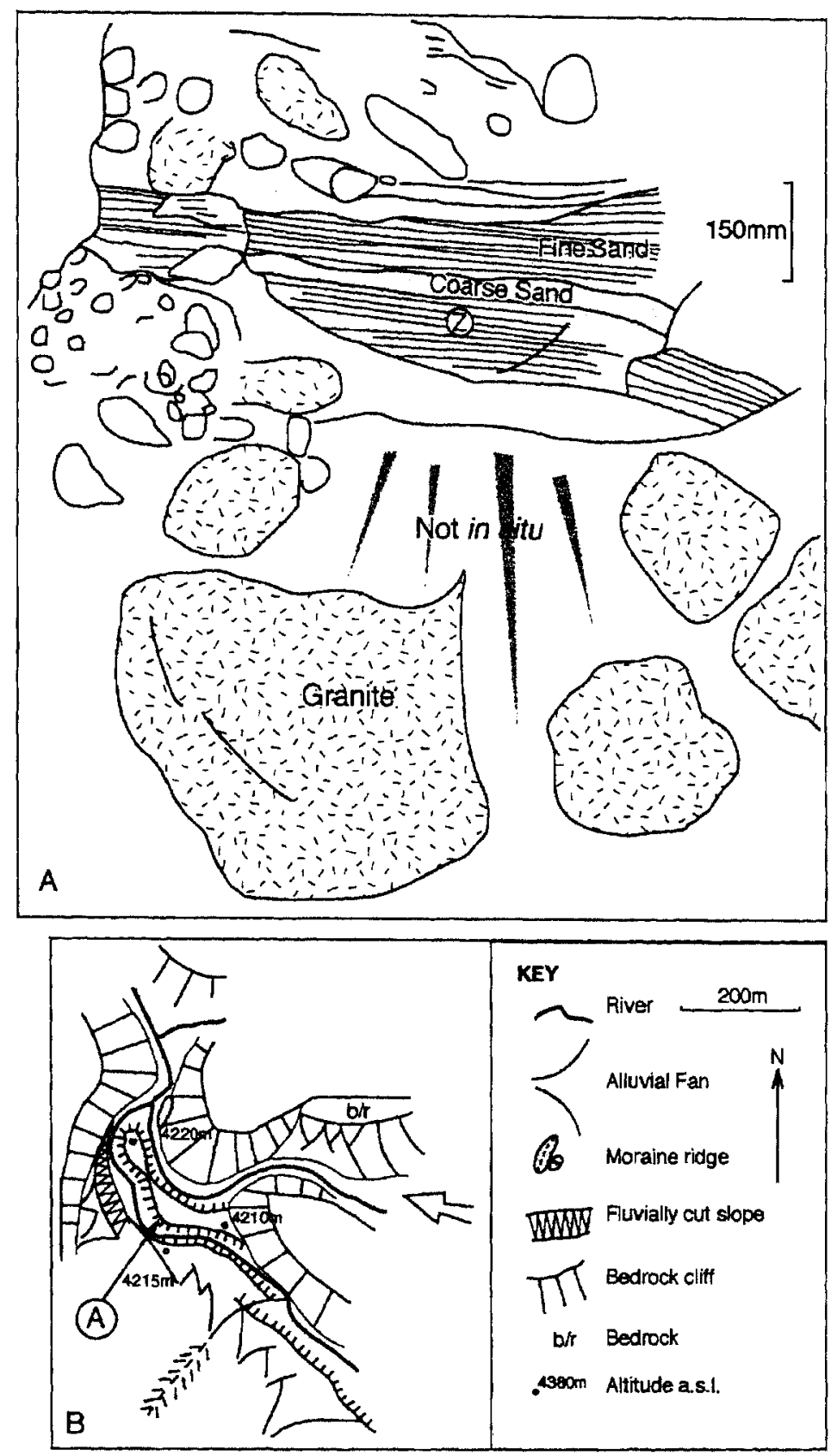

Figure 3.58 Sediments from the mouth of the Nimaling Plain. (A) Fluvioglacial sedimentation at the confluence of the Nimaling and Lungtung valleys. Geomorphological sketch map of the terrace, which has been trimmed back by on both sides to form a tongue, with the location of sketch (A). See Fig. 3.55 for location. 
former glacier terminus. The matrix supported deposit is poorly sorted with an average clast size of $\sim 200 \mathrm{~mm}$ and a maximum of $4 \mathrm{~m}$. No bedding was observed, other than a sand lens (Fig. 3.58) on the distal side, which was sampled for OSL dating (V065). The moraine/fluvioglacial deposit has been fluvially eroded to its present tongue form (Fig. 3.58), but would have been more expansive, perhaps forming a fan structure.

Moraine ridges high on the valley sides can be traced to the village of Hankar. Down-valley from Hankar (077153) the Markha continues as a broad trough with a floor of $\sim 500 \mathrm{~m}$, locally narrowed by a spur/pinnacle of bedrock. Valley-side deposits viewed distantly contained light coloured granite clasts, which contrast against the darker limestone bedrock. These deposits are interpreted as outwash from up-valley rather than till. In the middle and lower sections of the valley, well lithified alluvial sediments are locally $120 \mathrm{~m}$ thick where side valleys have supplied sediment, but are more typically of $40-50 \mathrm{~m}$ thickness. These well bedded clast supported deposits contain well rounded, well sorted clasts of up to $400 \mathrm{~mm}$ diameter and exhibit crossbedding and channel forms.

The trough begins to close, becoming $200 \mathrm{~m}-300 \mathrm{~m}$ wide at Skio village (050174), but never undergoes the dramatic narrowing in cross-section that the neighbouring Khurna exhibits at its limit of glaciation. The Markha does, however, strike parallel to the regional geology, following the Zanskar Backthrusts which are exposed on the northern valley flank (Fuchs, 1984; Searle et. al., 1992) and its form may largely be a function of structure rather than glacial erosion.

\subsection{Skio to Rumbak to Stok to Martselang}

(Fig. 3.59)

Evidence from the northem part of the field area is described in three tributary valleys of the Indus River, all of which flow north cutting the near vertically bedded Indus molasse (Fig. 3.59). 


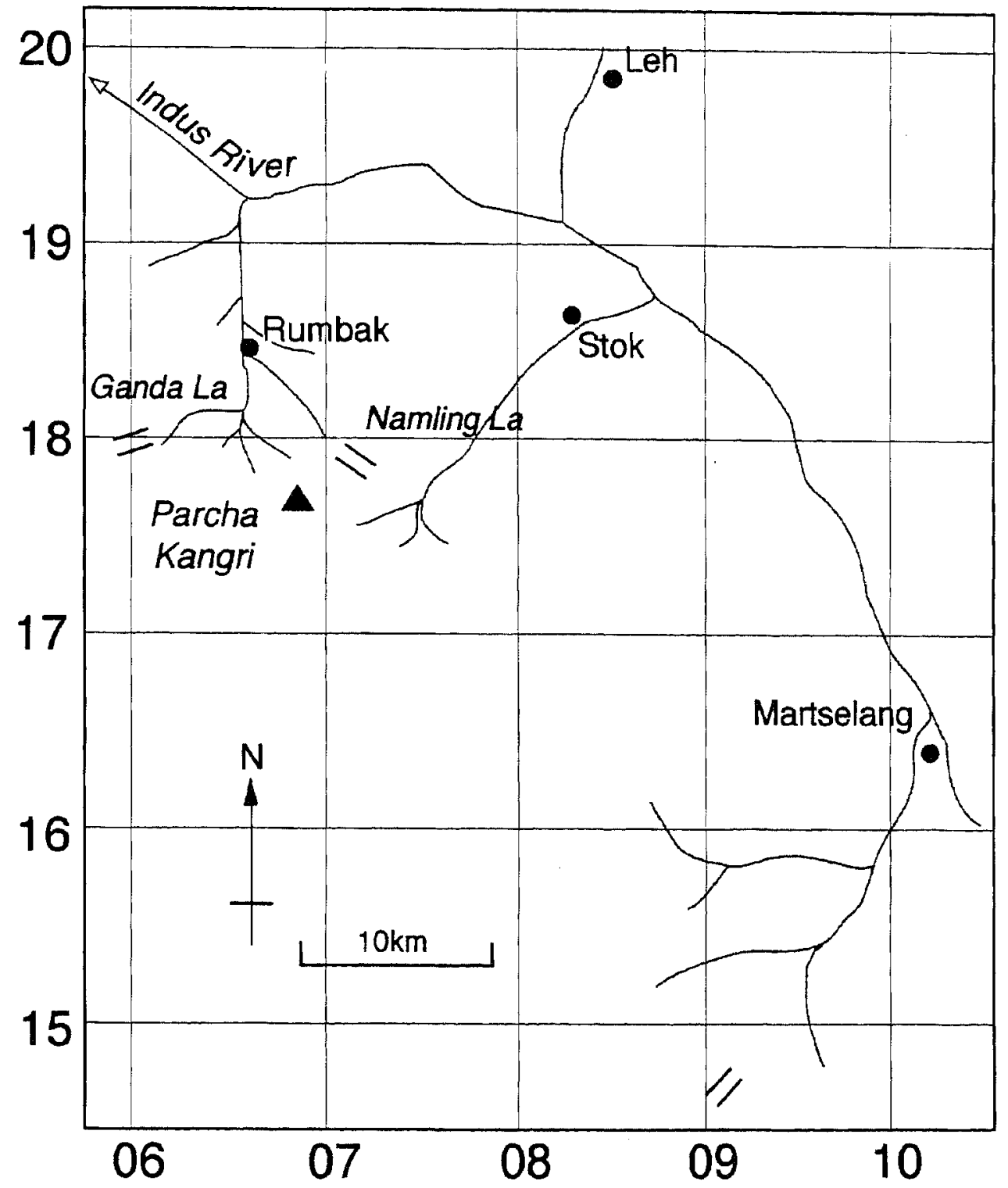

Figure 3.59 Location map for Section 3.9, showing the three north flowing tributaries of the Indus River visited in this study. 
No direct evidence for glaciation in the valley from Skio village (050174) to the Ganda La (060180) was observed. Although the upper and lower sections have a typically glacial U-shaped form, the middle section is sharply $\mathrm{V}$-shaped in section. On the north side of the pass there is a similar lack of unequivocal evidence for glaciation. The broad deep valley undergoes an abrupt change in form to become a narrow gorge near the village of Rumbak (066184), which in other valleys has been interpreted as the limit of glaciation, but here marks a lithological boundary with more resistant molasse replacing relatively easily eroded greywackes and sandy shales (both with vertical bedding). The gorge section, with a floor of $<20 \mathrm{~m}$ width, is non-glacial and the valley above the gorge entrance has a glacial form, so it may be that the lithological boundary is also (by coincidence) the maximum limit of glaciation.

An ice apron currently occupies the upper north-facing slopes of Parcha Kangri (5508m) (070179), with a lower altitude of $\sim 5200 \mathrm{~m}$. 'Fresh' looking moraines/rock glacier deposits, viewed from a distance, extend further to an altitude of $\sim 4400 \mathrm{~m}$.

On the eastern side of Namling La (071179), in the Stok valley, the bedrock configuration is again problematical, with vertical bedding and differential erosion creating changes in valley cross-sections. Upper slopes are cut into mudstone, forming a broad bowl, which becomes a narrow valley of interlocking saw-tooth edged spurs of vertically bedded limestone - distinctly non-glacial in appearance. There is, however, evidence for glaciation in the lower valley, which has ice-moulded bedrock with perched erratics and reworked till. Ice may have occupied the middle section, but was not erosive where locked to the rough bed, only deforming in its upper part. Further down the valley (with additional input from tributaries) the glacier may have been able to alter the bed destroying the jagged spurs, or alternatively the bedrock may be more easily eroded.

A large alluvial fan has been deposited in the valley mouth, where it enters the Indus (083186). There is no evidence of moraines, but the great thickness of alluvium is 
likely to have buried any such evidence and the small size of clasts liberated from the molasse, relative to the granitoids outcropping to the north of the Indus, are likely to have been more readily reworked.

To the south-east at Martselang Village (103164) a huge alluvial fan has built into the Indus and has since been reduced to a suite of terraces and mounds of $>50 \mathrm{~m}$ height by fluvial incision. The bedrock dips to the south at $30-40^{\circ}$ imposing a strong control on the slope angle of the sharp V-shaped valley, which is choked by rockfalls of the local limestone and molasse conglomerates. The gorge widens up-valley from a floor width of tens of metres to $\sim 400 \mathrm{~m}$, with the change being gradual like the glacial controlled Khurna valley, rather than a sharper lithological change. The actual limit of glaciation, in the absence of an appropriate source of erratics and the survival of moraines, cannot be defined.

Talus slopes flank a broad valley with debris cones eroded into terraces and earth pillars further up-valley. The debris flow deposits, which are now incised by $40 \mathrm{~m}$, may be reworked till given the poor sorting (sand to $2 \mathrm{~m}$ diameter boulders) and edge rounded, faceted shape of some clasts in the weakly stratified sediment, although no striated clasts could be found.

The upper section of the valley is a narrow rock gorge of $\sim 20 \mathrm{~m}$ across, perhaps surviving glaciation under weakly erosive cold-based ice or post-dating glaciation. Towards the pass (091147), the valley is a broad bowl dominated by mass movement and fluvial processes, with debris flow and avalanche modified talus. Much of these high slopes were obscured by fresh snow that lasted 2-4 days. 


\section{Optically Stimulated Luminescence (OSL) Dating Results}

\subsection{Introduction}

In order to relate a glacial sequence to fluctuations in climate, age estimates must be obtained to allow the construction of a glacial chronology. As discussed in Section 2.2, Optically Stimulated Luminescence (OSL) dating is the most appropriate method for providing numerical age estimates for the glaciogenic sediments of the semi-arid Zanskar Range (Chapter 3). In this chapter sites chosen for OSL dating will be described in turn and the suitability of the sediment, particularly its relationship to the glacial sequence and likelihood of having been bleached during or shortly before deposition, will be discussed. Some characteristics of the laboratory measurements of Thermoluminescence (TL), Infra-Red Stimulated Luminescence (IRSL) and OSL will be described and issues raised by these results such as possible feldspar signals will be discussed, before an Equivalent Dose $\left(D_{E}\right)$ and age are given.

Fifteen samples were collected, including several pairs, with this number reduced to the ten highest priority/most suitable samples at an early stage in the involved preparation. In practice many of the most promising sample sites could not be accessed on grounds of safety, especially when outcropping as lenses in unconsolidated diamict cliffs. Grid references for site locations relate to Figure 4.1 and sites are shown schematically superimposed upon a composite valley to give their relative chronology and show their overall relationship to proposed palaeoglacier margins in Figure 4.2. All the parameters required for the calculation of an age are given in Table 4.1 and summary results for each sample are presented in Table 4.2. 


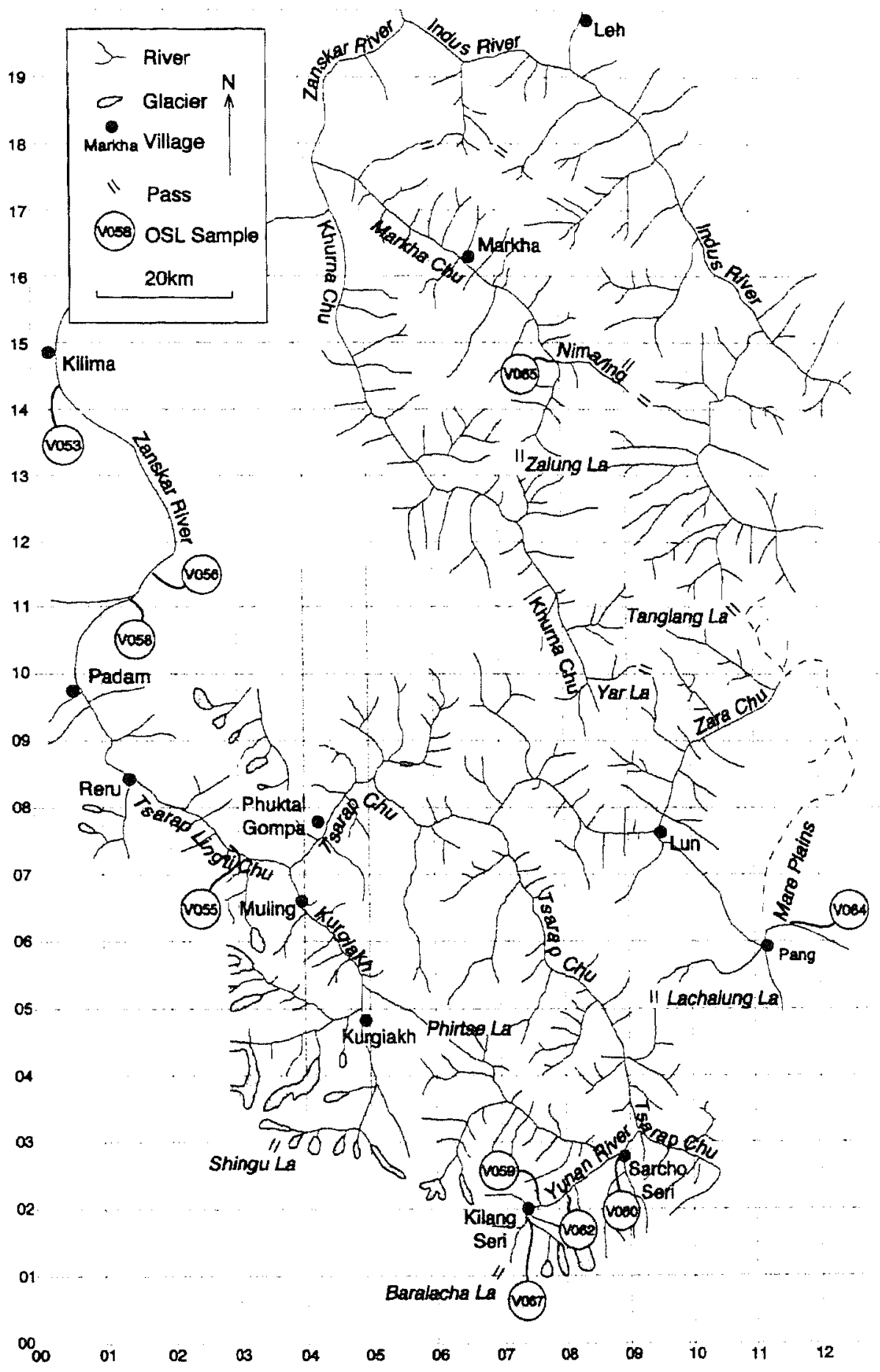

Figure 4.1 Location of OSL dating sample sites. 


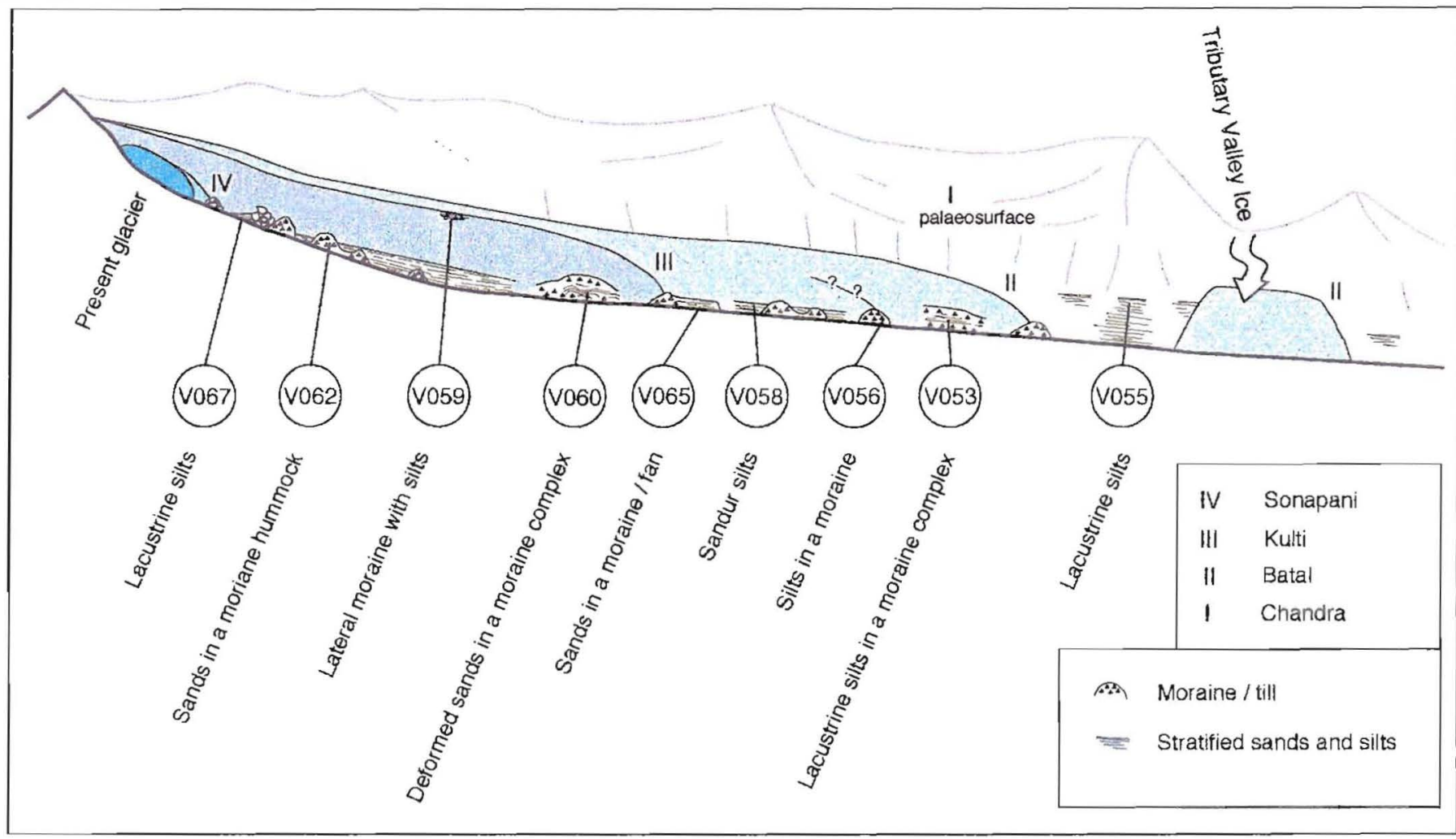

Figure 4.2 OSL dating sample sites shown on a schematic 'composite' valley. Sample sites are from several valleys as indicated in Figure 4.1, but are shown in this format to illustrate their interpreted relative positions and relationship to proposed glacial margins. 


\subsection{Samples}

\section{V053, Zanskar Valley Between Pishu and Hanumil Villages}

Sample V053 (004143) was collected by Henry Osmaston from consolidated silts in the Zanskar valley between Pishu and Hanumil villages at an altitude of $\sim 3500 \mathrm{~m}$ a.s.l. (Figs. 4.1 and 4.2). The silt occurs as a $20 \mathrm{~m}$ thick, $100 \mathrm{~m}$ long exposure in a cliff of weakly stratified to massive diamict composed of consolidated sub-angular poorly sorted clasts of up to $500 \mathrm{~mm}$ diameter (occasionally $1 \mathrm{~m}$ ). The diamict above and below the silt is interpreted as a till or reworked till from a lateral moraine complex associated with a limit at Kilima $15 \mathrm{~km}$ down-valley (Osmaston, pers. comm.). The silts are interpreted as an ice marginal lake deposit and are likely to have undergone multiple cycles of transport and deposition as supraglacial/ice marginal sediment, greatly increasing their likelihood of having been bleached. The sample was cut as a coherent unit from a large block that had clearly fallen from the inaccessible silt face.

The preferred sub-methodology using Fine Grained Quartz (FGQ) grains was employed and as for all the processed samples forty-eight discs were measured following a six disc Luminescence Initial Sample Assessment (LISA) test (Section 2.2). Green Light Stimulated Luminescence (GLSL) data gives a low degree of scatter with an average deviation from the best-fit line of $15 \%$ and a mean percentage of standard error for all dose points of $6 \%$. The IRSL signal is generally negligible in both the LISA and main measurements with the exception of measurements for one aliquot, which is consequently rejected on the grounds of likely feldspar contamination. TL glow curves give a peak at $320^{\circ} \mathrm{C}$ to $350^{\circ} \mathrm{C}$ with a bench above $410^{\circ} \mathrm{C}$ and following dosing there is an additional peak at $100^{\circ} \mathrm{C}$. The short-term decay of the GLSL signal at $160^{\circ} \mathrm{C}$ (plotted over 50 seconds) is very quick, although the long-term curve continues to decay slightly (plotted for 950 seconds). 


\begin{tabular}{|c|c|c|c|c|c|c|c|c|c|c|}
\hline \multirow{2}{*}{ 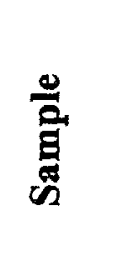 } & \multirow{2}{*}{ 苞 } & \multirow{2}{*}{ 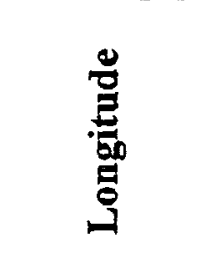 } & \multirow{2}{*}{ 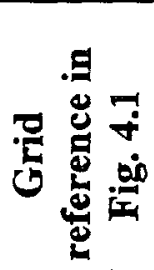 } & \multirow{2}{*}{ 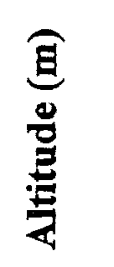 } & \multirow{2}{*}{ 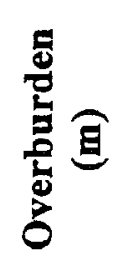 } & \multirow{2}{*}{ 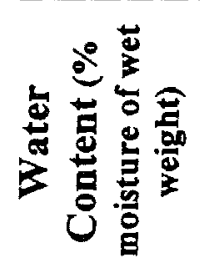 } & \multicolumn{4}{|c|}{ NAA results } \\
\hline & & & & & & & $K(\%)$ & $\begin{array}{c}\mathbf{R b} \\
\text { (ppm) }\end{array}$ & $\begin{array}{c}\text { Th } \\
\text { (ppm) }\end{array}$ & $\begin{array}{c}\mathrm{U} \\
\text { (ppm) }\end{array}$ \\
\hline V053 & $33^{\circ} 50^{\prime} 00 \mathrm{~N}$ & $76^{\circ} 53^{\prime} 00 \mathrm{E}$ & $0 \overline{04143}$ & 3500 & -5 & 0.02 & 1.20 & 61.0 & 10.5 & 2.11 \\
\hline V055 & $33^{\circ} 14^{\prime} 76 \mathrm{~N}$ & $77^{\circ} 53^{\prime} 64 \mathrm{E}$ & 029074 & 4040 & 15 & 0.02 & 1.64 & 101.0 & 12.9 & 2.75 \\
\hline V056 & $33^{\circ} 32^{\prime} 00 \mathrm{~N}$ & $76^{\circ} 59^{\prime} 00 \mathrm{E}$ & 018115 & 3600 & 3 & 0.02 & 1.93 & 106.0 & 17.2 & 3.93 \\
\hline V058 & $33^{\circ} 28^{\prime} 00 \mathrm{~N}$ & $76^{\circ} 55^{\prime} 00 \mathrm{E}$ & 014112 & 3600 & 3 & 0.00 & 3.68 & 270.0 & 31.2 & 4.64 \\
\hline V059 & $32^{\circ} 50^{\prime} 40 \mathrm{~N}$ & $77^{\circ} 26^{\prime} 96 \mathrm{E}$ & 076021 & 4850 & 0.5 & 0.15 & 4.02 & 245.0 & 22.1 & 3.22 \\
\hline V060 & $32^{\circ} 54^{\prime} 45 \mathrm{~N}$ & $77^{\circ} 34^{\prime} 78 \mathrm{E}$ & 089028 & 4210 & 3 & 0.00 & 2.06 & 138.0 & 20.6 & 2.97 \\
\hline V062 & $32^{\circ} 50^{\prime} 93 \mathrm{~N}$ & $77^{\circ} 29^{\prime} 61 \mathrm{E}$ & 080022 & 4550 & 1 & 0.02 & 1.70 & 96.1 & 16.8 & 2.53 \\
\hline V064 & $33^{\circ} 08^{\prime} 17 \mathrm{~N}$ & $77^{\circ} 49^{\prime} 31 \mathrm{E}$ & 115063 & 3308 & $>200$ & 0.01 & 1.92 & 133.0 & 19.2 & 2.76 \\
\hline V065 & $33^{\circ} 49^{\prime} 71 \mathrm{~N}$ & $77^{\circ} 30^{\prime} 50 \mathrm{E}$ & 080147 & 4200 & $\overline{6}$ & 0.00 & 1.50 & 115.0 & 14.4 & 3.22 \\
\hline V067 & $32^{\circ} 48^{\prime} 75 \mathrm{~N}$ & $77^{\circ} 27^{\prime} 41 \mathrm{E}$ & 073019 & 4710 & 20 & 0.16 & 3.78 & 219.0 & 22.5 & 3.48 \\
\hline
\end{tabular}

Table 4.1 Measurements required for the determination of the environmental dose 
Water content, as for most of the following samples, is negligible (Table. 4.1). The dose/intensity graph has a curve fitted proportional to intensity to give an $D_{E}$ of $267 \pm 38$ Gy (appendix A) which, combined with calculations for the cosmic dose and Neutron Activation Analysis (NAA) results gives an age of 78.0 $\pm 12.3 \mathrm{ka}$ BP.

\section{V055, Tsarap-Lingti Chu Up-valley from Reru Village}

This sample comes from one of two roughly cubic blocks of laminated silts and fine sands of $\sim 20 \mathrm{~m}$ unit length (029074) (Fig. 3.20). Remnants of valley fill are found from above a rock bench at $30 \mathrm{~m}$ a.r.l. to $200 \mathrm{~m}$ a.r.l. with the silts and fine sands forming the uppermost sediments and the limit of granite erratics. The fill which is predominantly a clast supported diamict is interpreted as relating to the confining and eventual damming of the main valley by tributary ice at Reru. In the upper sands and silts, small granite dropstones of a few tens of millimetres diameter support this icecontact lacustrine interpretation. The silts and fine sands are likely to have been exposed to light during several cycles of transport and deposition in the fluvial and/or glacial environments and during the final lacustrine sedimentation. The sample was taken as a consolidated block $>300 \mathrm{~mm}$ away from the granite dropstones.

Initial measurements on FGQ aliquots give a steep dose/intensity curve with a large extrapolation beyond the zero dose point necessary to find the $D_{E}$ relative to the data set. This gives a large error and, as the signal grows strongly a second set of fortyeight discs was prepared and given greater $\beta$-doses. GLSL data is very scattered with an average deviation from the best-fit line of $33 \%$ and a mean percentage of standard error for all dose points of $14 \%$. The IRSL signal is generally small with a few moderately high aliquots, but no justification for rejection of any datum. TL glow curves give a peak at $330^{\circ} \mathrm{C}$ with a step at $270^{\circ} \mathrm{C}$ to $310^{\circ} \mathrm{C}$ and a bench after $400^{\circ} \mathrm{C}$ and following dosing there is an additional peak at $100^{\circ} \mathrm{C}$. The decay of the GLSL signal at $160^{\circ} \mathrm{C}$ is very rapid with only a slight decay in the long-term plot. The 
dose/intensity curve gives an $D_{E}$ of $171 \pm 38$ Gy which provides an age of $40.0 \pm 9.3 \mathrm{ka}$ BP.

\section{V056, sTondge Terminal Moraine}

Sample V056 was collected as a block by Henry Osmaston from a silt lens from a terminal moraine complex at sTondge $(018115)$ at $\sim 3600 \mathrm{~m}$ a.s.1. Pure quartz could not be attained, so a Fine Grained Poly-Mineral (FGPM) sample was prepared and measured. The standard error for the $\mathrm{D}_{E}$ and age are large limiting the usefulness of the result. IRSL and GLSL give $\mathrm{D}_{\mathrm{E}}$ calculations of $589 \pm 218 \mathrm{~Gy}$ working out as $88.6 \pm 33.6 \mathrm{ka} \mathrm{BP}$ and $610 \pm 248 \mathrm{~Gy}$ which gives $98.8 \pm 41.0 \mathrm{ka}$ BP respectively.

\section{V058, Padam Sandur}

Sample V058 was collected by Henry Osmaston from silts within a sandur near the village of Padam (014112) at $\sim 3550 \mathrm{~m}$ a.s.1. The coherent block represents glacial outwash which has since been eroded into terraces and, as such, is likely to have undergone multiple cycles of deposition and erosion allowing bleaching. GLSL data from FGQ aliquots are very scattered with an average deviation from the best-fit line of $35.6 \%$ and a mean percentage of standard error for all dose points of $23 \%$. One of the forty-eight aliquots is rejected due to high IRSL measurements, which are otherwise negligible, and one is rejected due to spikes in its shine-down curve. TL glow curves show a modest peak at $320^{\circ} \mathrm{C}$ to $350^{\circ} \mathrm{C}$ and a rise after $430^{\circ} \mathrm{C}$, with an additional peak at $100^{\circ} \mathrm{C}$ following dosing. GLSL decay at $160^{\circ} \mathrm{C}$ is rapid with no long-term decay.

The $\mathrm{D}_{\mathrm{E}}$ is $184 \pm 46 \mathrm{~Gy}$ giving an age of $19.9 \pm 5.2 \mathrm{ka} \mathrm{BP}$. 


\section{V059, Kelang Seri}

Sample V059 was collected in an opaque tube from a lateral moraine at $4850 \mathrm{~m}$ a.s.l. (076021). The unconsolidated silt forms a massive matrix in the diamict interpreted as having been an ice marginal lacustrine deposit that became incorporated into the lateral moraine sequence (Fig. 4.3). If this is not the case the silts are likely to have been bleached as supraglacial debris given the dynamics of sediment observed on nearby debris covered glaciers.

Unlike the other samples, these data are not naturally normalised due to a mechanical failure during this process. Scatter of the GLSL data is moderate with an average deviation from the best-fit line of $20 \%$ and a mean percentage of standard error for all dose points of $14 \%$. Two aliquots are rejected as containing feldspar on the grounds of high IRSL signals, which are otherwise negligible. TL glow curves give a peak at $\sim 320^{\circ} \mathrm{C}$ and a gentle rise after $430^{\circ} \mathrm{C}$, and following dosing a peak just above $100^{\circ} \mathrm{C}$ and a slight step from $300^{\circ} \mathrm{C}$ to $340^{\circ} \mathrm{C}$. Decay of the GLSL signal at $160^{\circ} \mathrm{C}$ is quick with little decay in the long-term curve.

The $D_{E}$ is $133 \pm 45$ Gy which gives an age of $16.2 \pm 5.6 \mathrm{ka} \mathrm{BP}$.

\section{V060, Sarchu Seri}

Sample V060 was collected as a coherent block of fine sand from deformed beds in a fluvioglacial/glacial sequence associated with lateral moraines at Sarchu Seri (089028) at $4210 \mathrm{~m}$ a.s.l. (Figs. 3.26 and 4.4). The sediments, which may be glaciotectonised or deformed by the weight of overlying deposits, are closely related to the former ice margin and are likely to have undergone multiple cycles of deposition and are therefore likely to have been bleached. 
Chapter 4, Optically Stimuluted Luminescence (OSL) Results

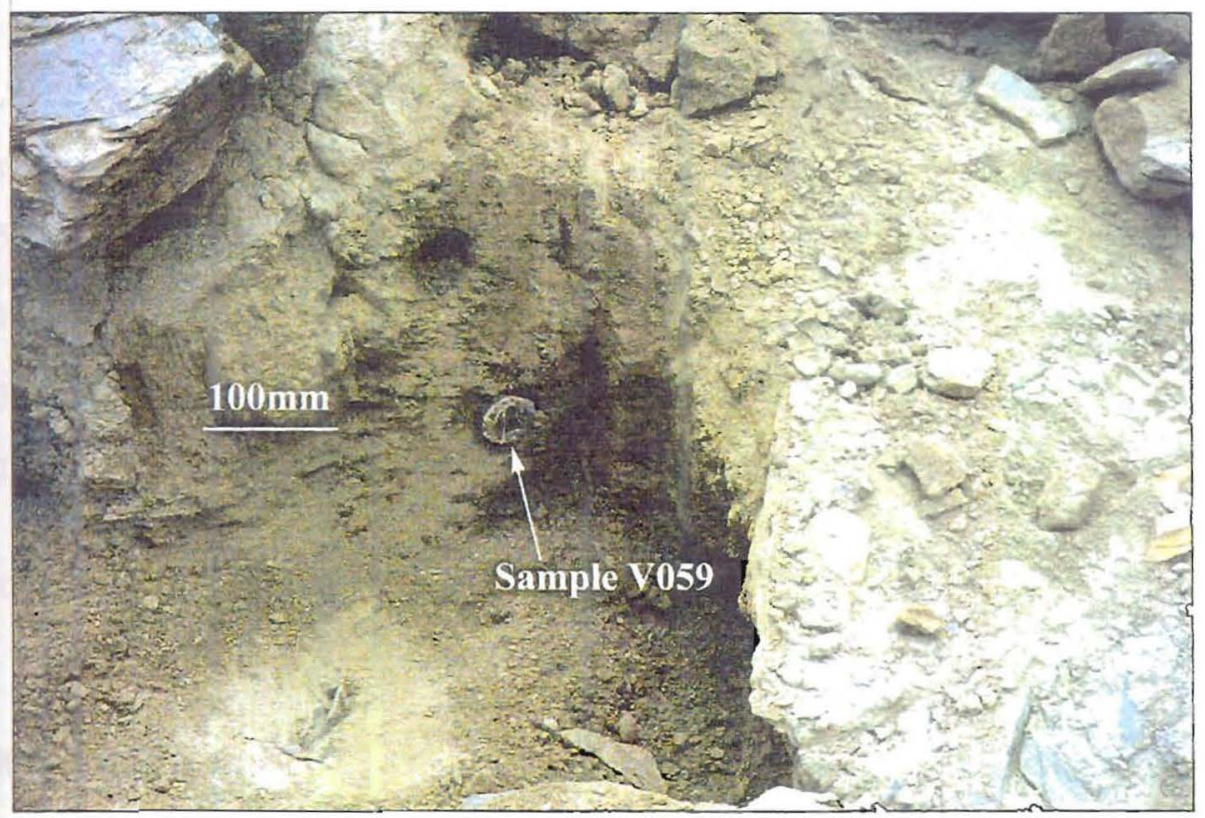

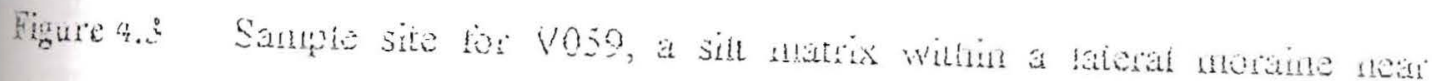

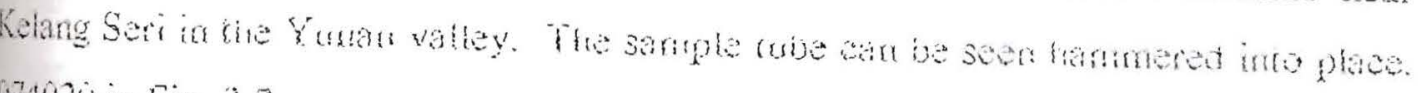
074020 in Fig. $; .2$.

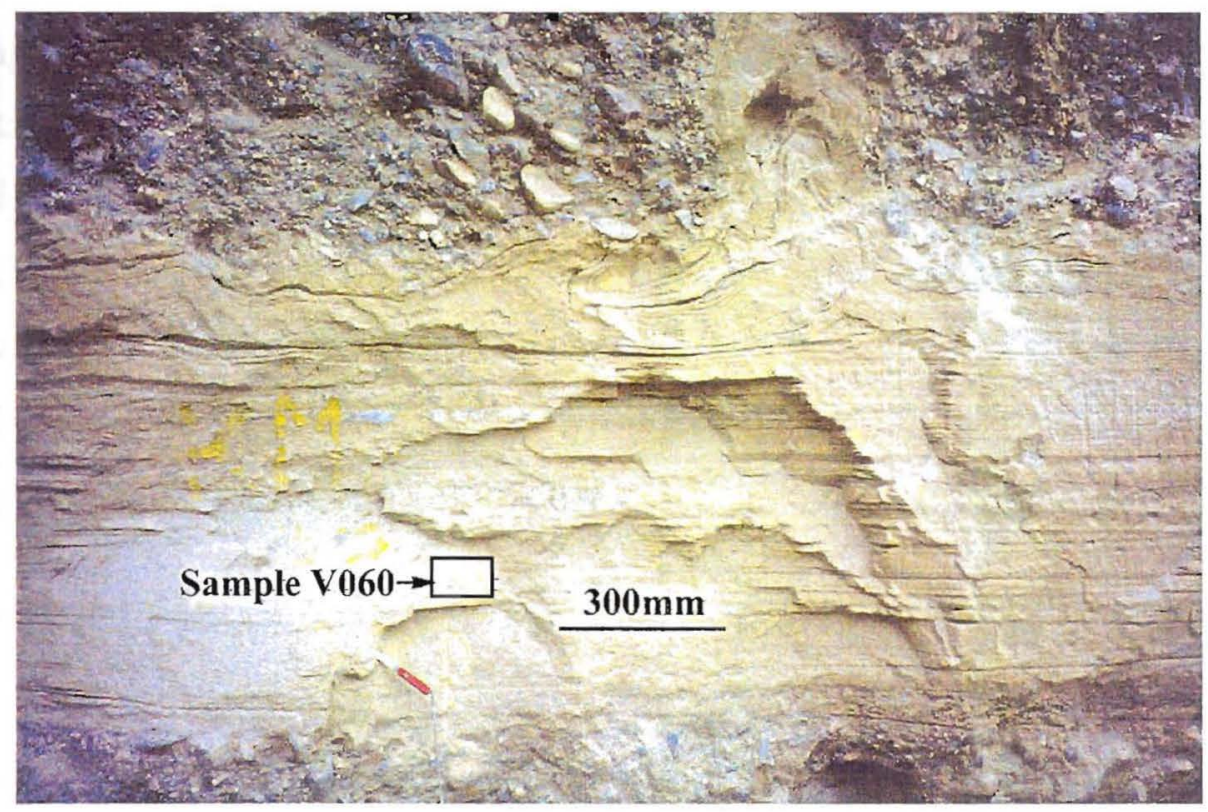

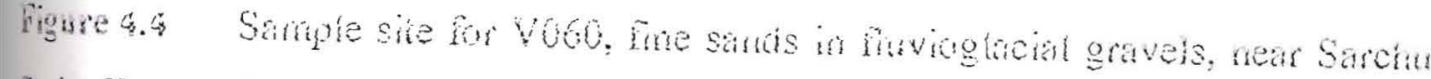

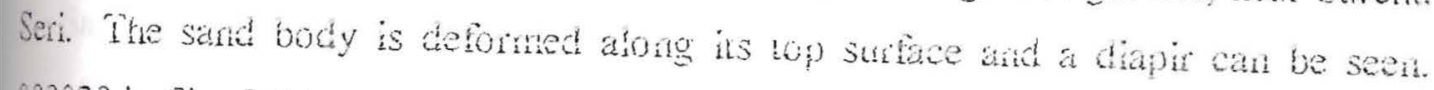
0र9ि028 iा: 5 is. 3.24. 
GLSL data gives a moderate degree of scatter with an average deviation from the best-fit line of $22 \%$ and a mean percentage of standard error for all dose points of $11 \%$. The IRSL signal is negligible and no aliquots are rejected. TL glow curves show a double peak at $270^{\circ} \mathrm{C}$ and $325^{\circ} \mathrm{C}$ with a small bench above $\sim 400^{\circ} \mathrm{C}$. A peak at just below $100^{\circ} \mathrm{C}$ can be observed following dosing. The decay of the GLSL signal at $160^{\circ} \mathrm{C}$ is rapid with some further decay seen in the long-term plot.

The $D_{E}$ is $76.2 \pm 28$ giving an age of $13.1 \pm 4.9 \mathrm{ka} \mathrm{BP}$.

\section{V062, Yunan Valley}

Sample V062 is from a fluvioglacial lens of unconsolidated fine sand within a partially buried moraine hummock in the Yunan valley (080022) (Fig 3.11). The series of moraines clearly represent recession of ice in the valley. The sand lens may have been deposited in the subglacial rather than the proglacial environment, but this is apparently not the case as the GLSL signal grows strongly. The degree of scatter of the GLSL data is relatively low with a $16 \%$ average deviation from the best-fit line and a mean percentage of standard error for all dose points of 7\%. The IRSL signal is negligible except for one moderately high aliquot, with no justification for the rejection of any datum. TL glow curves show a peak at $\sim 340^{\circ} \mathrm{C}$ and a bench above $\sim 400^{\circ} \mathrm{C}$ with an additional peak at $\sim 100^{\circ} \mathrm{C}$ following dosing. Decay of the GLSL signal at $160^{\circ} \mathrm{C}$ is rapid with a little decay shown in the long-term curve.

The $D_{E}$ is $50.4 \pm 9.8$ Gy giving an age of $10.2 \pm 2.1 \mathrm{ka} \mathrm{BP}$.

\section{V064, Pang}

Sample V064 was collected as a coherent block from a fine sand lens from the base of $240 \mathrm{~m}$ of alluvium near Pang (115063) at $3310 \mathrm{~m}$ a.s.l. (Fig 4.5). This sample is not directly related to the glacial history but to a fluvial infill and subsequent river 


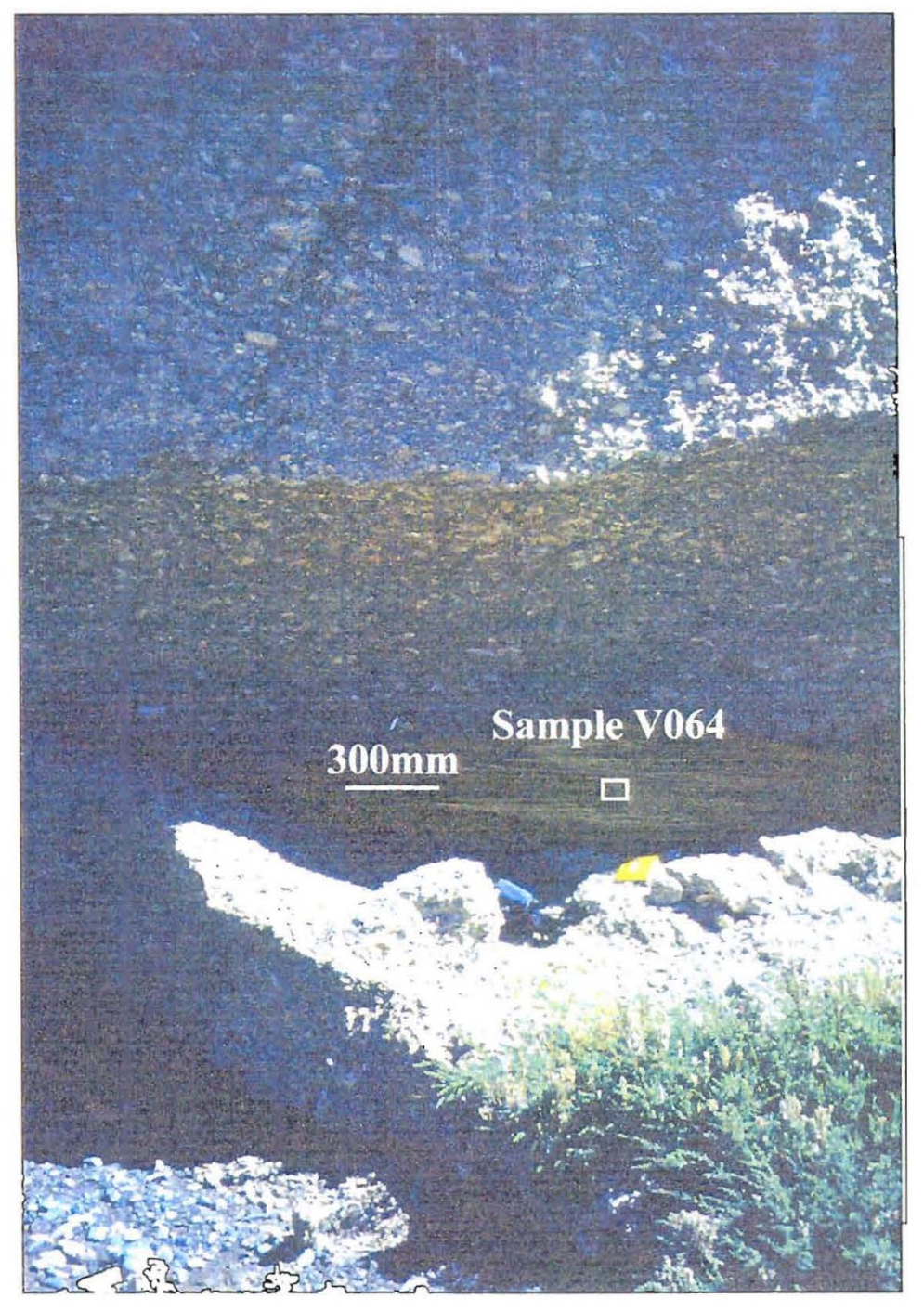

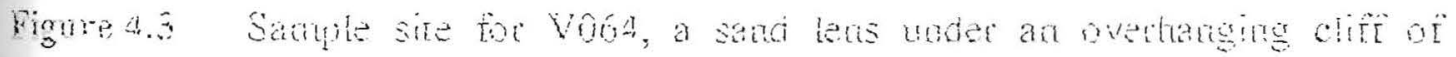

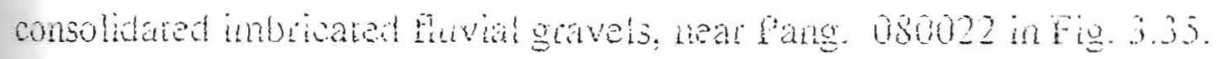


capture. GLSL data from the forty-eight FGQ discs shows a moderate scatter of 19\% average deviation from the best-fit curve and a mean percentage of standard error for all dose points of $10 \%$. The IRSL signal is negligible suggesting that feldspar grains have been successfully removed. One aliquot, which lies far off the curve, has been rejected. TL glow curves show a large peak at $360^{\circ} \mathrm{C}$ with a bench above $\sim 430^{\circ} \mathrm{C}$ and a peak at $\sim 100^{\circ} \mathrm{C}$ following dosing. The GLSL signal at $160^{\circ} \mathrm{C}$ decays speedily with some further decay shown in the long-term plot.

The $D_{E}$ is $191 \pm 107$ Gy giving an age of $37.5 \pm 21.2 \mathrm{ka} B P$

\section{V065, Mouth of the Nimaling Chu}

Sample V065 was collected in an opaque tube from a sand lens within a proglacial fan closely associated with a moraine sequence from the mouth of the Nimaling Chu (080147) at $4200 \mathrm{~m}$ a.s.l. The sediment is interpreted as proglacial outwash and as such is considered likely to have been exposed to light before and/or during deposition.

The sample contained too few fine grains for the FGQ sub-method, so the Coarse Grained Quartz (CGQ) sub-method was employed (Section 2.2). GLSL data is very scattered with an average deviation from the best fit-line of $37 \%$ and a mean percentage of standard error for all dose points of $17 \%$. The IRSL signal varies and is high for several aliquots possibly due to feldspar inclusions in the quartz grains. Only one datum is rejected, however, the possible feldspar content must be taken into account when considering the reliability of this date. TL glow curves show a broad moderate magnitude peak from $\sim 250^{\circ} \mathrm{C}$ to $340^{\circ} \mathrm{C}$ with a bench above $\sim 400^{\circ} \mathrm{C}$ and a post-dosing peak just below $100^{\circ} \mathrm{C}$. The GLSL decay curve for $160^{\circ} \mathrm{C}$ is rapid with some further decay seen in the long-term plot.

The $D_{E}$ is $48 \pm 17$ Gy giving an age of $12.8 \pm 4.7 \mathrm{ka} \mathrm{BP}$. 


\section{V067, Kelang Seri}

Sample V067, a coherent block of silt, was collected by Edward Rhodes (field code, $\mathrm{IN} 23$ ) from $12 \mathrm{~m}$ below the surface of a terrace of lacustrine sediments associated with the landslide damming of the valley near Kelang Seri (073019). This sample does not relate directly to the glacial sequence, but provides a constraint on the age of the landslide, which overlies moraines.

GLSL data does not plot in the Fit-sim program as the points are too scattered. IRSL measurements are generally low indicating that feldspar has been successfully removed. TL glow curves give a peak at $-330^{\circ} \mathrm{C}$ with a rise above $400^{\circ} \mathrm{C}$ and a peak just below $100^{\circ} \mathrm{C}$ following dosing. The GLSL decay curve for $160^{\circ} \mathrm{C}$ shows a moderately quick decay with no long-term component.

Data proved too scattered for the estimation of an $\mathrm{D}_{\mathrm{E}}$, however, viewing of the data in another program suggests a small value and hence a relatively young date.

\subsection{Discussion and Conclusion}

Dating results (Table 4.2) show mixed success with some ages well constrained, such as those from samples V053 and V062, while others are poorly defined with large error margins, like age estimates from samples V056 and V057. The problem of scatter associated with fluvioglacial samples remains for some samples, as can be seen in the dose response curve of V058 (appendix A).

All but two samples (V056 and V065) proved suitable for the preferred submethodology of FGQ. TL glow curves and green light shine-down curves have characteristics belonging to the quartz signal, particularly the post dose peak at $\sim 110^{\circ} \mathrm{C}$ in the former and rapid decay of the signal in the latter. These data, in combination with generally low IRSL signals, give confidence that undesirable grains 


\begin{tabular}{|c|c|c|c|c|c|c|}
\hline Sample & $\begin{array}{l}\text { Location, Fig. } \\
\qquad 4.1\end{array}$ & Description of Sediment & Method & $\mathbf{D}_{\mathrm{E}}(\mathrm{Gy})$ & $\begin{array}{l}\text { Dose rate } \\
\left(\mu \mathrm{Gya}^{-1}\right)\end{array}$ & $\begin{array}{l}\text { Age (ka } \\
\text { BP) }\end{array}$ \\
\hline V053 & $\begin{array}{c}\text { Zanskar valley } \\
004143\end{array}$ & $20 \mathrm{~m}$ thick ice marginal lacustrine silt deposit between lateral moraine tills. & FGQ & $267 \pm 38$ & $3421 \pm 232$ & $78.0 \pm 12.3$ \\
\hline V055 & $\begin{array}{l}\text { Tsarap-Lingti } \\
\text { valley } 029074\end{array}$ & $\begin{array}{l}20 \mathrm{~m} \text { thick lacustrine silts and fine sands capping } 180 \mathrm{~m} \text { of conglomerate and } \\
\text { gravel fill relating to damming of the trunk valley by tributary ice at Reru. }\end{array}$ & FGQ & $171 \pm 9.3$ & $4271 \pm 292$ & $40.0 \pm 9.3$ \\
\hline \multirow{2}{*}{ V056 } & Zanskar valley & \multirow{2}{*}{ Silt lens from a moraine ridge near sTondge. } & \multirow{2}{*}{$\begin{array}{ll}\sum_{\substack{0 \\
\text { S }}} \text { IRSL } \\
\text { GLSL }\end{array}$} & $589 \pm 218$ & $6648 \pm 539$ & $88.6 \pm 33.6$ \\
\hline & 018115 & & & $610 \pm 248$ & $6176 \pm 535$ & $98.8 \pm 41.0$ \\
\hline V058 & $\begin{array}{l}\text { Stod/Zanskar } \\
\text { valley } 014112\end{array}$ & Silts from within a sandur from the Padam Plain. & FGQ & $184 \pm 46$ & $9225 \pm 641$ & $19.9 \pm 5.2$ \\
\hline V059 & $\begin{array}{l}\text { Yunan valley } \\
076021\end{array}$ & $\begin{array}{l}\text { Silt from within a lateral moraine from the Yunan valley, possibly deposited } \\
\text { in an ice marginal lake before becoming incorporated in the moraine. }\end{array}$ & FGQ & $133 \pm 45$ & $8225 \pm 559$ & $16.2 \pm 5.6$ \\
\hline V060 & $\begin{array}{l}\text { Yunan valley } \\
089028\end{array}$ & $\begin{array}{l}\text { Fine sand from a deformed fluvioglacial sequence closely associated with } \\
\text { lateral moraines. }\end{array}$ & FGQ & $76.2 \pm 28$ & $5807 \pm 405$ & $13.1 \pm 4.9$ \\
\hline V062 & $\begin{array}{c}\text { Yunan valley } \\
080022\end{array}$ & Fine sand forming a lens within a moraine mound. & FGQ & $50.4 \pm 9.8$ & $4931 \pm 337$ & $10.2+2.1$ \\
\hline V064 & Pang 115063 & Fine sands forming a lens from near the base of $240 \mathrm{~m}$ of fluvial gravels. & FGQ & $191 \pm 107$ & $5092 \pm 369$ & $37.5 \pm 21.2$ \\
\hline V065 & $\begin{array}{l}\text { Nimaling valley } \\
080147\end{array}$ & Sand lens from a proglacial fan of fluvioglacial sediments. & CGQ & $48 \pm 17$ & $3742 \pm 292$ & $12.8 \pm 4.7$ \\
\hline V067 & $\begin{array}{l}\text { Yunan valley } \\
073019\end{array}$ & $\begin{array}{l}\text { Lacustrine silts associated with the damming of the river by a catastrophic } \\
\qquad \text { rock avalanche. }\end{array}$ & FGQ & - & & - \\
\hline
\end{tabular}

Table 4.2 Summary details of samples dated. 
have been successfully removed during the preparation procedure. Individual aliquots with possible feldspar contamination, V059 for example, have been successfully identified and rejected on the basis of IRSL measurements. Of the two samples not using the FGQ sub-methodology, V056 uses fine-grained poly-minerals, which may have produced a more constrained age had a more suitable additive dose been given, and V065 used CGQ, which may have contained quartz grains with feldspar inclusions. LISA tests proved useful, principally in the preliminary determination of the $D_{E}$ and assessment of feldspar contamination. Although with problems, a greater number of samples would have had to be re-run, as with V055, without these initial tests. 


\section{Style and Timing of Glaciation in the Zanskar Range}

Discussion of the style and timing of glaciation in the Zanskar Range will be undertaken in three sections. The first (Section 5.1) will propose a glacial chronology, based the geomorphological and sedimentological field evidence described in Chapter 3 and corresponding dating results from Chapter 4 . The second part (Section 5.2) will compare the new data and interpretation of this study to previously published information regarding the glaciation of Zanskar Range and adjacent areas, particularly where a new interpretation is being placed on published observations. In the third part (Section 5.3), Glacial Elevation Index (GEI) values calculated from reconstructed glacial limits from the Zanskar Range and Lahul will be presented. Together with previously published values from the Indus valley, their spatial pattern will be examined and palaeoclimatic inferences drawn.

\subsection{A Proposed Glacial Chronology for the Zanskar Range}

\subsubsection{Glacial Chronological Framework and Nomenclature}

The critical aims in glacial stratigraphy are to provide evidence from fundamental litho- and morphostratigraphic units for glacial activity, as represented by glacial advances, and to construct a chronology (Rose and Menzies, 1996). Glacial stratigraphy is intimately associated with the division of Quaternary stratigraphy into climatostratigraphic units of glacial and interglacial periods. These units form the main elements of chronostratigraphic subdivisions, referred to as glacial stages. For glacial stratigraphy, a glacial stage represents the major expansion of glaciers of long duration (Rose and Menzies, 1996; Lowe and Walker, 1997). 
Glacial deposition is discontinuous and laterally variable, and older deposits are commonly poorly preserved at or beyond the limit of younger advances (BrighamGrette, 1996). These problems are inherent in the establishment of a lithostratigraphy for glacial deposits. However, as glaciers form distinctive landforms over short periods of time and these can represent former glacial margins, morphostratigraphy is very important for glacial stratigraphy (Lowe and Walker, 1997, p303). The following section will propose a glacial chronology principally based on morphostratigraphy, relative weathering and OSL numerical age estimates.

The stratigraphic procedures suggested with reference to Himalayan glacial studies by Owen et al. (1998), which are partly based on those of Osmaston (1989), will be used as a basis for establishing a chronology of glacial events. These conditions, which follow fundamental geological principles, mean that the landforms and deposits of each stage should ideally meet the following criteria.

(1) They should be are unequivocally glacial in origin.

(2) They should be spatially, stratigraphically and sedimentologically separated.

(3) They should show a clear difference in timing, preferably through dating, or through relative weathering where numerical age estimates are not available.

Following these prerequisites three main glacial stages and a minor advance have been identified (Table 5.1). These glacial events are represented by evidence that can be distinguished on the grounds of its relative position within the landscape and the relative weathering of landforms and sediments. The proposed overall framework of four events is as follows. The oldest group of evidence is situated hundreds of metres above the present valley and is represented by palaeosurfaces and erratic blocks without deep tafoni weathering. Rare sediments associated with this group of evidence are lithified with advanced weathering of limestone clasts. The degree of lithification of sediments, although a broad expression of age, is not a good indicator of glacial stage. Lithified sediments have been observed in morphostratigraphic 
positions where they clearly belong to a younger group of glacial evidence and as such lithification is not an unequivocal proof of belonging to the oldest glacial event. A second set of evidence marks the limit of glacial erosion within the present valleys. Landforms belonging to this group have surface boulders that display well developed tafoni weathering. A third younger body of glacial evidence grouped further up valley does not have these tafoni weathered boulders, but shares well developed desert varnished rock surfaces. Although, the processes of tafoni development and rate of formation are poorly understood (Selby, 1993, p159), these weathering phenomena are a useful indicator of glacial stage. The fourth and youngest group of glacial evidence is close to modern glaciers and has rock surfaces without pronounced desert varnish or weathering.

As will be explicitly discussed in Section 5.2, the interpretation presented here disagrees with previous studies over the stratigraphic assignment of specific moraine limits. Crucially, two of these margins are used as the names of stages in the existing chronostratigraphy for the Zanskar Range (Osmaston, 1994), and as a consequence, this nomenclature is not extended to the area studied. Furthermore, attempts to correlate and extend the use of stage names should be avoided until absolute chronologies have been established (Owen et al., 1998). Rather than introduce yet more stratigraphic nomenclature, the partially age constrained chronology for neighbouring Lahul (Owen et al., 1997) is adopted. As will be demonstrated in Section 5.2, the chronology from the Zanskar Range correlates well with that from Lahul, although both are based on only a few dates. Indeed, the field areas belonging to each of the two studies are adjacent, with two sets of palaeoglaciers sharing the same high accumulation areas of the Shingu La and Baralacha La. Hereafter, therefore, the four events are referred to as the Chandra, Batal, Kulti and Sonapani (Table 5.1). 


\begin{tabular}{|c|c|c|}
\hline Event & Extent and Style & Main Evidence \\
\hline Modern Glaciers & $\begin{array}{l}\text { Small avalanche fed ice bodies at the heads } \\
\text { of valleys or in high corries. }\end{array}$ & - \\
\hline Sanopani & $\begin{array}{c}\text { Minor advance, }<2 \mathrm{~km} \text { from the present } \\
\text { glacier snouts. }\end{array}$ & $\begin{array}{l}\text { Sharp crested moraine ridges, typically } 5-10 \mathrm{~m} \text { high }(e . g . \\
\text { head of the Nimaling Plain) }\end{array}$ \\
\hline Kulti & $\begin{array}{l}\text { Valley glaciers occupying the upper sections } \\
\text { of many tributary valleys. }\end{array}$ & $\begin{array}{l}\text { Moraine ridges of a few tens of metres height forming a } \\
\text { pattern of inset chevrons (e.g. near Kurgiakh Village). }\end{array}$ \\
\hline Batal & $\begin{array}{l}\text { Extensive valley glaciers extending many } \\
\text { tens of kilometres down the main valleys. }\end{array}$ & $\begin{array}{l}\text { Subdued moraine ridges, often }>50 \mathrm{~m} \text { high, accompanied } \\
\text { by a down valley change in valley form, from broad } \\
\text { trough to narrow rock gorge (e.g. middle Tsarap valley). }\end{array}$ \\
\hline Chandra & $\begin{array}{l}\text { An ice-cap with its ice-shed over the High } \\
\text { Himalaya extending over much of the } \\
\text { southern part of the Zanskar Range. }\end{array}$ & $\begin{array}{c}\text { Glaciated palaeosurfaces }>280 \mathrm{~m} \text { a.r.l. and associated } \\
\text { High Himalaya Crystalline erratics (e.g. Phuctal Gompa, } \\
\text { Tsarap valley). }\end{array}$ \\
\hline Preglacial Landscape & - & $\begin{array}{l}\text { High interfluve areas and sediments, possibly beyond } \\
\text { Chandra limits. }\end{array}$ \\
\hline
\end{tabular}

Table 5.1 Chronostratigraphy and main evidence for the glaciation of the Zanskar Range. 


\subsubsection{Preglacial Landscape}

Many of the interfluve areas investigated, like the Phirtse La, are marked by their non-glacial appearance (Mitchell et al., 1999). Above the Tsarap Chu, well lithified fluvial sediments, which may be preglacial, occur as 'tors'. Delimitation of the earliest glaciation is problematic given the difficulties of access to upper slopes and sporadic nature of the evidence. Nevertheless, a number of these interfluve areas may never have been eroded by glacier ice, although they may have been covered by nonerosive cold based ice given their altitude above former Equilibrium Line Altitude (ELA) values. Consequently, the landscape of the Zanskar Range may have preglacial facets. The amount of Pleistocene erosion of these surfaces is difficult to assess, but may be low relative to the High Himalaya, given the position of the range on the hanging wall of the Zanskar Normal Fault (ZNF) and the suggested modest rates of uplift (Section 1.5).

\subsubsection{Chandra Stage}

The oldest recognised glacial event, the Chandra Stage, is represented by glaciated palaeosurface remnants and associated high grade metamorphic erratics in the Tsarap Chu and adjacent valleys in the southern part of the field area. Similar surfaces in the north are more equivocal and were only viewed distantly. In situ evidence, such as erratics, ice-moulded bedrock and a diamictite with erratic content (possibly a tillite), is restricted to upper valley slopes. Two of the best glaciated palaeosurfaces were observed to the north of Phuktal Gompa at 280m above the Tsarap Chu (049084 in Fig. 3.1; Section 3.4) and on Sarchu Mountain 200-300m above the Sarchu Nala (083024; Section 3.2). Both localities have high grade metamorphic erratics (Chapter 3), which were commonly observed relocated to valley floor positions through mass movement processes and occur $>100 \mathrm{~km}$ down the Tsarap system (Fig. 5.1). These 
are easily recognised against the local shelf sedimentary and low grade metamorphic rocks.

Evidence for this event satisfies the stratigraphic principles relating to the establishment of Himalayan glacial chronologies recommended by Owen et al. (1998) and listed in Section 5.1.1. A summary of how each stage meets these principles is given in Table 5.2. Many of the High Himalaya Crystalline erratic blocks could only have reached their present positions through glacial transport, verifying that the palaeosurface was occupied by ice. In addition, the evidence relating to this stage is spatially separate from the evidence of other stages. In the Tsarap valley, for example, in situ erratics are found $>200 \mathrm{~m}$ above the valley floor localities of younger glacial evidence and $>60 \mathrm{~km}$ down stream from their maximum extents. Temporal separation from the younger glacial evidence, although not confirmed by radiometric dating, is demonstrated by this vertical separation of evidence for the Chandra Stage and other events, with enough time past for $>200 \mathrm{~m}$ of incision to have taken place between the maxima of the two events.

Tracing this stage relies heavily on High Himalaya Crystalline indicator erratics. Delimitation and even recognition of the Chandra Stage in valleys without such markers is extremely difficult. This accounts for the lack of evidence from the north of the field area, which has no equivalent erratic supply. For example, the palaeosurface above the Khurna Chu (Fig. 3.53) exhibits textbook form, but has no direct evidence of glaciation, with only rocks of a local provenance. It is, however, a good candidate for being of Chandra age.

The limited number of accessible sites and the fragmentary nature of these palaeosurface remnants precludes accurate reconstruction of the style and extent of this glaciation. Nevertheless, a number of inferences can be made based on the observed evidence. The source of the high grade metamorphic erratics lies to the south of the Zanskar Normal Fault (ZNF) in the crystalline High Himalaya Range. Geological maps (e.g. Searle et al., 1997) show that such rocks have a limited outcrop 


\begin{tabular}{|c|c|c|c|c|c|c|c|c|c|c|}
\hline & \multicolumn{10}{|c|}{ Criteria for the stratigraphic separation of each glacial event } \\
\hline & \multicolumn{2}{|r|}{ Unequivocally glacial } & \multicolumn{2}{|r|}{ Spatial separation } & \multicolumn{2}{|c|}{ Stratigraphic separation } & \multicolumn{2}{|c|}{ Sedimentological separation } & \multicolumn{2}{|c|}{ Temporal separation } \\
\hline 言 & $\checkmark$ & $\begin{array}{l}\text { e.g. fluted moraines, } \\
\text { kettle holes and } \\
\text { striated bedrock, near } \\
\text { Kelang Seri tributary. }\end{array}$ & $\checkmark$ & $\begin{array}{l}\text { Within } 2 \mathrm{~km} \text { of present } \\
\text { glaciers and typically } \\
>10 \mathrm{~km} \text { from Kulti } \\
\text { moraines ridges. }\end{array}$ & $\checkmark$ & $\begin{array}{l}\text { Moraines overlying } \\
\text { those of Kuliti age, } \\
\text { Nimaling Plain. }\end{array}$ & $\checkmark$ & $\begin{array}{c}\text { Clasts from moraine } \\
\text { ridges have immature } \\
\text { shapes. }\end{array}$ & $\checkmark$ & $\begin{array}{l}\text { Desert varnish } \\
\text { poorly } \\
\text { developed. }\end{array}$ \\
\hline 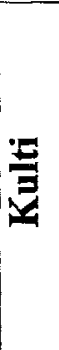 & $\checkmark$ & $\begin{array}{c}\text { e.g. moraine ridges } \\
\text { and striated bedrock, } \\
\text { Yunan valley. }\end{array}$ & $\checkmark$ & $\begin{array}{l}\text { Moraines grouped together } \\
\text { tens of km up valley from } \\
\text { Batal moraine ridges (little } \\
\text { depositional glacial } \\
\text { evidence between). }\end{array}$ & $\begin{array}{l}\checkmark \\
\times\end{array}$ & $\begin{array}{l}\text { Difficult to } \\
\text { demonstrate between } \\
\text { the Batal and Kulti } \\
\text { stages given the } \\
\text { discontinuous nature } \\
\text { of glacial landforms }\end{array}$ & $\begin{array}{l}\checkmark \\
\times\end{array}$ & $\begin{array}{l}\text { Distinct from Sonapani, } \\
\text { but sediments of the Batal } \\
\text { and Kulti stages are very }\end{array}$ & $\checkmark$ & $\begin{array}{l}\text { Desert varnish, } \\
\text { but poorly } \\
\text { developed tafoni } \\
\text { weathering. } \\
\text { Radiometric age } \\
\text { estimates. }\end{array}$ \\
\hline 茨 & $\checkmark$ & $\begin{array}{l}\text { e.g. striated clasts in } \\
\text { moraine ridges and } \\
\text { dropstones, Zara } \\
\text { valley. }\end{array}$ & $\checkmark$ & $\begin{array}{c}\text { Glacial evidence }>200 \mathrm{~m} \\
\text { below the Chandra } \\
\text { palaeosurface. }\end{array}$ & $\times$ & $\begin{array}{l}\text { and sediments, and } \\
\text { the large spatial } \\
\text { separation of the } \\
\text { evidence from the } \\
\text { two events. }\end{array}$ & $x$ & $\begin{array}{l}\text { have been formed under } \\
\text { similar processes. }\end{array}$ & $\checkmark$ & $\begin{array}{l}\text { Well developed } \\
\text { tafoni } \\
\text { weathering. } \\
\text { Radiometric age } \\
\text { estimates. }\end{array}$ \\
\hline 总 & $\checkmark$ & $\begin{array}{l}\text { e.g. High Himalaya } \\
\text { Crystalline erratics, } \\
\text { near Phuktal Gompa. }\end{array}$ & $\checkmark$ & $\begin{array}{l}\text { Evidence restricted to } \\
\text { paleosurface, with erratics } \\
\text { many tens of km down } \\
\text { valley from Batal limits. }\end{array}$ & $\checkmark$ & $\begin{array}{c}\text { Evidence on a high } \\
\text { palaeosurface. }\end{array}$ & $\mathbf{x}$ & $\begin{array}{l}\text { Too few sediments of } \\
\text { Chandra stage were } \\
\text { observed for a meaningful } \\
\text { comparison. }\end{array}$ & $\checkmark$ & $\begin{array}{l}\text { Sufficent time for } \\
>200 \mathrm{~m} \text { of valley } \\
\text { incision between } \\
\text { events. }\end{array}$ \\
\hline
\end{tabular}

Table 5.2 Summary of the evidence for the stratigraphic separation of each glacial event. 
at the head of the Kamirap Chu tributary, but rock from that area could not have supplied erratics to Sarchu Mountain, which lies up-valley from the mouth of the tributary (Fig. 5.1) unless the palaeodrainage was considerably different. Erratics in this part of the valley must have been transported from south of the ZNF, which is $\sim 15 \mathrm{~km}$ into the adjacent Bhaga valley ( $\mathrm{A}$ in Fig. 5.1). The direction of flow within a glacier, and hence debris transport, is determined by the direction of ice surface slope. Therefore, to facilitate the conveyance of these erratics, the ice-shed must have been to the south of this fault, with the ice surface sloping down from the source of the High Himalaya Crystalline rocks to the area of deposition. This scenario is depicted in Figure 5.2, which illustrates the most northerly position that the ice-shed could have occupied to distribute the observed pattern of erratics. It could, of course, have been many tens of kilometres to the south. The watershed may or may not have been further south than at present.

Present and past climatic gradients reflect attenuation of south-west monsoon precipitation. This precipitation gradient would almost certainly have existed during the Chandra Stage, delivering greater precipitation to the High Himalaya Range than the Zanskar Range. This, in combination with the probable greater elevation of the High Himalaya, explains the position of the Chandra ice-shed as demonstrated by the movement of High Himalaya Crystalline rocks into the Zanskar Range (Fig. 5.2).

Given the proposed position of the former ice-shed, the low relative relief of the former topography and the extent of erratic transport, Chandra Stage ice in the Zanskar Range may have been in the form of an ice-cap, which locally submerged the topography, rather than valley glaciers. This explains the position of erratics in otherwise problematic locations. For example, Osmaston (1994) describes gneiss erratics from near Tantak Gompa (B in Fig. 5.1), at $>100 \mathrm{~m}$ a.r.l. (Fig. 1.5 in Osmaston, 1994), which he reluctantly accepts as evidence for ice flowing $20 \mathrm{~km}$ upvalley from the Tsarap-Lingti Chu. Much of this improbable ice flow is unnecessary given that ice flowed down the Tsarap valley and the remaining comparatively short up-slope distance to Tantak Gompa could have been achieved had the area been 


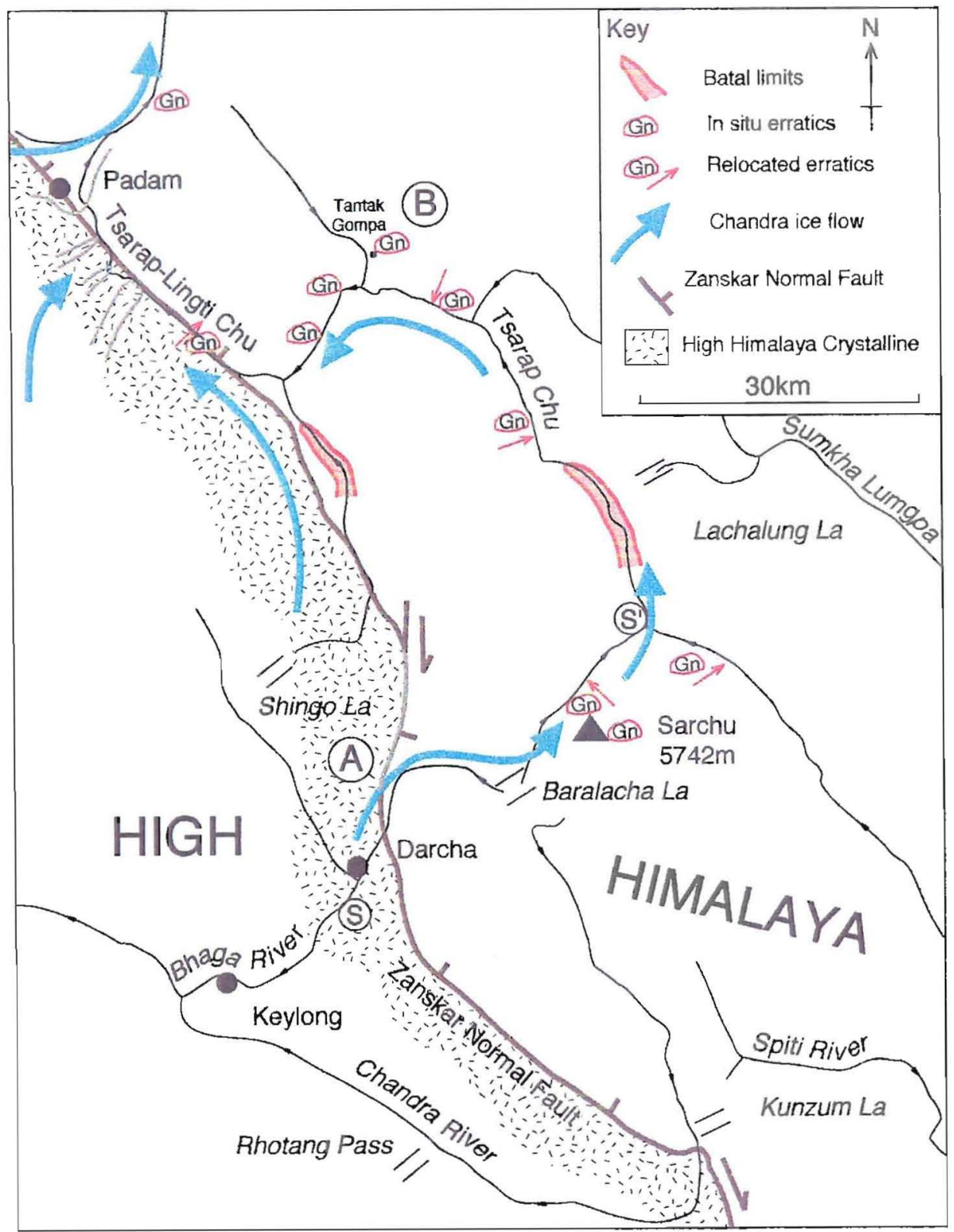

Figure 5.1 The Tsarap and Tsarap-Lingti rivers, showing the location of high level gneiss erratics, the Zanskar Normal Fault (which forms the north-eastern boundary of the High Himalaya Crystalline rocks) and proposed ice flow direction during the Chandra glaciation. A - the probable source of erratics on Mount Sarchu. B - Tantak Gompa (see text). S-S' is the section shown in Figure 5.2. 


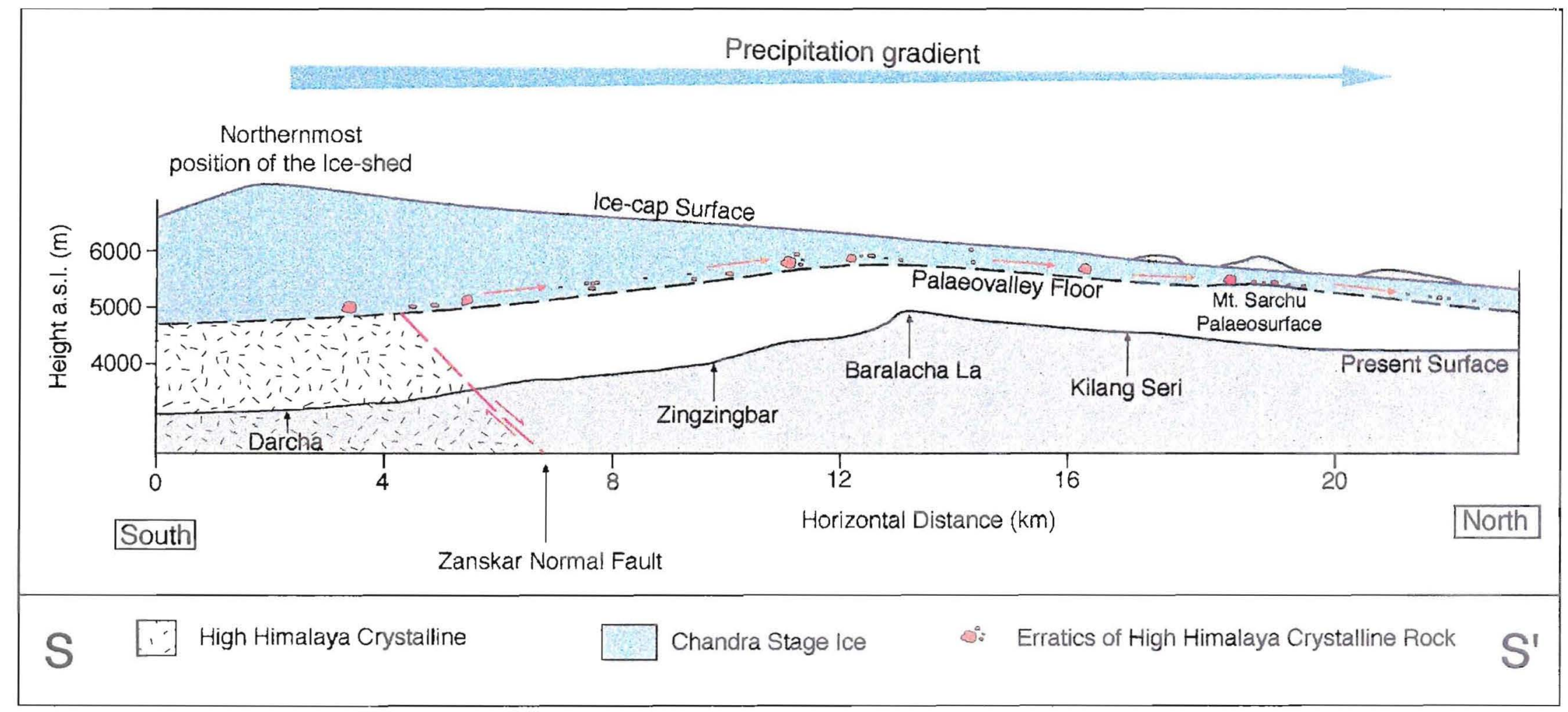

Figure 5.2 Schematic section (S-S' in Figure 5.1) along the Upper Bhaga and Yunan/Tsarap valleys, illustrating the northernmost possible position of the Chandra Stage ice-shed, as dictated by the presence of erratics on Mount Sarchu. 
submerged by an ice-cap. A more topographically confined valley glacier is less likely to have flowed up-valley.

No suitable samples for OSL dating relating to the Chandra Stage were found. It must, however, be older than the valley system cut into the surface that the ice occupied. Sediments from close to the valley floor have been dated, the oldest age estimate from these is $78.0 \pm 12.3 \mathrm{ka}$ BP (V053), which relates to the Batal Stage as discussed in the following section.

\subsubsection{Batal Stage}

Within the present incised valley system, a down-river change in valley form, from broad U-shaped troughs with much fill to narrow V-shaped rock gorges, is the most striking evidence for a former ice limit. This change in gross valley morphology from a typically glacial to distinctive non-glacial form, which is associated with subdued moraine ridges and allied geomorphological and sedimentological evidence, can be observed in most major valleys (e.g. the Kurgiakh, Tsarap, Zara, Gya and Khurma valleys). Two exceptions to this pattern were observed, with the Markha valley remaining broad to its mouth, probably due to the underlying structural geology (Section 5.2), and the Rumbak valley which owes its dramatic narrowing to a change in lithology rather than to glacial erosion.

Moraines associated with this stage often show considerable degradation, as observed for those of the Batal Stage in the Kurgiakh valley. In this example a large moraine ridge and drift limit are preserved on the eastern valley side, in contrast to the western flank, which has only a thick sequence of mass movement deposits. In the Zara valley only a lag of large erratics remains with any terminal moraine ridges having been removed by fluvial erosion, which is not surprising given that the relatively powerful river is confined to a narrow flood plain. Particular circumstances are required for extensive preservation, an example of which can be seen up-valley where the Zara undergoes a $90^{\circ}$ change in orientation. At this locality a moraine ridge on 
the outer side has been formed abutting the Mare Plain, which is broad and, following a pre-Batal river capture event, has only a feeble ephemeral drainage. Consequently the landform is little affected by fluvial erosion.

Evidence for the Batal Stage is unquestionably glacial in origin and shows spatial and temporal separation from the older and younger stages (Table 5.2). Demonstrating that the sediments relating to the Batal Stage are stratigraphically and sedimentologically distinct from those of the younger Kulti Stage is more difficult. Establishing the relative stratigraphic position of landforms and sediments is problematic due to the discontinuous nature of glacial sediments and landforms, and the large distances between the moraine groupings belonging to each stage. A sedimentological distinction is hard to make as sediments from each stage are similar, probably having been deposited by the same processes under similar environmental conditions.

The Batal Stage was an extensive valley glaciation confined within the deep troughs of the present valley system as demonstrated by the down-valley limit of moraines (e.g. Reru valley), erratic distribution (e.g. Gya and Kurgiakh valleys) and trimlines (e.g. Tsarap valley). Except for cross-cutting moraines near Reru, there is no evidence for multiple advances during this stage in the Zanskar Range.

There are two source areas for Batal Stage glaciers in the Zanskar Range, the High Himalaya feeding glaciers in the southern part of the field area (e.g. Reru) and the Nimaling Massif, which supported an ice-field draining into the Zara, Markha and Gya valleys (Fig. 5.3). Many valleys remain unexplored and, as such, the pattern displayed in Figure 5.3 is representative only, with the Sha-de valley (a major tributary of the Tsarap valley), for example, likely to have both Batal and Kulti Stage limits.

The most obvious and useful weathering indicator for Batal Stage landforms in the Zanskar Range is the presence of well developed tafoni boulders, a criteria used by Osmaston (1994) in correlation of moraine limits. Use of this weathering 
phenomenon is restricted to those palaeoglacier margins with boulders of coarse grained crystalline rock on stable moraine ridges. Fortunately, as the majority of palaeoglaciers of this stage issued from the two areas of such bedrock, the High Himalaya and Nimaling Massif (Fig. 5.3), the criterion is widely applicable.

H. Osmaston has collected OSL dating samples, prepared and interpreted as part of this study, from moraine limits near Kilima (V053) and from near sTongde (V056), both in the Zanskar valley. This study considers the Kilima limit to represent the maximum extent of the Batal Stage in the Zanskar valley (Fig. 5.3), given the position of the evidence close to the river level. This interpretation is in conflict with the existing chronology as will be discussed in Section 5.2.

Unfortunately, the sTongde sample (V056) did not work well, with preparation failing to produce fine grained quartz, and the fine grained polymineral dose response curve gives errors too large to provide meaningful data (Section 4.2). The other sample (V053) is from silt within a lateral moraine sequence associated with a downvalley limit at Kilima (Fig. 5.3). It was deposited at a time when the frontal position of the former glacier was between the sample site and the Kilima limit $15 \mathrm{~km}$ down valley, and it therefore represents an age close to the maximum extent of the palaeoglacier (Fig. 5.4). The sample worked well, producing pure quartz and the dose response curve displays a low degree of scatter. Consequently, a high degree of confidence is placed in the resultant age estimate of $78.0 \pm 12.3 \mathrm{ka} \mathrm{BP}$. The error, as with all the age estimates, is given to one standard deviation, which means that there is a $68 \%$ probability that the true age lies within the stated margin (Fig. 5.4). A third sample (V055) is also related to the Batal Stage. This sample is from the uppermost silts of a $180 \mathrm{~m}$ thick sequence of valley fill, which resulted from the constriction of drainage in the Tsarap-Lingti valley by ice entering from the tributary Reru valley. The deposition of these silts represents a period when ice had been close to its maximum position for enough time to have allowed the thick sediment sequence to have accumulated and therefore represents an age younger than the maximum advance, as illustrated in Figure 5.4. The age estimate is $40.0 \pm 9.3 \mathrm{ka} \mathrm{BP}$, with ice 
Chapter 5, Style and Timing of Glaciation in the Zanskar Range

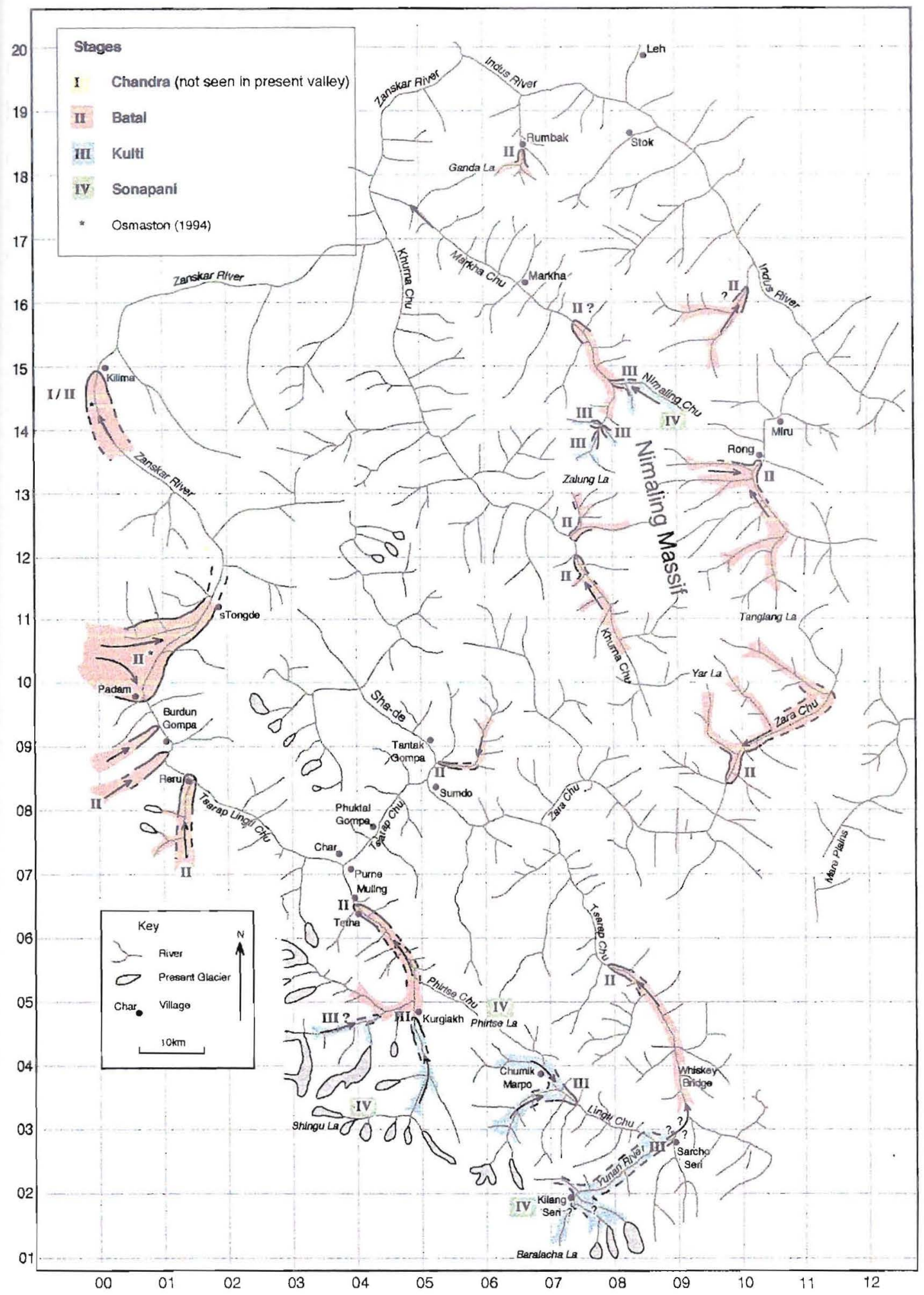

Figure 5.3 Palaeoglacier limits for the Batal and Kulti Stages and Sonapani Advance 
retreat and incision of the sediments following. The dose response curve shows a high degree of scatter, which is reflected in the error. A further date from a sample collected by $\mathrm{H}$. Osmaston from a sandur on the Padam Plain of the Zanskar valley (V058), well within the Batal limits, indicates that the ice had retreated to up-valley of this site by $19.9 \pm 5.2 \mathrm{ka} \mathrm{BP}$.

In summary, the palaeoglaciers of the Batal Stage represent the most extensive valley glaciation of the Zanskar Range (Fig. 5.3), having occupied all the major valleys. They reached their maximum positions in OIS 4 and were retreating by OIS 3 (Fig. $5.4)$.

\subsubsection{Kulti Stage}

Distinct moraine groupings, the Kulti Stage, exist above Batal Stage limits in the upper sections of several valleys (e.g. Kurgiakh, Tsarap/Yunan and Markha valleys). Moraine ridges and mounds associated with the ice limits of the Kulti Stage are well formed, although often partially modified by fluvial erosion, as observed in the Lungtung valley, or obscured by alluvial fan or sandur sedimentation, as described for the Yunan and Kargiakh valleys. The distinction between these moraine limits and those of the Batal Stage is less prominent than the distinction between evidence of the Chandra and Batal Stages. This is as anticipated considering the probable lesser time difference between palaeoglaciers of the younger two stages and their shared valley network. Nevertheless, the spatial and temporal separation between the main bodies of evidence for the Batal Stage and the Kulti Stage is more than sufficient to demonstrate a stratigraphic separation (Table 5.2). The inset chevron ridges of the Kulti Stage are typically followed down valley by a lack of depositional glacial evidence, with Batal Stage moraine ridges grouped close to their maximum palaeoglacier limits. Furthermore, sediments associated with the Kulti Stage yield radiometric age estimates that show a clear difference in age from those derived from 


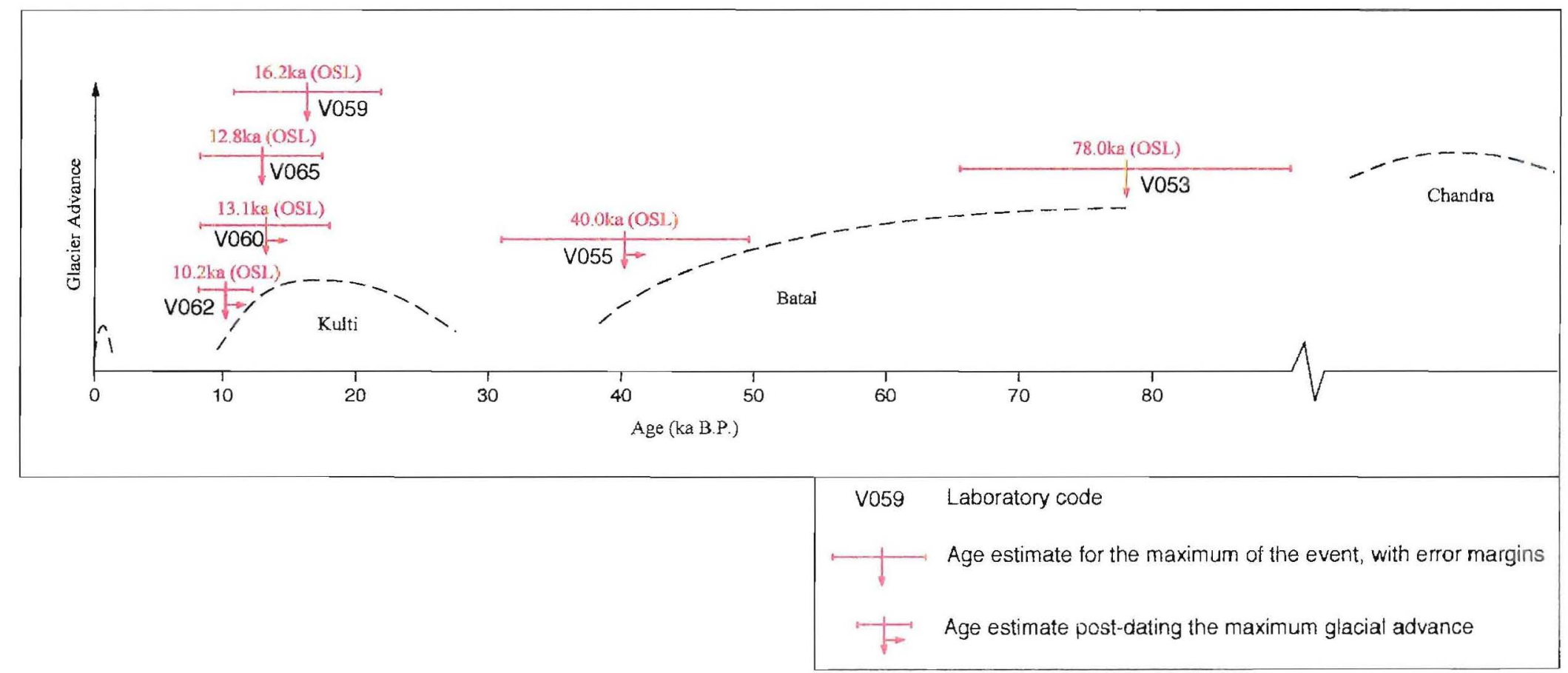

Figure 5.4 Age estimates from the Zanskar Range, showing their relationship to the glacial maxima. 
Batal Stage sediments (Fig. 5.4). This difference in timing is also demonstrated by the development of large debris cones, eroded back to form terraces of $>40 \mathrm{~m}$ height, between Kulti Stage and Batal Stage limits in the Lungtung valley. Only comparatively immature features, eroded to scarps of $<10 \mathrm{~m}$ height, exist within the Kulti Stage limits. There is also a distinct difference in relative weathering, with the well developed tafoni boulders observed on the crests of Batal Stage moraines absent from Kulti Stage moraines.

Geomorphological mapping of moraine limits belonging to the Kulti Stage (e.g. Figs. $3.15,3.17$ and 3.54) demonstrates that palaeoglaciers were restricted to the upper parts of the main valleys and high tributaries leaving many of the main valleys ice free (Fig. 5.3). In the upper Tsarap/Yunan valley, Kulti Stage moraines are particularly obvious and abundant, but become lost down valley with thickening outwash sands and gravels. Thus there is no clear down valley limit, which might be interpreted as evidence for a continuous retreat from the Batal Stage glacier extent, without a younger advance. This is not typical, however, with the Kulti Stage well delimited by moraine ridges in valleys without such an exceptional thickness of outwash (e.g. Sarchu Nala and Nimalaing Plain/upper Markha valley).

Four samples corresponding to Kulti limits have produced age estimates (V059, V060, V062 and V065). Where the Nimaling and Lungtung valleys join to become the Markha valley, a fan of morainic-material extends from the Nimaling limit mapped by Fort (1983) and represents the maximum of this stage. A sample from a fluvioglacial lens from within this landform (V065) dates to 12.8 $\pm 4.7 \mathrm{ka}$ BP (Fig. 5.4). The dose response curve for this sample is very scattered, which is manifest in the large error margin, and IRSL signals suggest that there may be some feldspar contamination (Section 4.2). Consequently, this age estimate has only a moderate degree of confidence. V059 is from a lateral moraine in the Yunan (upper Tsarap) valley, interpreted on grounds of form and position as being close to the maximum of this stage, and gives an age of $16.2 \pm 5.6 \mathrm{ka} \mathrm{BP}$ (Fig. 5.4). The scatter for this sample is moderate and the likelihood of feldspar contamination is shown to be minimal by 
IRSL measurements and as such it is considered to be more reliable than the previous date. V060 and V062 are from fluvioglacial sediments from within recessional moraine ridges from the same valley and show ages, which lie in the correct chronological order, of $13.1 \pm 4.9 \mathrm{ka} \mathrm{BP}$ and $10.2 \pm 2.1 \mathrm{ka} \mathrm{BP}$ respectively (Fig. 5.4). Scatter for these samples is moderate to low and IRSL signals are negligible, giving a reasonable degree of confidence in the age estimates.

Overall, errors on these dates are large, but it is likely that the maximum of this valley glaciation post-dates the global LGM of $\sim 20-18 \mathrm{ka} \mathrm{BP}$. Although the error margins for one standard deviation just extend to include the global LGM, there is a greater probability that the true age of the maximum lies close to the centre of the given range, notwithstanding likely variation between palaeoglaciers. The age estimate from the more proximal of the two relating to recessional landforms (V062) provides good evidence that ice had retreated to near its present position by the beginning of the Holocene.

\subsubsection{Sonapani Advance}

Sharp crested arcuate moraines, which are typically $5-10 \mathrm{~m}$ high with the exception of those at the head of the Nimaling Plain which are up to $100 \mathrm{~m}$, lie $<2 \mathrm{~km}$ from modern glaciers. Landforms and sediments relating to this event are clearly distinct from those of older stages (Table 5.2). There is a dense grouping of terminal/recessional moraine ridges, striated surfaces, kettle-holes, fluted moraines and associated evidence (e.g. Section 3.2, Fig. 3.7), which ceases abruptly down valley, with typically little glacial sedimentation for $>10 \mathrm{~km}$ until close to the Kulti Stage terminus. Nevertheless, moraine ridges of this event can be observed against larger Kulti Stage lateral moraine ridges, which can be distinguished by their well developed desert varnished exposed boulders, at the head of the Nimaling Plain (Section 3.8, Fig. 3.57). 
Detailed geomorphological mapping of glacial evidence from near the Baralacha La in the Yunan valley (Section 3.2) and the head of the Nimaling Plain (Section 3.7) show that moraines form complex multiple ridges. These do not, however, fall into distinct sets.

Clasts on the surface of moraines of this age do not have strong desert varnishes or tafoni weathering. Few sections exist through these fresh moraines leaving little opportunity for OSL sampling. It seems likely, however, on the grounds of position and morphology, that the Sonapani moraines belong to the Little Ice Age, although numerical dating is still required for this to be confirmed. Alternatively, these moraine ridges could represent an earlier Holocene advance.

\subsubsection{Landscape Evolution and Change in Style of Glaciation in the Zanskar Range}

Evidence for the earliest recorded glaciation suggests that ice occupied broad, gentle slopes, remnants of which are preserved as palaeosurfaces. More than $200 \mathrm{~m}$ of subsequent glacial and fluvial erosion has created an incised valley system. Glaciers have become laterally confined with the development of deep valleys, as demonstrated by the change in glacier style from a possible ice-cap to narrow trough glaciers. Upper glaciated parts of these valleys form deep U-shaped troughs, like the Kargiakh and upper Khurna valleys, and lower sections have been cut into deep narrow rock gorges, like the Tsarap-Lingti and lower Khurna valleys. Formation of these deep troughs is likely to be the result of fluvial and glacial erosion. With the Batal and Kulti Stages representing OIS 2 and 4 respectively (Fig. 5.4), the Chandra Stage may belong to the previous glacial (OIS 6), but could be older with several unrecorded cycles of glaciation eroding the landscape. If an OIS 6 age is assumed, $\sim 130 \mathrm{ka}$ BP for the sake of example, then to achieve the $200-300 \mathrm{~m}$ of erosion since the Chandra Stage, an incision rate of $1.5-2.3 \mathrm{mma}^{-1}$ is required, which is a value comparable to those from other Himalayan regions (Section 1.5). 
The proposed evolution of the Zanskar Range is illustrated in Figure 5.5, with the upper block diagram showing broad, gentle slopes occupied by Chandra ice. The lower diagram displays the present incised landscape, with the valley narrowing at its Batal limit as observed in many valleys from the study area, and with recent glaciation developed on otherwise unglaciated slopes. Erosion of deep valleys would have caused isostatic uplift such that previously ice-free upper slopes now occupy altitudes where small glaciers are able to develop, as can be observed around the Phirtse La, which is shown schematically in Figure 5.6. Narrow side gorges, like the Phirtse valley, are likely to have formed as a response to lowering of the local base level by glacial erosion during the Batal Stage and possibly during older unrecorded glaciations (Fig. 5.6).

Evidence for older restricted glaciations is normally erased by younger extensive events, and there are likely to have been many fluctuations of Batal Stage glaciers, and possibly expansions prior to the Batal Stage, which are not preserved in the geological record of the Zanskar Range. Had Chandra Stage ice been less extensive than Batal Stage ice, the former would still be recognised owing to the difference in altitude of evidence for each event (Fig. 5.5). Chandra Stage ice was more extensive, however, extending at least $60 \mathrm{~km}$ beyond Batal Stage margins in the Tsarap valley, although limits are poorly defined. The decrease in extent from the Chandra Stage to the Batal and Kulti Stages may be due to:

(1) Increased aridity due to the progressive restriction of monsoon precipitation caused by uplift of the Pir Panjal.

(2) Greater monsoon intensity at the time of the Chandra Stage relative to the Batal Stage.

(3) The incision of the landscape, which would have allowed late Pleistocene glaciers to reach lower altitudes, balancing their budgets, over shorter horizontal distances relative to earlier glaciers, given similar ELA depressions. 


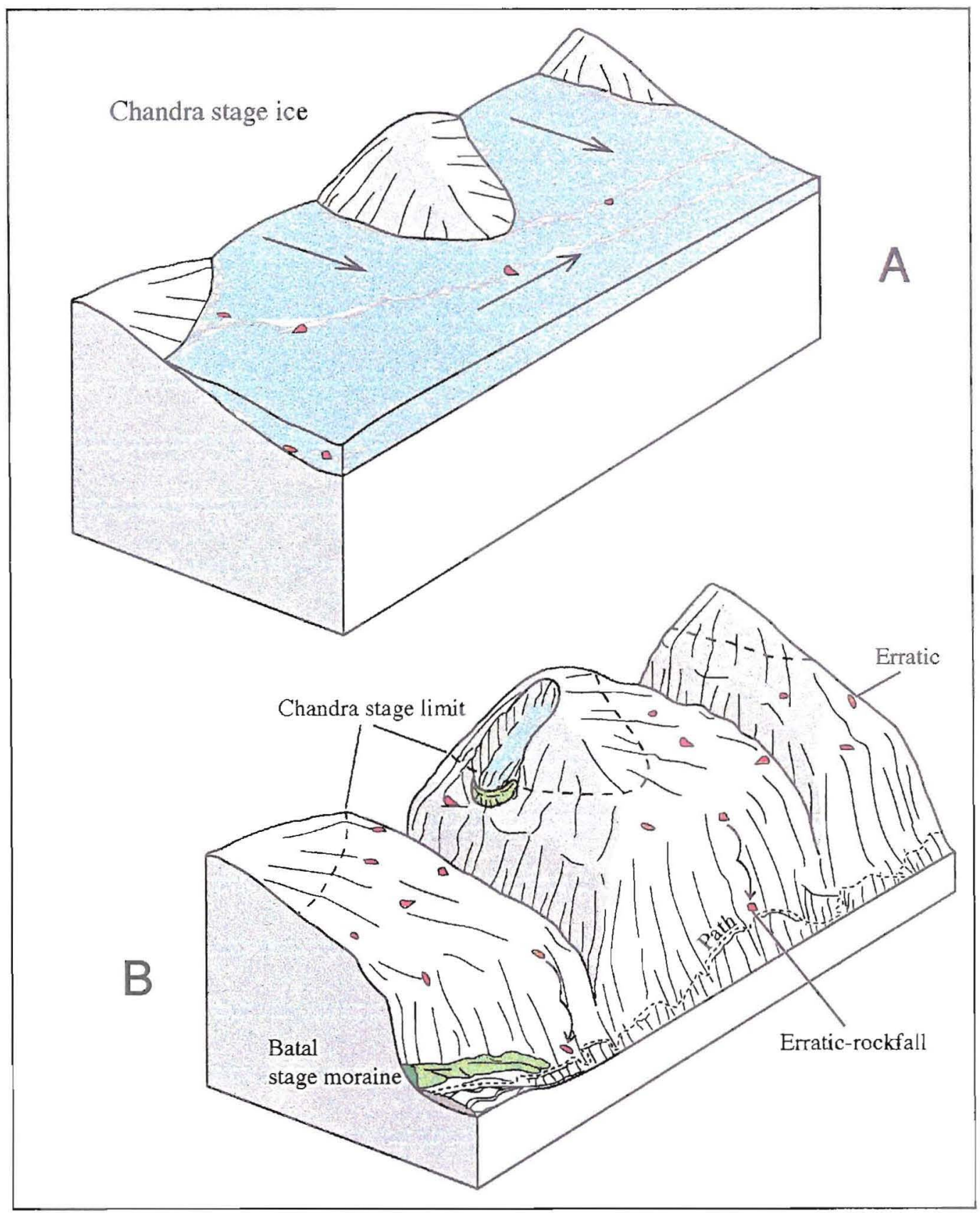

Figure 5.5 Landscape evolution of the Zanskar Range. (a) The Chandra glaciation on a broad, gently sloping land surface. (b) The present incised valley, with a change in valley cross-sectional form at the Batal limit. Erratics from the Chandra surface are shown as rockfalls in the non-glacial gorge as observed in the Tsarap valley. 


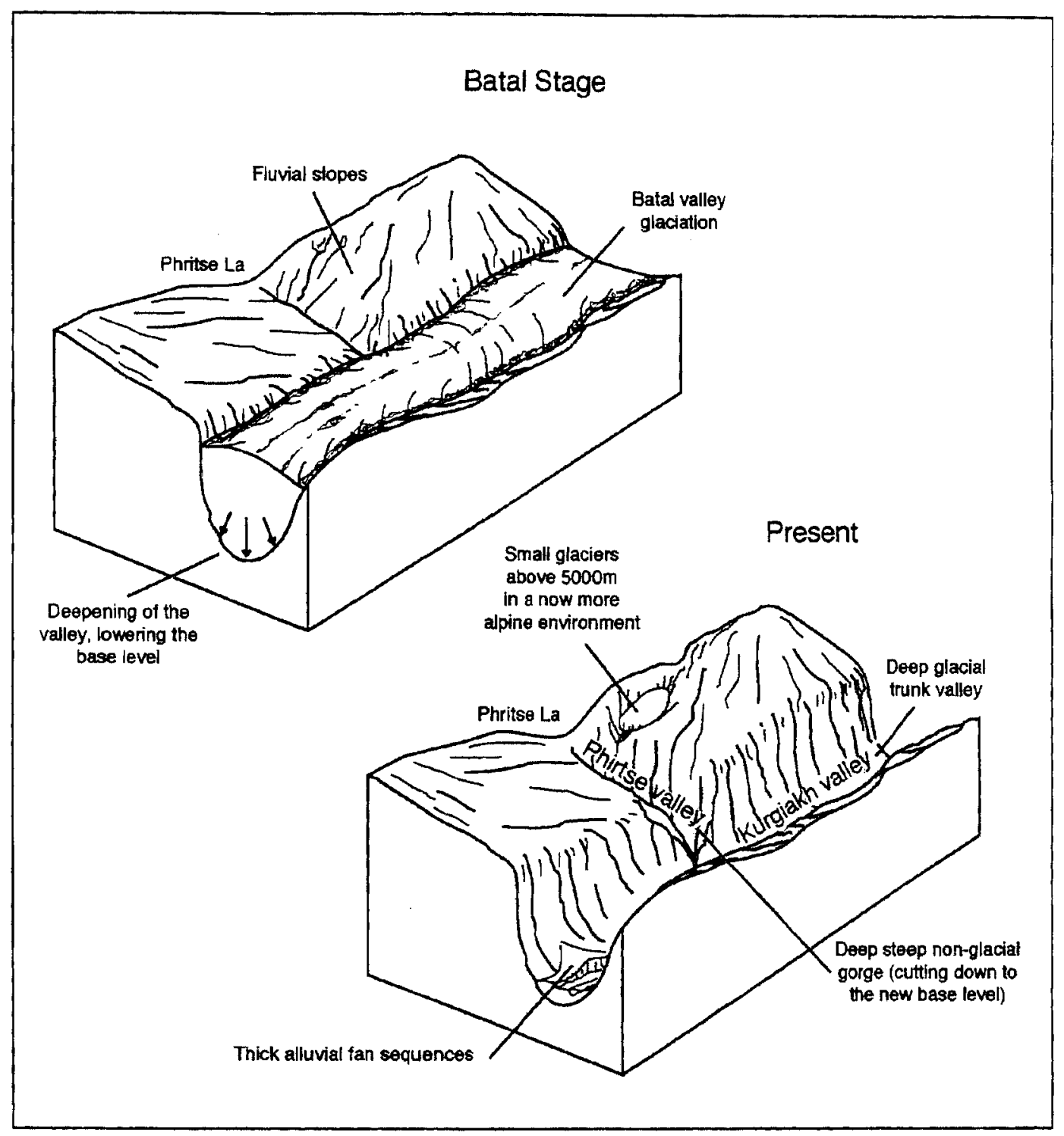

Figure 5.6 Schematic diagram showing the deepening of the Kurgiakh valley, the formation of the non-glacial Phirtse valley and the development of glaciers near the Phirtse La. 
Explanation (1) is likely to have contributed to some degree, however, surface uplift (the absolute altitude gain) during the Late Pleistocene is not known for this part of the Pir Panjal (Section 1.5). There is no evidence for monsoon intensity having been relatively strong during OIS 6 or 8 (Clemens et al. 1991), the likely age of the Chandra stage, suggesting that option (2) is unlikely. Explanation (3), combined with (1), is favoured, given that evidence for the necessary change in topography can be observed in the field, as shown schematically in Figure 5.5.

The greater extent of Batal Stage glaciers relative to Kulti Stage ice is dealt with in the following chapter as part of a wider discussion on the timing of the last glacial cycle in the Himalaya.

\subsection{Comparison with Existing Glacial Studies from the Zanskar Range and Adjacent Areas}

Table 5.3 demonstrates the overall agreement between the proposed chronology and published work from the Zanskar Range. There is, however, contention over specific moraine limits, such as that close to Hankar village in the Markha valley, which has been allocated to different stages in the correlation table of Osmaston (1994) on which Table 5.3 is based.

Much of the interpretation of the evidence from this study (Section 5.1) agrees with the work of Osmaston (1994). Evidence for the oldest event, the Chandra Stage (M1 in Osmaston, 1994; Table 5.3) is rare with erratics high above the present valley floor described from both studies. In the Tsarap-Lingti (Lung-nak) valley, this stage is 'not evident' (Osmaston, $1994 \mathrm{p} 25$ ), but is presumed to have been more extensive than the Batal/M2 Stage identified at Reru and Tema by both studies. The absence of evidence is explained by the former glacier occupying a valley that was well above the present incised gorge (Osmaston, 1994). Similarly, the lower Tsarap and Sha-de valleys are recognised as deep fluvial gorges, which are chiefly non-glacial in 


\begin{tabular}{|c|c|c|c|c|c|c|c|}
\hline $\begin{array}{l}\text { Dainelli (1923) } \\
\text { Upper Indus }\end{array}$ & $\begin{array}{l}\text { Dainelli } \\
\text { (1923) } \\
\text { Zanskar }\end{array}$ & $\begin{array}{c}\text { De Terra and } \\
\text { Paterson (1939) } \\
\text { Upper Indus }\end{array}$ & $\begin{array}{l}\text { Fort (1983) } \\
\text { Upper Indus } \\
\text { and Markha }\end{array}$ & \multicolumn{2}{|c|}{$\begin{array}{c}\text { Osmaston (1994) } \\
\text { Zanskar }\end{array}$} & $\begin{array}{l}\text { Osmaston (in prep. } \\
\text { a) Markha, Gya } \\
\text { and Indus }\end{array}$ & $\begin{array}{l}\text { This } \\
\text { study }\end{array}$ \\
\hline $\begin{array}{c}\text { Small tributary } \\
\text { glaciers }\end{array}$ & Upti moraine & $\begin{array}{l}\text { Small moraines in } \\
\text { upper tributaries }\end{array}$ & $\begin{array}{l}\text { Frontal } \\
\text { moraines Kar } \\
\text { and Nimaling* }\end{array}$ & M4 & $\begin{array}{l}\text { Drung- } \\
\text { drung }\end{array}$ & Pulu (Leh valley) & Sonapani \\
\hline $\begin{array}{l}\text { Tributary } \\
\text { glaciers (no } \\
\text { Indus glacier) }\end{array}$ & sTongde & Tributary glaciers & $\begin{array}{c}\text { Leh and } \\
\text { Hankar* } \\
\text { moraine stages }\end{array}$ & M3 & Tepuk & $\begin{array}{c}\text { Leh (Leh gompa and } \\
\text { main Nyimaling } \\
\text { moraines) }\end{array}$ & Kulti \\
\hline $\begin{array}{l}\text { Partial Indus } \\
\text { glaciation }\end{array}$ & & $\begin{array}{c}\text { Glacier in part of } \\
\text { the Indus }\end{array}$ & Indus* stage & M2 & sTongde & $\begin{array}{c}\text { Nimu and Hankar } \\
\text { moraines }\end{array}$ & Batal \\
\hline $\begin{array}{l}\text { Glacier fills the } \\
\text { Indus }\end{array}$ & & $\begin{array}{c}\text { Great Indus } \\
\text { glacier }\end{array}$ & $\begin{array}{l}\text { Possibly older } \\
\text { glaciations }\end{array}$ & M1 & Kilima & $\begin{array}{c}\text { Indus altiplano } \\
\text { moraines }\end{array}$ & Chandra \\
\hline & & $\begin{array}{c}\text { High glacial } \\
\text { troughs (Kargil) }\end{array}$ & & & & & \\
\hline
\end{tabular}

Table 5.3 Quaternary sequences from the Zanskar Range (after Osmaston, 1994). *These are as shown by Osmaston (1994), but are not given an age other than Pleistocene by Fort (1983) and as discussed in the text are probably better represented if moved one place down in the table. 
character, with evidence for glacial erosion and deposition restricted to sites $>100 \mathrm{~m}$ a.r.l. (Osmaston, 1994). This agrees well with the evidence and interpretation presented in Section 5.1.3 for the Chandra Stage.

There is, however, a difference in interpretation regarding the maximum extent of the Chandra Stage in the Zanskar valley. Osmaston (1994) places the limit of ice at a moraine limit near Kilima, with a second moraine ridge at sTongde ascribed to his M2 Stage. Both moraines and associated sediments are close to river level and have well developed tafoni weathering. This does not fit with the sequence observed in this study area, which has $>200 \mathrm{~m}$ of incision between evidence from the two stages and Chandra Stage erratics without deep tafoni hollows. It is unlikely that the Zanskar River, which occupies an impressive gorge, escaped the incision experienced by its tributaries, as demonstrated by palaeovalley remnants $280 \mathrm{~m}$ above the Tsarap Chu. Indeed, there has been $\sim 300 \mathrm{~m}$ down-cutting in the Indus valley since an early glaciation (probably equivalent to the Chandra Stage) where the Zanskar River enters, as demonstrated by an exemplary palaeosurface (Mitchell, pers. comm.). No high glaciated benches can be observed above Kilima (Osmaston, pers. comm.), but such palaeosurface remnants are rare and are also absent from valleys considered by both studies to have contained Chandra Stage ice (e.g. Tsarap-Lingti (Lung-nak) gorge). This glacial limit is, therefore, considered to represent ice extent during the Batal Stage. Dating results from sediment associated with this margin (Section 5.1.4) support this reinterpretation, giving an age estimate within OIS 4, which is younger than the assumed M1 age of "Middle Pleistocene or older" (Osmaston, 1994, p31) and agrees with other studies from the Himalaya (Chapter 6). It is because of this difference in interpretation that the chronostratigraphic names of Osmaston (1994) are not employed.

In the Tsarap-Lingti (Lung-nak) valley and its tributaries, where the two field areas overlap, Osmaston (1994) records M2 moraines at Reru, Tema, Tok and in the Kurgiakh valley, all correlated on the basis of tafoni weathering of boulders. Batal 
Stage glacial limits are independently recognised in this study at all of these locations.

A glacial limit to the north near Hankar village in the Markha valley (Fort, 1983; Damm, 1997; Osmaston, in prep. a) is also recorded as M2 by Osmaston (in prep. a), which is in agreement with this study. Fort (1983) does not suggest an age other than Pleistocene for this former glacial margin, but in a later paper a global LGM age for this Hankar/Leh Stage is assumed (Burbank and Fort, 1985). Osmaston (1994) considers the global LGM to be the M3 Stage. This is possibly the reason Osmaston (1994) places Fort's (1983) limit alongside the Kulti/M3 Stage (Table. 5.3). The floating chronologies make greater sense if the Kar/Nimaling Stage is correlated with the Kulti Stage, the Hankar/Leh with the Batal, and the Indus with the Chandra.

To the south in neighbouring Lahul, Owen et al. $(1996,1997)$ describe a similar glacial sequence. As the field areas for the Lahul and this study are adjacent and both chronologies are based on numerical age constraints, the nomenclature for Lahul has been adopted. There are only minor differences between the two glacial sequences, one of which is that the Batal Stage glaciation in Lahul is reported as having had two stades, principally on the basis of superimposed drumlins (Owen et al., 1996, 1997). The older group of drumlins are parallel to the north-west/south-east valley axis, with the younger landforms indicating an east-south-east ice flow. Modern glaciers all flow from the valley head and south-western valley wall, with no glaciers on the opposite side (Owen et al. 1996, 1997). During the maximum glacier extent, when the valley was full of ice, the flow and hence the drumlins would have been downvalley. During the later stages, however, ice may have flowed slightly oblique to the valley axis, given the dominant supply from one valley side and eventually would have flowed almost transverse to the trunk valley as ice retreated into its tributaries. A change in ice flow represented by superimposed drumlins does not, therefore, necessarily representing a distinct stade. 
Except for cross-cutting moraines near Reru village, no such evidence for two stades for the Batal Stage was observed. This may, however, be due to the resolution of the evidence, with large erosion-modified subdued moraines no longer preserving distinguishable ridges. Where the Reru valley enters the trunk valley, the TsarapLingti Chu is confined in a $30-40 \mathrm{~m}$ deep bedrock gorge in the north-easternmost edge of its valley, presenting an exceptional situation for preservation. An alternative explanation for the lack of evidence for two stades at all but one of the investigated former limits, is that the younger stade could have been more extensive than the older for the majority of palaeoglaciers. Indeed, there may have been many relatively old, less extensive advances, or given the rather limited and ambiguous evidence from Lahul there may not have been two stades.

Osmaston (1994, p20) noted that "the glacial history of the region [Zanskar] is most evident from the differing forms of its valleys". Indeed, the most obvious evidence for Batal Stage glacial limits in the Zanskar Range is the often dramatic change in gross valley morphology from clearly glacial to narrow fluvial gorges (Section 5.1.4). Similar changes in valley form have been employed in Central Nepal to delimit former glaciation remotely using a digital elevation model and various slope criteria (Duncan, et al., 1998). Given accurate topographic data this methodology would generally work for the Batal Stage in the Zanskar Range. However, the importance of ground truth is highlighted by the Markha valley, which remains broad beyond its limit of glaciation, to its confluence with the Zanskar River. More typical is the adjacent Khurma valley, which narrows to a rock gorge over a short distance around its proposed Batal limit.

No evidence for glaciation is found in the lower Markha, contrary to the findings of Damm (1997) who recognises several ice limits through geomorphological mapping. Beyond the limit at Hankar village, which is recognised by this study and those of Fort (1983), Osmaston (in prep. a) and Damm (1997), two glacial limits are recorded by Damm (1997). These are based almost entirely on 'Schiliffgrenze' (steps/junctions in the valley) and 'Mündungsstufe' (the limit of glacial polishing). All four limits are 
attributed to the late glacial, the most extensive of which reached the Zanskar River (Damm, 1997). Apart from contradicting the new numerical age estimate from this valley (V065, Section 5.1.5), the assumed age is unlikely given that $40-50 \mathrm{~m}$ of alluvium, which is locally $120 \mathrm{~m}$ thick, has been deposited, become well lithified and been incised since any possible glaciation (Section 3.8). Moreover, Glacier Elevation Index (GEI) values for a glacier filling the Markha valley to its mouth would give a depression of $>1000 \mathrm{~m}$ (Damm (1997), double that calculated for neighbouring former glaciers (Section 5.3). Ice may have occupied this section of the Markha valley prior to the Batal glaciation, as suggested by Fort (1983), although she did not find any corroborating evidence for this other than valley shape. The continued breadth of the valley may be due in part to pre-Batal glacial erosion and to its geological structure, the valley axis paralleling the line of the Zanskar Backthrusts (Section 1.5).

Sonapani moraine limits have been described in the Zanskar Range (Fort, 1983; Osmaston,1994, in prep. a; Damm, 1997) and from neighbouring Lahul (Owen et al., 1996, 1997). Although these moraines form complex multiple ridges in the Zanskar Range, they cannot be clearly divided into two distinct groupings as has been done in Lahul (Owen et al., 1996, 1997). This may be a consequence of different glacier dynamics on either side of the High Himalaya climatic divide, with relatively more continental glaciers in the more arid Zanskar Range having a slower response to climate fluctuation, perhaps not recording relatively high resolution changes. Alternatively, the lack of two sub-stages could be a function of preservation.

This advance is assumed to represent a Little Ice Age advance, although no dating evidence exists to support this supposition. Little Ice Age limits have, however, been dated using ${ }^{14} \mathrm{C}$ in the Central Himalya (Fushimi, 1978) and in northern Pakistan one of two ${ }^{14} \mathrm{C}$ dates may represent this period (Derbyshire et al., 1984). 


\subsection{GEI Values from the Zanskar Range}

PalaeoGEI values are calculated from the reconstructed Batal and Kulti Stage glacial margins from the Zanskar Range (Table 5.4) and from those reported from neighbouring Lahul (Owen et al., 1996, 1997) (Table 5.5). A Toe-Headwall Altitude Ratio (THAR) of 0.4 is used (Section 2.3) to allow direct comparison with neighbouring studies, with a ratio of 0.5 using the highest summit rather than twothirds of the headwall altitude also employed to provide data for a regional correlation programme (Lehmkuhl, pers. comm.). In the event of a ratio based on empirical calculations becoming available, toe, headwall and highest summit altitudes are also given (Tables 5.4 and 5.5).

PalaeoGEI values could not be calculated for the Chandra Stage given the uncertainties in its maximum extent, and the morphology and elevation of the landscape at this time. Reconstructed Batal and Kulti Stage GEI values show a mean depression from modern values of $5200-5400 \mathrm{~m}$ a.s.l. of $\sim 500 \mathrm{~m}$ and $\sim 300 \mathrm{~m}$ respectively in the Zanskar Range. This is in good agreement with the estimation of Osmaston (1994), which is $600 \mathrm{~m}$ for the M2/Batal Stage in the southern, less arid, part of the region. Less reliability can be placed on the Kulti Stage indices. Several of these are based on the lowest observed moraines (e.g. upper Tsarap/Yunan valley where moraine mounds are lost under thick outwash) or palaeoglaciers that had aqueous margins (e.g. Lingti valley, which had a glacier calving into a lake dammed by ice in the upper Tsarap/Yunan valley). Sonapani GEI values are not calculated due to the small sample number and the degree of error resulting from topographic uncertainties being greater than the modest depression. Nevertheless, the maximum altitude of Sonapani lateral moraines at the head of the Nimalaing Plain, $5260 \mathrm{~m}$, provides a minimum ELA value.

There are too many uncertainties and too few data points for meaningful comparison between glaciers, which might have examined the role of aspect and other factors in 


\begin{tabular}{|c|c|c|c|c|c|c|}
\hline Stage & Glacier & $\begin{array}{c}\text { Highest } \\
\text { summit (m) }\end{array}$ & $\begin{array}{c}\text { Estimated } \\
\text { upper limit of } \\
\text { ice (m) }\end{array}$ & $\begin{array}{l}\text { Lowest limit } \\
\text { of ice (m) }\end{array}$ & $\begin{array}{l}\text { GEI (0.4) } \\
(\mathrm{m}) \\
\text { (headwall) }\end{array}$ & $\begin{array}{l}\text { GEI (0.5) } \\
\text { (m) (highest } \\
\text { Summit) }\end{array}$ \\
\hline \multirow{13}{*}{ 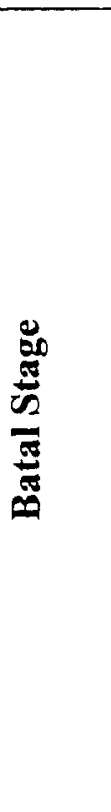 } & Trakkar & 5944 & 5940 & 3760 & 4632 & 4852 \\
\hline & Tema & 5944 & 5940 & 3750 & 4626 & 4847 \\
\hline & Reru & 6248 & 5940 & 3810 & 4662 & 5029 \\
\hline & Tok & 5639 & 5550 & 4170 & 4722 & 4905 \\
\hline & Muling & 6248 & 6100 & 3990 & 4834 & 5119 \\
\hline & Tsarap & 6111 & 5800 & 4030 & 4794 & 5070 \\
\hline & Zara & 6096 & 5940 & 4510 & 5082 & 5303 \\
\hline & Khurna & 6248 & 6100 & 4280 & 5008 & 5264 \\
\hline & Rumbak & 6121 & 5940 & 3900 & 4716 & 5011 \\
\hline & Larsa & 6096 & 5940 & 3510 & 4482 & 4803 \\
\hline & Gya & 6248 & 6100 & 4000 & 4840 & 5124 \\
\hline & Kurma & 6248 & 6100 & 4340 & 5044 & 5294 \\
\hline & & & & Mean & 4787 & 5052 \\
\hline \multirow{8}{*}{ 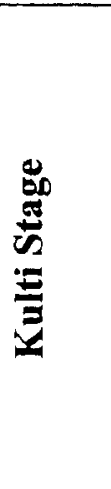 } & Kurgiakh & 6248 & 6100 & 4140 & 4924 & 5194 \\
\hline & Kenlung & 6111 & 5940 & 4590 & 5130 & 5351 \\
\hline & Lungtung N & 6096 & 5940 & 4530 & 5094 & 5313 \\
\hline & Lungtung $\mathrm{E}$ & 6096 & 5940 & 4500 & 4896 & 5298 \\
\hline & Lungtung W & 5640 & $59 \overline{40}$ & 4500 & 4896 & 5070 \\
\hline & Nimaling & 6401 & 6100 & 4200 & 4960 & 5301 \\
\hline & Lingti & 5899 & 5790 & 4500 & 5016 & 5200 \\
\hline & \multicolumn{4}{|r|}{ Mean } & 4983 & 5247 \\
\hline
\end{tabular}

Table 5.4 GEI values for the Batal and Kulti Stages fromthe Zanskar Range. 
glacier distribution, such as avalanching. The average GEI depressions, however, are of great use for regional comparisons.

Modern GEI values from the Zanskar Range fit with estimations given by Osmaston (1994) and with the maps of modern climatic snowlines produced by von Wisseman (1959) for the Himalaya. Von Wisseman's map (Fig. 1.14) clearly shows snowlines rising with north-easterly attenuation of the monsoon and an increase from west to east with the westerly climatic system. There is also a decrease in snowline elevation towards the Tibetan Plateau, possibly due to temperature. The centre of the area shown in this figure has a complex pattern with the Karakoram Range representing an area of low values. These mountains which have peaks $>1000 \mathrm{~m}$ higher than those of the Zanskar Range, may induce precipitation through disruption of the jet stream, but little is known of climatic systems in this region.

To provide a greater sample across a wider area, GEI values have also been calculated for the Batal and Kulti Stages from former glacial limits published for Lahul (Owen et al., 1996, 1997) (Table 5.5). Values are also taken from Burbank and Fort (1985) calculated for their undated Leh Stage (Table 5.5). Although suggested as representing the global LGM, this stage is reinterpreted as being equivalent to the Batal Stage (OIS 4) on the grounds of order in the sequence of moraine limits, morphology of the moraine ridges and palaeoglacier extent.

Batal and Kulti Stage GEI values from the Zanskar Range and adjacent areas are plotted along a south-west to north-east section to show the climatic gradient (Fig. 5.7). Batal Stage GEI values increase from south-west to north-east from $\sim 4200 \mathrm{~m}$ to $\sim 5000 \mathrm{~m}$ before decreasing to $\sim 4300 \mathrm{~m}$ around the Indus valley (Fig. 5.7). This northeasterly increase reflects the monsoon precipitation gradient, as illustrated by climatic data and modern snowlines. Burbank and Fort (1985) attribute the low values on the northern side of the Indus, relative to the southern side, to differences in bedrock configuration. They suggest that the near vertical molasse of the northern Zanskar Range prevented glaciers from descending as far as those on the northern side, the 


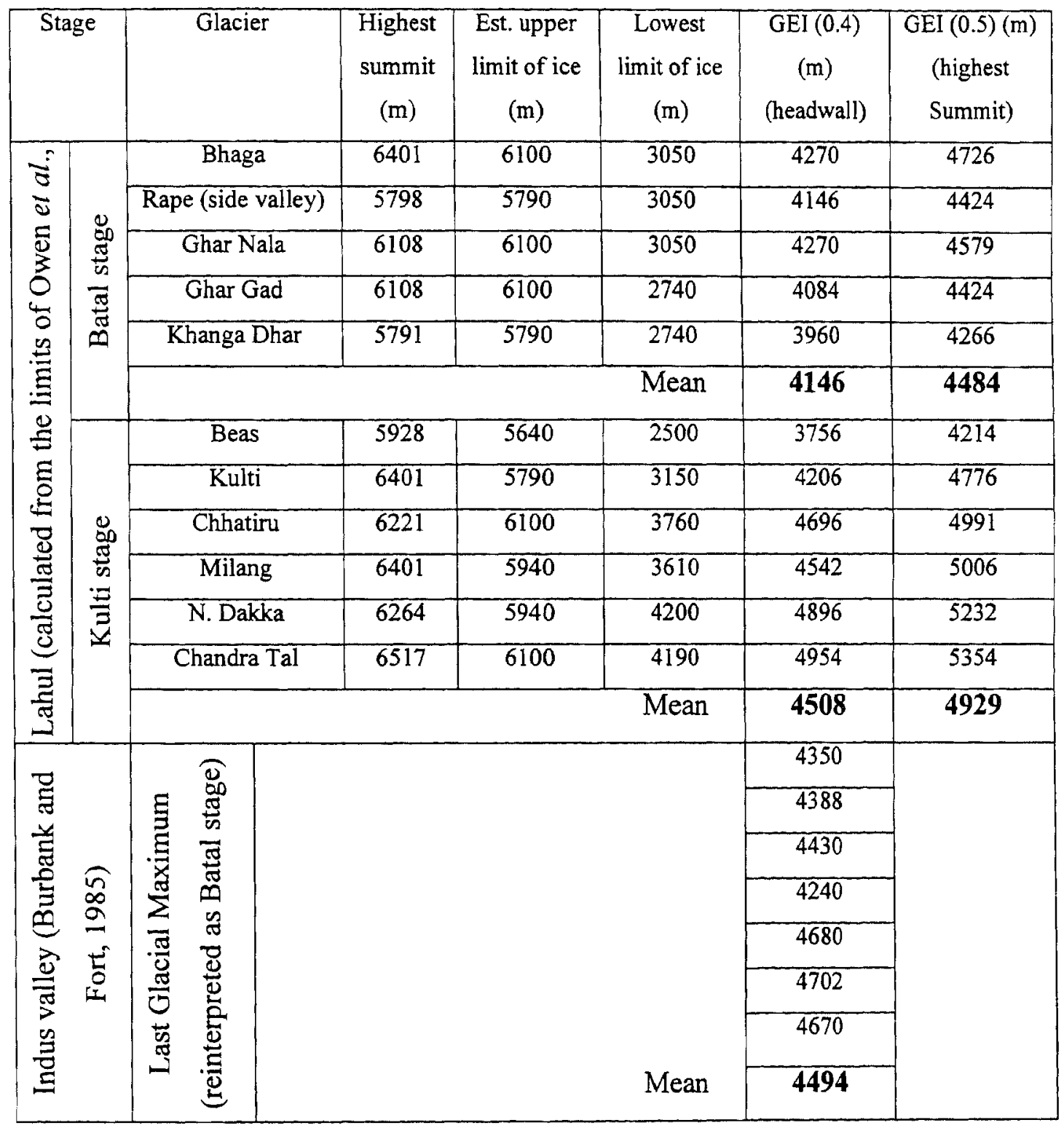

Table 5.5 GEI values for the Batal and Kulti Stages in Lahul and the Indus valley near Leh. 


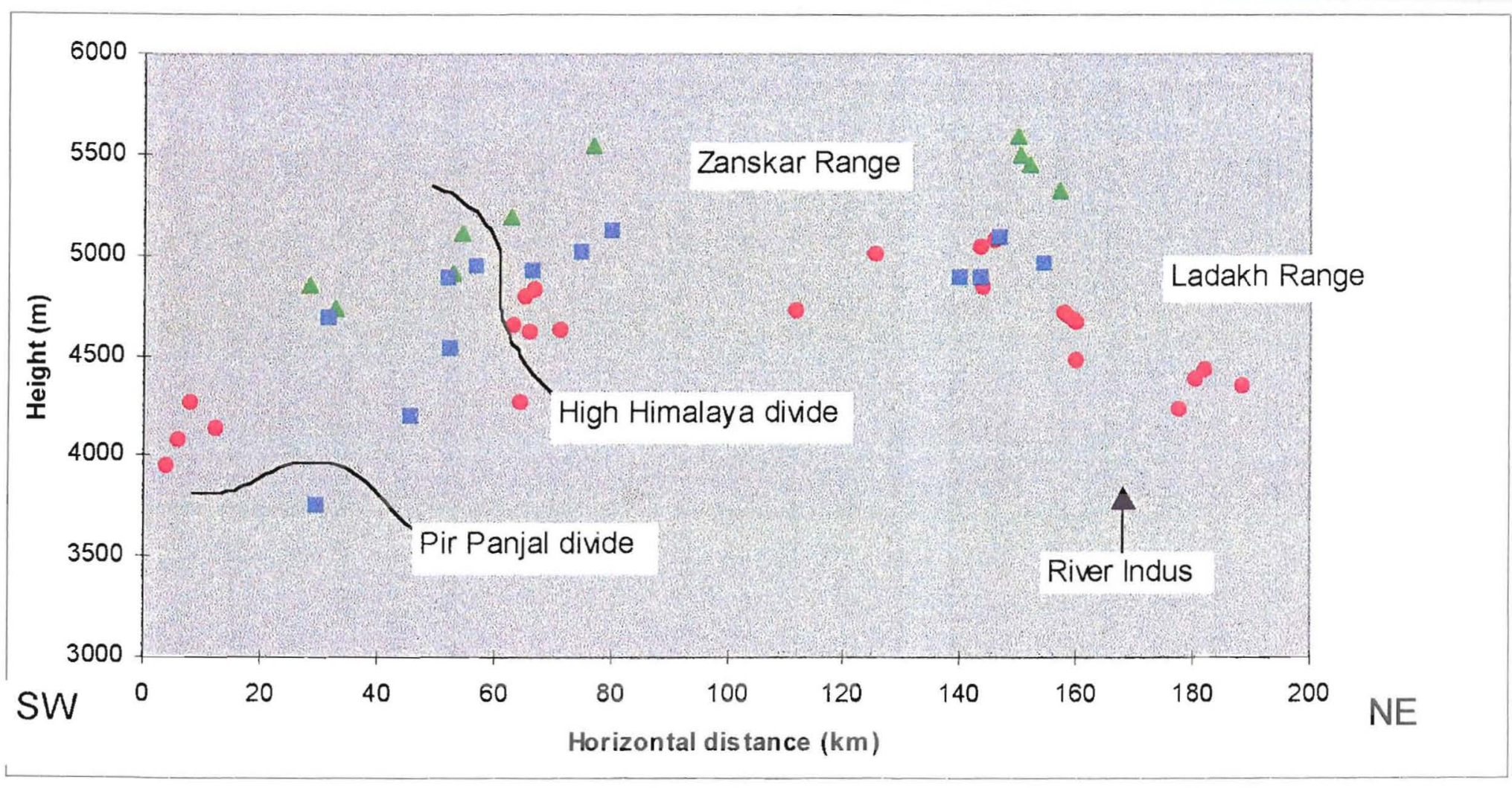

Figure 5.7 GEI values along a south-west to north-east section through Lahul and the Zanskar Range, for modern glaciers (green), those of the Kulti Stage (blue) and those of the Batal Stage (red). 
interlocking spurs presenting a "bulkward" to the ice (Burbank and Fort, 1985, p143). This explanation is rejected on glaciological grounds by Osmaston (in prep. b). Low values in the southern part of the Ladakh Range may represent channelling of westerlies along the broad upper Indus valley, or an increased influence from the Karakoram Range to the north, which also has large depressions (cf. Scott, 1992), although little is known of the climate of this region.

Correction for differential uplift has been attempted, but available data on uplift rates are for inappropriate time scales and are often too distant for reliable correlation (Section 1.5). It should be noted, however, that a rate of $1 \mathrm{mma}^{-1}$ for the High Himalaya would have raised glacial limits of the Batal Stage by $\sim 80 \mathrm{~m}$. A rate of 3.4$10.0 \mathrm{mma}^{-1}$ for the past $0.4 \mathrm{Ma}$ has been calculated for the Pir Panjal where it borders the Kashmir basin (Burbank, 1982; Burbank and Johnson, 1982). If, for the sake of argument, this rate is taken for the same range to the south of the field area (admittedly $350 \mathrm{~km}$ away), then the uplift would have been $\sim 560 \mathrm{~m}$ (taking $7 \mathrm{mma}^{-1}$ as the average). Uplift in the Zanskar Range is likely to have been far less extreme, with a rate of $<1 \mathrm{mma}^{-1}$ suggested by Burbank and Fort (1985). The north-east rising gradient shown in Figure 5.7, if anything, would steepen given the likely greater uplift for the Pir Panjal Range relative to the High Himalaya Range, which in turn is likely to have been greater relative to the Zanskar and Ladakh ranges.

\subsection{Conclusions}

Following stratigraphic procedures, the evidence described can be divided into three main glacial stages and a minor advance. As the pattern and dating correlates well with the adjacent Lahul area, the stratigraphic names proposed for that area are adopted. The oldest recognised glacial stage, the Chandra, was the most extensive glaciation, although evidence is sparse and found high above the present valley system, preventing accurate reconstruction of ice extent. Erratic distribution suggests that it formed an ice-cap centred over the High Himalaya. No numerical age 
estimates exist, but the Chandra Stage must be older than sediments from the incised valley system which date to $78.0 \pm 12.3 \mathrm{ka} B P$. The next oldest event, the Batal Stage, was an extensive glaciation of the present valley system, with its maximum close to $78.0 \pm 12.3 \mathrm{ka} \mathrm{BP}$. The third stage recorded, the Kulti, was a less extensive valley glaciation, dating to after the global LGM. A minor advance, the Sonapani, may represent the Little Ice Age. The landscape of the Zanskar Range has become incised with an increase in relative relief due to uplift induced dissection and/or glacial erosion. The change in glacial style from broad glaciers, possibly forming an ice-cap, to laterally constricted trough glaciers may be due to this incision of the landscape and/or uplift of south-westerly ranges, progressively blocking monsoon precipitation. The interpreted glacial chronology agrees well with existing studies from the Zanskar Range, although individual palaeoglacier margins are disputed. GEI values for the Batal and Kulti Stages in the Zanskar Range were depressed by $\sim 500 \mathrm{~m}$ and $\sim 300 \mathrm{~m}$ respectively. Reconstructed Batal Stage GEI values from across the region increased from the south-west to the north-east with the monsoon-orographic precipitation gradient. The trend then dips towards the south slope of the Ladakh Range, possibly representing channelling of westerly depressions along the Indus valley or an influence from the Karakoram Range to the north. Kulti Stage values follow a similar trend, but display a greater degree of scatter. 


\section{Regional Comparison and Climatic Inferences}

\subsection{Introduction}

The results of Chapters 3 and $\mathbf{4}$, as interpreted in Chapter $\mathbf{5}$, are discussed in a regional context. First, the style and timing of glaciation in the Zanskar Range will be compared to previously published research from the Himalaya. It will then be shown that there is an emerging pattern of asynchronous maxima for the last glaciation between the north-west Himalaya, the Kunlun and northern Karakoram Mountains, and the central and eastern Himalaya. As part of this discussion on the possible reasons for this variation, the relative roles of monsoon and westerly climatic fluctuation will be considered. Finally, regional trends of GEI values are reported and difficulties of comparison highlighted.

\subsection{Style of Glaciation}

The style of glaciation in the Zanskar Range (Chapter 5) for the most part agrees with those existing glacial chronologies from the Himalaya (Fig. 6.1). The majority of these recognize three glacial stages, the oldest being a glaciation of a broad valley, remnants of which remain as high palaeosurfaces, with two subsequent laterally confined glacial stages, recorded by moraine ridges within deep valleys (e.g. Porter, 1970; Shroder et al., 1989; Owen et al., 1996, 1997). One or two minor advances are also commonly reported (e.g. Sharma and Owen, 1996). This pattern, however, is not repeated in every Himalayan glacial record, with the number of stages and stades differing in a few published chronologies. The following paragraphs will examine those glacial chronologies that do not fit the general pattern. 


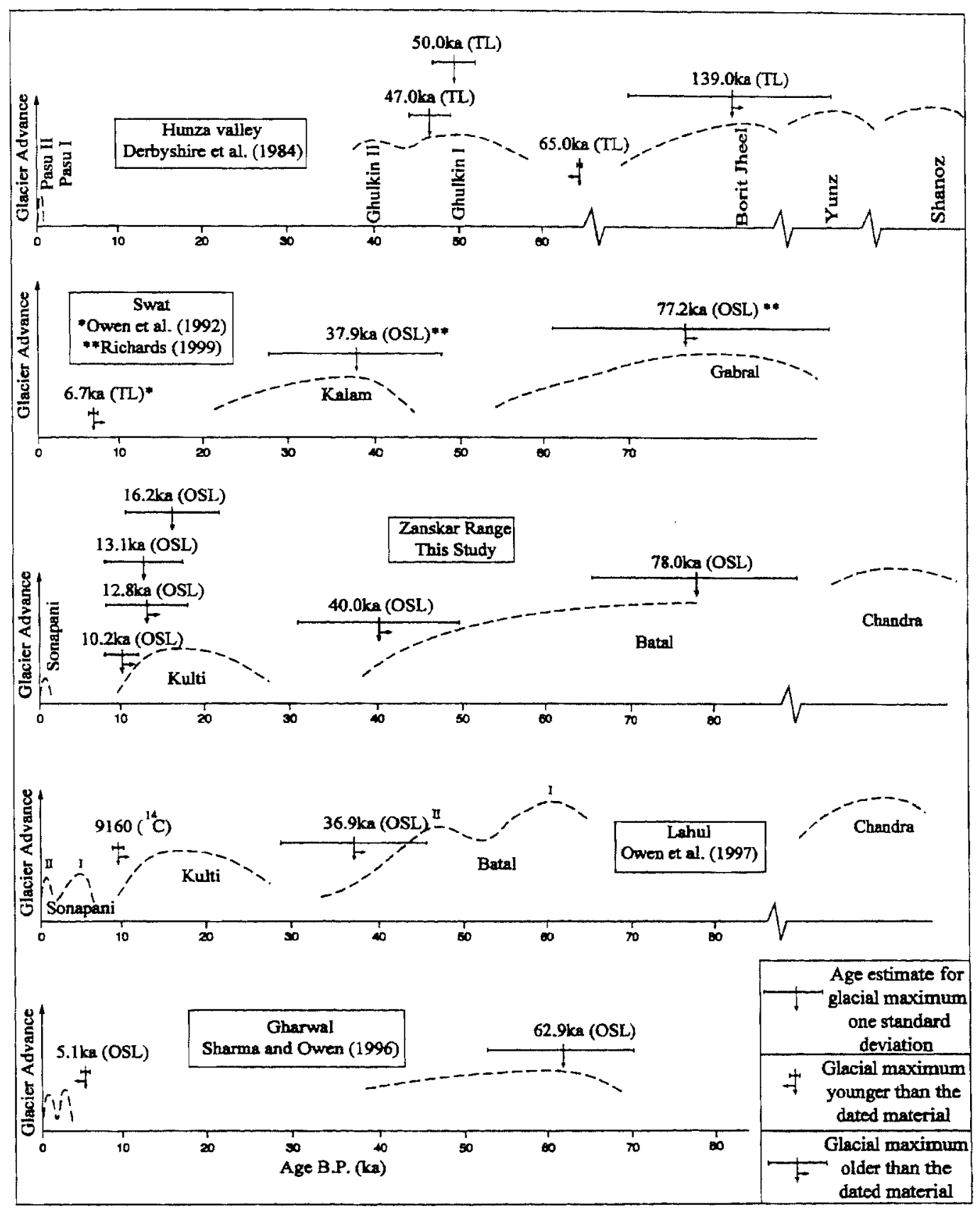

Figure 6.1 Selected glacial chronologies from the north-west Himalaya. 
The sequence determined in the Hunza valley indicates the existence of an additional stage, with two undated glaciated palaeosurfaces recognized, the Shanoz ( $850 \mathrm{~m}$ a.r.l.) and the Yunz Stages (550m a.r.1.), in addition to moraines within the present valley which represent the Borit Jheel and the Ghulkin Stages (Fig. 6.1; Derbyshire et al, 1984). This may be due to the rapid uplift of the Karakoram Mountains and their incision, which has been shown to have kept pace with uplift (Burbank et al., 1996). The Shanoz Stage surface may have been elevated and cut into it, such that the Yunz Stage ice occupied a relatively incised valley. Further incision prior to the Borit Jheel and Ghulkin Stages would then leave two palaeosurfaces. With lower uplift and erosion rates, ice belonging to both the early periods might have occupied the same valley, in which case the Yunz Stage ice would likely destroy evidence for the Shanoz glaciation. Alternatively, other areas studied may not have been glaciated during the Shanoz Stage, evidence for it may have been removed by erosion, or the high altitude inaccessible palaeosurfaces may not have been recognized as representing two events.

In the Garhwal no equivalent to the youngest glacial event ( $\equiv$ Kulti Stage of Lahul and the Zanskar Range) has been reported (Fig. 6.1; Sharma and Owen, 1996). There are two possible explanations for this:

(1) Evidence for this advance has been destroyed by erosion.

(2) There was a steady retreat from the Bhagirathi Stage (三 Batal Stage), without the standstill or advance of other regions.

It is unlikely that all traces of Kulti Stage moraine ridges would have been removed by erosion, given the extensive preservation of both older and younger ridges (Sharma and Owen, 1996). Margins of the Kulti Stage in the Zanskar Range are, however, eroded or obscured by out-wash in some valleys, and it may be that this stage is not well represented in the valley investigated by Sharma and Owen (1996). 
Whether this valley is an exception or is representative of the wider area will remain unclear until further investigation has been undertaken.

There are also fewer major glacial events reported from central Nepal, due to the youngest stage having been more extensive than the previous advance (Shiraiwa and Wantanabe, 1991; Duncan et al., 1998), as discussed in Section 6.4. In addition, mass-movement processes on the southern monsoon dominated flank of the Himalaya in central Nepal have eroded or buried much glacial evidence making recognition of older events difficult (Fort, 1995).

The number of stades belonging to each event also varies between studies (Fig. 6.1). The Batal Stage, and those glacial events assumed to be roughly contemporaneous, are reported as a single event (e.g. in the Garhwal, Sharma and Owen, 1996) and as having had two stades (e.g. in Swat, Porter, 1970; in Lahul, Owen et al., 1996, 1997). New evidence from the Zanskar Range identifies a single advance, except in one valley where exceptionally well preserved moraine ridges demonstrate a minor readvance (Chapter 5). Likewise, the Kulti Stage, and those stages assumed to be approximately coeval, has evidence for two stades in some areas (e.g. in Hunza, Derbyshire et al., 1984) and not in others (e.g. Lahul, Owen et al. 1996. 1997), although correlation is difficult due to the lack of reliable age estimates (see below). There are two possible explanations for these differences:

(1) Evidence for this glacial stage is of a low resolution, often relying on change in valley form and large but subdued moraine ridges. Consequently, the resolution required to distinguish the two stades may be inadequate for all but the best preserved marginal sites.

(2) It is likely that there were glacier to glacier variations, relating from local climatic and topographic conditions. Some palaeoglaciers may not have readvanced, or may have advanced further during the second stade, destroying evidence for the first. 


\subsection{Timing of Glaciation in the North-west Himalaya}

New dates from the Zanskar Range (Section 5.1) have greatly improved our understanding of the timing of glacial events in the north-west Himalaya (Fig. 6.2). Existing numerical age estimates for Himalayan glaciations, which are considered reliable, are few and from widely spaced studies (Section 1.6.3). Nowhere is the oldest event ( $\equiv$ Chandra Stage) numerically age constrained. It must, however, predate younger events by sufficient time to have allowed $200-300 \mathrm{~m}$ of valley deepening in the Zanskar Range (Chapter 5) and $\sim 550 \mathrm{~m}$ or $\sim 850 \mathrm{~m}$ in the Hunza valley (Derbyshire et al., 1984), depending on which of the two palaeosurfaces, if either, correlates with the Chandra Stage.

The second oldest event ( $\equiv$ Batal Stage) is constrained by OSL age estimates of $36.9 \pm 8.4 \mathrm{ka} \mathrm{BP}$ and $43.4 \pm 10.3 \mathrm{ka}$ BP from deltaic sediments from Lahul, which postdate the glacial maximum (Owen et al., 1997). The lake in which the deltas were formed existed because of a late stage tributary ice dam in the upper reaches of the valley, some $110 \mathrm{~km}$ from the maximum palaeoglacier extent. Thus, the age estimates are a minimum bracket as denoted in Figure 6.2. Similarly, a minimum date of $41.1 \pm 1 \mathrm{ka}$ BP $\left({ }^{14} \mathrm{C}\right)$ has been obtained from the Namunani Peak region, close to the western Nepalese/Indian border (Derbyshire et al., 1991). Although this fits exceptionally well with the emerging chronology shown in Figure 6.2, this date is excluded as its association with the glacial sequence is not reported. Three age estimates from landforms associated with the maximum glacial advance of this stage, dating fluvioglacial facies from the till complexes of moraine ridges, are given as

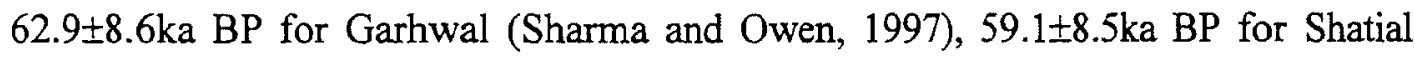
(Middle Indus valley) and $77.2 \pm 18 \mathrm{ka}$ BP for Swat (Richards, 1999). TL dates from the Hunza valley (Derbyshire et al., 1984) are not considered to be reliable given the unrealistically small errors and lack of information regarding the methodology, and as such are not included in Figure 6.2. The Borit Jheel stage may correlate with the 


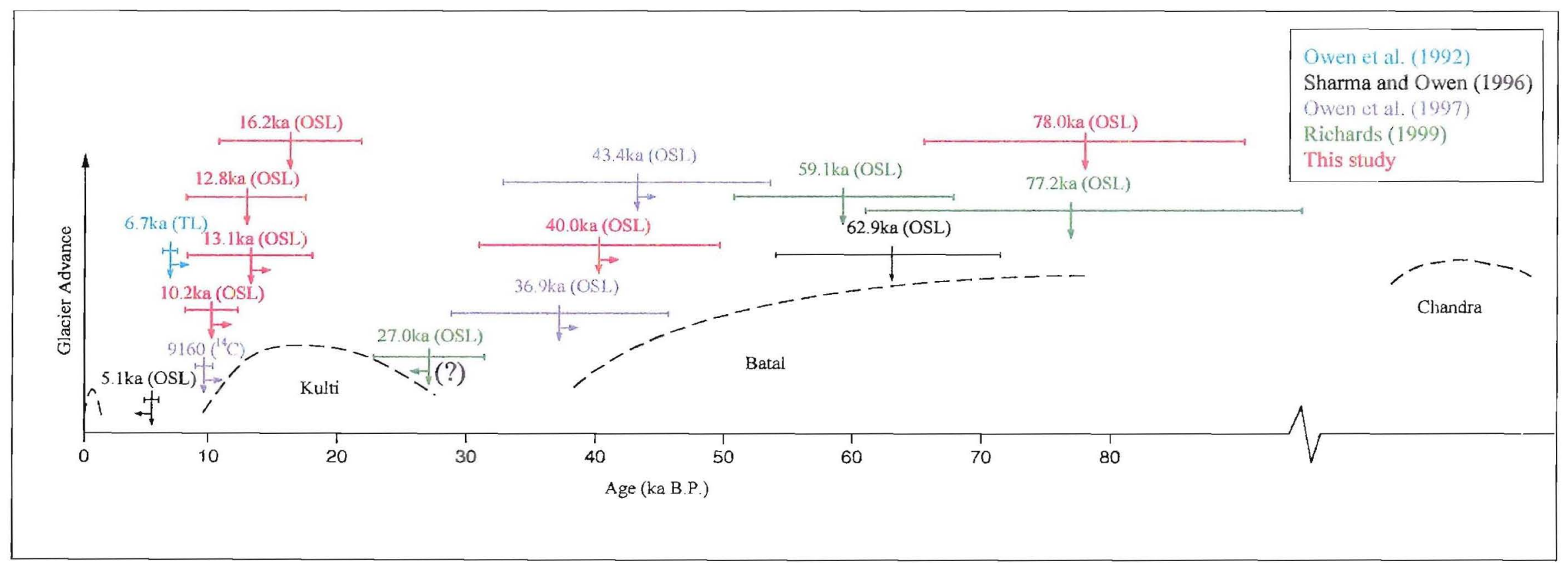

Figure 6.2 Age estimates from the north-west Himalaya superimposed onto the Zanskar Range sequence, assuming that the glaciation across the region was roughly contemporaneous. (?) denotes the Jalipur tillite, the interpretation of which is disputed (see text). 
Batal Stage and the Ghulkin Stage may be equivalent to the Kulti Stage, although this speculation remains to be tested. The new OSL age estimates from the Zanskar Range reinforce this emerging chronology, with a fourth age estimate relating to the maximum glacier extent of $78.0 \pm 12.3 \mathrm{ka} \mathrm{BP}$ and one which places this maximum before $40.0 \pm 9.3 \mathrm{ka} \mathrm{BP}$ (Fig. 6.1). All four age estimates for the maximum extent of the advance have overlapping errors (at one standard deviation), although these are large.

Without dates from the Hunza valley, the age of the third glacial event (झ Kulti Stage) is not well constrained. An OSL date from Swat in northern Pakistan of 37.9 $\pm 10 \mathrm{ka}$ BP is not included as, although the two sub-methods used give the similar ages, the sample shows considerable scatter (Richards, 1999).

An age estimate of $27.0 \pm 4.3 \mathrm{ka}$ BP for the Jalipur Tillite, from the Middle Indus valley in northern Pakistan, commands a high degree of confidence given that the same age has been attained employing several OSL techniques on sub-samples (Richards, 1999). The relationship of the tillite, which outcrops at a number of valley floor localities, to the glacial sequence is disputed (cf. Shroder et al., 1993). An early Pleistocene age is proposed by Shroder et al. (1989) on the basis that the deposits are well lithified and have undergone major tectonic deformation. The valley floor position of such old sediment, which would be expected to pre-date the valley floor formation, is explained by overthrusting, with the sediment protected from erosion in the foot-wall of a fault. Conversely, Owen (1989) suggests, through detailed sedimentology, that the tillite has undergone only minor tectonic modification, but major subglacial deformation, and proposes a relatively younger age. For an Early Pleistocene age, an equivalent till would be expected to have survived on at least some high palaeosurfaces, but no such till has been found (Shoder et al., 1993). Given the glacial deformation (Owen, 1989), the maximum of the advance is considered here as younger than the sediment over which it has ridden (Fig. 6.2). The tillite and associated facies must, however, have been deposited proglacially 
otherwise the OSL dating method would not have worked. Further investigation is required to resolve this issue and the uncertainty is indicated in Figure 6.2 .

A ${ }^{14} \mathrm{C}$ age estimate shows that peat overlying moraines in Lahul is of $9160 \pm 70$ radiocarbon years BP (Owen et al., 1997). Unfortunately, this date does not directly bracket the age of the Kulti Stage as the peat lies on older Batal Stage landforms (Fig. 7 in Owen et al. 1997). It does, nevertheless, suggest an increase in temperature and/or precipitation at this time (Owen et al., 1997). This may be taken as an indirect indication of glacier retreat, assuming that the negative effect on glacier mass balance of increase in temperature offset any positive effect of an increase in precipitation. Two age estimates from the Zanskar Range place the maximum of two Kulti Stage glaciers at $12.8 \pm 4.7 \mathrm{ka} \mathrm{BP}$ and $16.2 \pm 5.6 \mathrm{ka} \mathrm{BP}$, with two further age estimates from recessional landforms of $13.1 \pm 4.9 \mathrm{ka} \mathrm{BP}$ from close to the maximum palaeoglacier position, and 10.2 $\pm 2.1 \mathrm{ka}$ BP from a late stage landform (Section 5.1). In spite of having large error margins, age estimates from the Zanskar Range improve the age constraints on the Kulti Stage considering the lack of previously published age estimates, as illustrated in Figure 6.2.

Errors for age estimates relating to the Kulti Stage maximum just extend to include the LGM of 20-18ka BP and it is tempting to correlate this advance with global conditions. The uncertainty is presented to one standard deviation, which means that there is a $68 \%$ probability that the actual age lies within the given errors. There is, however, a greater chance that the true age lies towards the middle of the range and as such it is more likely that the advance post-dates the global LGM. Clearly, to test this additional dates from other parts of the north-west Himalaya are required.

No dates from the Zanskar Range were produced for the Sonapani advance, leaving the bracketing ${ }^{14} \mathrm{C}$ dates of $830 \pm 80 \mathrm{yr}$ and $325 \pm 60 \mathrm{yr}$ BP from the Hunza valley (Derbyshire et al., 1984) as the sole age constraints for a Late Holocene glacial maximum within the north-west Himalaya. As some areas such as Garhwal (Sharma 
and Owen, 1996) and Lahul (Owen et al., 1996, 1997) have two Holocene advances as opposed to one, caution is required with any correlation.

With the six additional OSL age estimates from the Zanskar Range, the maximum advance during the last glaciation of the north-west Himalaya appears to have been at $\sim 80-60 \mathrm{ka}$ BP (OIS 4 ), with a less extensive event shortly after the global LGM (OIS 2). This is assuming that glaciation over the region was roughly synchronous, so that the events being compared are broadly equivalent.

\subsection{Asynchronous Glacial Maxima Between the North-west Himalaya, the Kunlun and Northern Karakoram Mountains, and the Central and Eastern Himalaya.}

There is an increasing realization that mountain glaciations from around the world have often been out of phase with global ice volume, varying in both the relative magnitude and timing of advances (Gillespie and Molnar, 1995). Mountain glaciations also show variation between regions, reflecting local climatic conditions and responding to short term fluctuations, which are not recorded by mid-latitude icesheet advances (Gillespie and Molnar, 1995). This variation in the magnitude of advances is displayed by glaciation of the Himalaya and Tibetan Plateau ( $c f$. Benn and Owen, 1998). The maximum advance from the Kunlun and northern Karakoram Mountains and the central and eastern Himalaya was not during OIS 4, as for the north-west Himalaya (Section 6.3), but close to the global LGM of $20-18 \mathrm{ka}$ BP (Section 1.6.3).

Benn and Owen (1998) reason that the glacial maximum in the Kunlun Mountains, and the north of the Tibetan Plateau, related to global cooling and/or increased precipitation advected by westerly winds. A Global Circulation Model (GCM) simulation for $21 \mathrm{ka} \mathrm{BP}$ shows a strengthening of westerlies at this time, relative to modern conditions (Kutzbach et al., 1998). However, there is little geological 
evidence to confirm this from the Himalaya, except perhaps lacustrine and valley fill records to the south from Tso Kar and the Kashmir Basin (section 1.6.2; Krishnamurthy et al., 1982; Bhattacharyya, 1989). Unfortunately there are no suitable simulations for periods prior to the global LGM, which would have allowed comparison of conditions in OIS 4 and OIS 2 . It is likely that if there was a more vigorous westerly circulation during OIS 2 then similar conditions may have prevailed during OIS 4.

Given the low intensity of monsoon circulation at this time (Fig. 6.3; Section 1.6.1), Benn and Owen (1998) suggest that the maximum advance in the central and eastern Himalaya was due to global cooling. This would result in reduced ablation during the summer accumulation season causing an increase in effective precipitation. The positive effect of lower temperatures on glacier mass-balance must have outweighed the negative effects of reduced precipitation, due to low monsoon intensity, and an increase in evaporation/sublimation, due to a decrease in cloud cover, both of which are simulated by a GCM for $21 \mathrm{ka} \mathrm{BP} \mathrm{(Kutzbach} \mathrm{et} \mathrm{al.,} \mathrm{1998).}$

For the Karakoram, Lahul and Garhwal, Benn and Owen (1998) note a correlation of the glacial maximum at $60-30 \mathrm{ka}$ BP with a Northern Hemisphere radiation maximum and associated enhanced summer monsoon circulation, as reconstructed from Arabian Sea upwelling records (Section 1.6.1; Prell and Kutzbach, 1987; Clemens et al., 1991; Emeis et al., 1995). A glacial maximum during a monsoon maximum may seem paradoxical as the sensible and latent heat released from monsoon storms would have increased glacial ablation. Nevertheless, this could have been the case as much of the monsoon precipitation falls as snow in the high altitude glacial catchments, which is concentrated through avalanching, and debris covered snouts insulate the ablation zone from the effect of increased temperatures (Benn and Owen, 1998). There are two problems with this interpretation:

(1) The above reasoning can equally be applied to the Khumbu Himal, with its maximum advance coinciding with the monsoon minimum of the global 


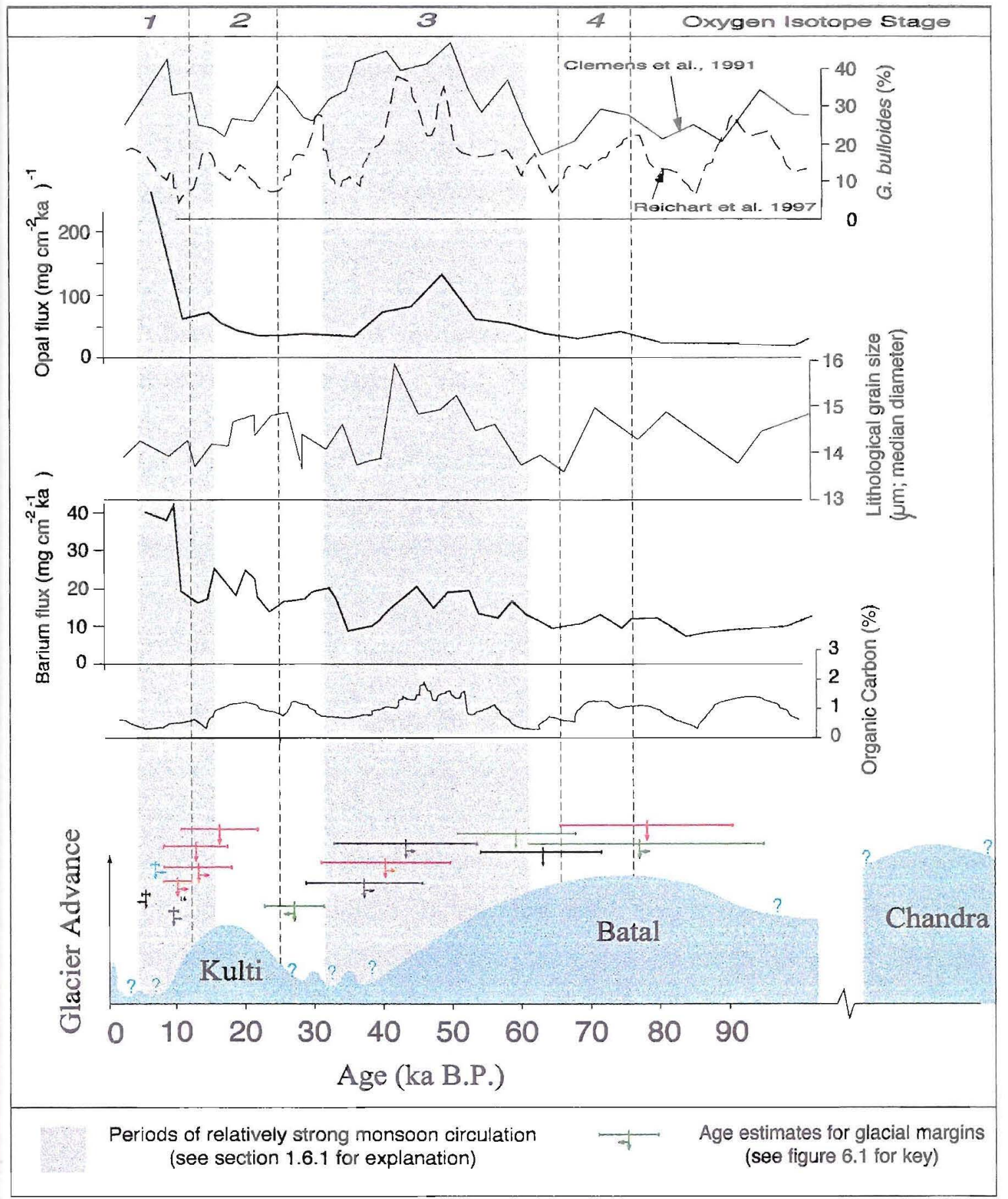

Figure 6.3 Palaeomonsoon proxy indicators (after Clemens et al, 1991; Reichart et al., 1997; see Section 1.6.1 for explanation), Oxygen Isotope Stages and glaciation of the north-west Himalaya. 
LGM. There too monsoon precipitation feeds glaciers via avalanches and snouts are debris covered ( $c f$. Inoue, 1977).

(2) With new dates from Swat (Richards, 1999) and the Zanskar Range (Chapters 4 and 5), which were unavailable to Benn and Owen (1998), it appears that the glacial maximum was at $\sim 80-60 \mathrm{ka}$ BP not $60-30 \mathrm{ka} \mathrm{BP}$, although glaciers may have retreated slowly. This period did not experience strong monsoon circulation, as implied by various proxy indicators from Arabian Sea sediments (Fig. 6.3; Section 1.6.1).

It would seem that in all three areas, glaciers were at their maximum when monsoon circulation was relatively weak, but global temperatures were low. Nevertheless, the question of why the glaciers of the Himalaya had asynchronous maxima during the last glaciation remains, with those of the north-west Himalaya advancing further during OIS 4 than OIS 2.

There is substantial variation between the different proxy indicators of palaeomonsoon strength and no conspicuous difference between OIS 2 and OIS 4 can be determined from these records (Fig 6.3). If, however, the glaciers of the northwest Himalaya, or those of central Nepal were particularly sensitive to fluctuations in monsoon precipitation compared to the other area, then a subtle difference in the monsoon strength could account for the asynchronous advances. In order to test this more detailed glacier mass balance data and higher resolution palaeomonsoon records are required.

Westerly winds may have been stronger, or had greater source areas from which moisture could have been collected during OIS 4, providing more advected precipitation to the north-west Himalaya. With a lack of proxy climate data for westerly circulation from the Himalaya, records from further afield must be considered. In Central China loess deposits have recorded palaeoclimatic fluctuations over the entire Quaternary period. Proxy indicators from the record, based on indices relating to grain size, have been used to indicate the variation in strength of the loess 
providing north-west (winter) East Asian Monsoon (Ding et al., 1995; Xiao et al., 1995). The winter monsoon is linked to the strength and position of the Siberian/Mongolian High pressure cell, which is part of the large scale northern hemisphere mid-latitude circulation system. Indices relating to grain size show a strong coherence with global ice volume and are dominated by a 100ka periodicity (Ding et al., 1995). In contrast to the Indian Monsoon system, where insolation forcing is dominant, glacial boundary conditions play a governing role in modulating and pacing the winter East Asian Monsoon (Ding et al., 1995). Neither of the records of winter monsoon strength (Ding et al., 1995; Xiao et al., 1995) show a discernible difference between OIS 4 and 2. It should be noted that, although these records may indicate fluctuations in the strength of northern hemisphere mid-latitude circulation, they are distant from the northwestern Himalaya.

The Caspian Sea forms a potential moisture source for westerly derived precipitation and its surface area has fluctuated during the late Pleistocene. Uranium-Ionium, radiocarbon and thermoluminescence numerical age estimates from sediments and landforms relating to former levels of the Caspian Sea have been employed to date transgression and regression events (Karpytchev, 1997; Mamedov, 1997). The overall pattern is of transgression and regression events corresponding to warm and cold stages respectively. Compared to Late Pleistocene transgression periods, which were before $75 \pm 2.6 \mathrm{ka} \mathrm{BP}$, from $32 \pm 3 \mathrm{ka}$ BP to $24 \pm 2 \mathrm{ka} \mathrm{BP}$ and $17-16 \mathrm{ka} \mathrm{BP}$ to $10 \mathrm{ka}$ $\mathrm{BP}$, little is known about the corresponding regression events, except for the most recent (cf. Mamedov, 1997). During OIS 2 the level of the landlocked sea was reduced from its present level of $-28.5 \mathrm{~m}$ a.s.l. to $-133 \mathrm{~m}$ a.s.l. with an associated reduced surface area (Karpytchev, 1997). During OIS 4, the Caspian Sea was also low, but no altitude is given, although Mamedov (1997) infers a similar level to OIS 2. The area available for evaporation of moisture from the Caspian Sea during OIS 4 and 2 was reduced relative to the present, but any difference between the two periods that may have existed cannot be determined from the available data. 
Lakes existed during the global LGM further to the west in central Turkey (Fontugue et al., 1999). In addition to reduced evaporation, Fontugue et al. (1999) speculate that the basin filled due to increased winter westerly precipitation high on nearby mountains. This is based on the observation of undated moraines in nearby mountains, which are assumed to be OIS 2 in age, but given the OIS 4 maximum to the west in the north-west Himalaya this may not be a sound supposition ( $c f$. Gillespie and Molnar, 1995). Again there is no data for OIS 4 to contrast with conditions in OIS 2.

It is unlikely that the southern branch of the westerlies would bring greater precipitation, without the same effect being seen in the northern branch, resulting in an advance in the Kunlun Mountains. Perhaps the glacial stage attributed to the Middle Pleistocene, in the western Kunlun Mountains, on the basis of a numerical age estimate of $206 \pm 17 \mathrm{ka}$ BP (TL) (Zheng et al., 1990) belongs to OIS 4 ? This age estimate is from a till, with no explanation of how the deposit was exposed to light during deposition or methodology given (Zheng et al., 1990). As such, this date is not regarded are reliable. Due to the presence of mid-latitude ice sheets, the westerly circulation may have been pushed south during OIS 4 , bringing greater precipitation to the southern part of the Himalaya, but not to the northern edge of the Tibetan Plateau. Again, this does not explain the greater extent during OIS 4, as the two glacials are likely to have experienced similar conditions.

The glaciers of the north-west Himalaya must have experienced a more favourable combination of temperature and precipitation in OIS 4 compared to OIS 2. Unfortunately, little is known about the mass balance characteristics of Himalayan glaciers as they are remote and form dangerous working environments. It is reasonable to conclude from data on precipitation (Murakawi, 1987) and snowlines (von Wisseman, 1959) that glaciers further to the west have a greater proportion of accumulation from winter westerly precipitation than from the summer monsoon relative to those ice bodies in the central and eastern Himalaya. Until palaeoclimate data regarding westerly circulation over the last $80 \mathrm{ka}$ becomes available, along with a 
higher resolution palaeomonsoon record, glacier mass balance data and additional dating control on glacial advances, the explanation for the asynchronous glacial maxima across the Himalaya will remain speculative.

\subsection{GEI Values}

Many glacial studies from the Himalaya have calculated ELA values, although as discussed in Section 1.6.3 most of these are more accurately referred to as GEI values (cf. Benn and Lehmkuhl, in press). GEI values from across the Himalaya cannot be compared with an appropriate degree of confidence for four main reasons:

(1) Most published GEI values are for the maximum valley glaciation, often with no numerical age estimates, but are assumed to belong to the LGM (e.g. Burbank and Fort, 1985). Given the asynchronous maximum glacial advances from the north-west and the central and eastern Himalaya, it seems likely that GEI values relating to OIS 2 glacial limits would be contrasted with those belonging to OIS 4, which is an invalid correlation. Apart from this study, only values from Garhwal (Sharma and Owen, 1996) and from Central Nepal (Duncan et al., 1998) are derived from dated margins and these belong to different periods (Fig. 6.4) and so a valid comparison cannot be made.

(2) Surface uplift, reported as having been up to $3.4-10 \mathrm{mma}^{-1}$ (Section 1.5; Burbank, 1982), may have elevated evidence on which glacial margins are reconstructed. This would give erroneous GEI values, especially for older glacial events. Rates of surface uplift are not generally known for the last one or two glacial cycles making correction for uplift all but impossible (Section 1.5).

(3) A variety of methodologies have been employed, which are usually not based on mass balance characteristics, and may not give values which can be 


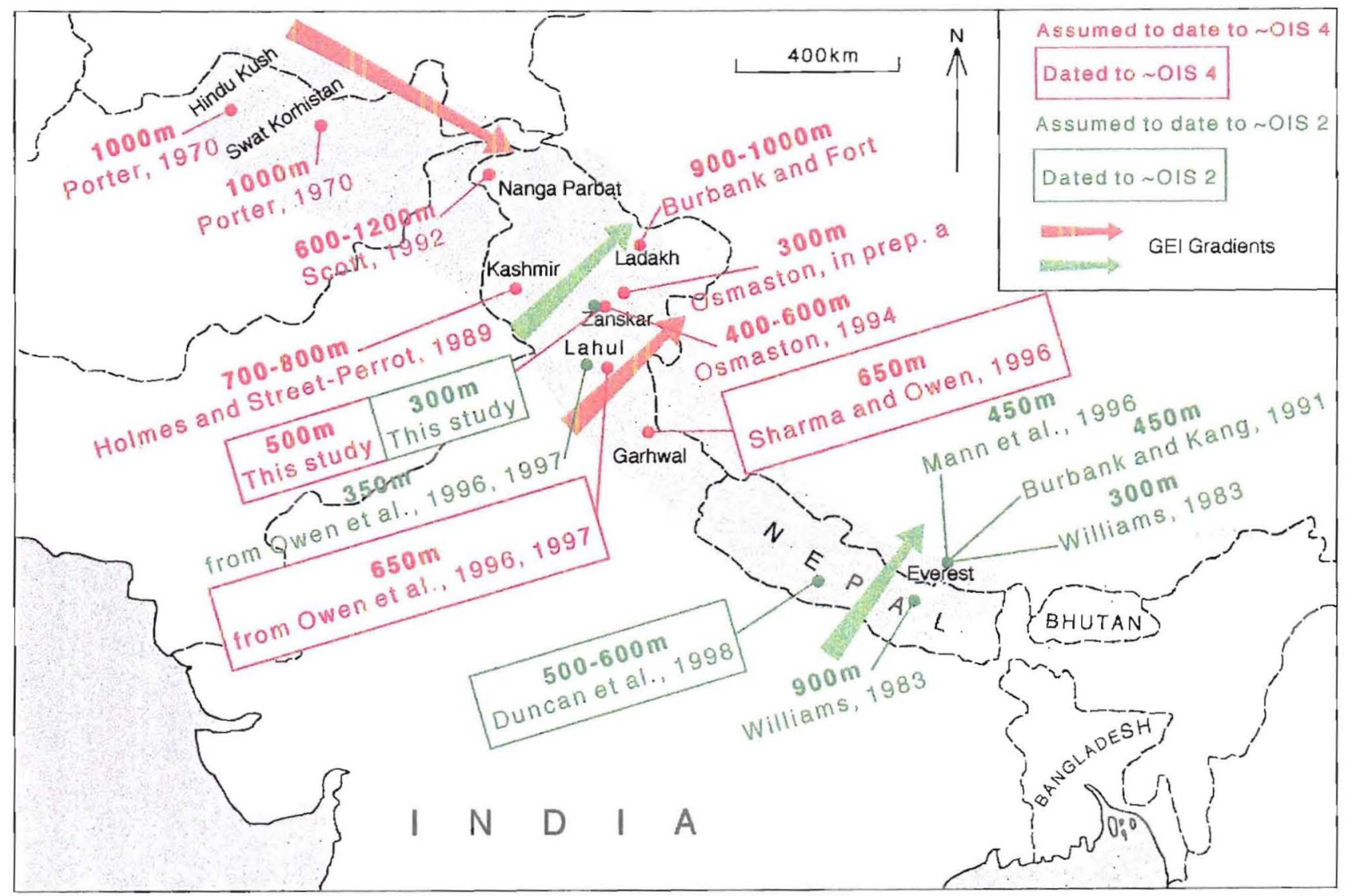

Figure 6.4 GEI depressions from the Himalaya. Values based on glacial margins with numerical age constraints are shown with a box, red for OIS 4 and green for OIS 2. Values from undated margins are shown in red text where assumed to be OIS 4 and in green where thought to belong to OIS 2 (based on the consideration of the author). 
confidently compared. For example, Porter (1970) uses an Accumulation Altitude Ratio of 0.6 for Swat Kohistan, as opposed to the Toe-Headwall Altitude Ratio of 0.4 used by Burbank and Fort (1985) in Ladakh, or the Maximum Elevation of Lateral Moraines used in Central Nepal by Williams (1983). While the trends reconstructed using each method will parallel the climatic ELA trend (Meierding, 1982), comparison between methods is not valid.

(4) There is a dearth of knowledge regarding the mass balance of Himalayan glaciers on which to base ELA calculation.

Nevertheless, ELA and GEI trends are useful indications of precipitation gradients for each area studied, as demonstrated for the Kashmir Basin (Holmes, 1993), LahulZanskar-Ladakh (Section 5.3) and Central Nepal (Williams, 1983). Comparative studies of methods for the calculation of glacial elevation indices shows that although altitudes vary between methods, the reconstructed trends are very similar (Meierding, 1982). Bearing in mind the problems of comparison, a pattern of GEI values can be observed if undated limits are given an assumed age (Fig. 6.4). This pattern reflects attenuation of monsoon precipitation, with values rising steeply with the orographic effect of the Himalaya, and lower values in the north-west rising to the east, reflecting the westerly precipitation gradient (Fig. 6.4).

\subsection{Conclusions}

The number of recorded glacial advances and style of glaciation that the Zanskar Range has experienced is broadly in agreement with results from other Himalayan glacial studies. Differences in the number of stages and stades can be accounted for through differential preservation, particularly where glaciers were more extensive during OIS 2 than OIS 4, destroying evidence for the older glaciation. 
With new age estimates from this study, knowledge regarding the timing of the last glaciation in the Himalaya is greatly improved. A new numerical age estimate from the Zanskar Range, albeit with large errors, adds a fourth age constraint on the maximum valley glacier advance in the north-western Himalaya ( $\equiv$ Batal Stage). All four of these age estimates lie within each others errors and straddle OIS 4. Based on fewer dates, this glacial maximum had been suggested as having been earlier, from $60-30 \mathrm{ka} \mathrm{BP}$, coinciding with a period of relatively enhanced monsoon circulation (Benn and Owen, 1998). This correlation now seems erroneous. Two new dates relating to the maximum of the youngest major event (三 Kulti Stage) and two from recessional sediments suggest that this event was close to or shortly followed the global LGM. With additional new dates from Nepal showing the maximum to have been from 25-18ka BP (Benn and Owen, 1998; Richards, 1999), there is now more substantial evidence for an asynchronous maximum for the last glaciation in the Himalaya. Improved glacier mass balance data and palaeo climatic data for monsoon and especially westerly circulation is required before this asynchrony can be explained.

Notwithstanding problems of comparison, palaeoGEI values reflect modern precipitation gradients. The north-west to south-east and south west to north-east decrease in GEI depression highlights the importance of westerly and monsoon precipitation bearing winds for Himalayan glaciations. 


\section{$7 \quad$ Conclusions}

The main conclusions of this study will be reported in this chapter. These describe the Quaternary glacial history of the Zanskar Range, as represented by four distinct glacial events. This study contributes to the wider investigation of Himalayan glaciations, particularly the asynchronous timing between the north-west and central and eastern areas, and conclusions relating to this are made. The role of Optically Stimulated Luminescence (OSL) dating will then be evaluated and areas identified for future research.

\subsection{The Number and Style of Glacial Events in the Zanskar Range}

Palaeoglacier limits have been reconstructed through detailed geomorphological mapping and sedimentological studies in a number of major valleys in the Zanskar Range. Three main glacial stages and a minor advance are recognised, which correlate well with the partially age constrained glacial sequence from the adjoining Lahul region (Owen et al., 1996; 1997). As such the existing stratigraphic nomenclature is adopted and extended to the Zanskar Range. Consequently the events are referred to, from oldest to youngest, as the Chandra, Batal and Kulti Stages, and the Sonapani advance respectively.

\section{Chandra Stage}

The oldest detected event, the Chandra Stage, occupied broad valleys with gentle slopes, remnants of which now form palaeosurfaces $200-300 \mathrm{~m}$ a.r.l. Erratic provenance and distribution indicate that during this period ice was at its most extensive of all four glacial events, possibly forming an ice-cap with its ice-shed to 
the south-west over the High Himalaya. The extent of this glaciation is not well defined due to the inaccessibility and fragmentary nature of the evidence.

\section{Batal Stage}

The second oldest identified glaciation, the Batal Stage, occupied the present deep troughs to their lowermost extents, where they undergo an often dramatic change in valley form, becoming narrow V-shaped bedrock gorges. Allied with this change in gross valley morphology are large subdued moraine ridges, some of which are $>50 \mathrm{~m}$ high. This extensive valley glaciation formed two groups, one with former glaciers flowing into the Zanskar Range from the High Himalaya and the other with former glaciers centred around the high ground of the Nimaling Massif. The Batal Stage may have had two stades, although evidence for this is restricted to one site, which has exceptional preservation of moraine ridges and allied glacial evidence. Boulders on stable crests of Batal Stage moraine ridges often have distinctive well developed tafoni weathering. These are not present on ridges of older or younger glacial stages.

\section{Kulti Stage}

The third oldest recognised glacial event, the Kulti Stage, formed a less extensive valley glaciation. Evidence for this stage is well preserved in the upper reaches of many valleys occupied by Batal Stage ice, but poorly preserved in others, due to erosion and burial. Moraine ridges are typically a few tens of metres high and commonly form a pattern of inset chevrons. Exposed boulders on these moraines have mature desert varnishes, but lack the well developed tafoni hollows displayed by some boulders of Batal age. 


\section{Sonapani Advance}

A minor advance, the Sonapani, is represented by moraines within $2 \mathrm{~km}$ of the small ice bodies that still occupy the heads of the highest valleys. The sharp crested moraine ridges are easily distinguished from older ridges through their proximity to modern glaciers and the lack of development of desert varnish.

\section{Style of Glaciation}

There was a marked change in the style of glaciation from the broad Chandra stage ice-cap to the relatively narrow valley glaciers of the Batal and Kulti Stages. Fluvial and glacial erosion incised the relatively gentle slopes occupied by Chandra ice, such that glaciers of the Batal and Kulti Stages were laterally confined in deep valleys. The reduction in the extent of ice from the Chandra Stage to the Batal and Kulti Stages may relate to a combination of reduced penetration of the summer monsoon, due to surface uplift of the Pir Panjal, and glaciers balancing their budgets over shorter horizontal distances, as the landscape evolved to have a greater relative relief. There is no evidence for the inundation of a global LGM Tibetan wide ice-sheet into the mountains, as has been proposed by Kulhe (1998).

\subsection{Timing of Glacial Events in the Zanskar Range}

Optically Stimulated Luminescence (OSL) dating of fluvioglacial and lacustrine sediments associated with former glacial margins has been employed to constrain the age of the glacial events. No suitable sample sites for the Chandra Stage or Sonapani advance could be found. The Chandra Stage predates the Batal Stage by enough time to have allowed $200-300 \mathrm{~m}$ of valley incision to have taken place. For the erosion rate to be realistic, the Chandra Stage must date to Oxygen Isotope Stage (OIS) 6 or older. The maximum of the Batal Stage was close to $78.0 \pm 12.3 \mathrm{ka} \mathrm{BP}$ and glaciers were retreating by $40.0 \pm 9.3 \mathrm{ka} \mathrm{BP}$. Two age estimates, $16.2 \pm 5.6 \mathrm{Ka} \mathrm{BP}$ and $12.8 \pm 4.7 \mathrm{ka} \mathrm{BP}$, 
represent the maximum of two Kulti Stage glaciers, with further age estimates from recessional landforms of $13.1 \pm 4.9 \mathrm{ka} \mathrm{BP}$, close to the palaeoglacier limit, and $10.2 \pm 2.1 \mathrm{ka} B P$ from a late stage moraine hummock.

\subsection{GEI Values from Lahul and the Zanskar Range}

Glacier Elevation Index (GEI) values have been calculated using a Toe-Headwall Altitude Ratio of 0.4, using glacial limits published for Lahul (Owen et al, 1996, 1997 ) and from those reconstructed by this study for the Zanskar Range. GEI values for modern glaciers increase from $\sim 4700 \mathrm{~m}$ a.s.l. in the south-west (Lahul) to $\sim 5500 \mathrm{~m}$ a.s.l. in the north-east (Zanskar Range). Values were depressed by $\sim 500 \mathrm{~m}$ and $\sim 300 \mathrm{~m}$ in the Zanskar Range during the Batal and Kulti Stages respectively. The GEI trend for the Batal Stage rises from $44000 \mathrm{~m}$ a.s.l. in Lahul to $\sim 5000 \mathrm{~m}$ in the Zanskar Range, but dips to $\sim 4300 \mathrm{~m}$ close to the Indus valley. This north-east rise reflects the precipitation gradient of the summer monsoon and the decrease towards the Indus valley may be due to channelling of westerly depressions along the broad Upper Indus valley. GEI values calculated from Kulti Stage glacial limits mirror the Batal Stage trend, but display a greater scatter. Correction for the effects of surface uplift could not be made due to the lack of relevant uplift data. Results from Lahul and the Zanskar Range fit well into the regional pattern, although comparison is difficult, due to the lack of dating control.

\subsection{Regional Comparisons and Implications}

The number and style of glacial events described from the Zanskar Range accords, in the most part, with the majority of studies from the north-west Himalaya. New OSL dates from the Zanskar Range greatly enhance the chronology of glacial events from the north-west Himalaya. The maximum advance during the last glaciation appears not to have been at 60-30ka BP as previously reported (Benn and Owen, 1998), but at 
80-60ka BP, as demonstrated by numerical age estimates from this study and independent results from Garhwal (Sharma and Owen, 1996), the Middle Indus valley and Swat (Richards, 1999). In combination with recent dates constraining the maximum glacial advance in the Central and Eastern Himalaya to 25-18ka BP (Benn and Owen, 1998; Richards, 1999), these age estimates confirm the asynchronous maximum advance of the last glaciation across the Himalaya. Whereas glaciers of the north-west Himalaya had their maximum advance during OIS 4, those of the northern Tibetan Plateau and the Central and Eastern Himalaya were most extensive close to the global Last Glacial Maximum of OIS 2.

The trend of modern snowlines and GEI values calculated for former glaciers in the Zanskar Range and from across the Himalaya demonstrate the importance of summer monsoon and winter westerly circulation in supplying precipitation to Himalayan glaciers. Glacier mass balance characteristics and palaeoclimatic proxy data for fluctuations of monsoon and westerly circulation are presently insufficiently detailed to determine why glaciers in the north-west Himalaya were more extensive during OIS 4 relative to OIS 2 . This is especially true of data for OIS 4 and relating to the winter westerlies.

\subsection{Evaluation of OSL Dating of Palaeoglacier Margins in the Zanskar Range}

Only one age estimate, with which the new dates can be compared, has previously been published for the Zanskar Range. This thermoluminescence date of 70-40ka BP for silts on the Padam Plain proved "difficult to analyse" (H. Rendell, pers. comm., cited in Osmaston, 1994, p31) and no details of the methodology are available. Consequently, it is not considered to be reliable.

There are few opportunities for the dating of glacial margins using non-luminescence methods. This is due mainly to the aridity of the mountains and consequent lack of 
organic carbon. In spite of extensive investigation of many sediment sections, during three field seasons, no organic deposits suitable for ${ }^{14} \mathrm{C}$ dating were found. Luminescence dating represents the best possibility for constraining the age of glacial margins in the Zanskar Range, except perhaps cosmogenic dating of bedrock surfaces and erratics, which has yet to be tested in this region (Section 2.2).

Several limitations on the applicability of the method in the field were encountered, the three most common being:

(1) Sample availability. Samples could not always be obtained, particularly for the Chandra Stage and Sonapani advance. Evidence for the Chandra Stage, apart from being inaccessible, is usually in the form of bedrock surfaces and large erratics, with a scarcity of fluvioglacial or lacustrine sand and silt deposits. While there are likely to be numerous fluvioglacial inclusions in the moraine complexes of the Sonapani advance, there are few eroded sections to expose them and, as such, no samples could be found.

(2) Association and bleaching history. Otherwise suitable samples often have unclear associations with the glacial sequence or were deemed unlikely to have had sufficient exposure to light.

(3) Sample size. Often fluvioglacial inclusions are too small to provide a sample $>300 \mathrm{~mm}$ away from clasts of gravel size and above, which would compromise the applicability of the Neutron Activation Analysis measurements (Section 2.2). This is the case for the glaciolacustrine sediments of the Gya valley, which form a rainout diamicton (Section 3.6).

In spite of these restrictions, appropriate sites are abundant compared to material for other forms of dating. Most large sections through moraine ridges of Batal and Kulti age, when thoroughly investigated, revealed a fluvioglacial lens suitable for OSL dating. Indeed, more samples were collected than could be processed. 
Not every sample processed produced an age estimate. This is mainly due to the low luminescence sensitivity of fluvioglacial sediments and problems of extracting pure quartz (Section 2.2). Having said that, seven out of the ten samples fully prepared have given age estimates, although some have large degrees of uncertainty. All the dates fall within the correct stratigraphic order and age estimates for landforms thought to belong to the same event lie within errors. Unfortunately, due to limitations of time and budget, duplicate samples, which were collected in the field, could not be processed. This would have tested the precision, or reproducibility, of the results, as has been achieved in the Khumbu Himal (Richards, 1999).

Considering that there were no reliable age estimates for the Zanskar Range prior to this study and few methods for obtaining them, the application of OSL dating to the Zanskar Range is a success.

\subsection{Future Work}

There are several directions for future work on the glaciation of the Zanskar Range which present themselves. The three most enticing being:

(1) Timing and extent of the Chandra glaciation. With the recognition of indicator erratics from the High Himalaya on palaeosurfaces above the Tsarap valley, the mountains in the southern part of the Zanskar Range provide an area where the extent of the Chandra glaciation might be traced. Although climbing to these high surfaces requires considerable effort, they are relatively easily accessed compared to palaeosurfaces from other areas, such as those from northern Pakistan. Once on the interfluves above the Tsarap valley, the undulating surfaces are not difficult to traverse. High resolution satellite imagery, although not available to this study, will no doubt be obtainable in the future and aid in the tracing of this surface. Dating should be possible using cosmogenic methods on large erratic boulders, although there will be 
uncertainty regarding the amount of surface uplift experienced. There is still a chance that sand or silt deposits, for OSL dating, relating to this glaciation will be identified with more extensive exploration.

(2) Former GEI values from the Upper Indus valley. Former glacial margins and GEI values are not well known for the northern part of the mountains, particularly the southern flank of the Indus valley. This area requires further investigation given the large reported difference in palaeoGEI values between the two flanks of the Indus valley (Burbank and Fort, 1985) and the possible palaeoclimatic implications of this pattern.

(3) Detailed reconstruction of a Batal ice-field. The Nimaling Massif has the potential for the reconstruction of a Batal Stage ice-field. This would provide more reliable GEI values, avoiding the glacier to glacier variations, resulting from local topographic and climatic differences common among smaller valley glaciers. Unlike other palaeoglacier limits examined, evidence from the marginal sections of this former ice-field which were investigated allow relatively continuous delimitation, recording both horizontal and vertical ice limits (Sections 3.6, 3.7 and 3.8). It is the vertical limit of Rupshu granite erratics against the dark desert varnished schist that provides an easily distinguished former ice boundary. The limiting factor in any reconstruction would be the poor quality of the available topographic maps and some survey work would be required.

With regard to the wider Himalaya region, each advance in our knowledge of the glacial history and the palaeoclimate poses many questions. Future research has a number of challenging problems to address. Chief among these are:

(1) Investigation into the fluctuations of the westerly climatic system from OIS 5 to the present. The interpretation of warm/humid conditions at the global LGM from the Tso Kar lake sediments (Bhattacharyya, 1989) and Kashmir Basin valley fill (Krishnamurthy et al., 1982), and its proposed correlation 
with Mediterranean climate (Bhattacharyya, 1989; Benn and Owen, 1998), must be tested. Preliminary work on the Lamayuru lake sediments of the northern Zanskar Range has shown that they represent a 35-30ka record and contain climatic proxy indicators (Kotlia et al., 1997). No climatic interpretation of these sediments has been attempted as yet, but they may help in the comparison of north-western Himalayan palaeoclimate with that for regions to the west.

(2) Glacier mass balance characteristics. Research into the mass balance of glaciers from across the Himalaya chain must be undertaken, so that a better understanding of their relationship with climate can be gained. In particular, the relative importance of summer and winter precipitation and temperature for glaciers from the north-west and the central and eastern Himalaya must be assessed. Winter westerly and monsoon precipitation may have distinctive stable isotope signatures which might resolve this problem.

(3) Dating. Although improved by this study and that of Richards (1999), the asynchrony between the maximum glacial advances of the north-west and central and eastern Himalaya is based on a small number of age estimates. Additional dating is required from a variety of areas to confirm the emerging glacial chronology. This is particularly so for the north-west where there are only four reliable dates for the maximum of the late Pleistocene glaciation. 


\section{References}

Abbot, L. D., Silver, E. A., Anderson, R. S., Smith, R., Ingle, J. C., Kling, S. A., Haig, D., Small, E., Galewsky, J. and Sliter, W. (1997) Measurement of tectonic surface uplift rate in a young collisional mountain belt. Nature 385, 501-507

Ageta, Y. and Higuchi, A. (1984) Estimation of mass balance components of a summeraccumulation type glacier in the Nepal Himalaya. Geografriska Annaler 66A, 249-255

Ageta, Y. and Kadota, T. (1992) Predictions of changes of glacier mass balance in the Nepal Himalaya and Tibetan Plateau: a case study of air temperature increase for three glaciers. Annals of Glaciology 16, 89-94

Aitken, M. J. (1985) Thermoluminescence dating. London, Academic Press, 359pp.

Aitken, M. J. (1998) An introduction to optical dating: the dating of Quaternary sediments by the use of photon-stimulated luminescence. Oxford University Press, $267 \mathrm{pp}$.

Aitken, M. J. and Xie, J. (1992) Optical dating using infrared diodes: young samples. Quaternary Science Reviews 11, 147-152

Anderson, D. M. and Prell, W. L. (1993) A 300kyr record of upwelling off Oman during the late Quaternary: evidence of the Asian southwest monsoon. Palaeoceanography 8, 193-208

Andrews, J. E., Singhvi, A. K., Kailath, A. J., Kuhn, R., Dennis, P. F., Tandon, S. K. and Dhir, R. P. (1998) Do stable isotope data from calcrete record late Pleistocene monsoonal climate variation in the Thar Desert of India? Quaternary Research 50, $240-251$

Andrews-Speed, C. P. and Brookfield, M. E. (1982) Middle Palaeozoic to Cenozoic geology and tectonic evolution of the Northwestern Himalaya. Tectonophysics 82, 253-275

Ballantyne, C. K. (1989) The Loch Lomond Readvance on the Isle of Skye, Scotland: glacier reconstruction and palaeoclimatic implications. Journal of Quaternary Science 4, 95-108 
Barry, R. G. (1981) Mountain weather and climate. Methuen, 313pp.

Barry, R. G. and Chorley, R. J. (1992) Atmosphere, weather and climate. Routledge, London ( $6^{\text {th }}$ edition), 392pp.

Baud, A., Gaetani, M., Gerazanti, E, Fois, E., Nicora, A. and Tintori, A. (1983) Geological observations in the Eastern Zanskar area, Ladakh Himalaya. Contributions to Himalayan Geolology 2, 130-142

Baud, A., Gaetani, M., Gerazanti, E, Fois, E., Nicora, A. and Tintori, A. (1984) Geological observations in the Eastern Zanskar area and adjacent Lahul area (northwestern Himalaya). Eclogae Geoleolicae Helvetiae 77, 171-197

Beaufort, L. (1996) Dynamics of the monsoon in the equatorial Indian Ocean over the last 260000 years. Quaternary International 31, 13-18

Benn D. I. and Owen, L.A. (1998) The role of the Indian summer monsoon and the midlatitude westerlies in Himalayan glaciation : review and speculative discussion. Journal of the Geological Society, London 155, 353-363

Benn, D. I. and Lehmkuhl, F. (in press) Estimating the equilibrium-line altitudes of former glaciers in high mountain environments. Quaternary International

Bennett, M. R. and Boulton, G. S. (1993) The deglaciation of the Younger Dryas or Loch Lomond Stadial ice-field in the Northern Highlands, Scotland. Journal of Quaternary Science 8, 133-146

Berthelsen, A. (1953) On the geology of the Rupshu District, NW Himalayas. Meddelelser fra Dansk Geologisk Forening, 12, 350-414

Bhattacharyya, A. (1989) Vegetation and climate during the last 30000 years in Ladakh. Palaeogeography, Palaeoclimatology, Palaeoecology 73, 25-38

Botter-Jensen, L. and Duller, G. A. T. (1992) A new system for measuring optically stimulated luminescence from quartz samples. Nuclear Tracks and Radiation Measurements 20, 549-553

Bradley, R. S. (1985) Quaternary Paleoclimatology. Allen and Unwin. London and Boston, 472pp. 
Brigham-Grette, J. (1996) Geochronology of glacial deposits. In J. Menzies (ed) Past glacial environments: sediments forms and techniques, Glacial environments volume 2. Butterworth-Heinemann Ltd. 377-410

Brookfield, M. E. and Andrews-Speed, C. P. (1984) Sedimentology, petrography and tectonic significance of the shelf flysch and molasse clastic deposits across the Indus Suture Zone, Ladakh, NW India. Sedimentary Geology 40, 249-286

Bryson, R. A. and Swain, A. M. (1981) Holocene variations of monsoon rainfall in Rajastan. Quaternary Research 16, 135-145

Bull, W. B. and $\mathrm{M}^{\mathrm{c} F a d d e n, ~ L . ~ D . ~(1977) ~ T e c t o n i c ~ g e o m o r p h o l o g y ~ n o r t h ~ a n d ~ s o u t h ~ o f ~ t h e ~}$ Garlock Fault, California. In D. Doehring (ed) Geomorphology in arid regions. Allen and Unwin, London, 115-138

Burbank, D. W. (1982) The Chronologic and stratigraphic evolution of the Kashmir and Peshawar imtermountane basins, Northwestern Himalaya. Unpublished Ph.D. thesis, Dartmouth College.

Burbank, D. W., and Johnson, G. D. (1982) Intermontane-basin development in the past 4Myr in the north-west Himalaya. Nature 298, 432-436

Burbank, D. W., and Johnson, G. D. (1983) The late Cenozoic chronologic and stratigraphic development of the Kashmir intermontane basin, northwestern Himalaya. Palaeogeography, Palaeoclimatology, Palaeoecology 43, 205-235

Burbank, D. W. and Fort, M. B. (1985) Bed rock control on glacial limits : examples from the Ladakh and Zanskar ranges, North-western Himalaya, India. Journal of Glaciology 31, 143-149

Burbank, D. W. and Kang, K. J. (1991) Relative dating of Quaternary moraines, Rongbuk Valley Mount Everest, Tibet : implications for an ice-sheet on the Tibetan Plateau. Quaternary Research 36, 1-18

Burbank, D. W., Leland, J., Fielding, E, Anderson, R. S., Brozovic, N., Reid, M. R. and Duncan C. (1996) Bedrock incision, rock uplift and threshold hillslopes in the northwestern Himalayas. Nature 379, 505-510

van Campo, E. (1986) Monsoon fluctuations in two 20000 yr B.P. oxygen isotope/pollen records off southwest India. Quaternary Research 26, 376-388 
van Campo, E. and Gasse, F. (1993) Pollen and Diatom-inferred climatic and hydrological changes in the Sumxi Co basin (West Tibet) since 13000 yr B.P. Quaternary Research 39, 300-313

van Campo, E., Duplessy, J. C. and Rossignol-Strick, M. (1982) Climatic conditions deduced from a 150kya oxygen isotope-pollen record from the Arabian Sea. Nature 295, 56-59

Charlesworth, J. K. (1957) The Quaternary era. Arnold, volume I, 591pp.

Chen, K. and Bowler, J. M. (1986) Late Pleistocene evolution of salt lakes in the Qaidarn basin, Qinghai provence, China. Palaeogeography, Palaeoclimatology, Palaeoecology 54, 87-104

Chung, S-L., Lo, C-H., Lee, T-Y., Zhang, Y., Xie, Y., Li, X., Wang, K-L. and Wang, P-L. (1998) Diachronous uplift of the Tibetan plateau starting 40Ma ago. Nature 394, 769-773

Clapperton, C. M. (1995) Fluctuations of local glaciers at the termination of the Pleistocene : 18-8ka B.P. Quaternary International 28, 41-50

Clemens, S. and Prell, W. (1990) Late Pleistocene variability of Arabian Sea summer monsoon winds and continental aridity: eolian records from the lithogenic component of deep-sea sediments. Palaeoceanography 5, 109-145

Clemens, S., Prell, W., Murray, D., Shimmield, G. and Weedon, G. (1991) Forcing mechanisms of the Indian Ocean Monsoon. Nature 353, 720-725

Coleman, M. and Hodges, K. (1995) Evidence for Tibetan plateau uplift before $14 \mathrm{Myr}$ ago from a new minimum age for east-west extension. Nature 374, 49-52

Collins, D. N. (1996) Sediment transport from glacierized basins in the Karakoram Mountains. In D. E. Walling and B. W. Webb (eds) Proceedings of an international symposium on erosion and sediment yields, global and regional perspective. International Association of Hydrological Sciences, 85-96

Cooke, R. U. and Doornkamp, J. C. (1974) Geomorphology in environmental management: an introduction. Clarendon Press. Oxford, 413pp. 
Copeland, P. (1997) The when and where of the growth of the Himalaya and the Tibetan Plateau. In W. F. Ruddiman, (ed) Tectonic uplift and climate change. Plenum Press. New York and London. 19-40

Cronin, V. S., Johnson, W. P., Johnson, N. M. and Johnson, G.P. (1989) Chronostratigraphy of the upper Cenozoic Bunthang sequence and possible mechanisms controlling base level in the Skardu intermontane basin, Karakoram Himalaya. In L.L. Malinconico and R. J. Lilli (eds) Tectonics and Geophysics of the Western Himalaya. Geological Society of America Special Paper 232, 295309

Czudek, T. (1995) Cryoplanation terraces - a brief review and some remarks. Geografiska Annaler 77A, 95-105

Dainelli G. (1923) Studisul glaciale. In Spedizioni italiane de Filippi nell 'Himalaia Caraorum e Turkestan Cinese (1913-1914) II Reseut. Geol. E Geograf 3, Bologna, Zanchelli

Damm, B. (1997) Vorzeitliche und aktuelle vergletscherung des Markhatales und der nordlichen Nimaling-berge Ladakh (Nordindien). Zeitschrift fur Gletscherkunde und glazialgeologie 33, 133-148

Demek, J. (1972) Manual of detailed geomorphological mapping. International Geographical Union. Subcommission on Geomorphological Survey and Mapping. Prague, 368pp.

Derbyshire, E. and Owen, L. A. (1990) Quaternary alluvial fans in the Karakoram Mountains, Pakistan. In, A. H. Radhocki and M. Church (eds) Alluvial fans : a field approach. Wiley, 55-68

Derbyshire, E. and Owen, L. A. (1997) Quaternary glacial history of the Karakoram Mountains and northwest Himalaya : A review. Quaternary International 38/39, 85-102

Derbyshire, E., Li, J., Perrott, F. A., Xu, S. and Waters, R. S. (1984) Quaternary glacial history of the Hunza valley, Pakistan. In K. A. Miller (ed) The International Karakoram Project 2, Cambridge University Press, 456-495 
Derbyshire, E., Shi, Y., Li., J., Zheng, B., Li, S. and Wang, J. (1991) Quaternary glaciation of Tibet, the geological evidence. Quaternary Science Reviews 10, 485510

Ding, Z., Rutter, N., Han, J. T. and Liu, T. S. (1992) A coupled environmental system formed at about 2.5Ma over eastern Asia. Palaeogeography, Palaeoclimatology, Palaeoecology 94, 223-242

Ding, Z., Liu, T., Rutter, N. W., Yu, Z., Guo, Z. and Zhu, R. (1995) Ice-volume forcing of East Asia Winter Monsoon variations in the past 800000 years. Quaternary Research 44, 149-159

Duller, G. A. T. (1991) Equivalent dose determination using single aliquots. Nuclear Tracks and Radiation Measurements 18, 371-378

Duller, G. A. T. (1995) Luminescence dating using single aliquots: methods and applications. Radiation Measurements 24, 217-226

Duller, G. A. T. (1996) Recent developments in luminescence dating of Quaternary sediments. Progress in Physical Geography 20, 127-145

Duncan, C. C., Klein, A. J., Masek, J. G. and Isacks, B. L. (1998) Comparison of late Pleistocene and modern glacier extents in the central Nepal based on digital elevation data and satellite imagery. Quaternary Research 49, 241-254

Duplessy, J. C. (1982) Glacial to interglacial contrasts in the northern Indian Ocean. Nature 295, 494-498

Embleton, C. and Verstappen, H. T. (1988) The nature and objectives of applied geomorpological mapping. Zeitschrift fur Geomorphologie, Supplementbande 68, $1-8$

Emeis, K. C., Anderson, D. M., Doose, H., Kroon, D. and Schulz-Bull, D. (1995) Sea surface temperatures and the history of monsoon upwelling in the northwest Arabian Sea during the last 500000 years. Quaternary Research 43, 355-361

England P. C. and Molnar, P. (1990) Right lateral shear and rotation as the explanation for strike-slip faulting in Eastern Tibet. Nature 344, 140-142

Ferguson, R. (1984) Sediment load of the Hunza river. In K. A. Miller (ed) The International Karakoram Project 2, Cambridge University Press, 374-382 
Fleming, S. J. (1979) Thermoluminescence techniques in archaeology. Clarendon Press, Oxford, 233pp.

Flint, R. F. (1971) Glacial and Quaternary Geology. Wiley, 892pp.

Flohn, H. (1981) The elevated heat source of the Tibetan Highlands and its role for the large-scale atmospheric circulation. In Geological and ecological studies of the Qinghai-Xizang Plateau, Vol. 2; environment and ecology of the Qinghai-Xizang Plateau. Science Press, Beijing, 1463-1470

Flohn, H. (1987) Recent investigations on the climatogenetic role of the Qinghai-Xizang Plateau : now and during the Late Cenozoic. In J. Hovermann and W. Wang (eds), Reports on the northeastern part of the Qinghai-Xizang (Tibet) Plateau. Science Press, Beijing, 387-416

Fontes, J. Ch., Melieres, F., Gilbert, E., Qing, L. and Gasse, F. (1993) Stable isotope and radiocarbon balances of two Tibetan lakes (Sumxi Co, Longgmu Co) from 13000 yrs B.P. Quaternary Science Reviews 12, 875-887

Fontugne, M. R. and Duplessy, J-C. (1986) Variations of the monsoon regime during the upper Quaternary : Evidence from carbon isotope record of organic matter in north Indian Ocean sediment cores. Palaeogeography, Palaeoclimatology, Palaeoecology 56, 69-88

Fontugne, M., Kuzucuoglu, C., Karabiyikoglu, M., Hatte, C. and Pastre, J-F. (1999) From Pleniglacial to Holocene: a ${ }^{14} \mathrm{C}$ chronostratigraphy of environmental changes in the Konya Plain, Turkey. Quaternary Science Reviews 18, 573-591

Fort, M. (1982) Apport de la teledetection a la connaissance des formations superficielles et des structures dans len bassin de Leh (Vallee de l'Indus, Himalaya du Ladakh). Bulletin de l'Association de Geographes Frances 24, 97-104

Fort, M. (1983) Geomorphological observations in the Ladakh area (Himalayas): Quaternary evolution and present dynamics. In V. J. Gupta (ed) Stratigraphy and Structure of Kashmir and Ladakh Himalaya. Hindustan Publishing Corporation (India), 39-58

Fort, M. (1995) The Himalayan glaciation : myth and reality. Journal of Nepal Geological Society 11, 257-272 
Fort, M. (1996) Late Cenozoic environmental changes and uplift on the northern side of the central Himalaya : a reappraisal from field data. Palaeogeography, Palaeoclimatology, Palaeoecology 120, 123-145

Fort, M., Burbank, D. W. and Freytet, P. (1989) Lacustrine sedimentation in a semiarid alpine setting : An example from Ladakh, northwest Himalaya. Quaternary Research 31, 332-350

Fuchs, G. (1979) On the Geology of western Ladahk. Jahrbuch der Geologishen Bundesanstatt Wien 122, 1-50

Fuchs, G. (1982) The geology of western Zanskar. Jahrbuch der Geologishen Bundesanstatt Wien 125, 513-540

Fuchs, G. (1984) Note on the geology of the Markha-Nimaling area in Ladakh (India). Jahrbuch der Geologishen Bundsanstatt Wien 127, 5-12

Fuchs, G. (1986) Geology of the Markha-Khurnak region in Ladakh (India). Jahrbuch der Geologishen Bundsanstatt Wien 128, 403-437

Fuchs, G. (1987) The geology of southern Zanskar (Ladakh) - Evidence for the autochthony of the Tethys zone of the Himalaya. Jahrbuch Geology 130, 465-491

Furbish, D. J. and Andrews, J. T. (1984) The use of hypsometry to indicate long-term stability and response of valley glaciers to changes in mass transfer. Journal of Glaciology 30, 199-211

Fushimi, H. (1978) Glaciations in the Khumbu Himal (2). Seppyo 40, 71-77

Gaetani, M. and Garzanti, E. (1991) Multicyclic history of the northern India continental margin (northwestern Himalaya). American Association of Petroleum Geologists Bulletin 75, 1427-1446

Gansser, A. (1964) Geology of the Himalayas. London, Interscience Publishers

Gansser, A. (1979) Map of Ophiolitic belts of the Himalayan and Tibetan region. In I.G.C.P. international atlas of Ophiolites. Scale 1:1 500 000. Boulder, Colorado. Geological Society of America

Garzanti, M., Baud, A. and Mascle, G. (1987) Sedimentary record of the northward flight of India and its collision with Eurasia. Geodynamica Acta 1, 87-102 
Gasse, F., Arnold, M., Fontes, J. C., Fort, M., Gibert, E., Huc, A., Bingyan, L., Yunanfang, L., Qing, L., Melieres, F., van Campo, E., Fubdao, W. and Qingsong, Z. (1991) A 13 000-year climate record from western Tibet. Nature 353, 742 745

Gemmell, A. M. D. (1988) Zeroing of the TL signal in sediment undergoing fluvioglacial transport. An example from Austerdalen, western Norway. Quaternary Science Reviews 7, 339-345

Gemmell, A. M. D. (1994) Environmental controls on the TL age of modern (zero-age) proglacial outwash sediments. Quaternary Science Reviews 13, 485-489

Gemmell, A. M. D. (1997) Fluctuations in the thermoluminescence signal of suspended sediment in an alpine glacial meltwater stream. Quaternary Science Reviews (Quaternary Geochronology) 16, 281-290

Gillespie, A. and Molnar, P. (1995) Asynchronous maximum advances of mountain and continental glaciers. Reviews of Geophysics 33, 311-364

Godfrey-Smith, D. I., Huntley, D. J. and Chen, W-H. (1988) Optical dating studies of quartz and feldspar. Quaternary Science Reviews 7, 373-380

Government of India, Indian Meterological department climatological tables of observations in India, 129-130

Grün, R. and Brundy, S. (1994) The assessment of errors in past radiation doses extrapolated from ESR/TL dose-response data. Radiation Measurements 23, 307315

Grün, R. and Rhodes, E.. J. (1991) On the selection of dose points for exponential ESR/TL dose response curves. Ancient TL 9, 40-46

Gross, G., Kerschner, H. and Patzelt, G. (1976) Methodische untersuchungen uber die scheegrenze in alpinen gletschergebieten. Zeitschrift fur Gletscherkunde und Glazialgeologie 12, 223-251

Guleria, J. S., Thakur, V. C., Virdi, N. S. and Lakhanpal, R. N. (1985) A Fossil wood of Prunus from the Kargil (=Liyan) formation of Ladakh. in V. C. Thakur and K. K. Sharma (eds) Geology of the Indus Suture Zone of Ladakh, Dehra Dun, India, Wadia Institute of Him. Geol. 187-193 
Gupta, S. K., Sharma, P. and Shah, S. K. (1992a) Constraints on ice-sheet thickness over Tibet during the last 40000 years. Journal of Quaternary Science 7, 283-290

Gupta, S. K., Sharma, P. and Shah, S. K. (1992b) Source of a freshwater influx at the last glacial maximum in the Indian Ocean : an alternative interpretation. Journal of Quaternary Science 7, 247-255

Hedin, S. (1899-1902) Scientific results of a journey in Central Asia, Vol. 4.

Hedin, S. (1922) Southern Tibet: Discoveries in former times compared with my own researches in 1906-1908, 9 vols., Lithographic Institute of the General Staff of Swedish Academy, Stockholm

Hewitt, K. (1999) Quaternary moraines vs catastrophic rock avalanches in the Karakoram Himalaya, northern Pakistan. Quaternary Research 51, 220-237

van Hofer, H. (1879) Gletscher und eiszeitstudien. Sitz. Ber. Akad. D. Wiss. Math.-phys. Kl. P 79

Holmes, J. A. (1988) Pliocene and Quaternary environmental change in Kashmir, northwest Himalayas. Unpublished D. Phil. University of Oxford

Holmes, J. A. (1993) Present and past patterns of glaciation in the Northwest Himalaya : climate, tectonic and topographic controls. In J. F. Shroder (ed) Himalaya to the Sea. Routledge. 72-90

Holmes, J. A. and Street-Perrott, F. A. (1989) The Quaternary glacial history of Kashmir, North West Himalaya : A revision of de Terra and Paterson's sequence. Zeitschrift fur Geomorphologie Suppl-Bd 76, 195-212

Hovermann, J. (1987) Climatic geomorphology and natural landscape in the northeastern part of the Qinghai-Xizang Plateau morphogenetic region in northest Xizang (Tibet). In Reports on the Northeastern part of the Qinghai-Xizang (Tibet) Plateau. Science Press Beijing, 112-139

Huang, W-P and Ji, H-X (1980) The climate and uplift of the Qinghai-Xizang (Tibet) Plateau in the late Pleistocene and Holocene.

Huntington, E. (1906) Pangong: A glacial lake on the Tibetan Plateau. Journal of Geology 14, 599-617 
Huntley, D. J. and Berger, G. W. (1995) Scatter in luminescence data for optical dating some models. Ancient TL 13, 5-9

Huntley, D. J., Godfrey-Smith, D. I. and Thewalt, M. L. W. (1985) Optical dating of sediments. Nature 313, 105-107

Hütt, G. and Jungner, H. (1992) Optical and TL dating on glaciofluvial sediments. Quaternary Science Reviews 11, 161-163

Inoue, J. (1977) Mass budget of Khumbu Glacier. Seppyo 39 special issue, 15-19

Karpytchev, Yu. A. (1993) Reconstruction of Caspian sea-level fluctuations: radiocarbon dating coastal and bottom deposits. Radiocarbon 35, 409-420

Kaufmann, G. and Lambeck, K. (1997) Implications of Late Pleistocene Glaciation of the Tibetan Plateau for present-day uplift rates and gravity anomalies. Quaternary Research 48, 267-279

Klootwijk, C., Gee, J., Peirce, J., Smith, G. and McFadden, P. (1992) An early India-Asia contact: Paleomagnetic constraints from Ninetyeast ridge, ODP leg 121. Geology 20, 395-398

Kotlia, B. S., Shukla, U. K., Bhalla, M. S., Mathur, P. D. and Pant, C. C. (1997) Quaternary fluvio-lacustrine deposits of the Lamayuru basin, Ladakh Himalaya: preliminary multidisciplinary investigations. Geological Magazine 134, 807-812

Krishnamurthy, R. V., DeNiro, M. J. and Pant, R. K. (1982) Isotope evidence for Pleistocene climatic Changes in Kashmir, India. Nature 298, 640-641

Kuhle, M. (1985) Glaciation research in Himalayas : a new ice age theory. Universitas 27, 281-294

Kuhle, M. (1986) Die vergletscherung Tibets und die entstehung von eiszeiten. Spektrum der Wissenschaft September, 42-54

Kuhle, M. (1987) Sub-tropical - and highland - glaciation as ice age triggers and the waning and waxing of the glacial periods in the Pleistocene. Geo-Journal 20, 319-323

Kuhle, M. (1988) Geomorphological findings on the build-up of Pleistocene Glaciation in Southern Tibet and on the problem of inland ice. Geo-Journal 17, 457-511 
Kuhle, M. (1990) Ice marginal ramps and alluvial fans in semiarid mountains; convergence and divergence. In Rachocki, A. H. and Church, M. (eds) Alluvial fans : a field approach. Wiley, 55-68

Kuhle, M. (1991) Observations supporting the Pleistocene inland glaciation of Central Asia. Geo-Journal 25, 133-232

Kuhle, M. (1998) Reconstruction of the 2.4 million $\mathrm{km}^{2}$ Late Pleistocene ice sheet on the Tibetan Plateau and its impact on the global climate. Quaternary International 45/46, 71-108

Kuhle, M., Klaus, H. and Calov, R. (1989) On the ice age glaciation of Tibetan Highlands and its transformation into a 3-D model. Geo-Journal 19, 201-206

Kuhn, M. (1984) Mass budget imbalances as criterion for a climatic classification of glaciers. Geografiska Annaler 66a, 229-238.

Kukla, G., and An, Z. S. (1989) Loess stratigraphy in Central China. Palaeogeography, Palaeoclimatology, Palaeoecology 72, 203-225

Kulkarni, A. V. (1992) Mass balance of Himalayan glaciers using AAR and ELA methods. Journal of Glaciology 38, 101-104

Kutzbach, J. E., Gutter, P. J., Ruddiman, W. F. and Prell, W. L. (1989) Sensitivity of climate to late Cenozoic uplift in Southern Asia and the American West ; numerical experiments. Journal of Geophysical Research: Series D, Atmosphere 94, 393-407

Kutzbach, J. E., Guetter, P. J., Behling, P. J. and Selin, R. (1993) Simulated climate changes: results of the COMAP climate-model experiments. In H. E. Wright Jr., J. E. Kutzbach, T. Web III, W. F. Ruddiman, F. A. Street-Perrott, P. J. Bartlein (eds) Global climates since the last glacial maximum. University of Minnestota Press, Minneapolis, 24-93

Kutzbach, J. E., Ruddiman, W. F. and Prell, W. L. (1997) Possible effects of Cenozoic uplift and $\mathrm{CO}_{2}$ lowering on global and regional hydrology. In W. F. Ruddiman, (ed) Tectonic uplift and climate change. Plenum Press. New York and London. $150-170$ 
Kutzbach, J. E., Gallimore, R., Harrison, S., Behling, P., Selin, R. and Laarif, F. (1998) Climate and biome simulations for the past 21000 years. Quaternary Science Reviews 17, 473-506

Lakhanpal, R. N., Sah, S. C. D., Sharma, K. K. and Guleria, J. S. (1983) Occurrence of Livistona in the Hemis conglomerate horizon of Ladakh in V. C. Thakur and K. K. Sharma (eds.) Geology of the Indus Suture Zone of Ladakh, Dehra Dun, India, Wadia Institute of Him. Geol. 179-185

Lehmkuhl, F. (1995) Geomorphologische untersuchungen zum klima des Holozans und Jungpleistozans Osttibets. Gottinger Geomorphische Abhandlung 102, 1-184

Lehmkuhl, F. (1997) Late Pleistocene, late glacial and Holocene glacier advances on the Tibetan Plateau. Quaternary International 38/39, 77-83

Lehmkuhl, F. (1998a) Extent and spatial distribution of Pleistocene glaciations in Eastern Tibet. Quaternary International 45/46, 123-134

Lehmkuhl, F. (1998b) Quaternary glaciations in Central and Western Mongolia. Quaternary Proceedings 6, 153-167

Lehmkuhl, F. and Lui, S. (1994) An outline of physical geology including Pleistocene glacier landforms of eastern Tibet (provinces Sichuan and Qinghai). Geo-Journal 34, 7-30

Lehmkuhl, F., Owen, L. A. and Derbyshire, E. (1998) Late Quaternary glacial history of northeast Tibet. Quaternary Proceedings 6, 121-142

Leland, J. Reid, M. R., Burbank, D. W., Finkel, R. and Caffee, M. (1998) Incision and differential bedrock uplift along the Indus River near Nanga Parbat, Pakistan Himalaya, from ${ }^{10} \mathrm{Be}$ and ${ }^{26} \mathrm{Al}$ exposure age dating of bedrock straths. Earth and Planetary Science Letters 154, 93-107

Leroy, S. A. G., Giralt, S., Francus, P. and Seret, G. (1996) The high sensitivity of the palynological record in the Vico Maar lacustrine sequence (Latium, Italy) highlights the climatic gradient through Europe for the last 90ka. Quaternary Science Reviews 15, 189-201 
Lietchtenecker, N. (1938) Die gegenwartige und die eiszeitliche Schneegrenze in den Ostalpen, In G. Gotzinger (ed) Verhandlungen der III Internationalen QuartarConferenz, Vienna, Sempember 1936, 141-147 INQUA, Vienna, Austria

Li, S. and Shi, Y. (1992) Glacial and lake fluctuations in the area of West Kunlun mountains during the last 45000 years. Annals of Glaciology 16, 79-84

Li., J., Wen, S., Zhong, Q., Wong, F., Zheng, B. and Li, B. (1979) A discussion on the period, amplitude and type of uplift of the Qinghai-Xizang Plateau. Scientia Sinica 22,1314-1327

Lister, G. S., Kelts, K., Zao, C. K., Yu, J-Q and Niessen, F. (1991) Lake Qinghai, China: closed-basin lake levels and the oxygen isotope record for ostrocada since the latest Pleistocene. Palaeogeography, Palaeoclimatology, Palaeoecology 84, 141162

Liu, T., Ding, M. and Derbyshire, E. (1996) Gravel deposits on the margins of the Qinghai-Xizang Plateau, and their environmenttal significance. Palaeogeography, Palaeoclimatology, Palaeoecology 120, 159-170

Locke, W. W. (1990) Late Pleistocene glaciers and the climate of western Montana, U.S.A. Arctic and Alpine Research 22, 1-13

Lowe, J. J. and Walker, M. J. C. (1997) Reconstructing Quaternary environments. Longman ( $2^{\text {nd }}$ edition), 446pp.

Mamedov, A. V. (1997) The Late Pleistocene-Holocene history of the Caspian Sea. Quaternary International 41/42, 161-166

Mani, A. (1981) The climate of the Himalaya. In J. Lall and S. Moddie (eds) The Himalaya : Aspects of change. OUP Delhi, 2-15

Manabe, S. and Broccoli, A. J. (1990) Mountains and arid climate of middle latitudes. Science 245, 192-195

Mann, D. H., Sletten, R. S. and Reanier, R. E. (1996) Quaternary glaciations of the Rongbuk Valley, Tibet. Journal of Quaternary Science 11, 267-280

Mayewski, P. A., Pregent, G. P., Jeschke, P. A. and Ahmad, N. (1980) Himalayan and Trans-Himalayan glacier fluctuations and the South Asian Monsoon record. Arctic and Alpine Research 12, 171-182 
Mazari, R. K. (1996) Glaciation, tectonic uplift and equilibrium line altitude fluctuation in the Tethys Himalaya, Eleventh Himalaya-Karakoram-Tibet, Workshop, Arizona Mehta, P. K. (1980) Tectonic significance of the young mineral dates and the rates of cooling and uplift in the Himalaya. Tectonophysics 62, 205-217

Meierding, T. C. (1982) Late Pleistocene glacial equilibrium-line altitudes in the Colorado Front Range : A comparason of methods. Quaternary Research 18, 289-310

Mitchell, W. A. (1991) Glaciation of Upper Wensleydale and adjoining watershed regions. Unpublished Ph.D. thesis, University of London

Mitchell, W. A., Osmaston, H. and Owen, L. A. (1996) Pattern of Glaciations in the Indian Himalaya. Eleventh Himalaya-Karakoram-Tibetan Workshop, Arizona, 99 Mitchell, W. A., Taylor, P. J. and Osmaston, H. (1999) Quaternary geology in Zanskar, NW Indian Himalaya: evidence for restricted glaciation and preglacial topography. Journal of Asian Earth Sciences 17, 307-318

Molnar, P. (1988) A review of geophysical constraints on the deep structure of the Tibetan Plateau, the Himalaya and the Karakoram and their tectonic implications. Philosophical Transactions of the Royal Society of London, Series A 326, 33-88

Molnar, P. and England, P. (1990) Late Cenozoic uplift of mountain ranges and global climate change : chicken or egg? Nature 346, 29-34

Molnar, P. and England, P. and Martinod, J. (1993) Mantle dynamics, uplift of the Tibetan Plateau and the Indian Monsoon. Reviews of Geophisics 31, 357-396

Murakami, T. (1987) Effects of the Tibetan Plateau. In C. P. Chang and T. N. Krishnamurti (eds.) Monsoon Meteorology. OUP Oxford, 235-270

Murphy, M. A., Yin, A., Harrison, T. M., Durr, S. B., Chen, Z., Ryerson, F. J., Kidd, W. S. F., Wang, X., Zhou, X. (1997) Did the Indo-Asian collision alone create the Tibetan Plateau? Geology 25, 719-722

Murry, D. W. and Prell, W. L. (1992) Late Pliocene and Pleistocene climate oscillations and monsoon upwelling record in sediments from the Owen Ridge, northwestern Arabian Sea. In C. P. Summerhayes, W. L. Prell and K. C. Emeis (eds) 
Upwelling systems: Evolution since the Early Miocene. Geological Society Special Publication 64, 301-321

Narain, H. (1975) National report on the geodetic and gravimetric work done in India by various organisations and institutions during the period 1971-1974. $6^{\text {th }}$ Gen. Ass. Meeting of IUGC, Grenoble

Nelson, F. E. (1989) Cryoplanation terraces: periglacial cirque analogs. Geografiska Annaler 71A, 31-41

Nimmergut, A. P., Allen, J. R. M., Jones, V. J., Huntley, B. and Battarbee, R. W. (1999)

Submillennial environmental fluctuations during marine Oxygen Isotope Stage 2:

a comparative analysis of diatom and pollen evidence from Lago Grande di

Monticchio. South Italy. Journal of Quaternary Science 14, 111-123

O'Hare, G. (1997) The Indian Monsoon. Geomorphology 82, 218-230

Ohmura, A., Kasser, P. and Funk, M. (1992) Climate at the equilibrium line of glaciers. Journal of Glaciology 38, 397-411

Osmaston, H. A. (1975) Models for the estimation of firnlines of present and Pleistocene glaciers. In R. Peel, M. Chisholm and P. Haggett (eds) Process in physical and human geography. Heinemen Educational, 218-245

Osmaston, H. A. (1989) Problems of the Quaternary geomorphology of the Xixabangma region in South Tibet and Nepal. Zeitschrift fur Geomorphology 76, 147-180

Osmaston, H. A. (1994) The Geology, Geomorphology and Quaternary History of Zanskar. in J. H. Crook and H. A. Osmaston (eds) Himalayan Buddhist Villages. Jainendra prakash jain at shri jainendra press. Delhi, 1-36

Osmaston, H. A., Frazer, J. and Crook, S (1994) Human adaptation to environment in Zanskar. in J. H. Crook and H. A. Osmaston (eds) Himalayan Buddhist Villages. Jainendra prakash jain at shri jainendra press. Delhi, 39-110

Osmaston, H. A. (in prep. a) The Glacial History of the Markha and Gya Valleys, Ladakh.

Osmaston, H. A. (in prep. b) Does bedrock control glacial limits in Ladakh (NW Himalaya) and thus invalidate indirect estimates of equilibrium line altitudes? 
Østrem, G. (1966) The height of the glaciation limit in southern Brittish Columbia and Alberta. Geografiska Annaler 48, 126-138

Owen, L. A. (1988) Terraces, uplift and climate, the Karakoram Mountains, Northern Pakistan. Unpublished Ph.D. thesis, University of Leicester

Owen, L. A. (1989) Neotectonics and glacier deformation in the Karakoram Mountains and Nanga Parbat Himalaya. Tectonophysics 163, 227-265

Owen, L. A. and Derbyshire, E. (1988) Glacially deformed diamictons in the Karakoram Mountains, northern Pakistan. In D. G. Croot (ed) Glaciotectonics : Forms and Process, Rotterdam : Balkerma, 149-176

Owen, L. A. and Derbyshire, E. (1993) Quaternary and Holocene intermontane basin sedimentation in the Karakoram mountains. In J. F. Shroder (ed) Himalaya to the Sea. Routledge. 108-131

Owen, L. A., White, B. J., Rendell, H. and Derbyshire, E. (1992) Loessic silt deposits in the western Himalayas: their sedimentology, genesis and age. Catena 19, 493-509

Owen, L. A., Derbyshire, E., Richardson, S., Benn, D. I, Evans, D. J. A. and Mitchell, W. A. (1996) The Quaternary glacial history of the Lahul Himalaya, northern India. Journal of Quaternary Science 11, 25-42

Owen, L. A., Mitchell, W. A., Bailey, R. M., Coxon, P. and Rhodes, E. (1997) Style and Timing of Glaciation in the Lahul Himalaya, northern India. Journal of Quaternary Science 12, 83-109

Owen, L. A., Derbyshire, E. and Fort, M. (1998) The Quaternary Glacial History of the Himalaya. Quaternary Proceedings 6, 91-120

Pachur, H-J., Wunnemann, B. and Zhang, H. (1995) Lake evolution in the Tengger Desert, Northwestern China, during the last 40000 years. Quaternary Research 44, $171-180$

Perkins, N. K. and Rhodes, E. J. (1994) Optical dating of fluvial sediments from Tattershall, U.K. Quaternary Science Reviews (Quaternary Geochronology) 13, $517-520$

Porter, S. C. (1970) Quaternary glacial record in Swat Kohistan, West Pakistan. Geology Society of America Bulletin 81, 1421-1446 
Porter, S. C. (1977) Present and past glaciation threshold in the Cascade Range, Washington USA : topographic and climatic implications. Journal of Glaciology 18, 101-116

Prell, W. L. and Curry, W. B. (1981) Faunal and isotopic indices of monsoon upwelling: western Arabian Sea. Oceanologica Acta 4, 91-98

Prell, W. L. and Streeter, H. F. (1982) Temporal and spatial patterns of monsoonal upwelling along Arabia: A modern analogue for the interpretation of Quaternary SST anomalies. Journal of Marine Research 40, 143-155

Prell, W. L. and van Campo, E. (1986) Coherent response of Arabian Sea upwelling and pollen transport to late Quaternary monsoonal winds. Nature 260, 232

Prell, W. L. and Kutzbach, J. E. (1992) Sensitivity of the Indian Monsoon to forcing parameters and implications for its evolution. Nature 360, 647-652

Prell, W. L. and Kutzbach, J. E. (1997) The impact of the Tibet-Himalayan elevation on the sensitivity of the monsoon climate system to changes in solar radiation. In W. F. Ruddiman, (ed) Tectonic uplift and climate change. Plenum Press. New York and London. 172-201

Prell, W. L., Hutson, W. H., Williams, D. F., Be, A. W. H., Geitzenauer, K. and Molfino, B. (1980) Surface circulations of the Indian Ocean during the last Glacial Maximum, approximately 18000 years ago. Quaternary Research 14, 309-339

Prescott, J. R. and Hutton, J. T. (1994) Cosmic ray contributions to dose rates for luminescence and ESR dating: large depths and long-term time variations. Radiation Measurements 23, 497-500

Prescott, J. R., Huntley, D. J. and Hutton, J. T. (1993) Estimation of equivalent dose in thermoluminescence dating - the Austrailian slide method. Ancient TL 11, 1-5

Raymo, M. E. and Ruddiman, W. F. (1992) Tectonic forcing of late Cenozoic climate. Nature 359, 117-122

Raymo, M. E., Ruddiman, W. F. and Froelich, P. N. (1988) Influence of late Cenozoic mountain building on ocean geochemical cycles. Geology 16, 649-653

Rees-Jones, J. (1995) Optical dating of selected British archaeological sediments. Unpublished D. Phil. thesis, University of Oxford 
Reichart, G. J., den Dulk, M., Visser, H. J., van der Weijden, C. H. and Zachariasse, W. J. (1997) A 225kyr record of dust supply, palaeoproductivity and oxygen minimum zone from the Murray Ridge (northern Arabian Sea). Palaeogeography, Palaeoclimatology, Palaeoecology 134, 149-169

Rendell, H. M., Webster, S. E. and Sheffer, N. L. (1994) Underwater bleaching of signals from sediment grains: new experimental data. Quaternary Science Reviews (Quaternary Geochronology) 13, 433-436

Rhodes, E. J. (1988) Methodological considerations in the optical dating of quartz. Quaternary Science Reviews 7, 395-400

Rhodes, E. J. (1990) Optical dating of quartz from sediments. Unpublished D. Phil. thesis, University of Oxford

Rhodes, E. J. and Pownall, L. (1994) Zeroing of the OSL signal in quartz from young glaciofluvial sediments. Radiation Measurements 23, 581-585

Rhodes, E. J. and Bailey, R. M. (1997) Thermal transfer effects observed in the luminescence of quartz from recent glaciofluvial sediments. Quaternary Science Reviews (Quaternary Geochronology) 16, 291-298

Rhodes, T. E., Gasse, F., Ruifen, L., Fontes, J-C., Wei, K., Bertrand, P., Gibert, E., Melieres, F., Tucholka, P., Wang, Z. and Cheng, Z. Y. (1996) A late PleistoceneHolocene lacustrine record from lake Manas, Zunggar (northern Xinjiang, western China. Palaeogeography, Palaeoclimatology, Palaeoecology 120, 105-121

Richards, B. (1999) Palaeoclimate of south Asia over the last $80 \mathrm{ka}$ : luminescence ages of sediments from former glaciations in Nepal and Pakistan. Unpublished Ph.D. thesis, University of London

Rose, J. and Menzies, J. (1996) Glacial Stratigraphy. In J. Menzies (ed) Past glacial environments: sediments forms and techniques, Glacial environments volume 2. Butterworth-Heinemann Ltd. 253-284

Rossingnol-Strict, M. (1995) Sea-land correlation of pollen records in the eastern Mediterranean for the glacial-interglacial transition: biostratigraphy versus radiometric time-scale. Quaternary Science Reviews 14, 893-915 
Rostek, F., Ruhland, G., Bassinot, F. C., Muller, P. J., Labeyrie, L. D., Lancelot, Y. and Bard, E. (1993) Reconstructing sea surface temperature and salinity using $\delta^{18} \mathrm{O}$ and alkenone records. Nature 364, 319-321

Ruddiman, W. F. and Kutzbach, J. E. (1989) Effects of plateau uplift on late Cenozoic climate. Ecos, Transactions, American Geophysical Union 70, 294

Ruddiman, W. F. and Raymo, M. E. (1988) Northern Hemisphere climate regions during the past $3 \mathrm{Ma}$; possible tectonic connections. Philosophical Transactions of the Royal Society of London. Series B : Biological Sciences 318, 411-430

Ruddiman, W. F., Raymo, M. E., Prell, W. L. and Kutzbach, J. E. (1997) The UpliftClimate Connection: A Synthesis. In W. F. Ruddiman, (ed) Tectonic uplift and climate change. Plenum Press. New York and London. 471-515

Rutter, N. (1995) Problematic ice-sheets. Quaternary International 28, 19-37

Sarkar, A., Ramesh, R., Bhattacharyya, A., Rajagopalan, A. G. (1990) Oxygen isotope evidence for a stronger winter monsoon current during the last glaciation. Nature 343, 549-551

Schmitz, B. (1987) Barium, high productivity, and northward wandering of the Indian continent. Palaeoceanography 2, 63-77

Schulz, H., von Rad, U. and Erlenkeuser, H. (1998) Correlation between Arabian Sea and Greenland climate oscillations of the past 110000 years. Nature 393,54-57

Scott, C. H. (1992) Contemporary sediment transfer in the Himalayan glacial system : implications for the interpretation of the Quaternary record. Unpublished Ph.D. thesis, University of Leicester, 352

Searle, M. P. (1983) Stratigraphy, structure and evolution of the Tibetan-tethys zone in Zanskar and the Indus suture zone in the Ladakh Himalaya. Transactions of the Royal Society of Edinburgh : Earth Sciences 73, 205-219

Searle, M. P. (1986) Structural evolution and sequence of thrusting in the High Himalaya, Tibetan Tethys and Indus suture zones of Zanskar and Ladakh, Western Himalaya. Journal of Structural Geology 8, 923-936 
Searle, M. P. (1999) Extensional and compressional faults in the Everest-Lhotse massif, Khumbu Himalaya, Nepal. Journal of the Geological Society, London 156, $227-$ 240

Searle, M. P. and Fryer, B. J. (1986) Garnet, tourmaline and muscovite-bearing leucogranites, gneisses and migmatites of the Higher Himalaya from Zanskar, Kulu, Lahoul and Kashmir, In M. P. Coward and A. Ries (Ed.s) Collision Tectonics. Geological Society, London, Special Publication, 19, 185-201

Searle, M. P., Windley, B. F., Coward, M. P., Cooper, D. J. W., Rex, A. J., Rex, D. C., Tingdong, L., Xuchang, X., Jan, M. Q., Thankur, V. and Kumar, S. (1987) The closing of Tethys and the tectonics of the Himalayas. Bulletin of the Geological Society of America 98, 678-701

Searle, M. P., Cooper, D. J. W. and Rex, A. J. (1988) Collision tectonics of the LadakhZanskar Himalaya. Philosophical Transactions of the Royal Society of London, Series $A$ 326, 117-150

Searle, M. P., Waters, D. J., Rex, D. C. and Wilson, R. N. (1992) Pressure, temperature and time constraints on Himalayan metamorphism from eastern Kashmir and western Zanskar. Journal of the Geological Society, London 149, 753-773

Searle, M. P., Corfield, R. I., Stephenson, B. and McCarron, J. (1997) Structure of the North Indian Continental margin in the Ladakh-Zanskar Himalayas : implications for the timing of obduction of the Spontang Ophiolite, India-Asian collision and deformation events in the Himalaya. Geological Magazine 134, 297-316

Selby, M. J. (1993) Hillslope materials and processes. Oxford University Press, 451pp.

Sharma, K. K., Saini, H. S. and Nagpaul, K. K. (1978) Fission track annealing, ages of apatites from Mandi granite and their application to tectonic problems.

Sharma, M. C. and Owen, L. A. (1996) Quaternary History of the NW Garhwal, Central Himalayas. Quaternary Science Reviews 15, 335-365

Shi, Y., Zheng, B. and Li, S. (1992a) Last glaciation and maximum glaciation on the Qinghai-Xizang (Tibet) Plateau : A controversy to M. Kuhle's Ice-sheet hypothesis. Chinese Geographical Science. 2, 293-311 
Shi, Y., Zheng, B. and Li, S. (1992b) Last glaciation and maximum glaciation in the Qinghai-Xizang (Tibet) Plateau : A controversy to M. Kuhle's Ice-sheet hypothesis. Zeitschrift fur Geomorphology 84, 19-35

Shimmield, G. B. (1992) Can sediment geochemistry record changes in coastal upwelling palaeoproductivity? Evidence from northwest Africa and the Arabian Sea. In C. P. Summerhayes, W. L. Prell and K. C. Emeis (eds) Upwelling systems: Evolution since the Early Miocene. Geological Society Special Publication 64, 29-46

Shiraiwa, T. and Wantanabe, T. (1991) Late glacial fluctuations in the Langtang Valley, Nepal Himalaya, reconstructed by relative dating methods. Arctic and Alpine Research 23, 404-416

Shroder, J. F., Khan, M. S., Lawrence, R. D., Madin, I. and Higgins, S. M. (1989) Quaternary glacial chronology and neotectonics in the Himalaya of northern Pakistan. In L. L. Malinconico and R. J. Lillie (eds) Tectonics and geophysics of the western Himalaya Geological Society of America, Special Paper 232 : 275293

Shroder, J. F., Owen, L A. and Derbyshire, E. (1993) Quaternary glaciation of the Karakoram and Nanga Parbat Himalaya. In J. F. Shroder (ed) Himalaya to the sea. Routledge London, 132-158

Singh, R. P. and Mishra, N. C. (1998) Characterization of snow cover region using SSM/I data. Abstract, 1998 annual meeting of IGCP 415 and meetings of working groups 2 and 7

Sinha, A. K. (1992) Himalayan mountain building and the tectonic processes involved in it. In A. K. Shinha (ed) Himalayan Orogen and Global tectonics. A. A. Balkema, Rotterdam, 219pp.

Sirocko, F., Sarnthein, M., Lange, H. and Erlenkeuser, H. (1991) Atmospheric summer circulation and coastal and coastal upwelling in the Arabian Sea during the Holocene and last glaciation. Quaternary Research 36, 72-93 
Sirocko, F., Sarnthein, M., Erlenkeuser, H., Lange, H., Arnold, M., and Duplessy, J. C.

(1993) Century-scale events in monsoonal climate over the past 24000 years. Nature 364, 322-324

Sissons, J. B. (1974) A late glacial ice-cap in the central Grampians, Scotland. Transactions of the Institute of British Geographers 62, 95-113

Sissons, J. B. and Sutherland, D. G. (1976) Climatic inferences from former glaciers in the south-east Grampian Highlands, Scotland. Journal of Glaciology 17, 325-346

Smith, B. W. (1988) More cautions on laboratory illumination. Ancient TL 6, 9

Spooner, N. A. (1992) Optical dating : Preliminary results on the anomalous fading of luminescence from feldspars. Quaternary Science Reviews 11, 139-145

Spooner, N. A. (1994) The anomalous fading of infra-red stimulated luminescence from feldspars. Radiation Measurements 23, 625-632

Stokes, S. (1992) Optical dating of quartz from sediments. Quaternary Science Reviews 11, 153-159

Summerfield, M. A. (1991) Global Geomorphology. Longman Scientific and Technical, $537 \mathrm{pp}$.

Sutherland, D. G. (1984) Modern glacier characteristics as a basis for inferring former climates with particular reference to the Loch Lomond Stadial. Quaternary Science Reviews 3, 291-309

Swain, A. M., Kutzbach, J. E. and Hastenrath, S, (1983) Estimates of Holocene precipitation for Rajastan, India, based on pollen and lake level data. Quaternary Research 19, 1-17

de Terra, H. and Huntington, G. E. (1934) Evidence of recent climatic changes shown by Tibetan highland lakes. Geographical Journal 84, 311-320

de Terra, H. and Patterson, T. T. (1939) Studies on the ice age in India and association human cultures. Carnegie institute, Washington D.C., 354pp.

Thompson, L. G., Mosley-Tompson, E., Davis, M. E., Bolzan, J. F., Dai, J., Yao, T., Gundestrup, N., Wu, X., Klein, L. and Xie, Z. (1989) Holocene-Late Pleistocene climate ice core records from Qinghai-Tibetan Plateau. Science 246, 474-477 
Thompson, L. G., Tompson, E. M., Davis, M. E., Bolzan, J. F., Dai, J., Klein, L., Gundestrup, N., Yao, T., Wu, X., and Xie, Z. (1990) Glacial stage ice core records from the subtropical Dunde ice cap, China. Annals of Glaciology 14, 288297

Thompson, L. G., Yao, T., Davis, M. E., Henderson, K. A., Mosley-Tompson, E., Lin, PN., Beer, J., Synal, H. -A., Cole-Dai, J. and Bolzan, J. F. (1997) Tropical climate instability: the last glacial cycle from a Qinghai-Tibetan ice core. Science 276, $1821-1825$

Torsnes, I., Rye, N. and Nesje, A. (1993) Modern and Little Ice Age equilibrium-line altitudes on outlet valley glaciers from Jostedalsbreen, western Norway: an evaluation of different approaches to their calculation. Arctic and Alpine Research 25, 106-116

Trinkler, E. (1930) Ice age on the Tibetan Plateau and in the adjacent region. Geographical Journal 75, 225

Turner, S., Hawkesworth, C., Lui, J., Rogers, N., Kelley, S. and van Calsteren, P. (1993) Timing of Tibetan uplift constrained by analysis of volcanic rocks. Nature 364, 50-54

Visser, P. C. (1938) Wissenschaftliche Ergebnisse der Niederlandischen Expeditionen in den Karakoram und die angrenzenden Gebiete in den Jahren 1922-1935. In E. J. Brill (ed) Glaziologie. Leiden, Netherlands

Watts, W. A., Allen, J. R. M. and Huntley, B. (1996) Vegetational history and palaeoclimate of the last glacial period at Lago Grandedi Monticchio, southern Italy. Quaternary Science Reviews 15, 133-153

Weedon, G. P. and Shimmield, G. B. (1991) Late Pleistocene upwelling and productivity variations in the northwest Indian Ocean deduced from spectral analyses of geochemical data from sties 722 and 724. Proceedings of the Ocean Drilling Program, Scientific Results 117, 431-444

Williams, V. S. (1983) Present and former equilibrium line altitudes near Mount Everest, Nepal and Tibet. Arctic and Alpine Research 15, 201-211 
Wintle, A. G. and Huntlley, D. J. (1980) Thermoluminescence of ocean sediments. Canadian Journal of Earth Sciences 17, 348-360

von Wissmann, H. (1959) Die heutige Vergletscherung und Schnecgrenze in Hochasien mit Hinweisen auf die Vergletscherung der letzten Eiszeit. Akad. D. Wiss. U. d. Lit. Abh. D. Math.-Nat. wiss. Kl. 14, 1103-1407, Mainz.

Wood, P. (1994) Optically stimulated luminescence dating of a late Quaternary shoreline deposit, Tunisia. Quaternary Science Reviews 13, 513-516

Xiao, J., Porter, S.C., An, Z., Kumai, H. and Yoshikawa, S. (1995) Grain size of quartz as an Indicator of winter monsoon strength on the Loess Plateau of Central China during the last 130000 yr. Quaternary Research 43, 22-29

Ye, D. Z. and Gao, Y.X. (1981) The seasonal variation of the heat source and sink over Qinghai-Xizang Plateau and its role in the general circulation. In Geological and ecological studies of the Qinghai-Xizang Plateau, Vol. 2; environment and ecology of the Qinghai-Xizang Plateau. Science Press, Beijing, 1453-1462

van Zeist, W. and Bottema, S. (1982) Vegetational history of the eastern Mediterranean and the near east during the past 20000 years. In J. L. Binliff and W. van Zeist (eds) Palaeoclimates, palaeoenvironments and Human Communities in the eastern Mediterranean region in later pre-history. BAR International Ser., 277321

Zhang, X. and Shi, Y. (1980) Changes of Batura Glacier in the Quaternary and recent times. Professional Papers on the Batura Glacier, Karakoram mountains Science Press, Beijing, 173-190

Zeitler, P. K. (1985) Cooling history of the NW Himalaya, Pakistan. Tectonics 4, 127151

Zheng, B. (1988) Quaternary glaciation of Mt. Qomolongma-Xixabangma region. GeoJournal 17, 525-542

Zheng, B. (1989a) Controversy regarding the existence of a large ice sheet on the Qinghai-Xizang (Tibetan) Plateau during the Quaternary Period. Quaternary Research 32, 121-123 
Zheng, B. (1989b) Did a large ice sheet really occur on the Qinghai-Xizang (Tibet) Plateau during the Quaternary Period. Geology Review 35, 543-551

Zheng, B. (1989c) The influence of Himalayan uplift on the development of Quaternary glaciers. Zeitcrift fur Geomorphologie 76, 89-115

Zheng, B. and Rutter, N. (1998) On the problems of Quaternary glaciations and the extent and patterns of Pleistocene ice cover in the Qinghai-Xizang (Tibet) Plateau. Quaternary International 45/46, 109-121

Zheng, B. X., Jiao, K. Q, Ma, Q. H., Li, S. J. and Fushimi, H. (1990) The evolution of the Quaternary glaciations and environmental change in the West Kunlun Mountains, Western China. Bull. Gl. Research 8, 61-72

Zhu, F. K., Lu, L. H., Chen, X. J., Zhao, W., Li, G. Q., Zhang, H. C., Liu, F. M. and Sun, G. W. (1981) The South Asian High. In Geological and ecological studies of the Qinghai-Xizang Plateau, Vol. 2; environment and ecology of the Qinghai-Xizang Plateau. Science Press, Beijing, 1519-1529

Zonneveld, K. A. F. (1996) Palaeoclimatic reconstruction of the last deglaciation (18-8ka B.P.) in the Adriatic Sea region: a land-sea correlation based on palynological evidence. Palaeogography, Palaeoclimatology, Palaeoecology 122, 89-106 
Appendix A Dose response curves (additive method)

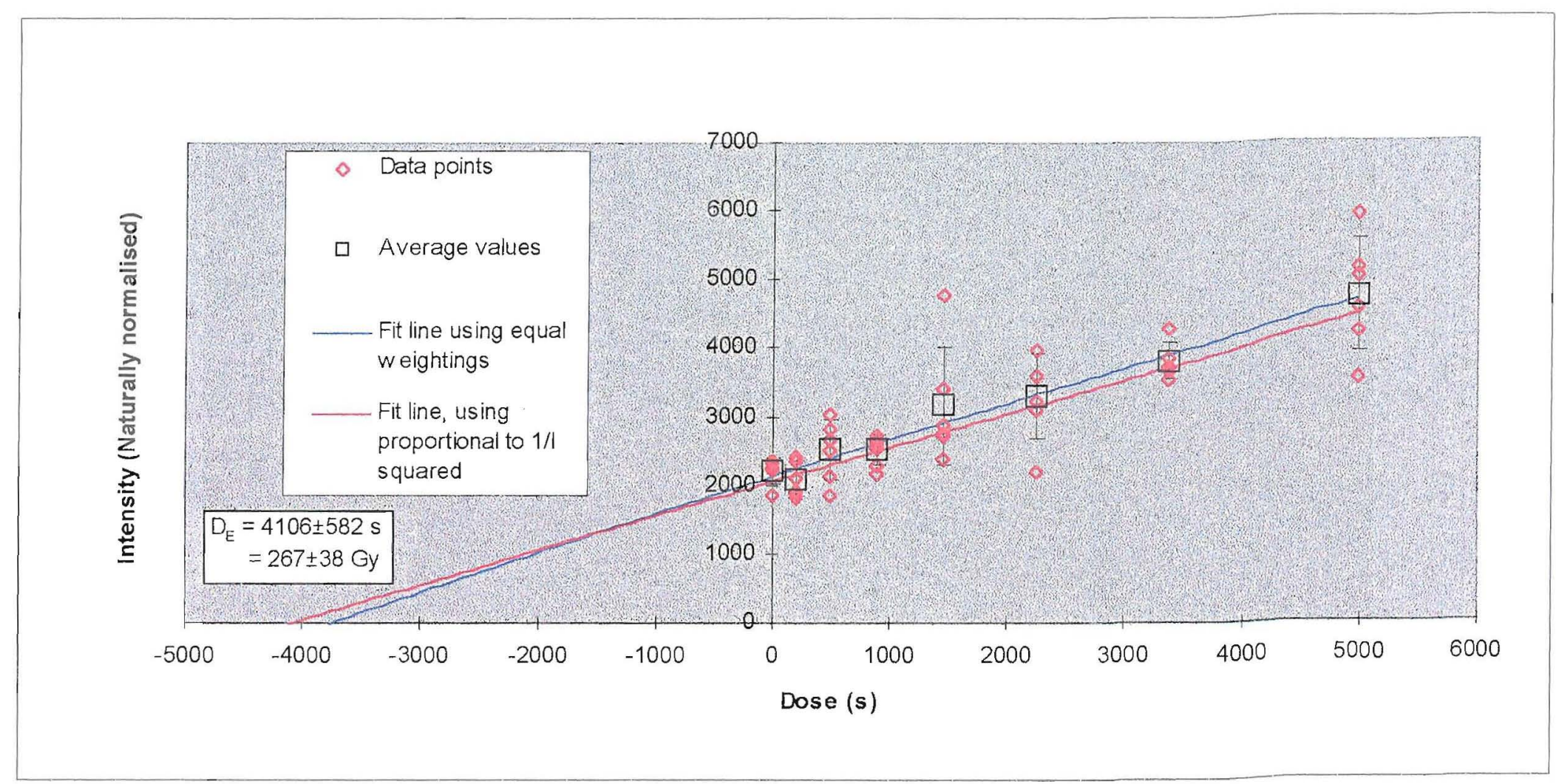

Dose response curve for sample V053, The samples are irradiated in seconds (s) on the ELSEC machine (Chapter 2) at a rate of $3.9 \mathrm{~Gy} /$ minute. The $\mathrm{D}_{\mathrm{E}}$ is shown in units of both $\mathrm{s}$ and $\mathrm{Gy}$ in the following graphs. 


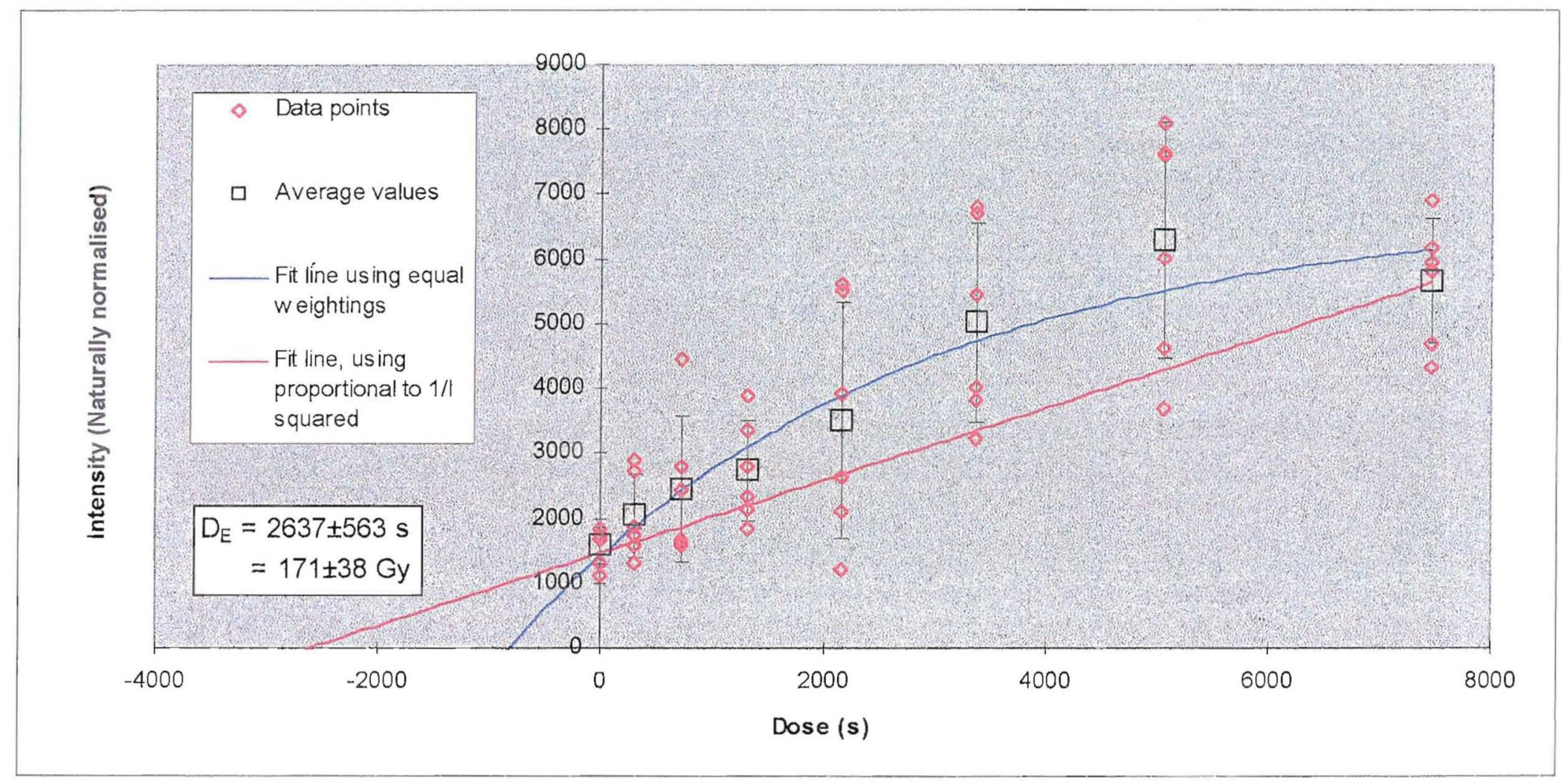

Dose response curve for sample V055 


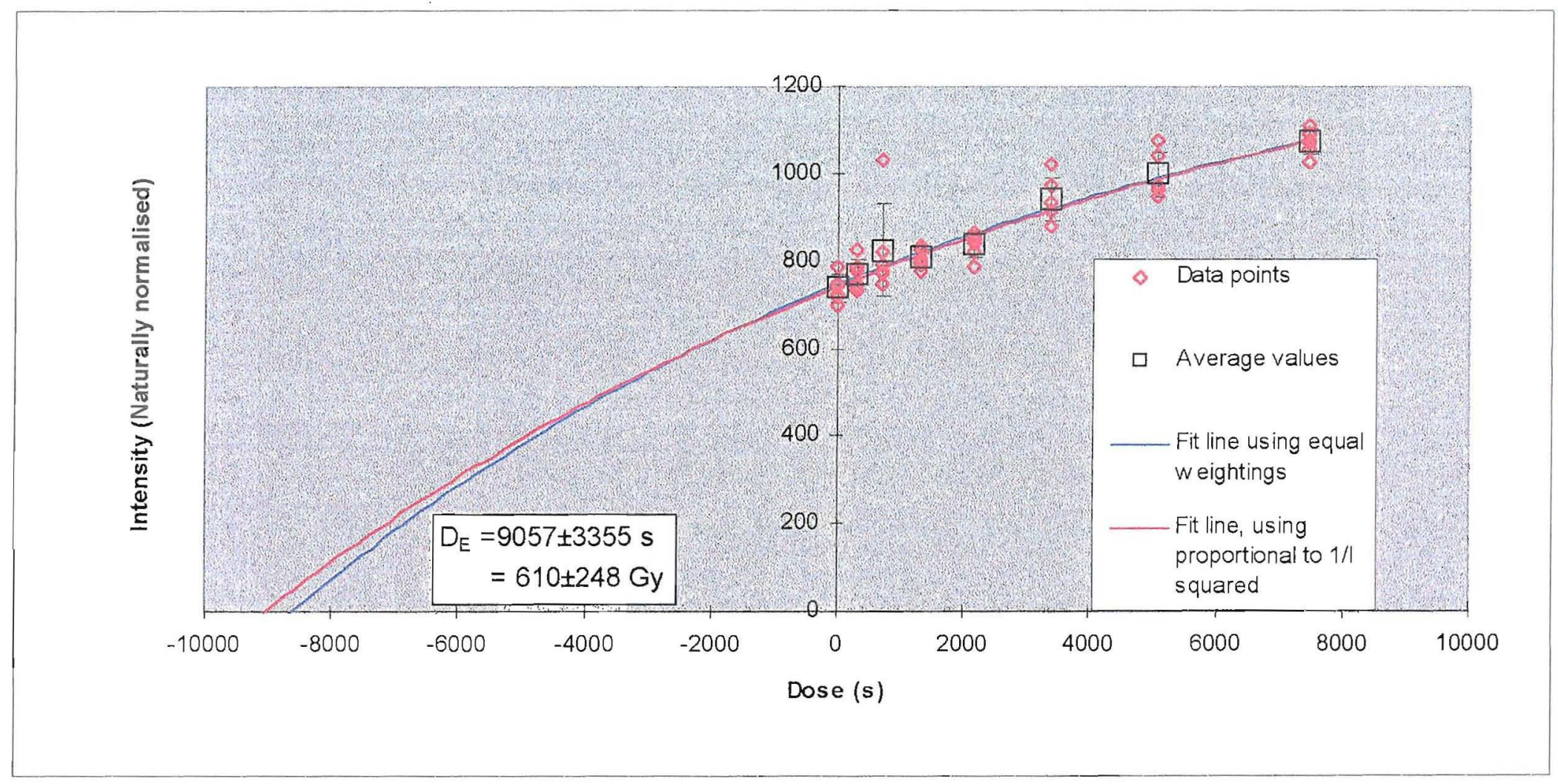

\section{Dose response curve for sample V056}




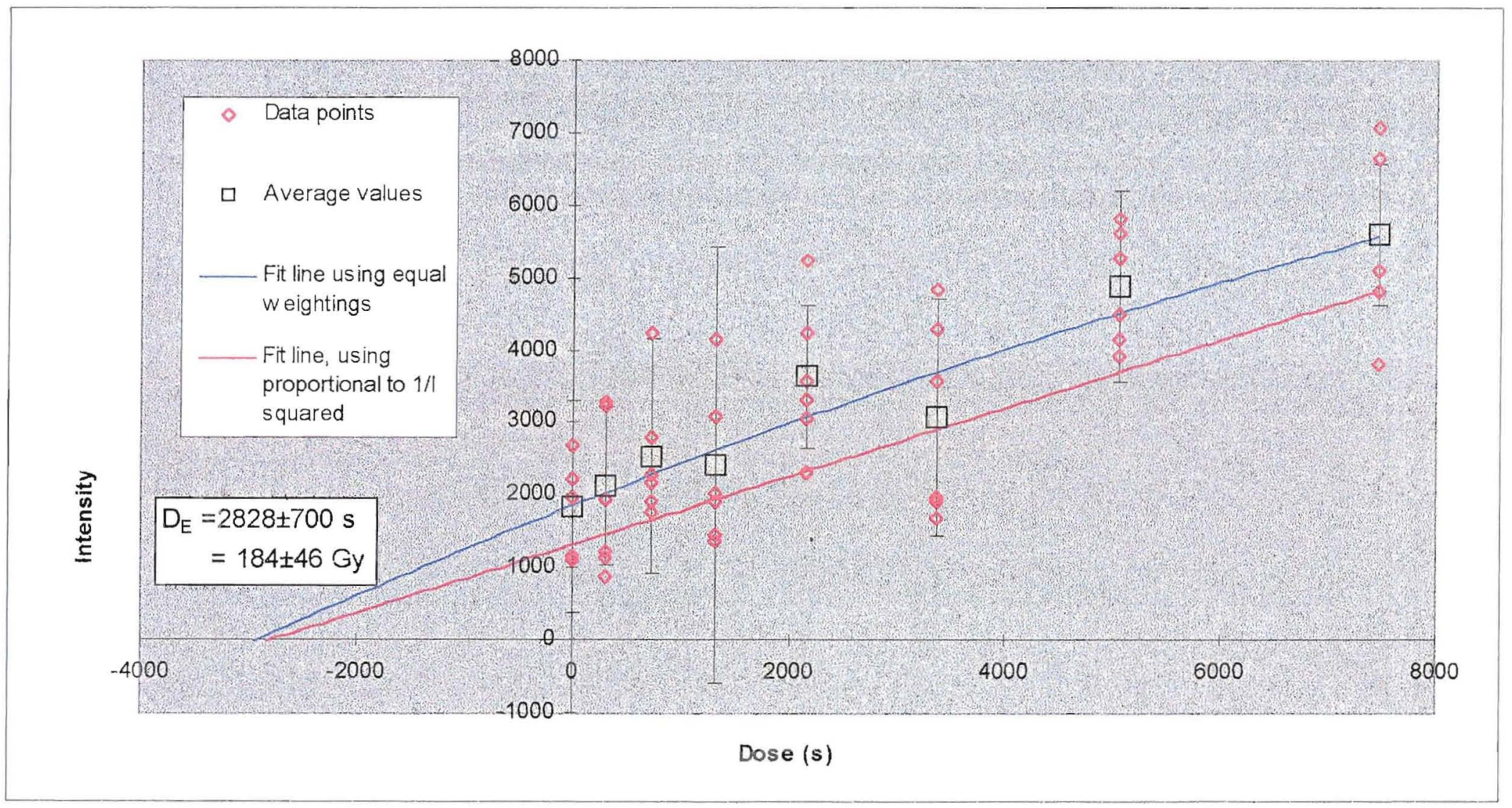

Dose response curve for sample V058 


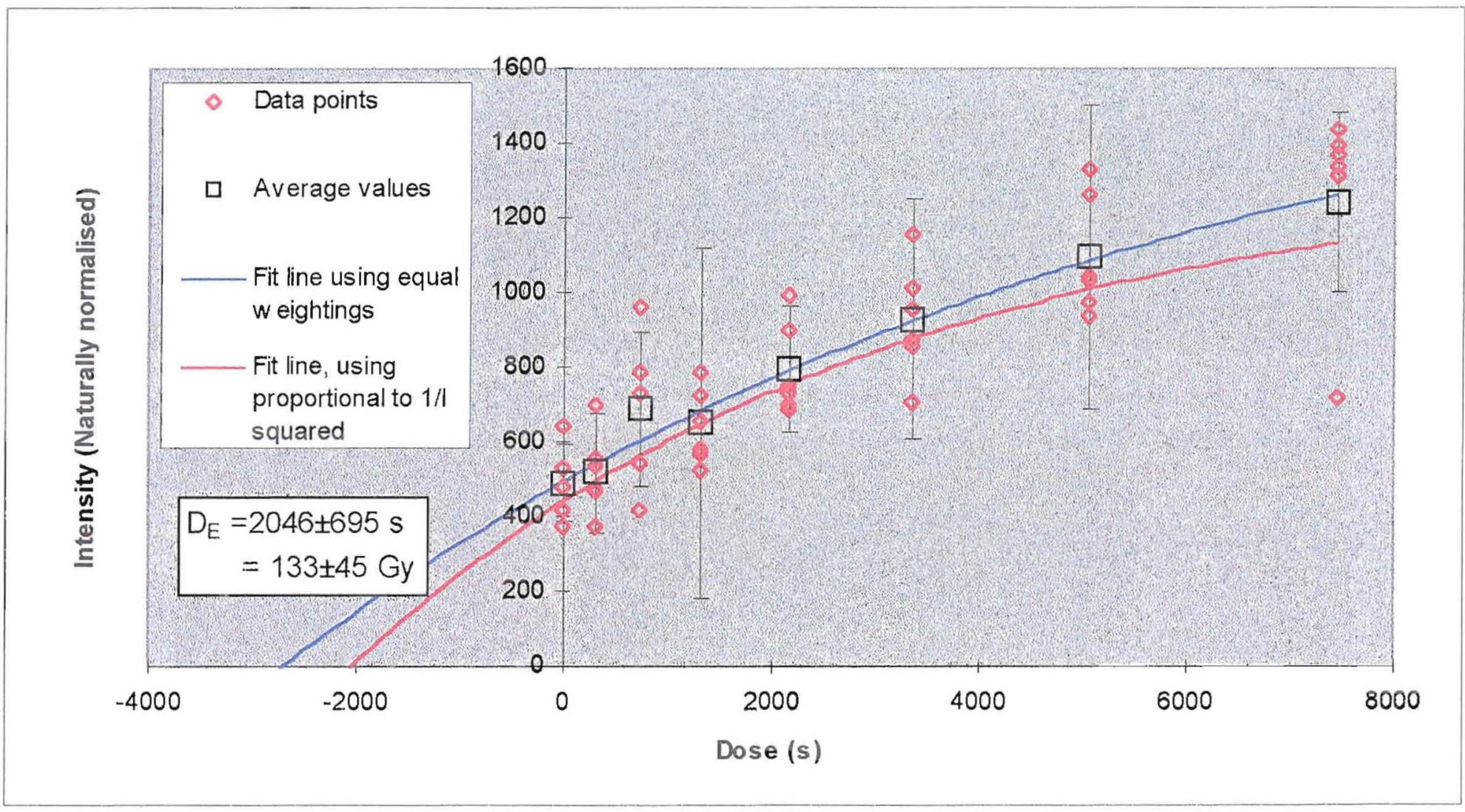

Dose response curve for sample V059 


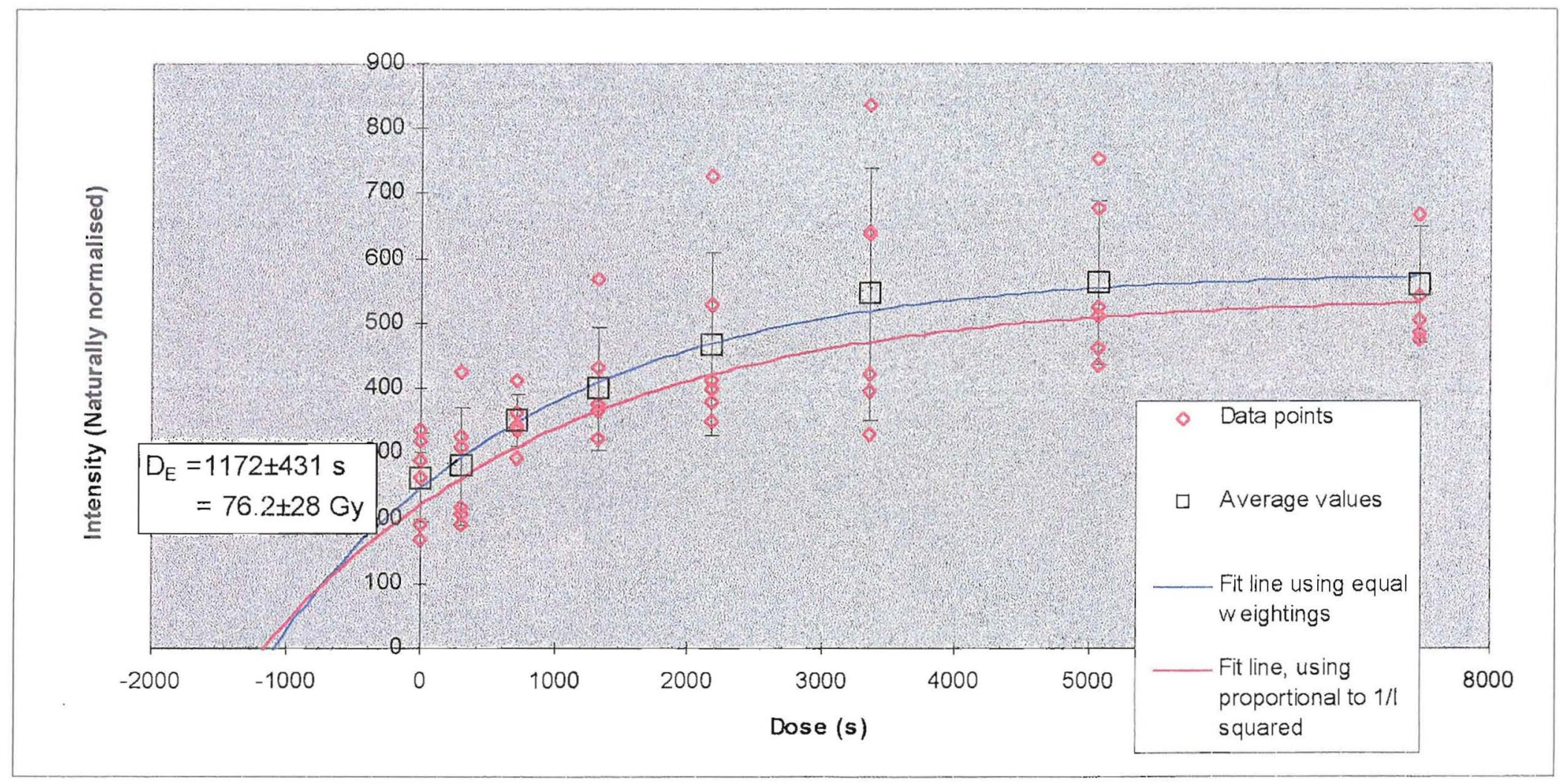

Dose response curve for sample V060 


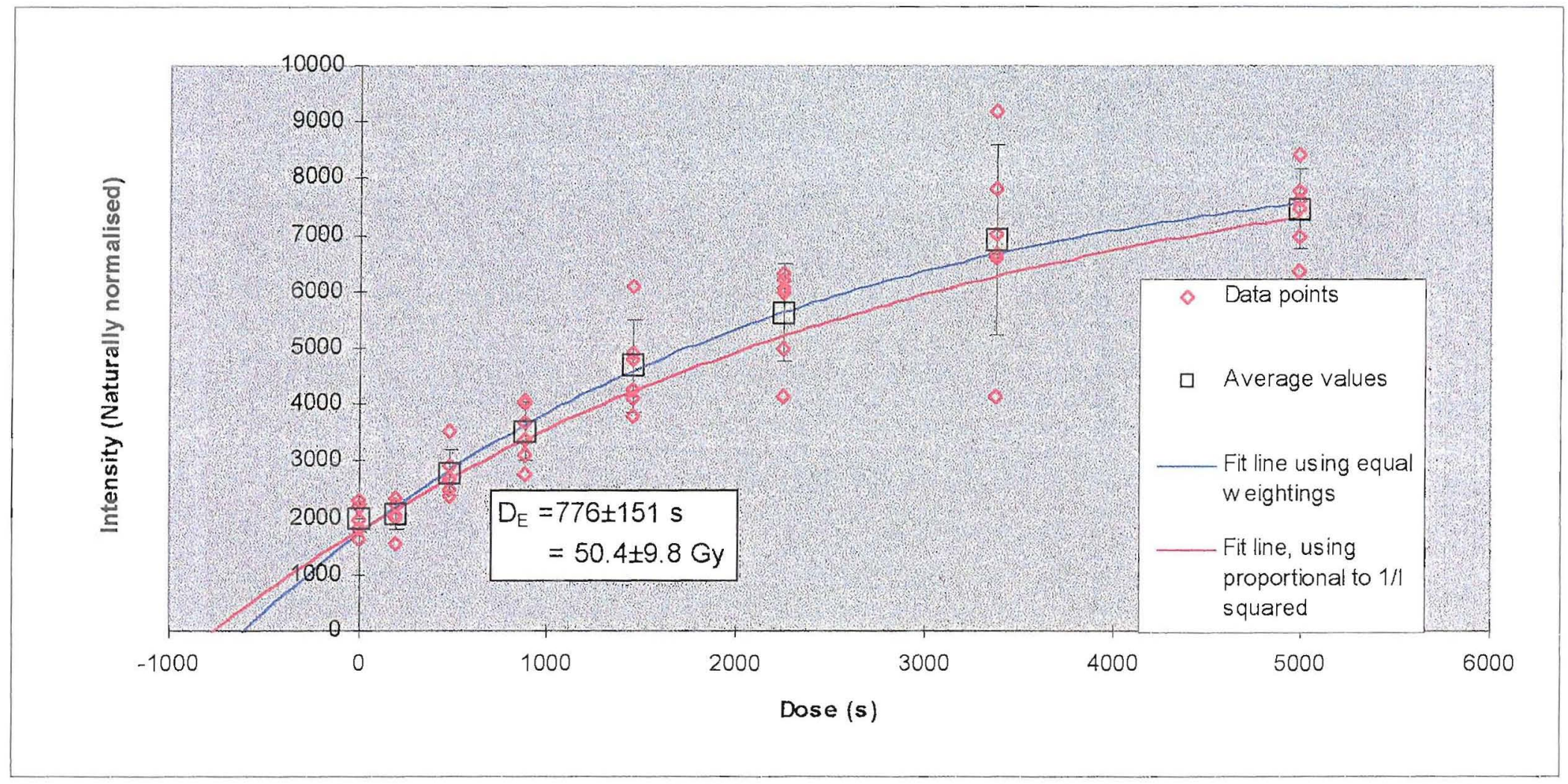

Dose response curve for sample V062 


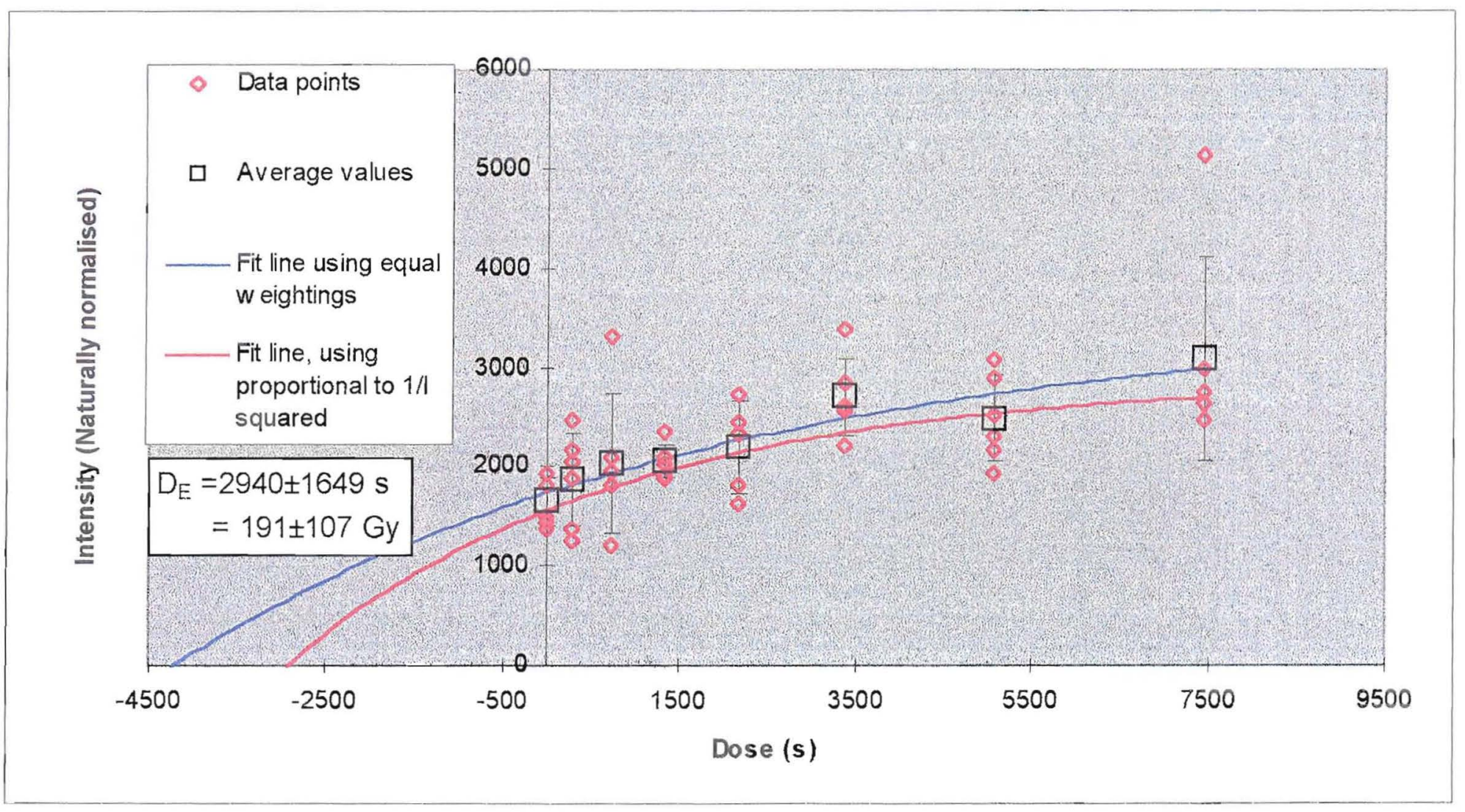

Dose response curve for sample V064 


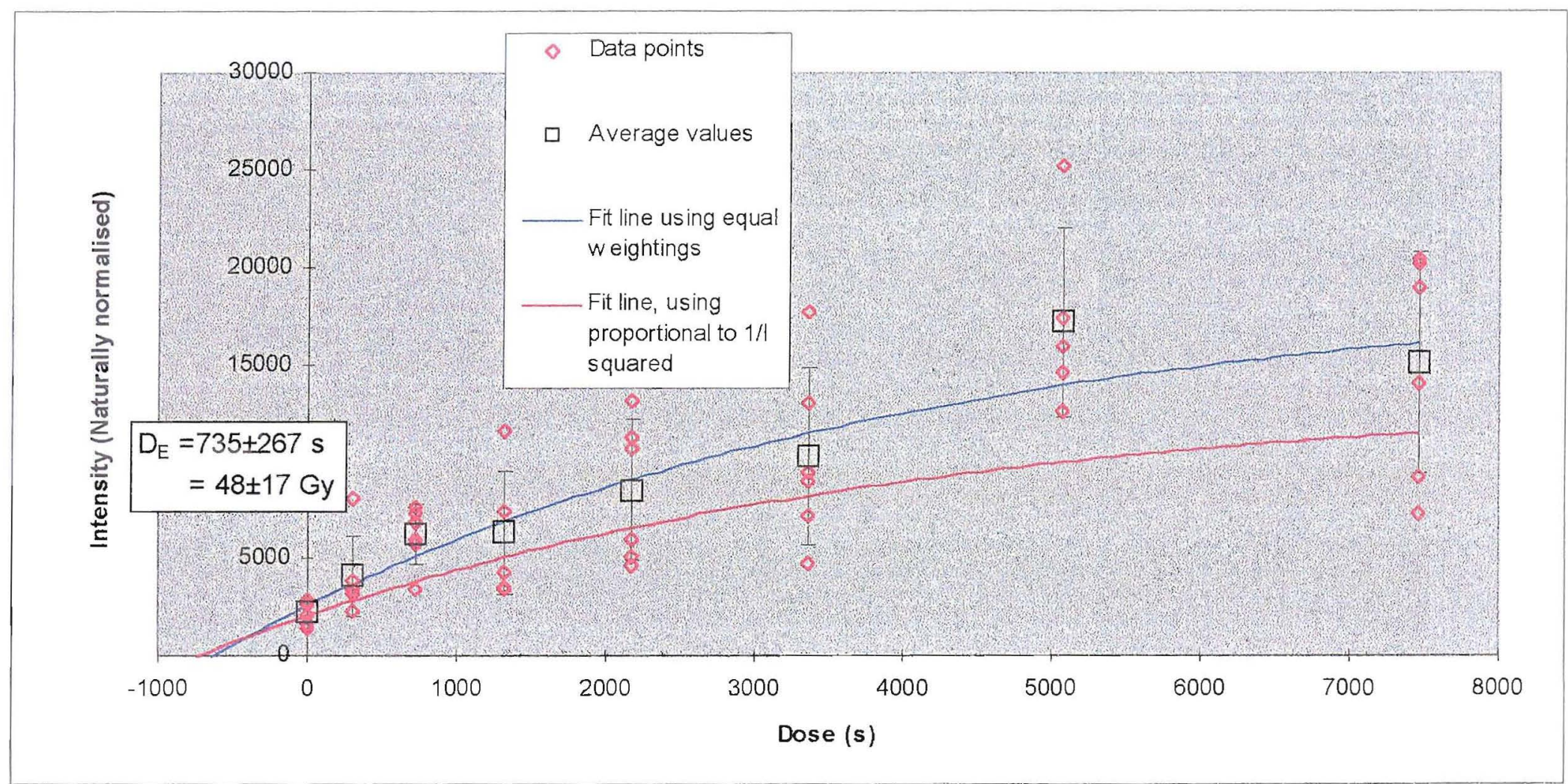

\section{Dose response curve for sample V065}


Appendix B Published Paper 


\section{Appendix C A Worked Example of an OSL Age Estimate}

The major stages in the determination of an age estimate from sample V053 are outlined below. This appendix follows the measurement methodology set out in chapter 2, expanding on the results given in chapter 4 . Initial tests on sample V053 indicate that the aliquot preparation has produced quartz grains and gives an $\mathrm{D}_{\mathrm{E}}$. The dose response curve from the main measurement is then presented and the dose rate reported, before the age calculation is made.

\section{Luminescence Initial Sample Assessment (LISA)}

The shine-down curves and TL glow curves for sample V053 show rapid initial decay of the luminescence signal and post-dose traps at $\sim 100^{\circ} \mathrm{C}$ respectively (see chapter 2 for full explanation).

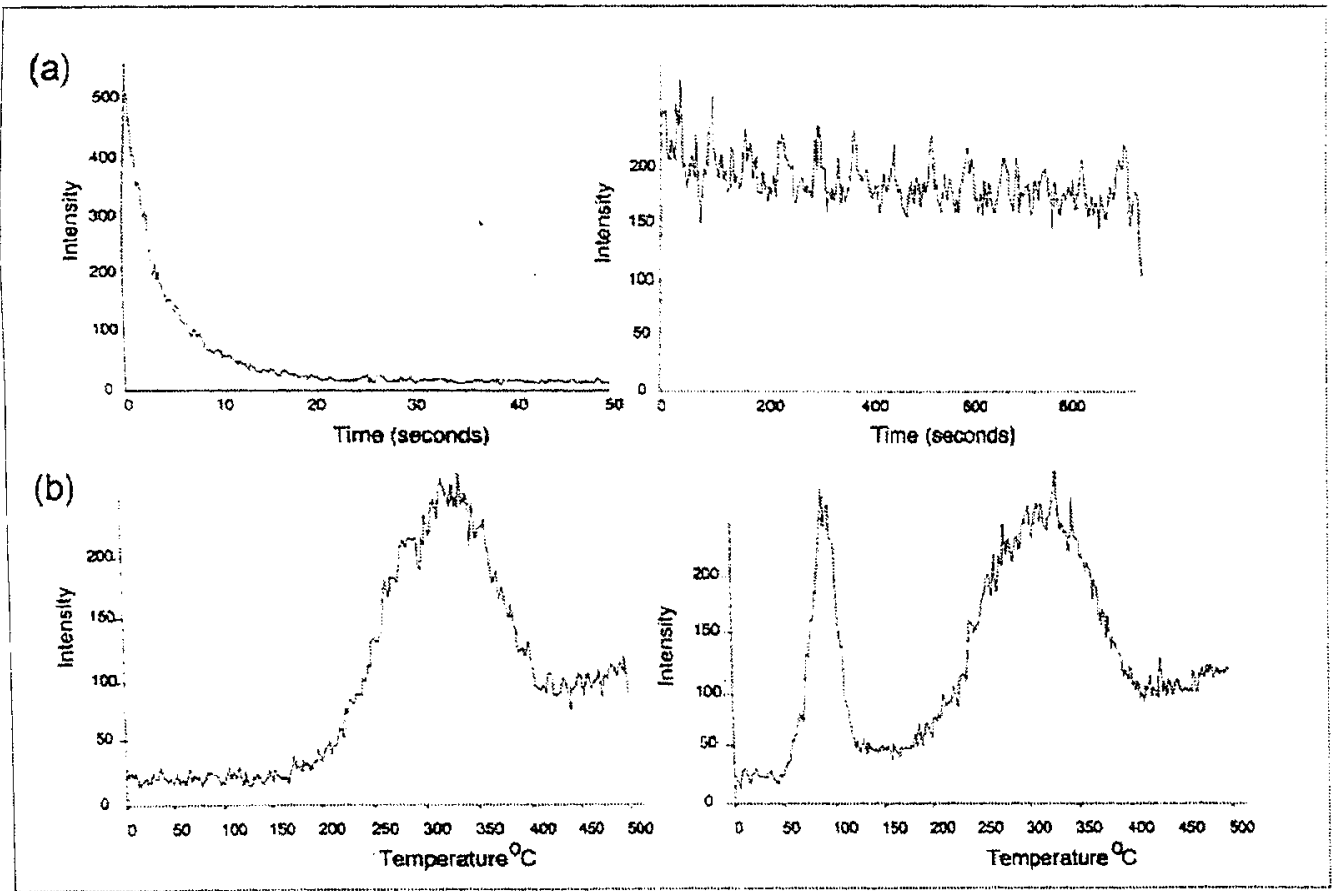

Shine-down curves (a) and TL glow curves (b) for sample V053. 
These characteristics, combined with low IRSL results from the LISA test, are indicative of quartz and suggest that the preparation of aliquots has been successful.

The single aliquot dose response curve plotted for sample V053, as part of the LISA test, gives a $D_{\mathrm{E}}$ of $60-70 \mathrm{~Gy}$. This datum is used to decide what range of doses to give the aliquots of the main measurement.

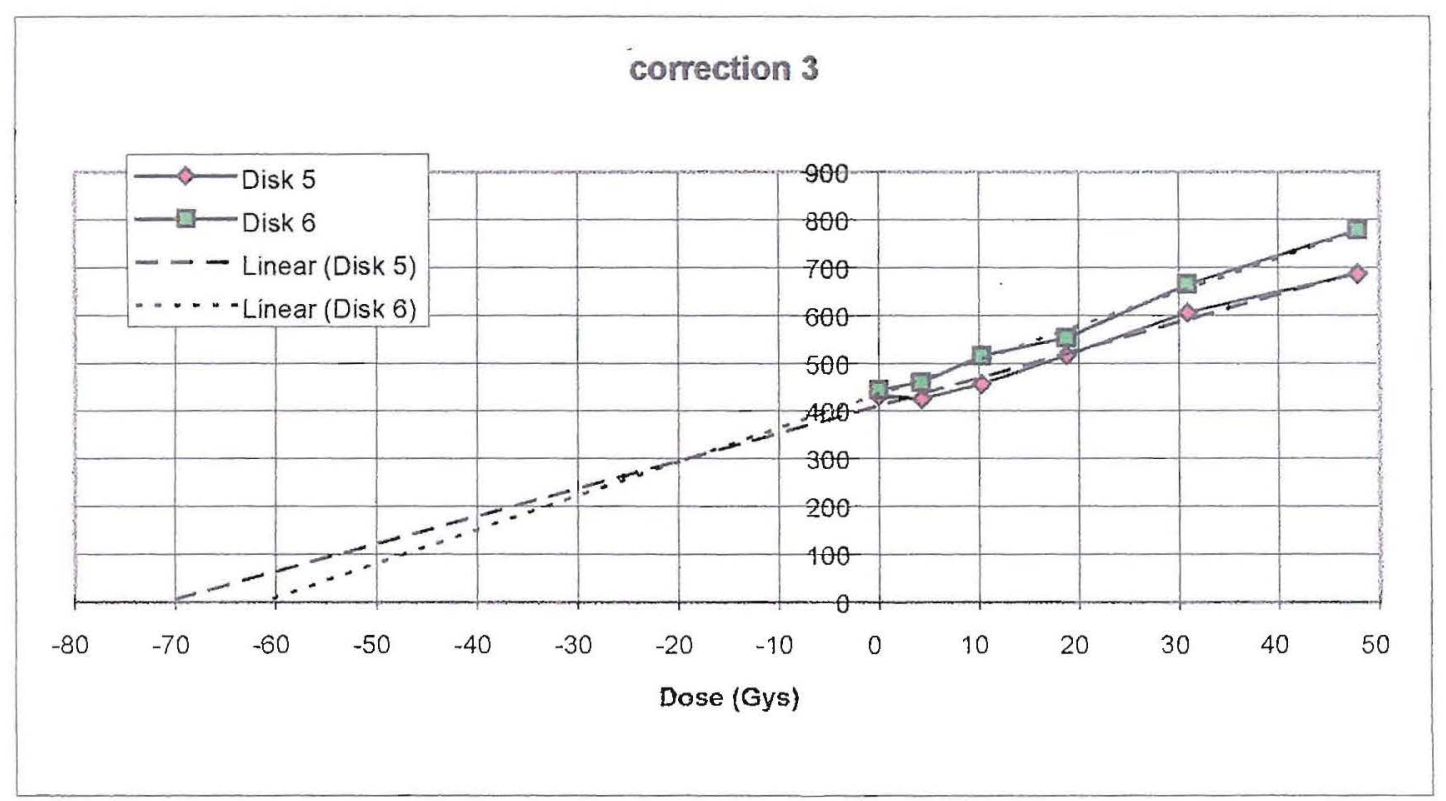

Single aliquot dose response curve for sample V053, from the LISA spreadsheet for V053

\section{Main Measurement}

Forty-eight discs were employed in the production of a multi-aliquot dose response curve. Luminescence readings were naturally normalised by measuring $0.3 \mathrm{~s}$ of GLSL from each disc prior to the administration of a dose, preheat and the final measurement. 


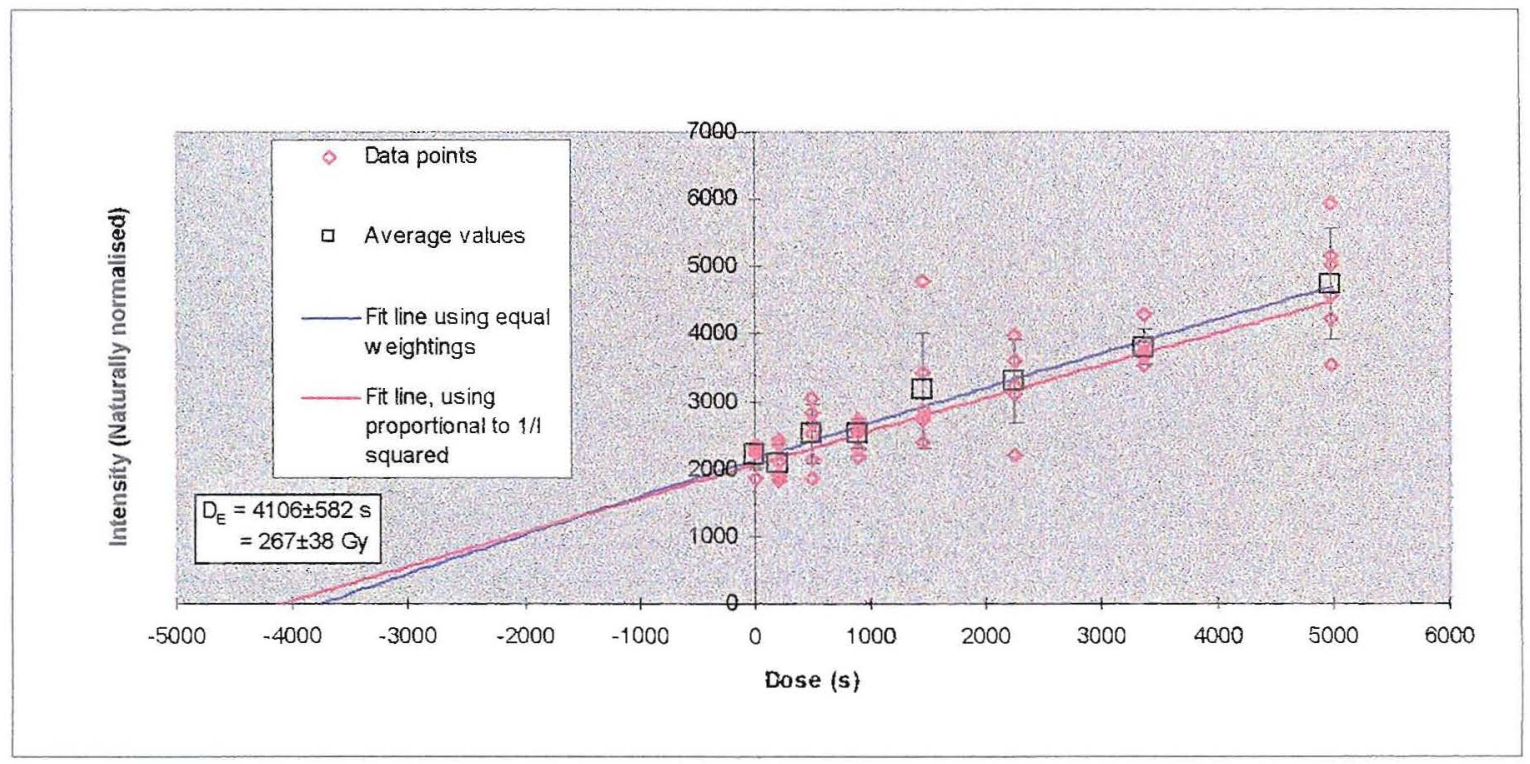

Multi-aliquot dose response curve for sample V053

The aliquots are irradiated at $3.9 \mathrm{Gymin}^{-1}$ with the doses given in seconds (s). The dose response curve shown above, with a fit line weighting inversely proportional to 1 / the intensity squared to take greater account of lower intensity points, gives a $D_{E}$ of $4106 \pm 582 \mathrm{~s}$. Converting to units of Greys, the $\mathrm{D}_{\mathrm{E}}$ for sample V053 is $267 \pm 38 \mathrm{~Gy}$.

\section{Environmental Dose Rate}

The environmental dose rate for sample V053 is $3421 \pm 232 \mu \mathrm{Gya}^{-1}$. This is calculated using NAA to determine the dose rate from the sediment (measured externally chapter 2) and the longitude, latitude and altitude to determine the cosmic dose rate (chapter 2; Prescott and Hutton, 1994). Water content of sample V053 was $0.02 \%$ moisture of wet weight and consequently has a negligible affect. 


\section{Age Estimate}

As described in chapter 2, an equation for age can be written.

$$
\operatorname{Age}(\mathrm{ka})=\frac{\text { Equivalent dose }\left(D_{E}\right)(G y)}{\text { Dose Rate }(G y / k a)}
$$

Substituting the values determined for sample V053, an age estimate can be calculated.

$$
\text { Age }(\mathrm{ka})=\frac{267 \pm 38 \mathrm{~Gy}}{3.421 \pm 0.232 \mathrm{Gya}^{-1}}
$$

Age $(\mathrm{ka})=78.0 \pm 12.3 \mathrm{ka} \mathrm{BP}$ 